\title{
Nanostructure and Chemistry Evolution of Solid Oxide Fuel Cells upon Cell Operation
}

\author{
Song Chen \\ West Virginia University
}

Follow this and additional works at: https://researchrepository.wvu.edu/etd

\section{Recommended Citation}

Chen, Song, "Nanostructure and Chemistry Evolution of Solid Oxide Fuel Cells upon Cell Operation" (2012). Graduate Theses, Dissertations, and Problem Reports. 4840.

https://researchrepository.wvu.edu/etd/4840

This Dissertation is protected by copyright and/or related rights. It has been brought to you by the The Research Repository @ WVU with permission from the rights-holder(s). You are free to use this Dissertation in any way that is permitted by the copyright and related rights legislation that applies to your use. For other uses you must obtain permission from the rights-holder(s) directly, unless additional rights are indicated by a Creative Commons license in the record and/ or on the work itself. This Dissertation has been accepted for inclusion in WVU Graduate Theses, Dissertations, and Problem Reports collection by an authorized administrator of The Research Repository @ WVU.

For more information, please contact researchrepository@mail.wvu.edu. 


\title{
Nanostructure and Chemistry Evolution of Solid Oxide Fuel Cells upon Cell Operation
}

\author{
Song Chen \\ Dissertation submitted to the \\ Benjamin M. Statler College of Engineering and Mineral Resources \\ at West Virginia University \\ in partial fulfillment of the requirements \\ for the degree of
}

Doctor of Philosophy

in

Mechanical Engineering

\author{
Xueyan Song, Ph.D., Committee Chairperson \\ Darran R. Cairns, Ph.D. \\ Harry O. Finklea, Ph.D. \\ Xingbo Liu, Ph.D. \\ Edward M. Sabolsky, Ph.D.
}

Department of Mechanical and Aerospace Engineering

\author{
Morgantown, West Virginia
}

2012

Keywords: Solid Oxide Fuel Cell, Cell Degradation, Contamination, Syngas, Transmission Electron Microscopy, Triple Phase Boundary, Yttria-stabilized Zirconia, Interface, Cathode infiltration.

Copyright 2012 Song Chen 


\section{Abstract \\ Nanostructure and Chemistry Evolution of Solid Oxide Fuel Cells upon Cell Operation}

\section{By Song Chen}

Solid Oxide Fuel Cells (SOFCs) are clean and efficient alternatives to conventional power generation technology. In SOFC, electrochemical reactions take place on the triple-phase boundaries (TPBs) between the electrolyte, the electrode and the gaseous fuel. Small changes in TPB structure or chemistry, and the interface between electrode and electrolyte can drastically affect SOFC performance and lifetime. However, very limited experimental work has been reported on the nanostructure and chemistry evolution of interface and TPBs in the SOFC upon cell operation.

The main goal of this dissertation is to investigate the nanostructure and chemistry of the grain boundaries and interfaces including TPB in SOFC, and their evolution with respect to the cell operation, and the variation of the fuel chemistry. The nanostructure and chemistry of the SOFC was investigated using Transmission Electron Microscopy. The analysis of microstructural and chemical evolution of anode was focused on the grain boundaries and TPB junctions of Ni/YSZ anode, in the two different aspects detailed in the following. (1). Comparisons were made between an as-received cell and a cell operated at $800^{\circ} \mathrm{C}$ for several hundred hours using $\mathrm{H}_{2}$ and syngas as fuel. Significant crystallographic evolution, including the formation of previously un-acknowledged $\mathrm{NiO}$ interface ribbon phase and the $\mathrm{Y}$ migration along the Ni/YSZ interface, was studied systematically. (2). The interaction of trace (ppm) phosphine with Ni-YSZ anode of commercial SOFC has also been investigated and evaluated for both synthesis gas and hydrogen fuels in an effort to examine the reactions between phosphine and YSZ. A principal benefit of SOFC is that it can utilize diverse fuels, including those derived from fossil and biotic sources. At elevated temperatures, SOFCs demonstrate some tolerance to fuel impurities that poison most other fuel cell systems. However, for coal-derived synthesis gas (syngas) under typical SOFC operating conditions, some trace material species may escape gas cleanup processing to impact the SOFC anode performance and long term stability. Among such trace species, phosphorus is of particular interest because the nickel anode is known to rapidly react with volatile phosphorus compounds to form a series of nickel phosphide products, which results in severe depletion of the nickel component and degradation of the anode. The particular focus of the present study is to analyze the interaction of $\mathrm{P}$ with YSZ, so as to elucidate the complete set of cell degradation modes induced by phosphine. In this study, a new $\mathrm{YPO}_{4}$ phase was observed at YSZ/Ni/YSZ triple phase junctions, which indicates the reaction between $\mathrm{PH}_{3}$ and $\mathrm{YSZ}$ in SOFCs.

In addition to the work on the anode, the microstructure and chemistry evolution of the cathode upon cell operation is studied as well. The focus is on the infiltration of cathode which has been proved to be effective in enhancing the cathode performance. Detailed study on the infiltration include crystallinity of infiltrates, chemistry of infiltrates (such as Fe content in the infiltrates), interaction between infiltrates and backbone materials, and their evolutions upon cell operation. The microstructure and 
chemistry at electrolyte/cathode interface is studied as well. Cations inter-diffusion between YSZ electrolyte and SDC buffer layer is detected, which leads $\mathrm{SrZrO}_{3}$ formation and structure change of YSZ. 


\section{Table of Contents}

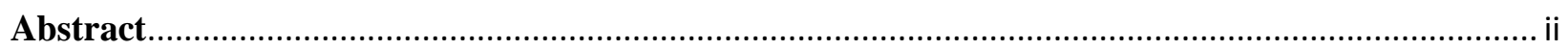

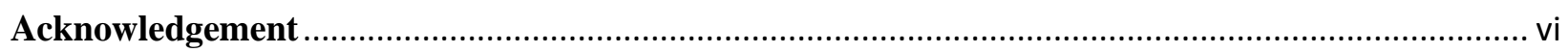

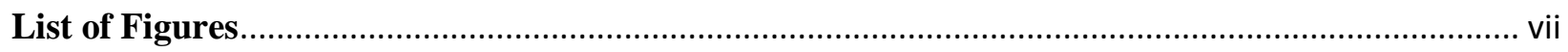

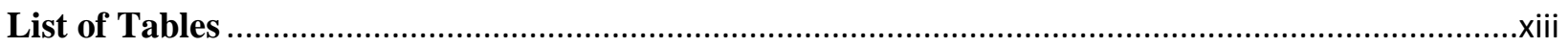

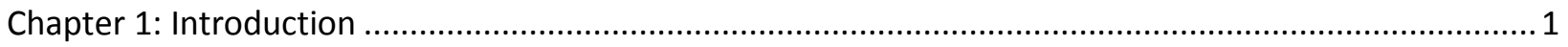

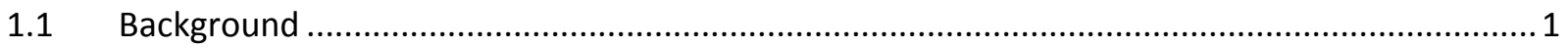

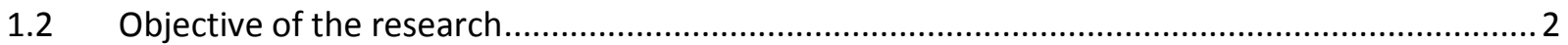

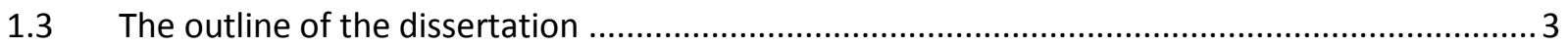

Chapter 2: Background and Literature Review............................................................................ 4

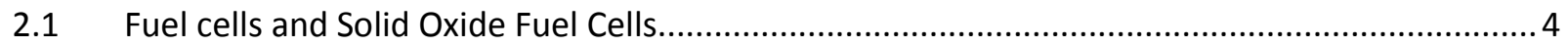

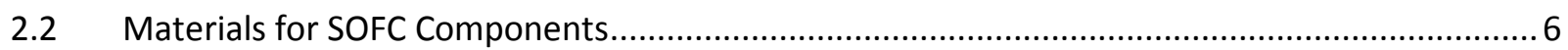

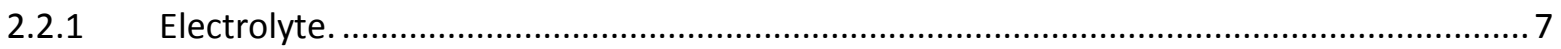

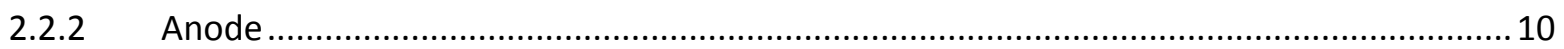

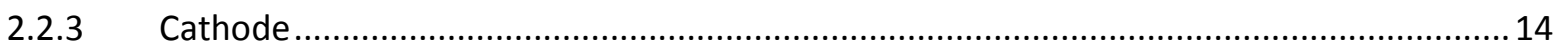

2.3 Characterization of SOFC from materials to operated cells with TEM ....................................15

2.3.1 Materials synthesis and modification ........................................................................ 16

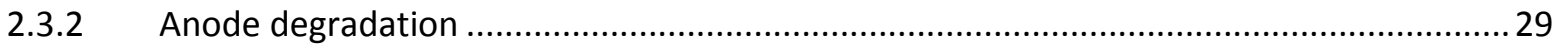

2.3.3 Cathode degradation and performance enhancement by infiltration .............................37

Chapter 3: Nanostructure and chemistry evolution of the anode in SOFCs operated in $\mathrm{H}_{2}$ or syngas .......50

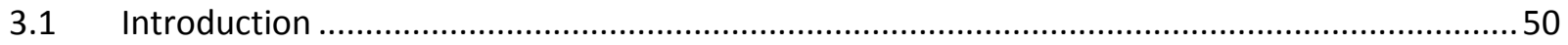

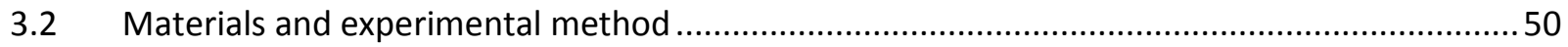

3.3 YSZ structure in different components and anode TPB area in as-received SOFC ....................52

3.4 YSZ structure in the different components and anode TPB area in SOFC operated with syngas 
3.5 YSZ structure in the different components and anode TPB area in SOFC operated with wet hydrogen

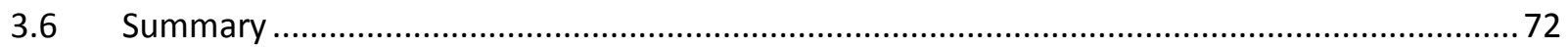

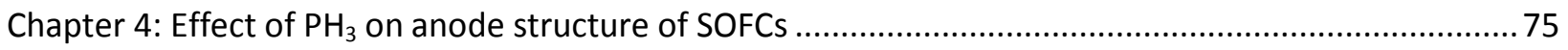

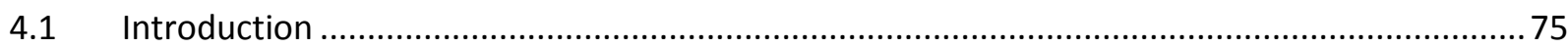

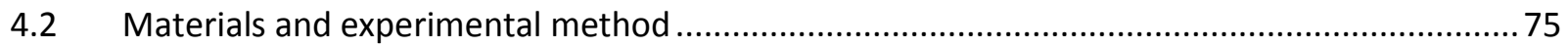

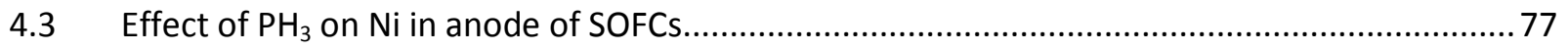

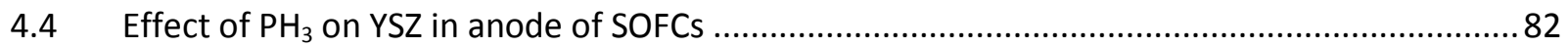

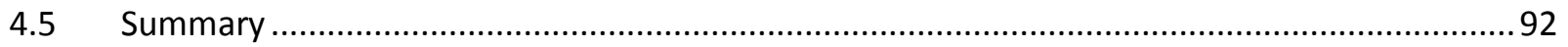

Chapter 5: Evolution of the nanostructure and chemistry of SOFC cathode with infiltration ..................95

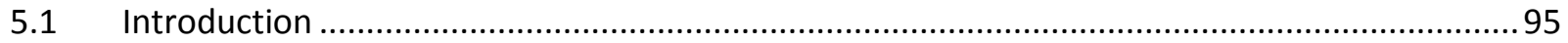

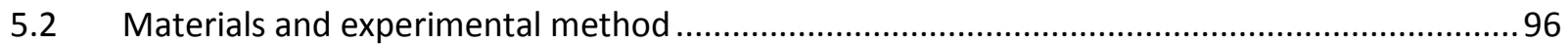

5.3 Cathode structure of LSCo infiltrated SOFCs without operation .........................................97

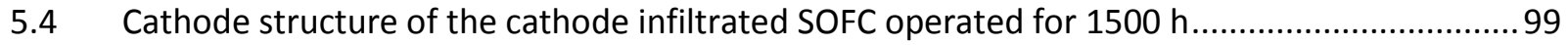

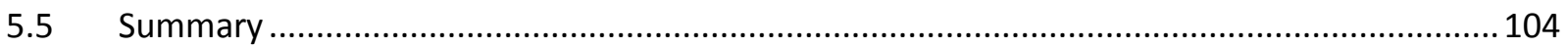

Chapter 6: Conclusions and recommendations for the future works ................................................ 106

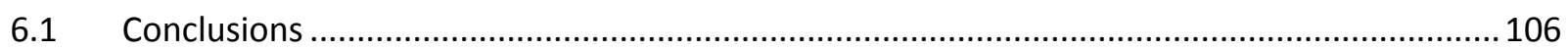

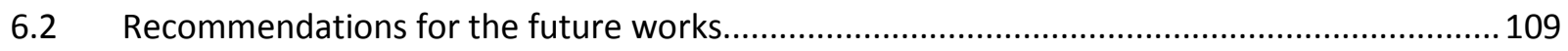

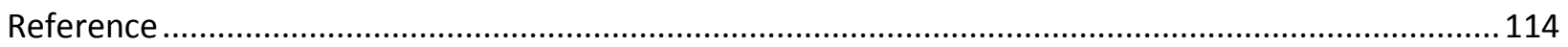

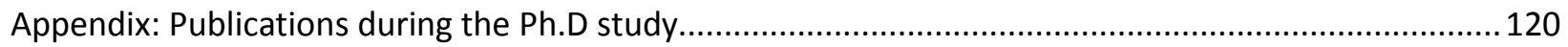




\section{Acknowledgement}

I would like to express my gratitude to my advisor Dr. Xueyan Song for her guidance through the whole research project. She has been a great support throughout my doctorate program in both academic and extracurricular activities. I am glad to have the opportunity to finish the doctoral degree under her guidance.

I would also thank all committee members: Dr. Darran R. Cairns, Dr. Harry O. Finklea, Dr. Xingbo Liu and Dr. Edward M. Sabolsky, for their valuable support and suggestions.

I also appreciate the help from my group members, especially Dr. Yun Chen, who gave me huge help in cell operation and discussion. I also appreciate the help from the colleagues of National Energy Technology Lab for the cell testing.

Finally, I would like to dedicate this dissertation to my family, especially my wife Xueting Zhao, for their consistent support during my study. 


\section{List of Figures}

Figure 1. Schematic diagram of a working SOFC. Source: NASA website[10]. ........................................ 5

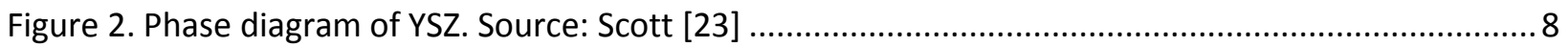

Figure 3. Conductivity of nickel/ $\mathrm{ZrO}_{2}$ cermet as a function of nickel content $\left(\mathrm{T}=1000^{\circ} \mathrm{C}\right)$. Source: Dees

[44].

Figure 4. Scanning electron micrographs of a $\mathrm{Cu} / \mathrm{CeO}_{2} / \mathrm{YSZ}$ composite (18 vol\%Cu, 9 vol\% ceria) following reduction in humidified $\mathrm{H}_{2}$ at (a) $973 \mathrm{~K}$ for $2 \mathrm{~h}$ and (b) $1173 \mathrm{~K}$ for $5 \mathrm{~h}$. Source: Park [47].

Figure 5. TEM images of $\mathrm{IOO}_{2}-\mathrm{YSZ}$ composite thin films at $200 \mathrm{Kv}$. a) $250 \mathrm{Kx}$ and b) $400 \mathrm{Kx}$. Source: TorresHuerta [58].

Figure 6. (a) SAED pattern and (b-d) typical low magnification TEM images of nanocrystalline GDC powder calcined at $500^{\circ} \mathrm{C}$ for $1 \mathrm{~h}$. The SAED pattern is labelled with interplanar spacings (in $\AA$ ) and the corresponding Miller indices of the fluorite structure. Source: Baker [59].

Figure 7. HRTEM images of GDC calcined at $500^{\circ} \mathrm{C}$ for $1 \mathrm{~h}$ showing nanocrystals aligned in the (a-c) [110], (d) [100], (e) [211] and (f) [411] zone axes. DDPs are inset and the diffraction spots are indexed to the fluorite structure. Source: Baker [59].

Figure 8. TEM images of nanocrystalline GDC powder calcined at $500{ }^{\circ} \mathrm{C}$ for $1 \mathrm{~h}$ and ball-milled at 400rpm for $1 \mathrm{~h}$ : ( $\mathrm{a}$ and b) low magnification, (c) intermediate magnification and (d) HRTEM image showing a nanocrystal aligned in the [110] zone axis. The corresponding DDP is inset and the diffraction spots are indexed to the fluorite structure. Source: Baker [59].

Figure 9. HRTEM images showing the macroporous microstructure of YSZ (a) formed by nanometric particles (b) of approximately 5-10nm (c). Source: Nunez [63].

Figure 10. SEM images of 30wt\% NiO-YSZ composites prepared under air atmosphere at different magnification (a) and (b), and after reduction at $700^{\circ} \mathrm{C}$ under $5 \% \mathrm{H}_{2}-\mathrm{Ar}(\mathrm{c})$. HRTEM images showing the microstructure formed by nanometric (d) and homogenous distribution of $\mathrm{NiO}$ and YSZ particles (e). Source: Nunez [63]

Figure 11. Surface and cross-sectional morphologies of the as-deposited coating: (a) surface morphology, (b) cross-sectional morphology, (c) magnified cross-sectional morphology. Source: He [64].

Figure 12. A bright-field TEM image of the YSZ coating. Source: He [64].....

Figure 13. TEM micrograph of $\mathrm{NiAl}_{2} \mathrm{O}_{4}$ grain (marked with arrow) prior to anode reduction, with <011> selected area diffraction inset. Source: Knibbe [67]. 
Figure 14. STEM micrograph of anode | electrolyte interface after anode reduction, with corresponding Al (b) and $\mathrm{Ni}$ (c) elemental maps. From nickel elemental map, nickel aluminate is still found in electrolyte and appears unaltered after anode reduction. Source: Knibbe [67].................................................26

Figure 15. Dark-field TEM micrograph of $\mathrm{NiAl}_{2} \mathrm{O}_{4}$ grain after anode reduction, in $\mathrm{YSZ}$ matrix with <011> selected area diffraction pattern inset. Additional reflections in pattern, indicated by arrows, are attributed to $\mathrm{YSZ}$ from adjacent grain. $\mathrm{NiAl}_{2} \mathrm{O}_{4}$ grows out into surrounding grain boundaries. Source: Knibbe [67].

Figure 16. STEM images of anode / electrolyte interface after $500 \mathrm{~h}$ of fuel cell operation, with <011> selected area diffraction pattern inset. Source: Knibbe [67].

Figure 17. Dark-field images taken with a $\{112\}$ reflection of tetragonal phase indicated by a triangle in (e) of (a) 8YSZ, (b) 8YSZ-H, (c) 10YSZ and (d) 10 YSZ-H . 28

Figure 18. SAED patterns along the [110] zone axis from (a) 8YSZ, (b) 10YSZ and (c) 16YSZ .29

Figure 19. (a) ATEM bright field micrograph showing the whole length of the anode/electrolyte interface. (b) ATEM dark field micrograph of a part of the anode/ electrolyte interface. Imaged with the diffracted beam of the Si-glass phase, the Si-glass phase appears bright. Diffraction pattern of the Siglass phase is also shown. Source: Liu [82]. 30

Figure 20. A TEM micrograph showing the presence of the silicate glass film at a $\mathrm{Ni} / \mathrm{YSZ}$ grain boundary in the anode bulk. Source: Liu [82].....

Figure 21. BSE SEM image of a fresh fractured, as prepared (oxidized) sample. Source: Waldbillig [83].. 32

Figure 22. A BF TEM image of an as prepared sample. Source: Waldbillig [83]. .33

Figure 23. A BF TEM image of a partly reduced sample. Source: Waldbillig [83]. .33

Figure 24. A BF TEM image of a reoxidized sample. Source: Waldbillig [83]. 34

Figure 25. A BF TEM image of a rereduced sample. Source: Waldbillig [83]. 34

Figure 26. TEM image and chemical element distribution mapping analyzed in the vicinity of the NiSDC/LSGM interface after cell performance evaluation. Source: Kawahara [84]. 36

Figure 27. TEM image and chemical element distribution mapping of Ni-SDC anode after cell performance evaluation. Both $\mathrm{Ni}$ and SDC grains were in this area. Source: Kawahara [84]. 36

Figure 28. Spot analysis of YSZ grains in the electrolyte (A) and in the cathode (B). Source: Grosjean [89].

Figure 29. Chemical map analyses of La, Sr, Mn, Zr, Y and O in the cathode. Source: Grosjean [89]........40 
Figure 30. Cross section of an SOFC with screen-printed GDC layer. Tungsten (W) has been deposited indicating the lamella that is to be prepared by FIB. (left: SEM image, right: in situ lift-out lamella, TEM bright field image). Source: Uhlenbruck [93]...

Figure 31. TEM bright-field image of an electrolyte-GDC interface of an SOFC with EB-PVD GDC layer with the element distribution map by TEM-EDS. Source: Uhlenbruck [93].

Figure 32. SEM image of LSM-YSZ composite prepared by impregation. Source: He [95].....

Figure 33. Electrical conductivities at 973K for LSM-YSZ composites as a function of composition. Data are shown for samples prepared from the $(\square)$ mixed powders and by impregnation followed by sintering to (घ) 1523 or $(\bullet) 1073$ K. Source: He [95]. .43

Figure 34. An SEM image of the electrode following infiltration of $40 \mathrm{wt} \% \mathrm{LSF}$ and calcination to $1123 \mathrm{~K}$.

Source: Bidrawn [96]. .44

Figure 35. SEM of the LSCo-YSZ composite prepared by impregnation. Source: Huang [97]. .45

Figure 36. Impedance spectra from symmetric cells, measured in air at $973 \mathrm{~K}$ as a function of time, using $30 \mathrm{wt} \%$ LSCo in YSZ as electrodes. The measurements were taken after the following times: $\bullet 2,05.5$,

$\Delta 24, \Delta 72, \mathbf{2 5 0}$ h. Source: Huang [97]. .45

Figure 37. SEM image of cathode with 6 wt\% LSCo infiltration. Source: Lee [99]. 46

Figure 38. IR-corrected electrode overpotential-current desity plot for LSCo infiltrated SOFCs. Electrode overpotential was estimated by subtracting ohmic resistance contribution from an overall V-I polarization curve of the SOFCs, which was measured after applying a current density of $0.25 \mathrm{~A} / \mathrm{cm}^{2}$ for

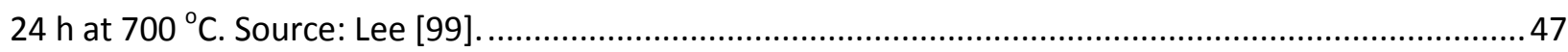

Figure 39. TEM image of Pd-YSZ cathode with a Pd loading of 5 wt.\%.Source: Liang [100]. ................... 48

Figure 40. Diffraction contrast image from the anode side of the as-received cell. ................................53

Figure 41. High resolution TEM image showing the morphology of the grain boundary between $\mathrm{NiO}$ and YSZ in the as-received cell. The YSZ grain is aligned in the [110] direction .... 54

Figure 42. Electron diffraction patterns taken from the [110] zone axis of YSZ grains in the (a) cathode active layer (b) electrolyte, and (c) anode active layer. The indices are given according to the fcc fluorite structure.

Figure 43. Electron diffraction patterns taken from the [110] zone axis of YSZ grains from (a) pure YSZ pellet and (b) YSZ/LSM composite pellet sintered at $1100^{\circ} \mathrm{C}$.

Figure 44. Electron diffraction and diffraction contrast images taken from $550 \mathrm{~h}$ operated cell. (a) cathode active layer, and (b) anode active layer. The inserted images show the diffraction patterns taken from [110] YSZ. In addition, an intergranular ribbon phase between YSZ and Ni can be observed and is pointed out by arrows. 
Figure 45. Systematic electron diffraction patterns from different zone axis of YSZ in the anode of the cell operated in syngas. The indices are given according to the fcc fluorite structure. 59

Figure 46. High resolution TEM image and the corresponding power spectrum from the YSZ in the SOFC anode of the cell operated in syngas. 60

Figure 47. (a) High resolution TEM image taken from the YSZ in the anode side; and (b) the same HRTEM image with dot lines circling the regions which clearly feature $t$-YSZ domains. 61

Figure 48. (a) EDS spectrum taken from the new Ni/YSZ intergranular phase. (b) Diffraction pattern taken from the new Ni/YSZ intergranular phase matching the diffraction pattern of $\mathrm{NiO}$ [011] zone axis.

Figure 49 TEM image taken from the Ni/YSZ GBs (pointed out by a red arrow) close to TPB area in the fully reduced cell (SOFC-R), revealing free of NiO interphase at Ni/YSZ GBs in the anode of the unoperated cell.

Figure 50. Microstructure of anode TPB and ribbon phase in the cell No.5 operated for $24 \mathrm{~h}$ in syngas. The inserted image magnifies the thickness of the ribbon. 64

Figure 51. High resolution TEM images showing (a) a $~ 5-10 \mathrm{~nm} t$-YSZ layer and (b) a $c$-YSZ domain between $t$-YSZ layers along the original Ni/YSZ GB.

Figure 52. High resolution TEM image of a YSZ/YSZ grain boundary in the anode active layer.

Figure 53. High resolution TEM image showing the grain boundary between a YSZ grain and a LSM grain.

Figure 54. TEM image showing the $\mathrm{Ni} / \mathrm{Ni}$ GBs and $\mathrm{Ni} / \mathrm{YSZ}$ interface close to TPB area of the cell operated in $\mathrm{H}_{2}$ for $24 \mathrm{~h}$ (SOFC-H-1). Ni/YSZ GBs are indicated by red solid arrows, and $\mathrm{Ni} / \mathrm{Ni}$ GBs are indicated by yellow dash arrows. The inserted image magnifies the thickness of the ribbon phase.

Figure 55. TEM image showing the NiO layer at Ni/YSZ interface close to TPB area of the cell operated in $\mathrm{H}_{2}$ for $540 \mathrm{~h}$ (SOFC-H-2). The inserted image showing the diffraction pattern from YSZ grain.

Figure 56. TEM image showing the NiO layer at Ni/YSZ interface close to TPB area of the cell operated in (a) $97 \% \mathrm{H}_{2}+3 \% \mathrm{H}_{2} \mathrm{O}$ (SOFC-H-3) and (b) $25 \% \mathrm{H}_{2}+3 \% \mathrm{H}_{2} \mathrm{O}+72 \% \mathrm{~N}_{2}$ (SOFC-H-4) for $200 \mathrm{~h}$. 72

Figure 57. SEM cross-sectional image showing the baseline cell operated in hydrogen for only $24 \mathrm{~h}$, the inserted image showing the enlarged view of the anode surface.

Figure 58. SEM cross-sectional image showing the cell SOFC-P-1 operated in syngas containing phosphine for $117 \mathrm{~h}$, the left inserted image showing the enlarged view of the anode surface and the right one showing the plane-view the anode surface.

Figure 59. SEM cross-sectional image showing the the cell SOFC-P-2 operated in $\mathrm{H}_{2}$ containing phosphine for $117 \mathrm{~h}$. 
Figure 60. TEM contrast images of SOFC-P-1 (a) overall anode, rectangle area indicating the new phase and (b) enlarged image of the new phase area, the dot indicating the position of EDS spectrum (c) obtained.

Figure 61. The SAED patterns and HRTEM images of Ni-P phase, taken from different zone axes (a) zone axis 1 SAED pattern, (b) zone axis 2 SAED pattern, (c) HRTEM image from zone axis 1, (d) HRTEM image from zone axis 2 .

Figure 62. HRTEM images showing the $t$-YSZ ribbon phase (a\&b) and $c$-YSZ domain (c) along the Ni/YSZ interface for the sample (SOFC-P-1) operated in syngas with phosphine for $117 \mathrm{~h}$.

Figure 63. (a) TEM image showing a Ni/YSZ interface of the SOFC-P-2 operated in hydrogen with phosphine for $117 \mathrm{~h}$. Two insert fast Fourier transformation images were taken from two different regions as enclosed by a dash line box I and two dash line boxes II and III, indicating the mixture of $c$-YSZ and $t$-YSZ in YSZ grains and $t$-YSZ domains along the Ni/YSZ interface, respectively. $t$-YSZ domains indicated with the dash circles, the enlarged image of which is shown in (b), could be observed to form along the $\mathrm{Ni} / \mathrm{YSZ}$ interface.

Figure 64. (a) TEM image showing a typical Ni/YSZ interface showing the $t$-YSZ and $c-Y S Z$ domains formation. (b) the EDS acquisition positions denoted by the circles along the Ni/YSZ interface and towards the Ni or YSZ grain. (c) Y/Z ratio along the four directions in the (b), dash line representing the 8 mol\% $\mathrm{Y}_{2} \mathrm{O}_{3}$ doping YSZ (8YSZ), four sets of symbols representing four directions, each symbol representing one EDS acquisition.

Figure 65. (a) TEM image of a new Y-P-O phase (arrow indicating) formation at the Ni/YSZ interface, (b) the EDS spectrum of the Y-P-O phase and (c) diffraction pattern of the Y-P-O phase matching the [001] zone axis of $\mathrm{YPO}_{4}$.

Figure 66. (a) and (b) show the microstructure of the $\mathrm{Ni} / \mathrm{YPO}_{4}$ and $\mathrm{YPO}_{4} / \mathrm{YSZ}$ boundaries, respectively. Two particles which were indicated by arrows are precipitates.

Figure 67. Diffraction contrast images from the cathode side of the as-received cell with $6 \mathrm{wt} \% \mathrm{LSCo}$ infiltration. The numbers in the images showing the EDS acquisition positions.

Figure 68. Diffraction pattern taken from the infiltrates in infiltrated SOFC without operation, diffraction rings are indexed as those from different planes of LSCo with cubic structure......

Figure 69. (a) Typical diffraction contrast image of cathode with LSCo infiltration in SOFC operated at $750^{\circ} \mathrm{C}$ for $1500 \mathrm{~h}$. (b) enlarged image of dashed area in (a) showing the infiltration particles. (c) HRTEM image of dashed area in (b) showing the new phase formation, inserted diffraction pattern is taken from the new phase confirming it is $\mathrm{CO}_{3} \mathrm{O}_{4}$. 101

Figure 70. Diffraction contrast image at interface of YSZ electrolyte and SDC buffer layer showing the $\mathrm{SrZrO}_{3}$ formation and $\mathrm{YSZ} / \mathrm{SDC}$ inter-diffusion. 
Figure 71. Diffraction contrast image showing the YSZ electrolyte and YSZ with minor SDC diffusion, the inserted SAED patterns taken from different regions in this area. ...................................................... 103 


\section{List of Tables}

Table 1 The information of the operation and cooling condition of the SOFCs in chapter $3 \ldots \ldots \ldots \ldots \ldots \ldots . . . . . .52$

Table 2 EDS chemical composition examination on YSZ grains showing the Y/Zr Atomic Ratio in the anode, cathode, and electrolyte of the as-received cell ....................................................................... 55

Table 3 The information of the operation and cooling condition of the SOFCs in chapter $4 \ldots \ldots \ldots \ldots \ldots \ldots . . . . . . . .76$

Table 4 EDS chemical composition examination on LSCo infiltrates in Figure 67 (atomic percentage is used in this table).

Table 5 EDS chemical composition examination on LSCo infiltrated cathode in SOFC operated at $750^{\circ} \mathrm{C}$ for $1500 \mathrm{~h}$ (atomic percentage is used in this table) 


\section{Chapter 1: Introduction}

\subsection{Background}

Solid Oxide Fuel Cells (SOFCs) are clean and efficient alternatives to conventional power generation technology [1]. In comparison to other type of fuel cells, SOFCs have the additional versatility of using multiple fuels, including coal-derived syngas. Yttria-stabilized zirconia (YSZ) based SOFCs are typically composed of a YSZ electrolyte, a (La, $\mathrm{Sr}$ ) $\mathrm{MnO}_{3} / \mathrm{YSZ}$ composite as the cathode, and a porous composite of Ni-YSZ cermets as the anode. Electrochemical reactions take place on the triple-phase boundaries (TPBs) between the YSZ electrolyte, the electrode and the gaseous fuel. Small changes in TPB chemistry can drastically modify the SOFC oxygen exchange rate, and affect SOFC performance and lifetime [2-6].

During operation of SOFCs at elevated temperature, some impurities and dopants segregate to GBs and the chemistry and atomic structure of electrolyte/electrode interface changes, both of which affect the subsequent electrochemical reactions. Understanding how SOFC performance depends on the atomic structure and chemistry of TPBs is critical to use realistically coal-derived syngas as fuel. The nanostructure and chemistry analysis of contaminant and dopant distribution will provide information critical to understanding the tolerance and microstructural stability of anode materials to trace contaminants in coal-derived syngas. This analysis also is important to controlling the YSZ microstructure at the nanoscale and the design of the high quality electrolyte for SOFC. So far, very limited experimental work has been reported on the structure and defects inside YSZ, and particularly with regard to the defect evolution in the SOFC anode upon cell operation. For example, the performance of the nickel-YSZ anode is known to degrade during 
operation; however, there has been limited report on the detailed analysis of defects inside YSZ and the defect evolution of anode of SOFC upon cell operation.

\subsection{Objective of the research}

The main goal of this research is to use transmission electron microscopy (TEM) to investigate the nanostructure and chemistry of grain boundaries and interfaces including triple phase boundary (TPB) in the SOFC, and their evolution with respect to the cell operation time and types of contaminants in the fuel. And structure and chemistry changes of the cathode with infiltration will be studied as well. In particular, the following aspects are addressed in the present work.

I. Nanostructure and chemistry of the YSZ in the anode, cathode and electrolyte of the as-received commercial SOFC and the evolution of nanostructure and chemistry of the YSZ in the SOFC operated with different conditions.

II. The nanostructure and chemistry of TPB junctions of Ni/YSZ anode from asreceived commercial SOFC.

III. Evolution of the nanostructure and chemistry of anode grain boundaries and TPB junctions of Ni/YSZ anode supported commercial SOFC, upon (1) cell operation duration, (2) fuel of $\mathrm{H}_{2}$ or syngas,

IV. Effect of major trace contaminant such as phosphine on the nanostructure and chemistry of SOFCs operated with different fuel of $\mathrm{H}_{2}$ or syngas. 
V. Evolution of the nanostructure and chemistry of cathode grain boundaries and TPB junctions of Ni/YSZ anode supported commercial SOFC with cathode infiltration.

\subsection{The outline of the dissertation}

The dissertation consists of six chapters including the introduction. Chapter 2 gives the literature review about the major materials used in SOFCs and the previous works which analyzed the nanostructure of the SOFCs with TEM. Chapter 3 investigates the evolution of the nanostructure and chemistry of the anode in SOFCs operated with clean fuel, which is $\mathrm{H}_{2}$ or simulated syngas. Chapter 4 analyzes the effect of contaminant, phosphine $\left(\mathrm{PH}_{3}\right)$, on the nanostructure and chemistry of SOFCs operated with different fuel of $\mathrm{H}_{2}$ or simulated syngas. Chapter 5 presents the evolution of the nanostructure and chemistry of cathode and infiltrated particles in anode supported commercial SOFC with cathode infiltration. Chapter 6 summarizes the present study and recommends some future works. 


\section{Chapter 2: Background and Literature Review}

As mentioned previously, electrochemical reactions take place on the triple-phase boundaries (TPBs) between the YSZ electrolyte, the electrode and the gaseous fuel. Small changes in TPB chemistry can drastically modify the SOFC oxygen exchange rate, and affect SOFC performance and lifetime. During operation of SOFCs at elevated temperature, some impurities and dopants segregate to GBs and the chemistry and atomic structure of electrolyte/electrode interface changes, both of which affect the subsequent electrochemical reactions. Because of the importance of the nanostructure for the electrochemical reactions, a comprehensive literature review is carried out. In particular, a part of the review is focusing on the nanostructure analysis using TEM.

\subsection{Fuel cells and Solid Oxide Fuel Cells}

The fuel cell is a kind of device which could convert the chemical energy from solid, liquid and gas fuels directly to electricity with very high efficiency [1]. Typically, a fuel cell consists of anode, electrolyte and cathode. Fuel fed to the anode is oxidized and the electrons are released to the external circuit, and then the electrons go to the cathode side to reduce the oxidant. The ions (e.g. protons, $\mathrm{O}^{2-}$, etc.) transfer through the electrolyte to make a closed circuit. The first fuel cell with diluted sulphuric acid as electrolyte operated as room temperature was reported by William Grove in 1839 [7]. After Nernst discovered the solid oxide electrolytes in 1899 [8], Baur and Preis operated the first ceramic fuel cell at $1000^{\circ} \mathrm{C}$ in 1937 [9]. Since the fuel cells are commonly named by the type of electrolyte used and to date, only oxides are considered for ceramic fuel cell electrolytes [1], Solid oxide fuel cell (SOFC) became the popular name for the 
ceramic fuel cell. Figure 1 shows the schematic diagram of a working SOFC. In SOFC, the $\mathrm{O}^{2-}$ is the charge carrier through the electrolyte.

\section{Solid Oxide Fuel Cell}

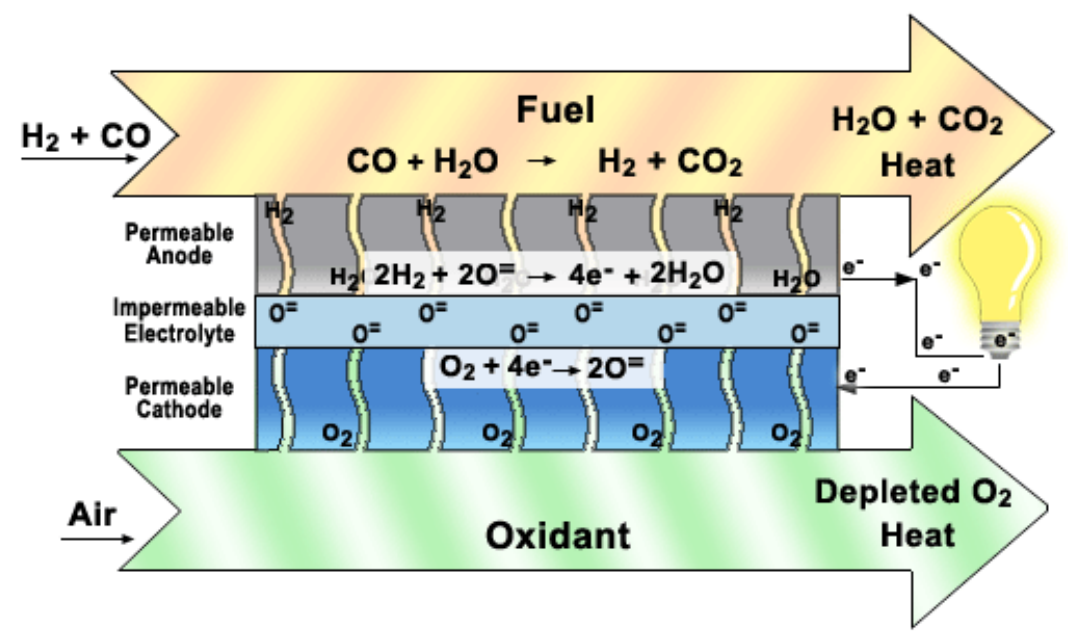

Figure 1. Schematic diagram of a working SOFC. Source: NASA website[10].

Comparing with the other types of fuel cells, the SOFC has several obvious advantages, such as non-precious materials, no liquids involved in the fuel cell and relatively stable electrolyte. The SOFC is usually operated at high temperature $\left(>500^{\circ} \mathrm{C}\right)$, which improves the kinetics of the reaction, tolerance to some impurities in the fuels, and provides a good place to reform the fuels, if needed. The high quality byproduct heat derived from the SOFC could be used for the combined system to further improve the system efficiency. Moreover, since all the components are solid, the SOFC could be easily fabricated into different shapes and very thin layers, which can reduce the loss of the system.

Since the SOFC is operated at very high temperature, there are many requirements for the different components. Firstly, the chemical stability is required. The anode materials should be chemical stable in reducing environment while the cathode materials should be stable in 
oxidizing environment. Both of the electrodes must be porous to promote the gas transport. The electrolyte must be stable in either reducing or oxidizing atmosphere and compatible with electrodes, which means it is not only reaction-free with the electrodes but also with similar thermal expansion coefficients with them. The electrolyte should be dense to prevent gas leakage between the electrodes, since it could decrease the output voltage. The mechanical properties are also considered for all components. All of these requirements should be satisfied at even higher temperature than the operating temperature, because the fabrication (e.g. sintering) temperature is usually higher than the operating temperature. For the commercial consideration, the cost is another important issue.

There are a lot of fuels, which could be used in SOFC, such as hydrogen, natural gas, coal synthesis gas (syngas), hydrocarbons, etc. The hydrogen is the most common fuel in research, but its cost is high. Since the United States has the No.1 estimated world coal reserves [11], the coal syngas became more and more attractive fuel for the SOFC [12-21]. In order to investigate the effects of impurities in the syngas on the cell performance and cell degradation, the simulated syngas, which only contains $\mathrm{H}_{2}, \mathrm{CO}, \mathrm{CO}_{2}$ and $\mathrm{H}_{2} \mathrm{O}$, is used with or without impurities.

\subsection{Materials for SOFC Components}

As mentioned in the last section, the materials used in the different components of SOFC should meet some certain requirements. There is no material, which can be perfect in every aspect. This section will give the summary for the materials used in different components of SOFC. 


\subsubsection{Electrolyte.}

Stabilized Zirconia: Stabilized zirconia $\left(\mathrm{ZrO}_{2}\right)$, is the most common electrolyte material used in SOFC, especially yttria-stabilized zirconia (YSZ), because this material has good oxygen-ion conductivity and shows required stability in both reducing and oxidizing atmospheres [22]. The undoped $\mathrm{ZrO}_{2}$ is not a good electrolyte due to its very low oxygen-ion conductivity. From the phase diagram in Figure 2 reported by Scott in 1975 [23], at room temperature, $\mathrm{ZrO}_{2}$ is with monoclinic $(m)$ crystal structure. The monoclinic structure changes to a tetragonal (t) structure above $1170^{\circ} \mathrm{C}$ and to a cubic fluorite form above $2370^{\circ} \mathrm{C}$ [1]. Adding certain bivalent or trivalent oxides can not only stabilizes the cubic fluorite structure of $\mathrm{ZrO}_{2}$ from room temperature to its melting point, but also increase the oxygen vacancy concentration, which can enhance the ionic conductivity, making stabilized $\mathrm{ZrO}_{2}$ suitable for use as an electrolyte in SOFC. Some oxides with bivalent or trivalent cations with proper size, comparing to $\mathrm{Zr}^{4+}$, could be used as stabilizing dopants, such as $\mathrm{CaO}, \mathrm{MgO}, \mathrm{Y}_{2} \mathrm{O}_{3}, \mathrm{Sc}_{2} \mathrm{O}_{3}$ and certain rare-earth oxides. Among these oxides, the YSZ is most widely used. Yttria doping can increase the oxygen vacancy concentration and change the YSZ structure from monoclinic phase to tetragonal phase and then cubic fluorite phase at room temperature. Figure 2 shows the $\mathrm{ZrO}_{2}$ could be stabilized as cubic phase with about 9 mole\% of $\mathrm{Y}_{2} \mathrm{O}_{3}$ doping. The conductivity of $\mathrm{YSZ}$ increases with increasing yttria doping content up to about 8 mole\% and then decreases for higher yttria additions [2426]. The decrease of conductivity at higher dopant level is due to reduction of defect mobility. 


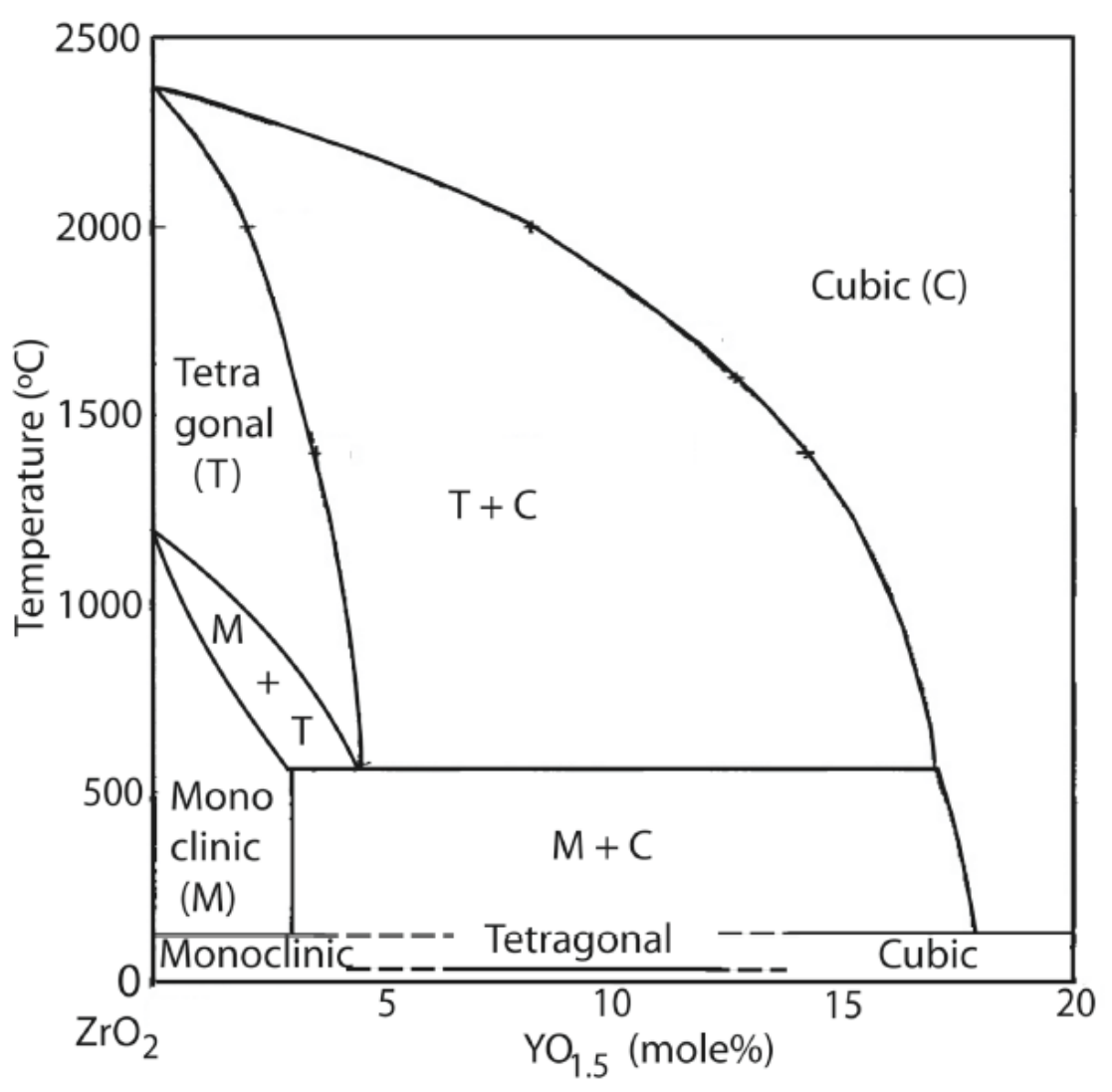

Figure 2. Phase diagram of YSZ. Source: Scott [23]

Comparing with the YSZ, the scandia-stabilized zirconia (ScSZ) shows a higher conductivity in the range of SOFC operation temperatures. The higher conductivity of ScSZ is due to the smaller mismatch in size between $\mathrm{Zr}^{4+}$ and $\mathrm{Sc}^{3+}$, which increase mobility and thus conductivity [26-28]. With higher scandia contents (e.g. 10-12 mole\%) in ScSZ, the cubic phase can transform to a rhombohedral phase with lower conductivity at lower temperature. This phase transform can be limited by controlling the scandia content up to 8 mole\% $[25,29]$ or co-doping with other oxides [30,31]. Although the YSZ does not show the 
highest conductivity, it is still most widely used as SOFC electrolyte due to its availability and cost.

(II) Doped ceria: ceria, which forms the cubic fluorite structure, is another common electrolyte material for SOFC. As compared to zirconia, ceria possesses a higher conductivity, especially at low temperatures, and a lower polarization resistance [32]. Like zirconia, the conductivity of ceria can be improved by doping other oxides. And the ions in oxides with lowest size mismatch to $\mathrm{Ce}^{4+}$ represent the highest conductivity, which is gadolinium and samarium [33, 34]. Compared with YSZ or ScSZ, the most popular ceria-based electrolyte, gadolinia doped ceria (GDC) shows higher conductivity below $600^{\circ} \mathrm{C}$. Like zirconia, the conductivity of GDC increases with increasing doping content to a maximum point then decreases due to the reduction of defect mobility. The main drawback of ceria is electronic conduction at low oxygen partial pressures [27, 32, 34]. However, the chemical stability of ceria with cathode materials is greater than that of zirconia. GDC shows to be stable with all common cathode materials, such as lanthanum strontium manganite (LSM) and lanthanum strontium cobalt ferrite (LSCF) [35, 36]. Since the ceria-based materials have excellent stability with cathode materials, the ceria-based interlayers are used between YSZ and the cathode to prevent reactions [37-42]. Since both the YSZ and ceria phases are with cubic fluorite structure, inter-diffusion could occur, which can form a region with low conductivity due to cations ordering. 
(III) Strontium/magnesium-doped lanthanum gallate (LSGM): $\mathrm{La}_{1-\mathrm{x}} \mathrm{Sr}_{\mathrm{x}} \mathrm{Ga}_{1-\mathrm{y}} \mathrm{Mg}_{\mathrm{y}} \mathrm{O}_{3}$ is a good oxygen-ion conductor at low temperature with perovskite structure. Comparing to the materials mentioned above, LSGM has higher conductivity than YSZ and ScSZ and similar or lower one than GDC. But LSGM is better than GDC for use in low oxygen partial pressures. Since most of the cathode materials forms perovskite structure, the reaction of LSGM with cathodes is usually through inter-diffusion rather than forming a new phase. The most common diffusing element is cobalt. Since the most common anode material is a nickel-YSZ cermet, the interaction between the YSZ electrolyte and anode is not a problem. However, LSGM electrolyte can react with Ni-containing anode to form a resistive phase. Moreover, since formation of a single-phase perovskite could be difficult, it is challenging to develop cost-effective fabrication method for LSGM with desired single-phase perovskite structure.

\subsubsection{Anode}

(I) Nickel-YSZ cermet: Because of the reducing atmosphere, metals can be used in SOFC anode. Nickel is most commonly used in SOFC anode due to its availability and cost. For the real SOFC anode fabrication, one commonly used method [43] is to co-sinter $\mathrm{NiO}$ and YSZ powders in air at high temperatures above $1300^{\circ} \mathrm{C}$. Then, the NiO/YSZ anode and dense YSZ electrolyte are co-fired together. The $\mathrm{NiO}$ is reduced to metallic $\mathrm{Ni}$ with $\mathrm{H}_{2}$ at $800^{\circ} \mathrm{C}$ or above before cell operation. During the reduction from $\mathrm{NiO}$ to $\mathrm{Ni}$, the porosity is created in the anode layer. A sufficient porosity in anode provides good gas transfer. It is importance to connect the YSZ in the anode to the YSZ electrolyte well, because 
this connection can provide a conduction path for $\mathrm{O}^{2-}$ from electrolyte to the anode, which can increase the triple phase boundary (TPB), where the anode reaction takes place. On the other hand, a good connection of $\mathrm{Ni}$ in anode is necessary to provide electrical conductivity. It is reported [44] that the volume \% of $\mathrm{Ni}$ in the anode required to achieve high electronic conductivity is about $30 \%$, at which the $\mathrm{Ni}$ can form an interconnected network. Figure 3 shows the conductivity of $\mathrm{Ni} / \mathrm{ZrO}_{2}$ cermet with different $\mathrm{Ni}$ content. A finer microstructure is good to increase the TPB, thus improve the cell performance. The anode is usually used as supported part for the SOFC, so the potential mechanical problem of this porous part is always considered. Since the active region in the anode extends less than approximately $10 \mu \mathrm{m}$ from the anode-electrolyte interface, a graded porosity is applied to maximum the amount of TPB in the active region and simultaneously provides required mechanical support. The Ni in the anode provides both the electronic conductivity and catalytic activity for the fuel oxidation. The Ni can also catalyze the reforming of the hydrocarbons (eg. $\left.\mathrm{CH}_{4}\right)$ to produce syngas. During this process, carbonaceous deposition becomes a problem, which could be solved by adding steam $\left(\mathrm{H}_{2} \mathrm{O}\right)$ to the fuel. One disadvantage of this Ni/YSZ anode is low tolerance to the sulfur and phosphine impurities, which can poison the Ni catalyst and exists in most fuels. 


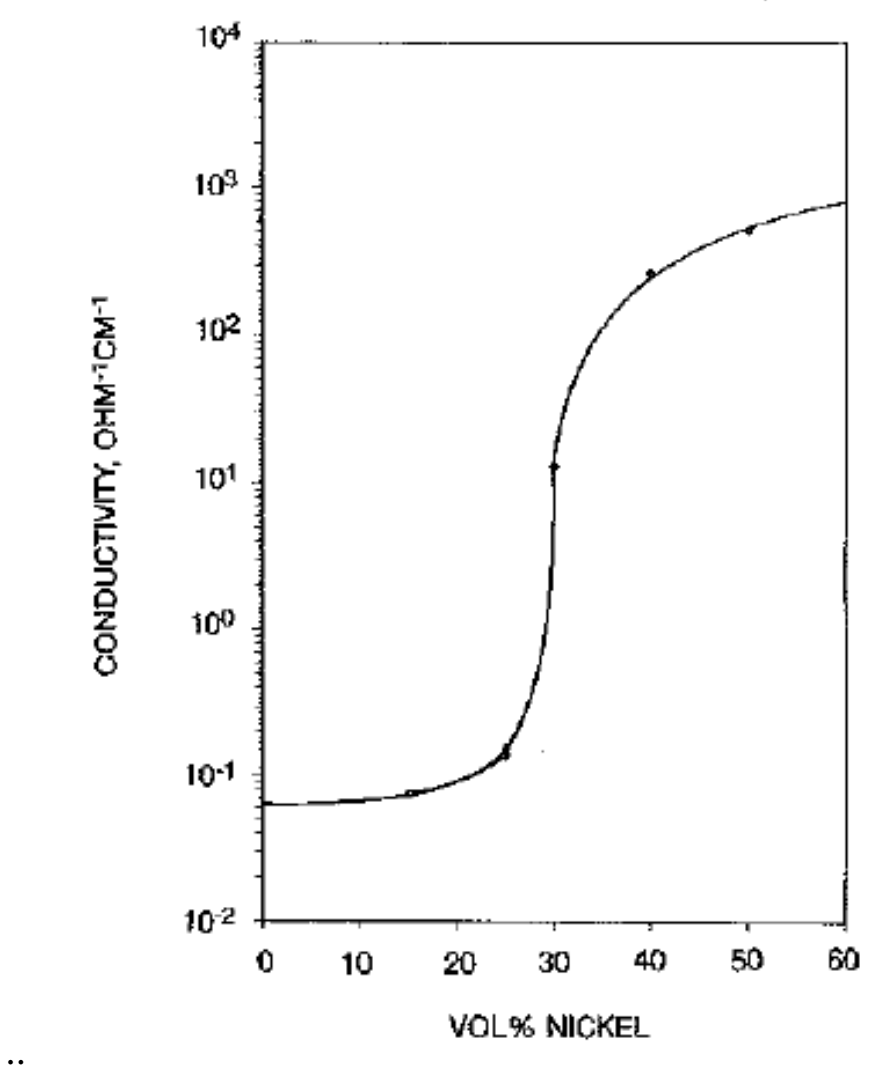

Figure 3. Conductivity of nickel/ $\mathrm{ZrO}_{2}$ cermet as a function of nickel content $\left(\mathrm{T}=1000^{\circ} \mathrm{C}\right)$. Source: Dees [44].

(II) Other anode materials: in order to overcome the drawbacks of $\mathrm{Ni}$ mentioned above, one approach is to use a much less catalytically active metal to replace the $\mathrm{Ni}$ in the anode. One promising choice is $\mathrm{Cu}$. Since the $\mathrm{Cu}$ and copper oxides have lower melting point than the sintering temperature, the traditional anode synthesis technique for $\mathrm{Ni}$ is not suitable for $\mathrm{Cu}$. So the infiltration methods are developed for the fabrication of Cu-based SOFC anode [45, 46]. The general protocol of this method is as follows: porous YSZ anode and dense YSZ electrolyte is sintered first. Then, the porous YSZ scaffold is infiltrated with an aqueous solution of $\mathrm{Cu}\left(\mathrm{NO}_{3}\right)_{2}$ followed by drying and reduced in hydrogen at 
$400^{\circ} \mathrm{C}$ [46]. Another $\mathrm{Cu} / \mathrm{CeO}_{2} / \mathrm{YSZ}$ composite anode developed in ref. [47] is shown in Figure 4. The sintering temperature is critical to form a well-connected $\mathrm{Cu}$ network for electronic conduction. With this anode, the SOFC shows direct electrochemical oxidation activity of hydrocarbons without promoting coke or carbon fiber formation. More than that, this anode exhibits very high sulfur tolerance up to $400 \mathrm{ppm}$. Another choice is to use another ceramic material with electronic conductivity to replace the Ni. The ceramic materials are usually $\mathrm{ABO}_{3}$ oxides with perovskite structure, such as $\mathrm{La}_{0.75} \mathrm{Sr}_{0.25} \mathrm{Cr}_{0.5} \mathrm{Mn}_{0.5} \mathrm{O}_{3}$ (LSCM) [48] and $\mathrm{La}_{0.4} \mathrm{Sr}_{0.6} \mathrm{Ti}_{1-\mathrm{x}} \mathrm{Mn}_{\mathrm{x}} \mathrm{O}_{3}$ (LSTM) [49, 50]. Although the ceramic anodes are stable when operated on hydrocarbons without promoting carbon deposition, the cell performance with ceramic anodes is very poor due to the low catalytic activity for hydrocarbon oxidation. Another interesting anode, especially used in direct carbon SOFC (DC-SOFC), is Liquid metal anode. Tin is the most investigated material for this anode [51-54]. The formation of $\mathrm{SnO}_{2}$ between the YSZ-Sn interfaces should be well considered. 


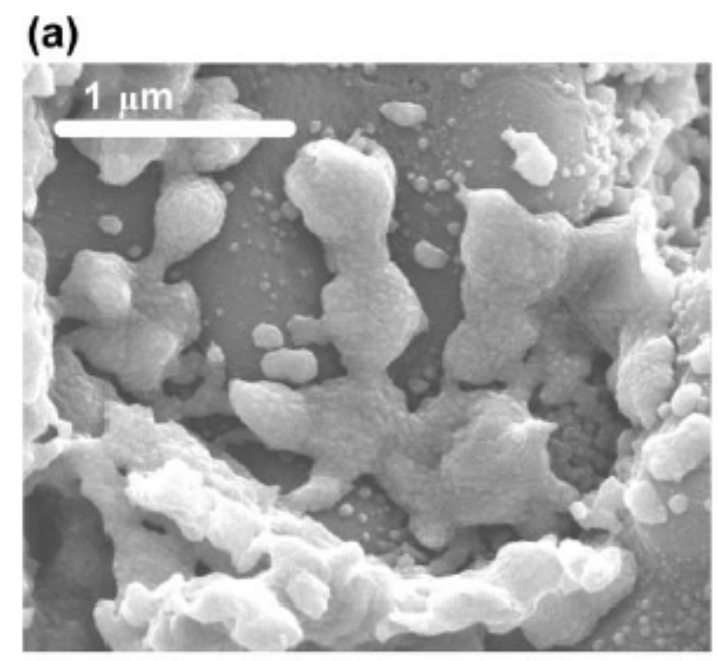

(b)

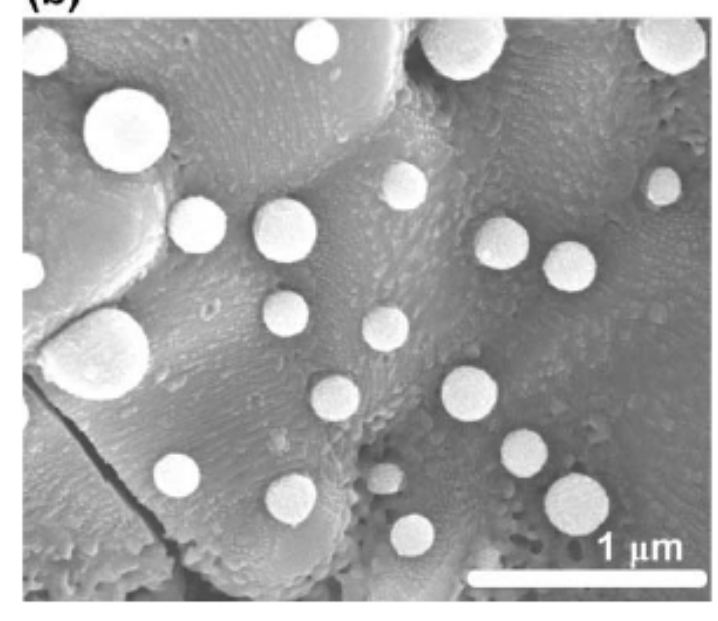

Figure 4. Scanning electron micrographs of a $\mathrm{Cu} / \mathrm{CeO}_{2} / \mathrm{YSZ}$ composite (18 vol\%Cu, 9 vol\% ceria) following reduction in humidified $\mathrm{H}_{2}$ at (a) $973 \mathrm{~K}$ for $2 \mathrm{~h}$ and (b) $1173 \mathrm{~K}$ for $5 \mathrm{~h}$. Source: Park [47].

\subsubsection{Cathode}

(I) Doped Lanthanum Manganite: due to the high temperature and oxidizing atmosphere in the cathode, only noble metals, such as platinum, palladium, or silver, and electronic conducting oxides can be used as cathode materials. Considering the cost issue, the noble metals are not suitable. The most commonly used oxide for the cathode is doped lanthanum manganite $\left(\mathrm{LaMnO}_{3}\right)$, which is a p-type perovskite structure. The conductivity of $\mathrm{LaMnO}_{3}$ is due to the cation 
vacancy, so the conductivity of this material can be enhanced by doping a lowervalence ion on either $\mathrm{La}$ or Mn sites. Strontium doped $\mathrm{LaMnO}_{3}$ (LSM) is the most preferred doping cathode material in SOFC. The electronic conductivity of $\mathrm{LaMnO}_{3}$ is enhanced with doping Strontium by increasing the $\mathrm{Mn}^{4+}$ content [1]

(II) Other Cathode Materials: ferrites and cobaltite shows better electronic or mixed conductivity, but higher chemical and thermal expansion, which may lead to thermomechanical incompatibility to the common electrolyte, such as YSZ [55]. Especially, $\mathrm{La}_{0.6} \mathrm{Sr}_{0.4} \mathrm{Co}_{0.2} \mathrm{Fe}_{0.8} \mathrm{O}_{3-\delta}$ is a promising cathode for SOFCs due to its higher power density than LSM [56]. But it does not exhibit good long term stability. The formation of electrically insulating materials, such as $\mathrm{La}_{2} \mathrm{Zr}_{2} \mathrm{O}_{7}$ and/or $\mathrm{SrZrO}_{3}$, is the major cause to accelerate the cell degradation [57].

\subsection{Characterization of SOFC from materials to operated cells with TEM}

Structural and chemical stability is desired, however, there is no SOFC with perfect materials in all components. Degradation always happens in both electrodes and electrolyte with structure and/or chemistry changes. Small changes in the structure and chemistry of the Ni/YSZ interface and the LSM/YSZ interface, as well as the TPB will affect SOFC performance and lifetime [25]. In the following parts in this section, the characterization of SOFC, from materials to operated cells, will be addressed in term of structure and chemistry. In the materials part, TEM can be used to analyze many aspects, such as particle size, phase homogeneity, effect of material modification and material stability. In the cell part, the long term stability of the cell is the most important issue in SOFCs application. In order to investigate the degradation mechanism, TEM is a powerful technique to analyze the impurities segregation and interface reaction during the 
cell fabrication or cell operation. So the application of TEM in characterizing SOFC will be reviewed in this section.

\subsubsection{Materials synthesis and modification}

In order to enhance the performance of SOFC, many studies are focusing on developing the microstructure of TPB areas. Synthesizing nano-particles is an effective method. In A.M. TorresHuerta's work [58], nanocrystalline $\mathrm{IrO}_{2}$-YSZ composites were synthesized by metalorganic chemical vapor deposition (MOVCD) in order to use in zirconia-based devices. $\mathrm{IrO}_{2}-\mathrm{YSZ}$ films displayed superior electrochemical properties as electrodes to zirconia electrolytes than that exhibited for the Pt-C and conventional Pt paste electrodes. TEM was used to determine the crystalline nature and morphology of the electrodes. The observations of TEM revealed that the $\mathrm{IrO}_{2}$-YSZ composites are constituted by single-phase particles, between 4 and $10 \mathrm{~nm}$ in size, with an excellent composite distribution, which was showed as Figure 5. According to EDS analysis, the dark area corresponds to $\mathrm{IrO}_{2}$ particles that combined or dispersed on cubic YSZ. Selected area diffraction patterns confirm nanometric average particle size obtained during CVD process for $\mathrm{IrO}_{2}-\mathrm{YSZ}$ cermet composites (figure insert).

(a)

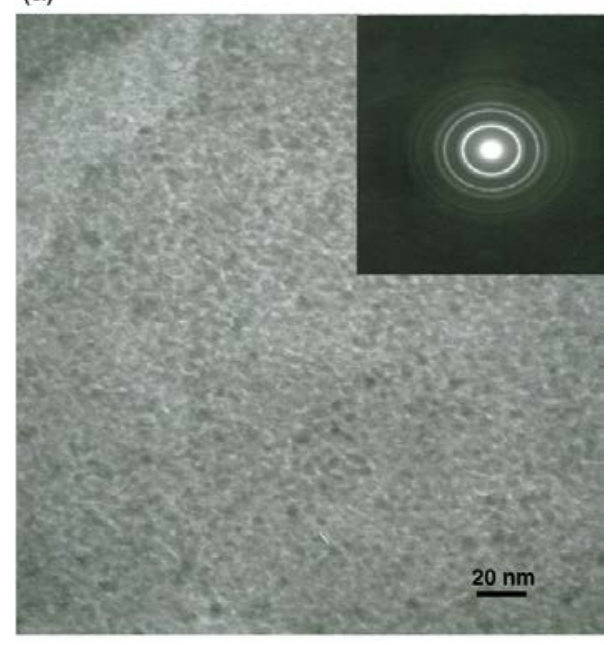

(b)

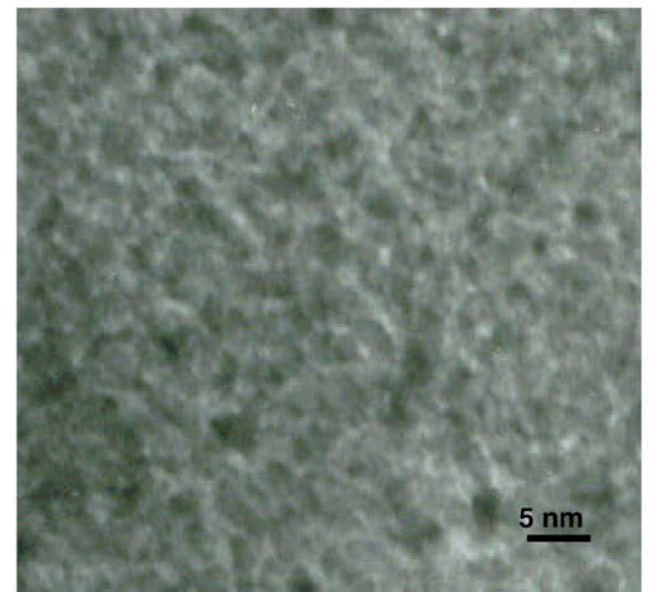


Figure 5. TEM images of $\mathrm{IrO}_{2}-\mathrm{YSZ}$ composite thin films at $200 \mathrm{Kv}$. a) $250 \mathrm{Kx}$ and b) $400 \mathrm{Kx}$. Source: Torres-Huerta [58].

In order to make fine and homogenous particles of different materials, sol-gel technique is widely used in synthesizing both anode [59, 60] and cathode [61] materials for SOFCs. The work, reported by Richard T. Baker [59], provided a variant of the sol-gel technique known as cation complexation, as proposed by Muccillo et al. [62] for preparation of the ceria-gadolinia solid solution. The final nanopowders were evaluated by X-ray diffraction (XRD), SEM and HRTEM. Figure 6 presents an SAED pattern for the as-calcined GDC powder $\left(500^{\circ} \mathrm{C}, 1 \mathrm{~h}\right)$. This is completely consistent with the fluorite structure, which was also found in the XRD results. The TEM images in Figure 6b-d show in more detail the sheet-like structures which were seen at lower magnifications in the SEM images of the powder. It is clear that the sheets consisted of a thin layer of nanoparticles. In the high resolution (HR) TEM images of Figure 7, the morphology and internal crystal structure of individual nanoparticles are seen. The effect of ball milling the as-calcined GDC powder at 400rpm for $1 \mathrm{~h}$ is seen in the TEM images of Figure 8. At low magnifications, the sheet-like structures are much less evident and the secondary structure of the material is considerably more open and less agglomerated than in the unmilled material. The higher magnification images show that the morphology and crystal structure of the individual nanoparticles is no different from those seen in the powder before milling. 


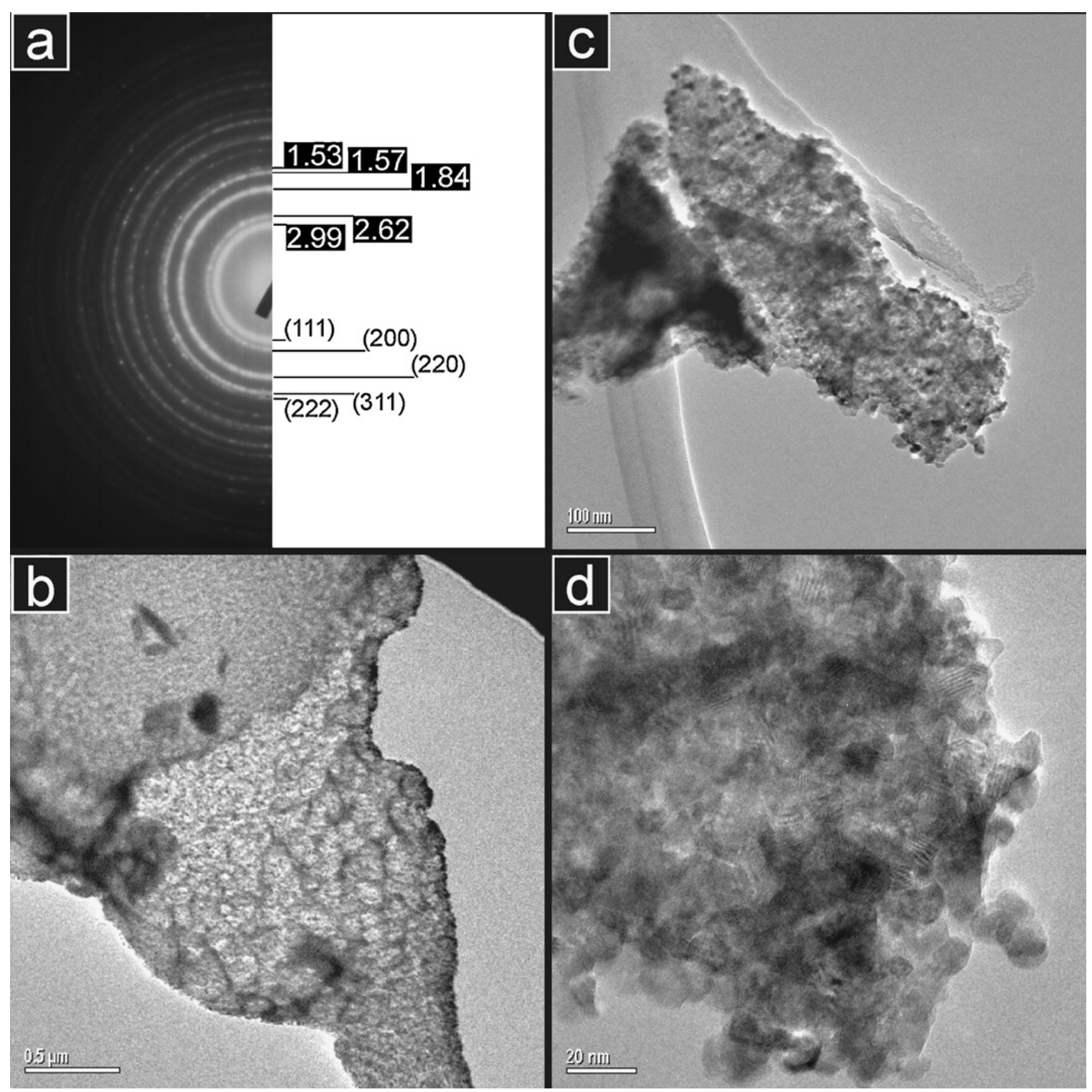

Figure 6. (a) SAED pattern and (b-d) typical low magnification TEM images of nanocrystalline GDC powder calcined at $500^{\circ} \mathrm{C}$ for $1 \mathrm{~h}$. The SAED pattern is labelled with interplanar spacings (in $\AA$ ) and the corresponding Miller indices of the fluorite structure. Source: Baker [59]. 


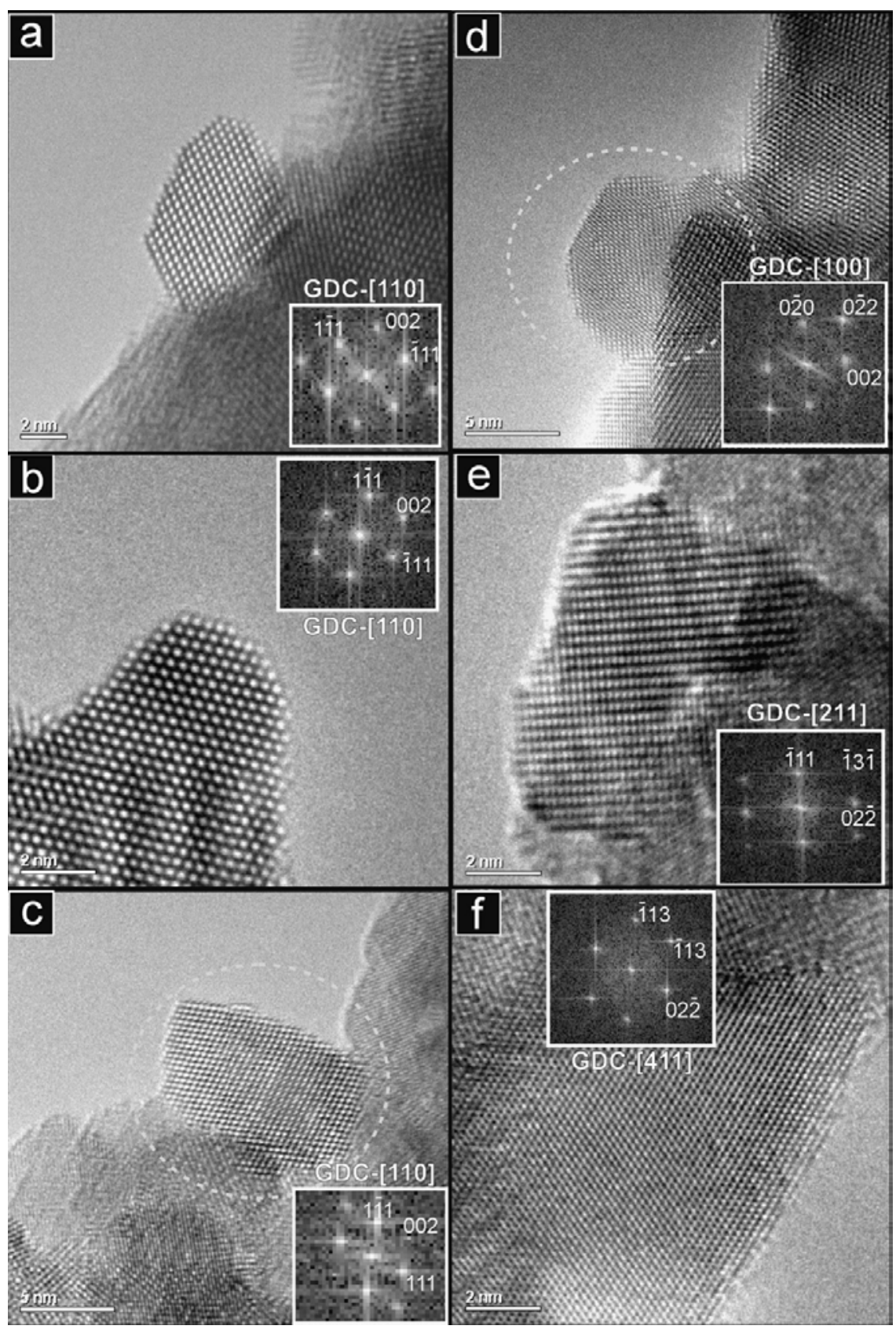

Figure 7. HRTEM images of GDC calcined at $500^{\circ} \mathrm{C}$ for $1 \mathrm{~h}$ showing nanocrystals aligned in the (a-c) [110], (d) [100], (e) [211] and (f) [411] zone axes. DDPs are inset and the diffraction spots are indexed to the fluorite structure. Source: Baker [59]. 


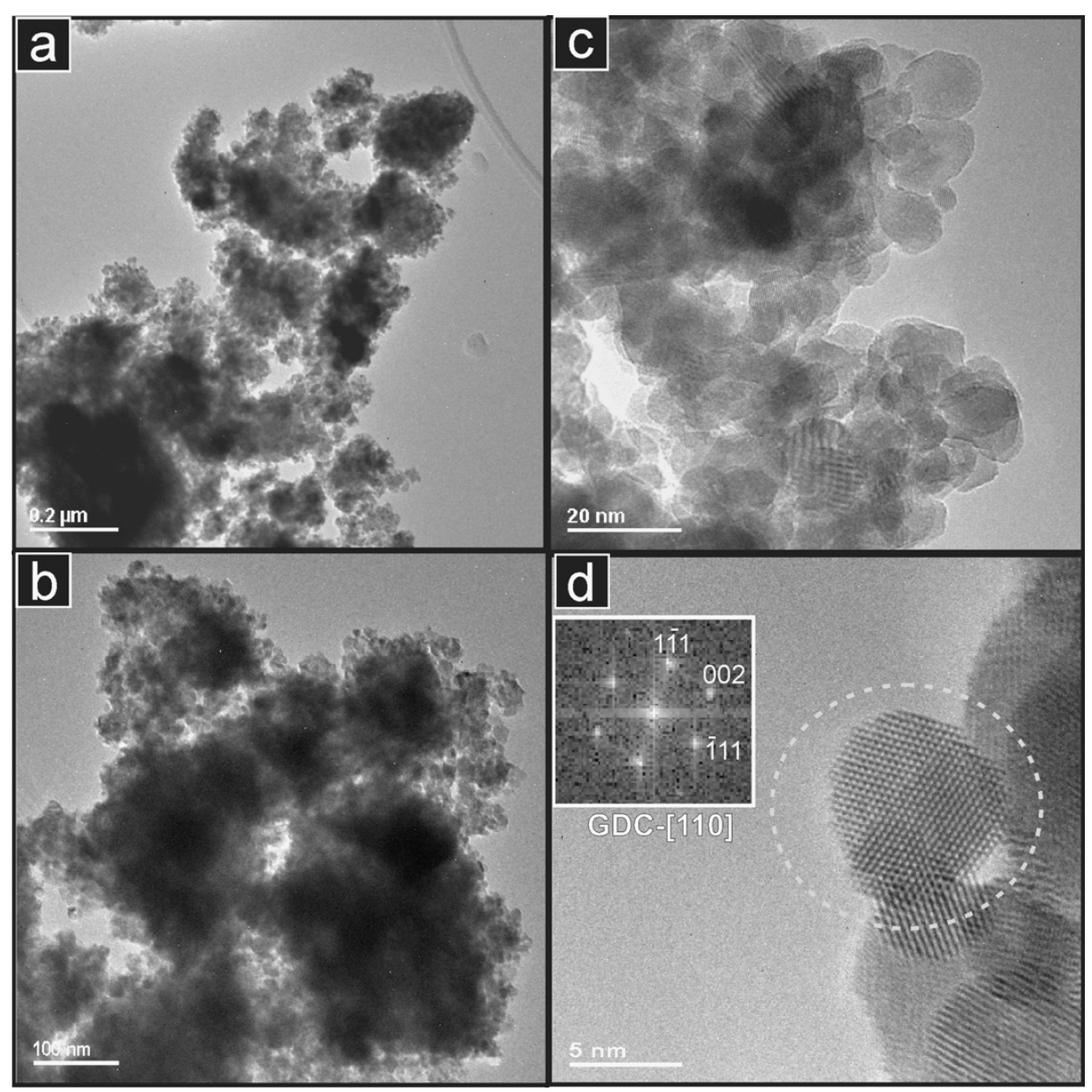

Figure 8. TEM images of nanocrystalline GDC powder calcined at $500{ }^{\circ} \mathrm{C}$ for $1 \mathrm{~h}$ and ball-milled at 400rpm for 1 h: (a and b) low magnification, (c) intermediate magnification and (d) HRTEM image showing a nanocrystal aligned in the [110] zone axis. The corresponding DDP is inset and the diffraction spots are indexed to the fluorite structure. Source: Baker [59].

The porosity of the electrode is an important factor for the cell performance. In this work by P. Nunez [63], a facile and general new method was used to prepare thin layer oxides with controlled pore size for SOFC applications. The method uses aqueous stoichiometric cation solutions of metal nitrates, citric acid as complexing agent and PMMA microspheres as pore former. Yttria stabilized zirconia (YSZ), gadolinium doped ceria (GDC), $\mathrm{La}_{2} \mathrm{Mo}_{2} \mathrm{O}_{9}$ (LMO), $\mathrm{La}_{0.7} \mathrm{Sr}_{0.3} \mathrm{FeO}_{3-\delta}$ (LSF), $\mathrm{La}_{0.8} \mathrm{Sr}_{0.2} \mathrm{MnO}_{3-\delta}$ (LSM), the anode materials $\mathrm{La}_{4} \mathrm{Sr}_{8} \mathrm{Ti}_{11} \mathrm{Mn}_{0.5} \mathrm{Ga}_{0.5} \mathrm{O}_{38-} \delta$ 
(LSTMG) and NiO-YSZ composites were prepared using this approach. The samples were characterized by XRD, SEM, TEM, nitrogen adsorption and mercury porosimetry. Figure 9 shows the microstructure of YSZ formed by nanometric particles of approximately 5-10nm. The SEM and TEM images in Figure 10 show the NiO-YSZ composites microstructure formed by nanometric and homogenous distribution of $\mathrm{NiO}$ and $\mathrm{YSZ}$ particles.
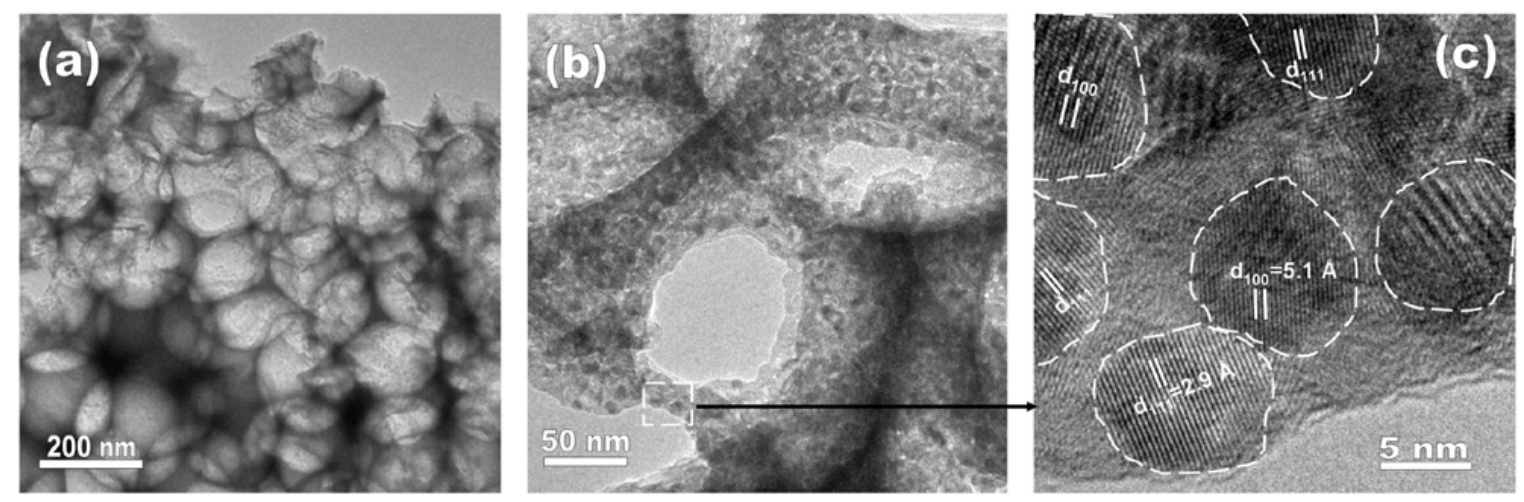

Figure 9. HRTEM images showing the macroporous microstructure of YSZ (a) formed by nanometric particles (b) of approximately 5-10nm (c). Source: Nunez [63].
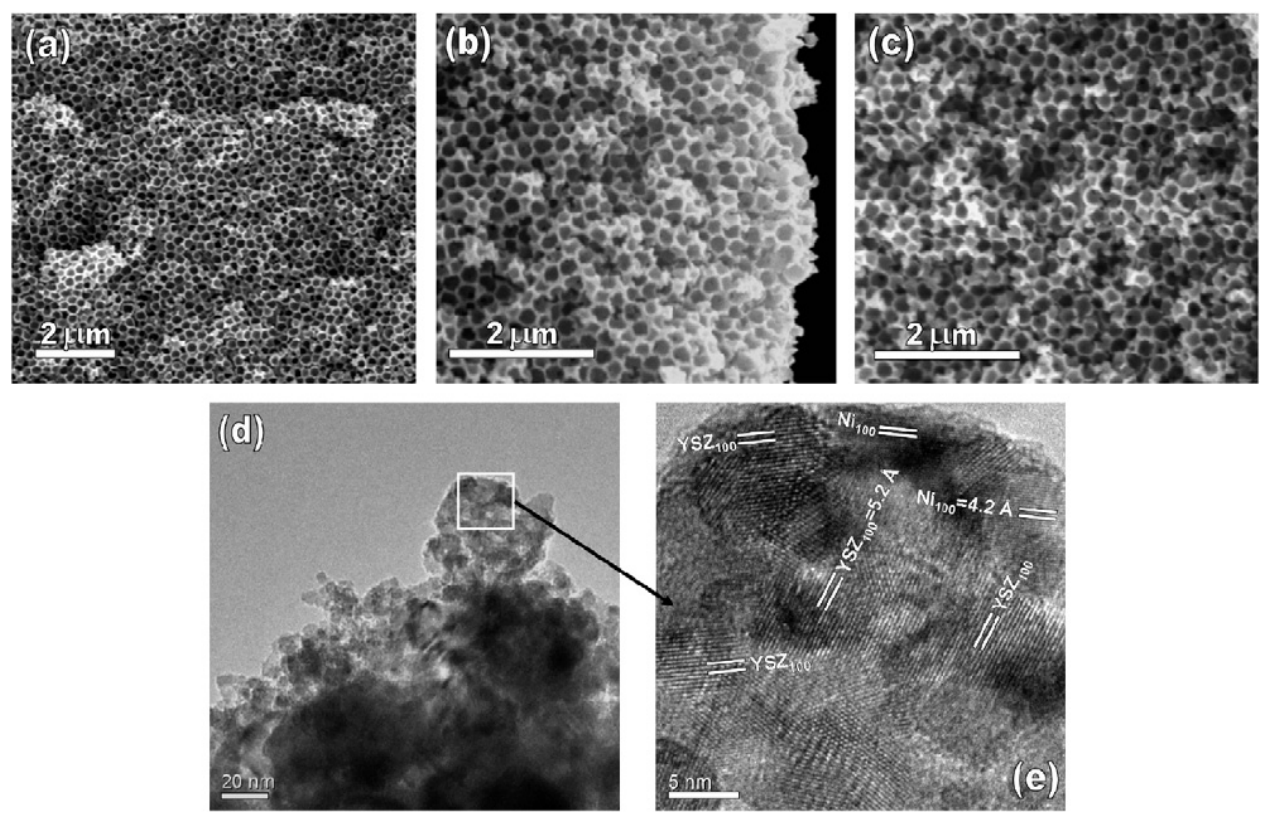

Figure 10. SEM images of 30wt\% NiO-YSZ composites prepared under air atmosphere at different magnification (a) and (b), and after reduction at $700^{\circ} \mathrm{C}$ under $5 \% \mathrm{H}_{2}-\mathrm{Ar}$ (c). HRTEM images showing 
the microstructure formed by nanometric (d) and homogenous distribution of NiO and YSZ particles (e). Source: Nunez [63].

Another potential method to enhance the performance is increasing the conductivity of the electrode and electrolyte. Coating and doping are often used. Coating by using electron beam physical vapor deposition (EB-PVD) [64] or pulsed laser deposition (PLD) [65, 66] is a good method to achieve aligned structure for electrolyte or electrode. In the work by Xiaodong He [64], the 8YSZ coating was prepared by EB-PVD technique at a high deposition rate of 1 $\mathrm{mm} / \mathrm{min}$. Then the microstructure of this coating was characterized and the properties, such as electrical conductivity and gas tightness, were measured. The surface and cross-sectional morphologies were observed by SEM. Before the TEM analysis was conducted, two coating samples were firstly adhered face to face and then inserted into a copper tube with a diameter of $3 \mathrm{~mm}$. Then a slice was cut down from this tube and was thinned in the direction perpendicular to the cross-section of the coating by mechanical grinding combined with Ar ion etching process. The element distribution of the coating was characterized by electron probe microanalysis (EPMA). The surface and cross-sectional morphologies of the as deposited coating are shown in Figure 11. The surface SEM image shows many micron-sized particles in the coating surface and every particle consists of many crystal clusters. The cross-sectional SEM image shows the thickness of the coating, which is about $11 \mu \mathrm{m}$, and good adhesion to the substrate. The coating represents a typical columnar structure normal to the substrate. The diameters of the columnar grains range from several microns to $10 \mu \mathrm{m}$. Figure 12 shows a bright-field TEM image of the YSZ coating, in which many white lines are observed in the YSZ grain in a certain direction. The conductivity of the coating YSZ is measured in both directions perpendicular and parallel to coating surface in temperature range from 500 to $800^{\circ} \mathrm{C}$. An anisotropic behavior of the electrical 
conductivity of the coating is shown. The electrical conductivity in the direction perpendicular to coating surface is remarkably higher than that in the direction parallel to coating surface. But the electrical conductivity of the deposited coating is still lower than the previous 8YSZ bulk due to the existence of many nanopores within the columnar grains.
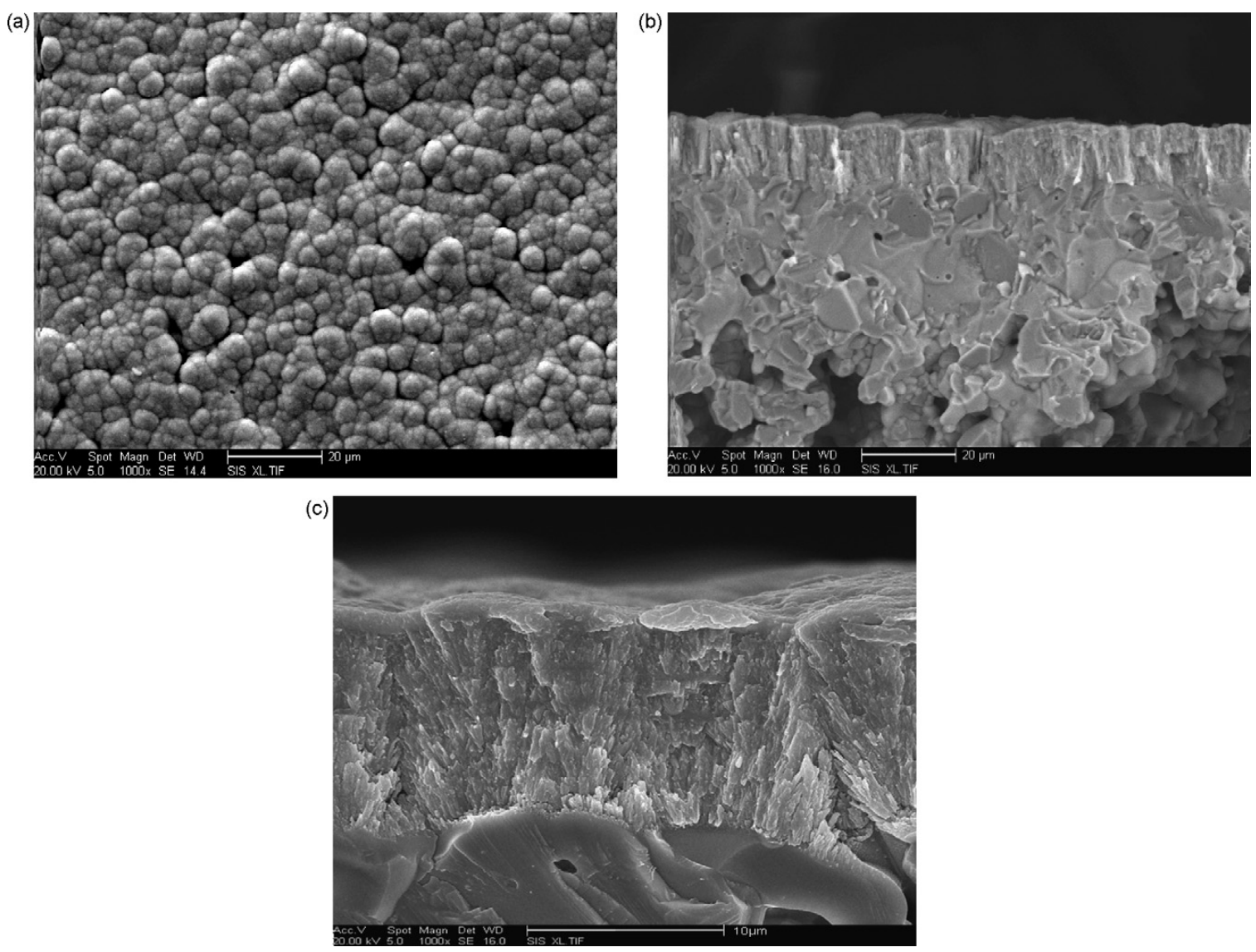

Figure 11. Surface and cross-sectional morphologies of the as-deposited coating: (a) surface morphology, (b) cross-sectional morphology, (c) magnified cross-sectional morphology. Source: He [64]. 


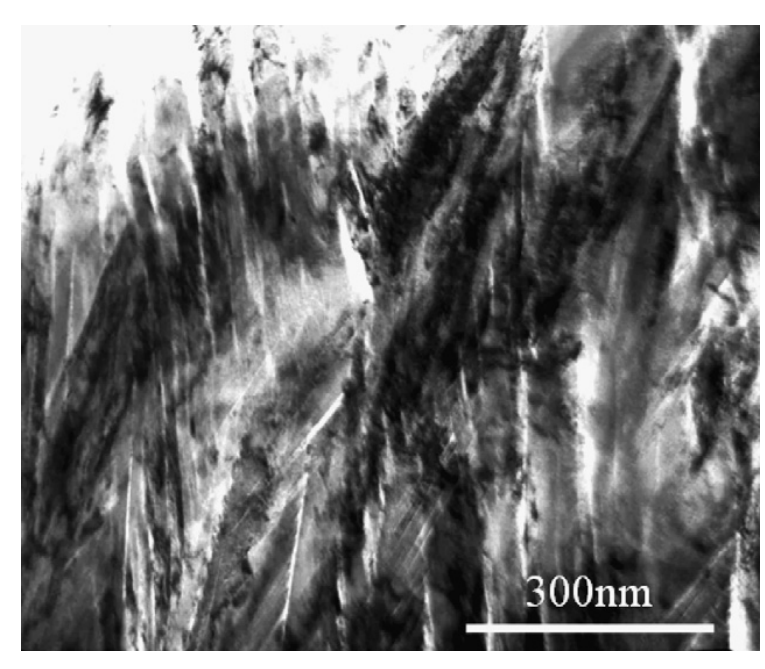

Figure 12. A bright-field TEM image of the YSZ coating. Source: He [64].

Besides the coating, doping materials into the part of SOFCs is a good way to enhance some properties. Two studies, reported by Knibbe, added alumina into the electrolyte to investigate the microstructure and degradation of anode|electrolyte [67] and cathode|electrolyte interface [68] respectively. Anode|electrolyte interfaces are examined after fuel cell production, anode reduction and prolonged fuel cell operation using XRD, SEM and scanning transmission electron microscope (STEM). Subsequently, the influence of anode|electrolyte interactions on the electrical performance is investigated using impedance spectroscopy. $15 \mathrm{wt} . \%$ alumina is added to the commonly used $10 \mathrm{~mol} \%$ YSZ electrolyte to improve both the fracture toughness and grain-boundary conductivity of the electrolyte. TEM selected area diffraction (SAD) (Figure 13) provides further irrefutable evidence that the grains forming in the electrolyte are $\mathrm{NiAl}_{2} \mathrm{O}_{4}$. Nickel and aluminium elemental maps (Figure 14) of the focused ion beam (FIB) TEM sample clearly show the presence of nickel in the alumina grains in the electrolyte. A typical $\mathrm{NiAl}_{2} \mathrm{O}_{4}$ grain taken in dark-field mode using TEM SAD is shown in Figure 15. Furthermore, the lack of additional reflections in the TEM SAD pattern (Figure 16) and the homogeneity of the $\mathrm{NiAl}_{2} \mathrm{O}_{4}$ 
grain confirm that the $\mathrm{NiAl}_{2} \mathrm{O}_{4}$ is still stable after $500 \mathrm{~h}$ of fuel cell operation. The impedance spectroscopy is performed on unreacted sample and reacted sample to evaluate the effect of $\mathrm{NiAl}_{2} \mathrm{O}_{4}$ formation on the ionic conductivity of the electrolyte. The results show that the $\mathrm{NiAl}_{2} \mathrm{O}_{4}$ formation decreases the conductivity of the grain boundaries in the electrolyte, but does not influence the bulk/grain conductivity. At low temperature, the total conductivity is impeded, but at SOFC operating temperature of $850^{\circ} \mathrm{C}$ the total conductivity of the electrolyte is not affected by the formation of $\mathrm{NiAl}_{2} \mathrm{O}_{4}$.

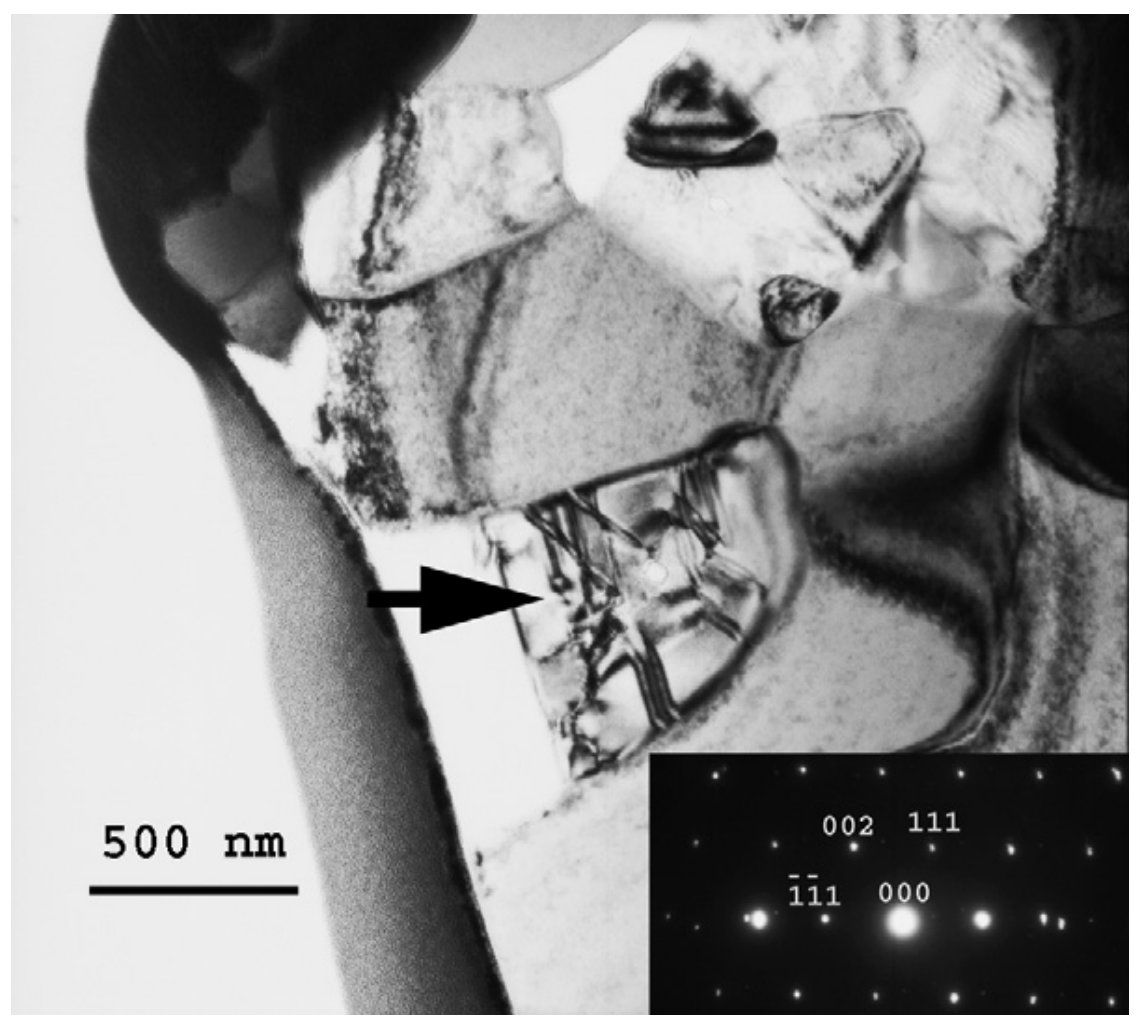

Figure 13. TEM micrograph of $\mathrm{NiAl}_{2} \mathrm{O}_{4}$ grain (marked with arrow) prior to anode reduction, with $<011>$ selected area diffraction inset. Source: Knibbe [67]. 
(a)

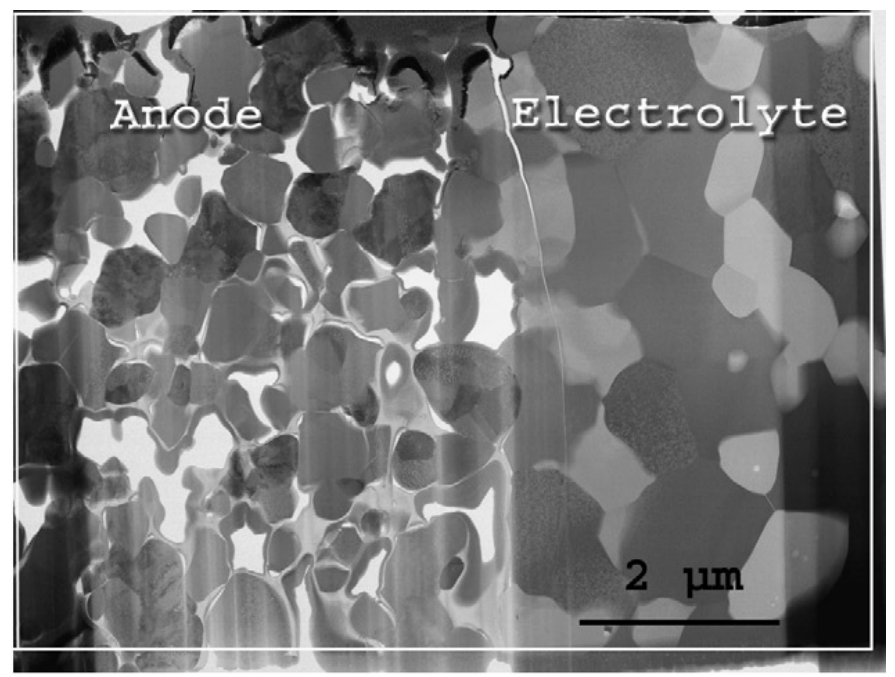

(b)

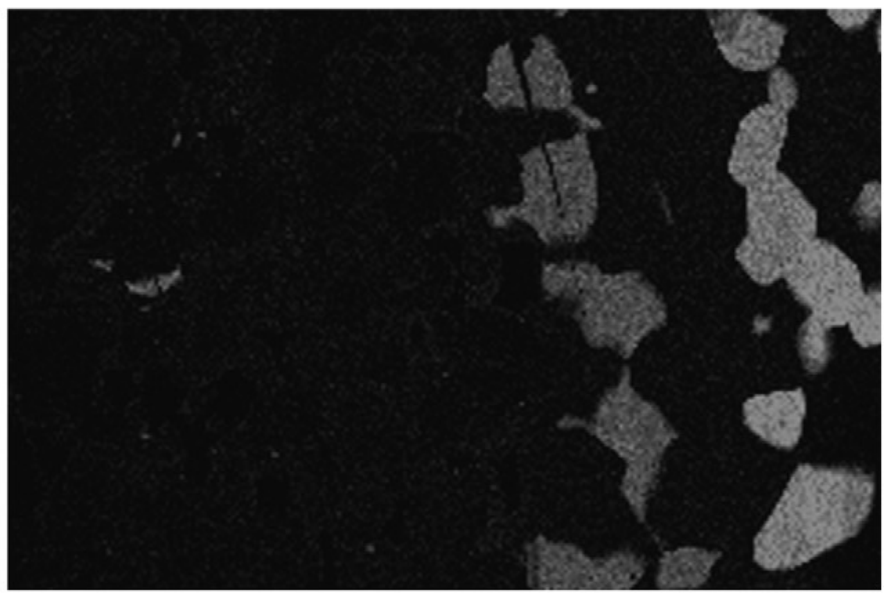

(c)

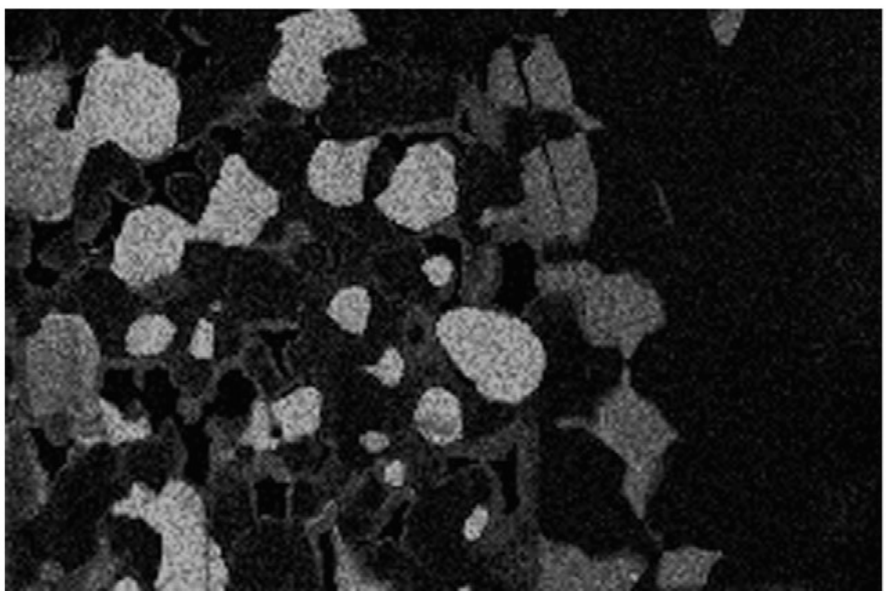

Figure 14. STEM micrograph of anode|electrolyte interface after anode reduction, with corresponding Al (b) and Ni (c) elemental maps. From nickel elemental map, nickel aluminate is still found in electrolyte and appears unaltered after anode reduction. Source: Knibbe [67]. 


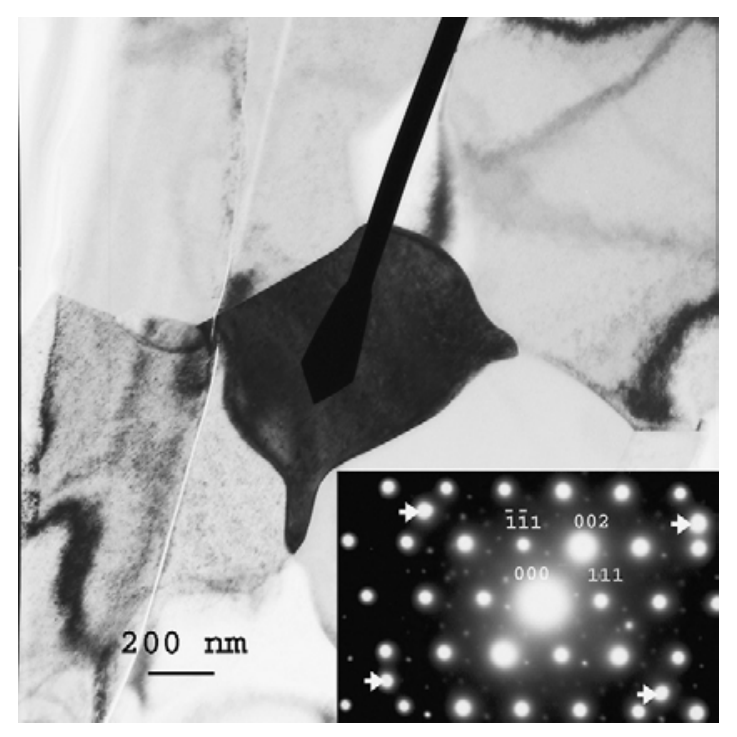

Figure 15. Dark-field TEM micrograph of $\mathrm{NiAl}_{2} \mathrm{O}_{4}$ grain after anode reduction, in YSZ matrix with $<011>$ selected area diffraction pattern inset. Additional reflections in pattern, indicated by arrows, are attributed to YSZ from adjacent grain. $\mathrm{NiAl}_{2} \mathrm{O}_{4}$ grows out into surrounding grain boundaries. Source: Knibbe [67].

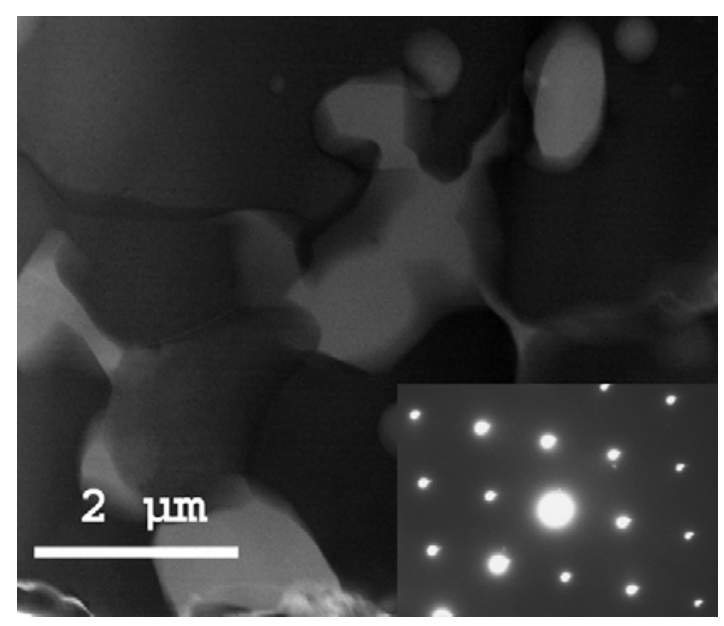

Figure 16. STEM images of anode|electrolyte interface after $500 \mathrm{~h}$ of fuel cell operation, with $<011>$ selected area diffraction pattern inset. Source: Knibbe [67].

On the other hand, cell degradation is an important issue in SOFCs research. In order to understand the mechanism of cell degradation, there are a lot of works focusing on the materials 
used in electrolyte, anode and cathode. It is known that ionic conductivity of YSZ degrades significantly when aged at high temperatures [69-75]. In general, two mechanisms are proposed to explain the high temperature degradation of ionic conductivity: formation of short-range ordering of oxygen vacancies [70, 71, 76, 77]; and precipitation of tetragonal $\mathrm{ZrO}_{2}$ phase from the cubic $\mathrm{ZrO}_{2}$ matrix [72, 73]. Figure 17 shows the tetragonal YSZ particles in 8 mole\% YSZ and 10 mole\% YSZ before and after $1000^{\circ} \mathrm{C}$ heating treatment respectively. The dark field images are taken from the $\{112\}$-reflection of $t-\mathrm{ZrO}_{2}$ in the [110] zone axis (marked by a triangle in Figure 17e). The particles grow after thermal treatment from about $1 \mathrm{~nm}$ to about $10 \sim 15 \mathrm{~nm}$ in the 8YSZ sample. And this tetragonal phase indicated by the weak spot disappeared when the $\mathrm{Y}_{2} \mathrm{O}_{3}$ doping increased to 16 mole\%, which is shown in Figure 18. Comparing with the electron diffraction, Raman is a better tool to detect tetragonal YSZ [75] in large scale, but in the operated cell specimen, it is hard to determine the position, where the tetragonal YSZ form, by Raman.
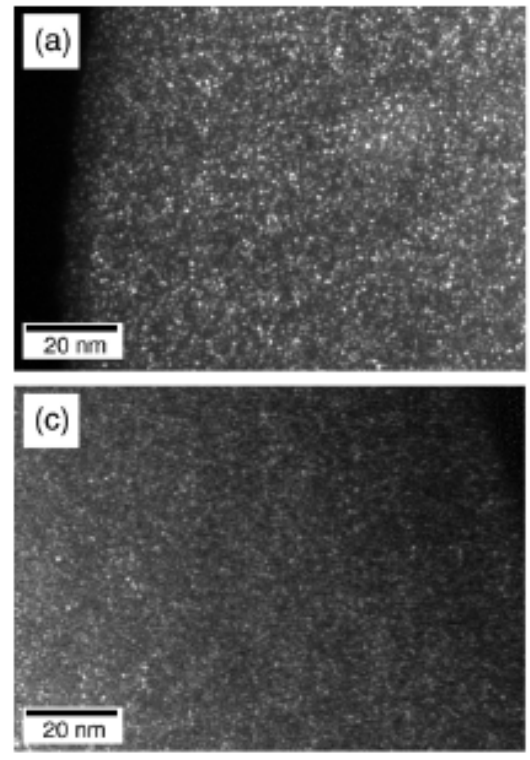
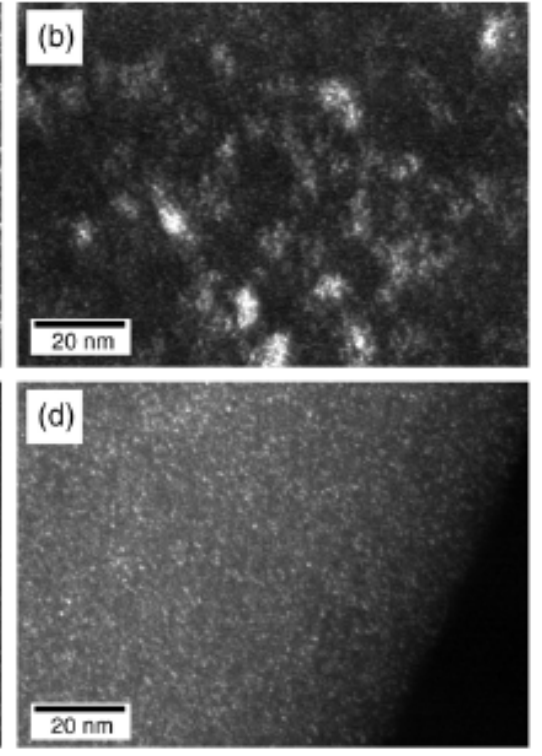

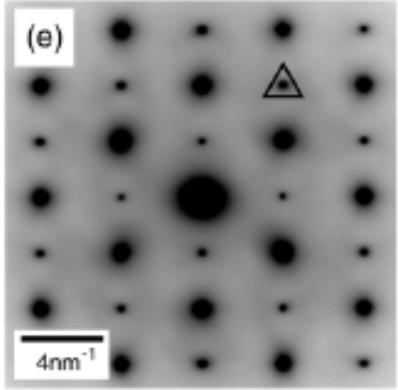

Figure 17. Dark-field images taken with a $\{112\}$ reflection of tetragonal phase indicated by a triangle in (e) of (a) 8YSZ, (b) 8YSZ-H, (c) 10YSZ and (d) 10 YSZ-H 

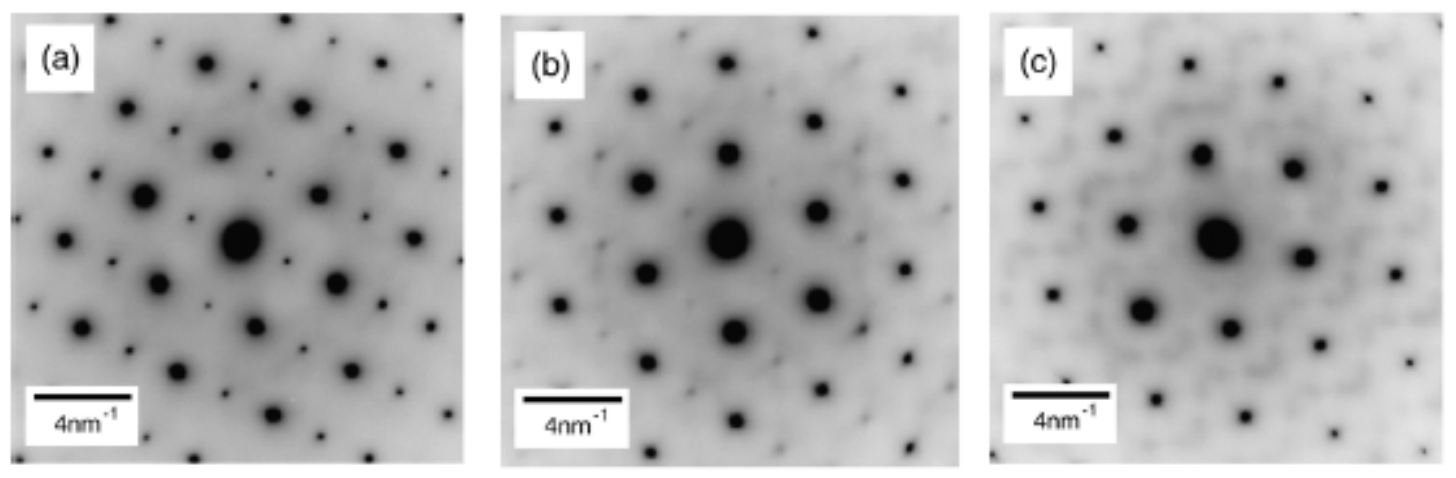

Figure 18. SAED patterns along the [110] zone axis from (a) 8YSZ, (b) 10YSZ and (c) 16YSZ

\subsubsection{Anode degradation}

The performance of the Ni/YSZ anode is known to degrade during operation. The suggested degradation mechanisms are generally attributed to microstructural failure including $\mathrm{Ni}$ migration and Ni dusting in high carbon activity environments, phase transformation such as oxidation/corrosion of $\mathrm{Ni}[78,79]$, and formation of secondary phases such as $\mathrm{Ni}_{5} \mathrm{Zr}$ [80]. $\mathrm{Ni} / \mathrm{YSZ}$ anode is fabricated by reducing NiO/YSZ co-sintered anode. In order to investigate the effect of $\mathrm{NiO}$ on the conductivity degradation of YSZ electrolyte during reduction, Coors [81] co-sintered $\mathrm{NiO}$ and YSZ and used TEM to investigate the structure and chemistry changes after reducing. Nano-sized metallic nickel precipitates were observed after reducing, which decrease the oxygen ion conductivity in Ni-doped 8YSZ. Since it is hard to make TEM specimens of SOFCs before the focused ion beam/lift-out (FIB/lift-out) technique was used, there is limited works on the operated SOFCs characterization by TEM.

In Y.L. Liu's paper [82], FIB/lift-out technique was first used to prepare TEM specimens containing electrode/electrolyte interfaces in SOFC. The microstructure and phase chemistry in the interfacial region was analyzed using a JEM-3000F and EDS with a lateral resolution of nanometers. This work shows that through segregation and accumulation a very low $\mathrm{SiO}_{2}$ 
content ( 100 ppm), among other impurities, introduced by the raw materials degrades the anode/electrolyte interface and Ni/YSZ grain boundaries by forming nanometer-thin silicate glass films after long-term testing. Figure 19 shows the bright and dark field images of the interface. Figure 20 shows the silicate glass film at a Ni/YSZ grain boundary in the anode bulk.

(a)

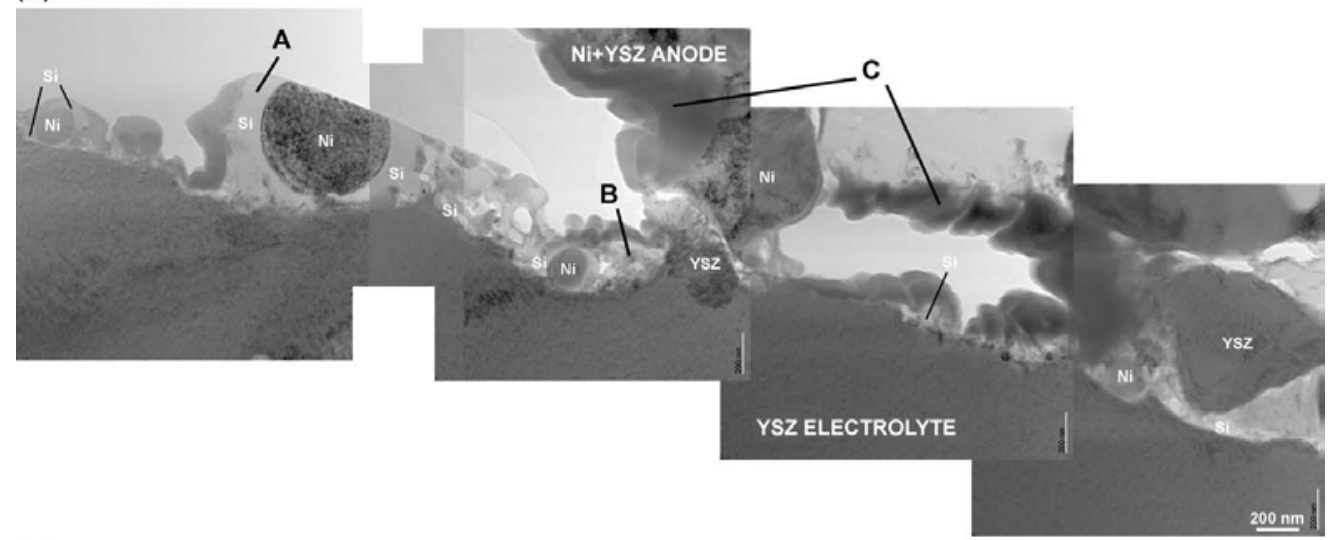

(b)

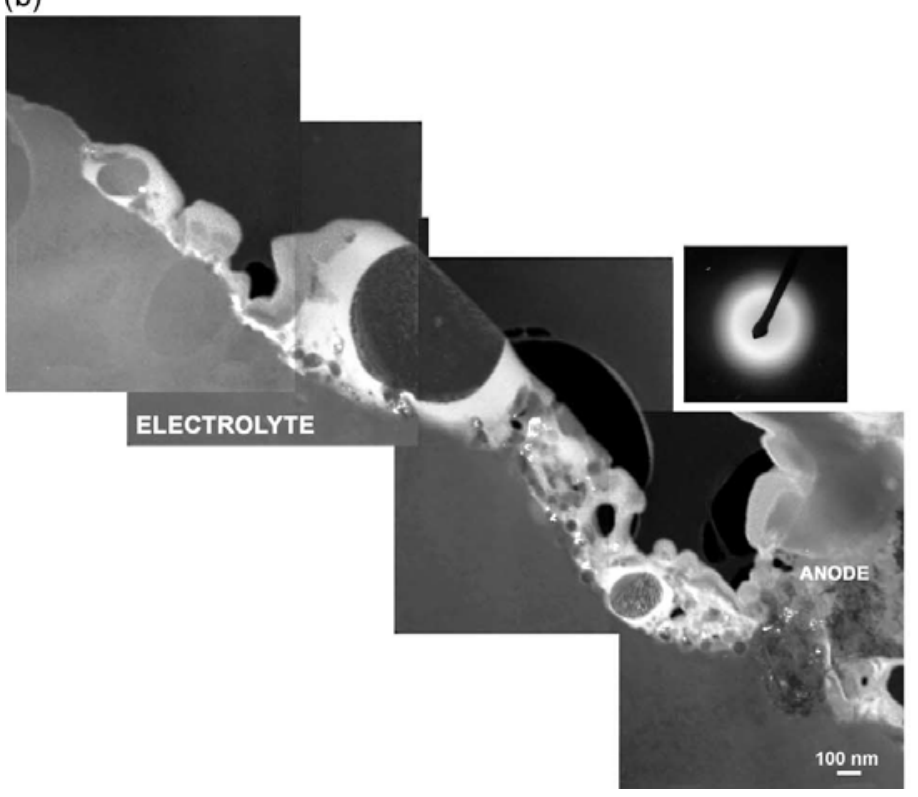

Figure 19. (a) ATEM bright field micrograph showing the whole length of the anode/electrolyte interface. (b) ATEM dark field micrograph of a part of the anode/ electrolyte interface. Imaged with the diffracted beam of the Si-glass phase, the Si-glass phase appears bright. Diffraction pattern of the Si-glass phase is also shown. Source: Liu [82]. 


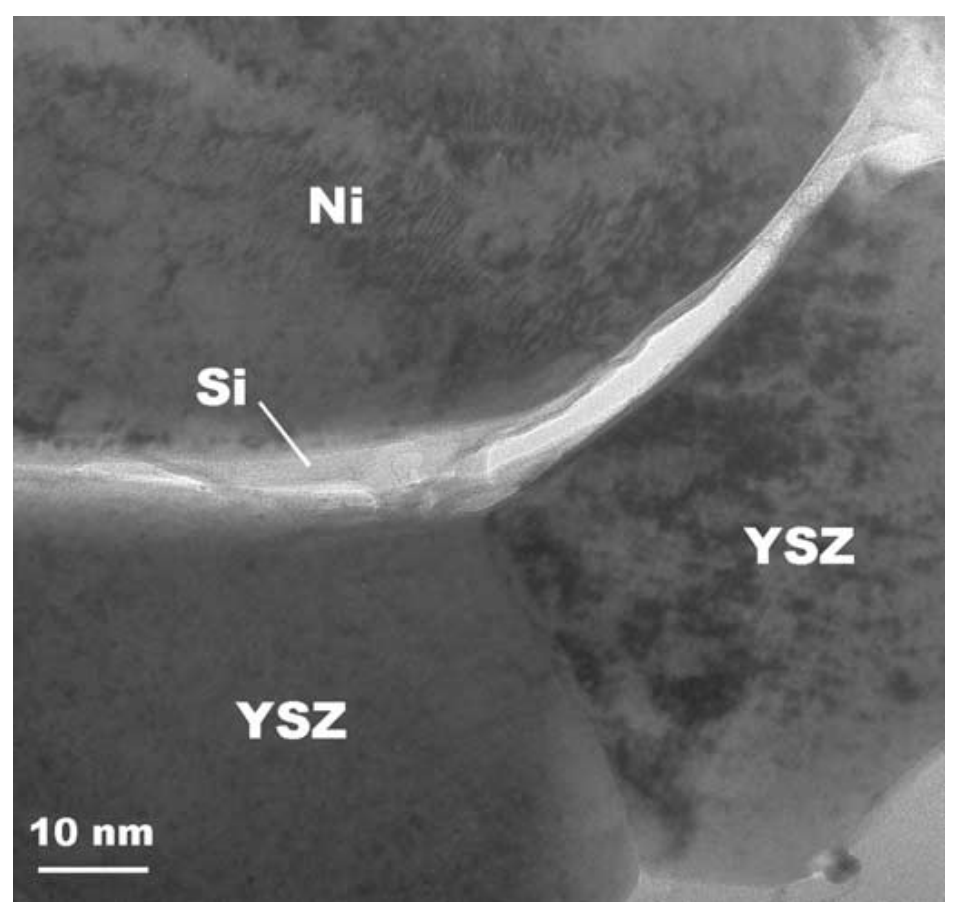

Figure 20. A TEM micrograph showing the presence of the silicate glass film at a Ni/YSZ grain boundary in the anode bulk. Source: Liu [82].

In another study by D. Waldbillig [83], the electrochemical performance degradation and microstructural changes were characterized after redox cycling an anode-supported SOFC produced using Versa Power Systems Ltd.'s (VPS, formerly Global Thermoelectric) TSC-2 cell production process. Cell performance decreased slightly after each redox cycle, especially for redox times greater than 1 hour. The microstructural changes that occurred after redox cycling were characterized using scanning and transmission electron microscopy. Redox cycling significantly changed the microstructure of the anode substrate in the cell. Figure 21 shows a backscattered electron (BSE) SEM image of a fresh fractured, as prepared (oxidized) microstructure. The YSZ phase is light in color, with a grain size around 1um, while the NiO grains appear grey and are several microns in size. Figure 22 is a bright field (BF) TEM image of an as prepared sample and provides confirmation of the SEM results. The pores and holes in the 
BF image appear white. Selected area electron diffraction (SAD) (insets in Figure 22) and energy-dispersive $\mathrm{x}$-ray analysis (EDX) techniques were used to confirm the phases present, i.e., $\mathrm{NiO}$ and YSZ. Figure 23 is a BF TEM micrograph of a partially reduced NiO/YSZ anode. This image clearly shows the distribution of reduced $\mathrm{Ni}$ and unaffected YSZ within the sample. The diffraction pattern of the partially reduced sample (inset of Figure 23) contains satellite spots, which indicate that multiple diffraction is occurring. The more intense spots in the diffraction pattern correspond to nickel while the satellite spots correspond to both $\mathrm{Ni}$ and $\mathrm{NiO}$ reflections. TEM imaging (Figure 24) of reoxidized samples show an interesting result - the formation of very fine grains of $\mathrm{NiO}$ less than $100 \mathrm{~nm}$ in size. After rereduction, the overall Ni grain size remains small $(<200 \mathrm{~nm})$ as can be seen in Figure 25.

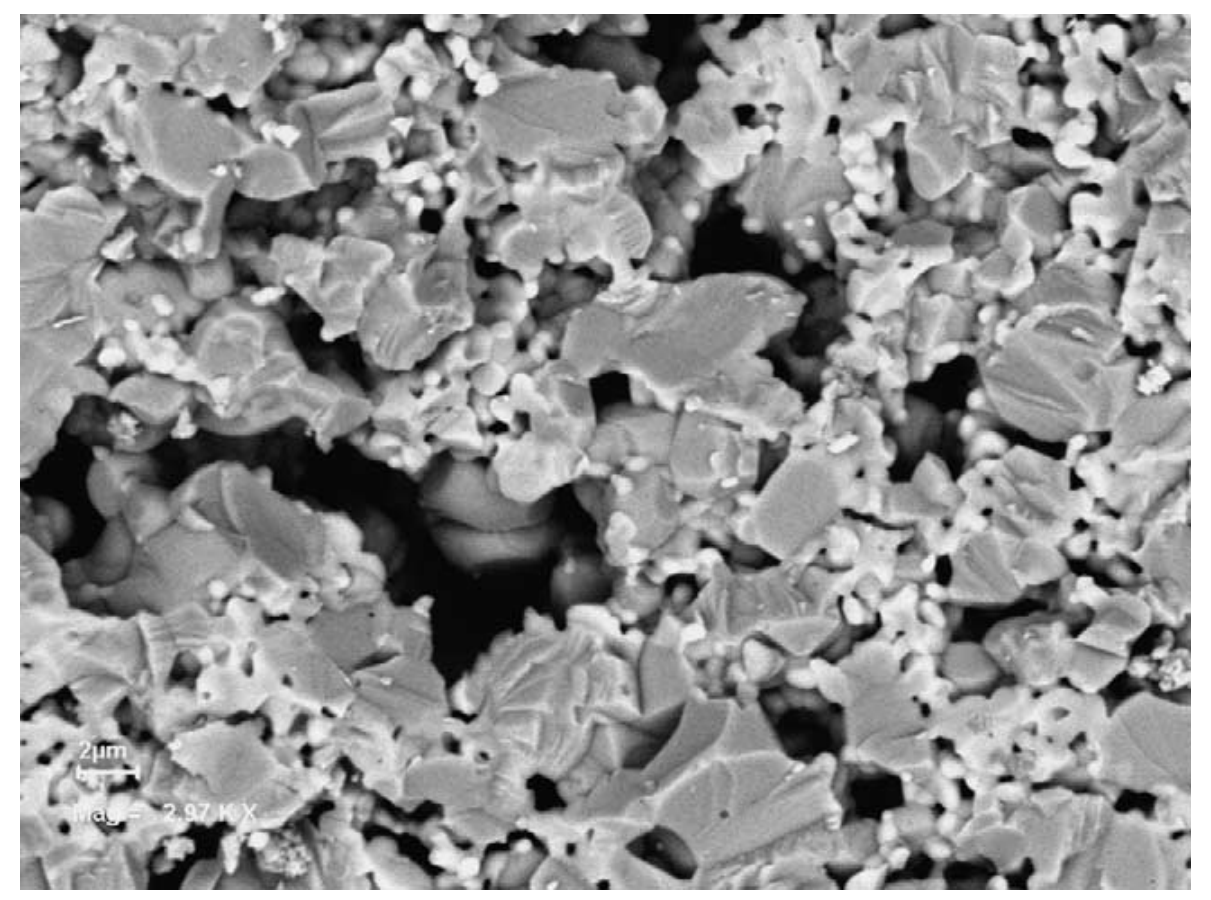

Figure 21. BSE SEM image of a fresh fractured, as prepared (oxidized) sample. Source: Waldbillig [83]. 


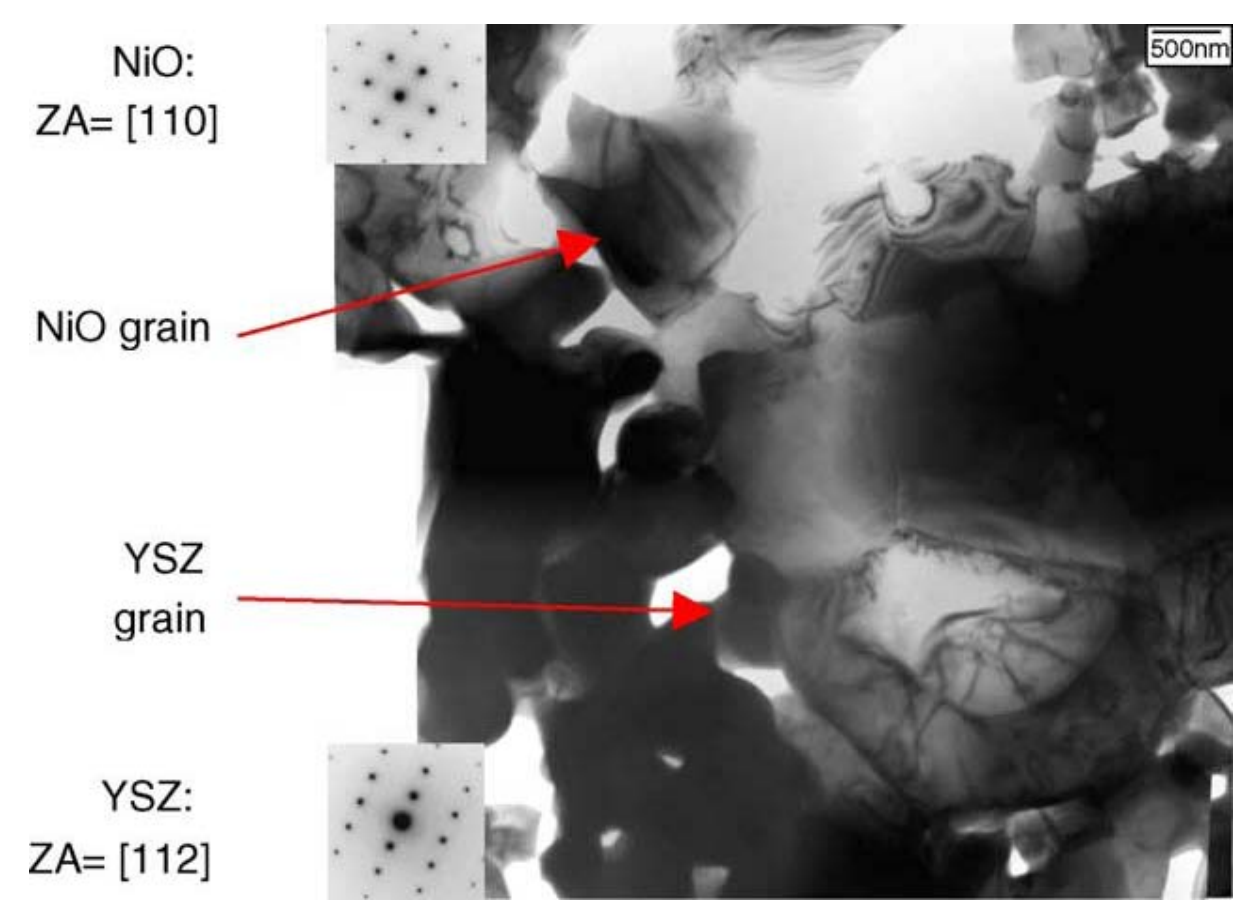

Figure 22. A BF TEM image of an as prepared sample. Source: Waldbillig [83].

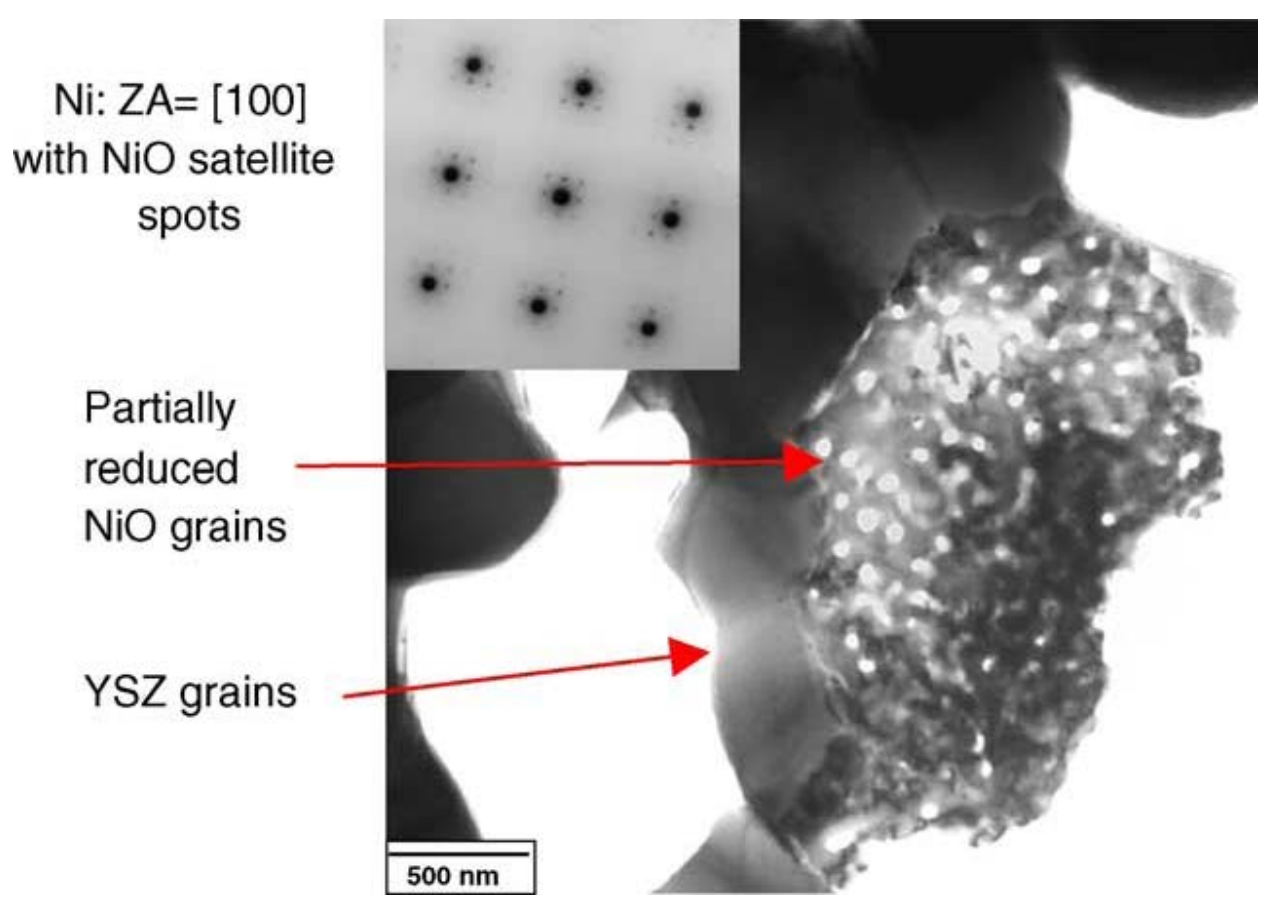

Figure 23. A BF TEM image of a partly reduced sample. Source: Waldbillig [83]. 


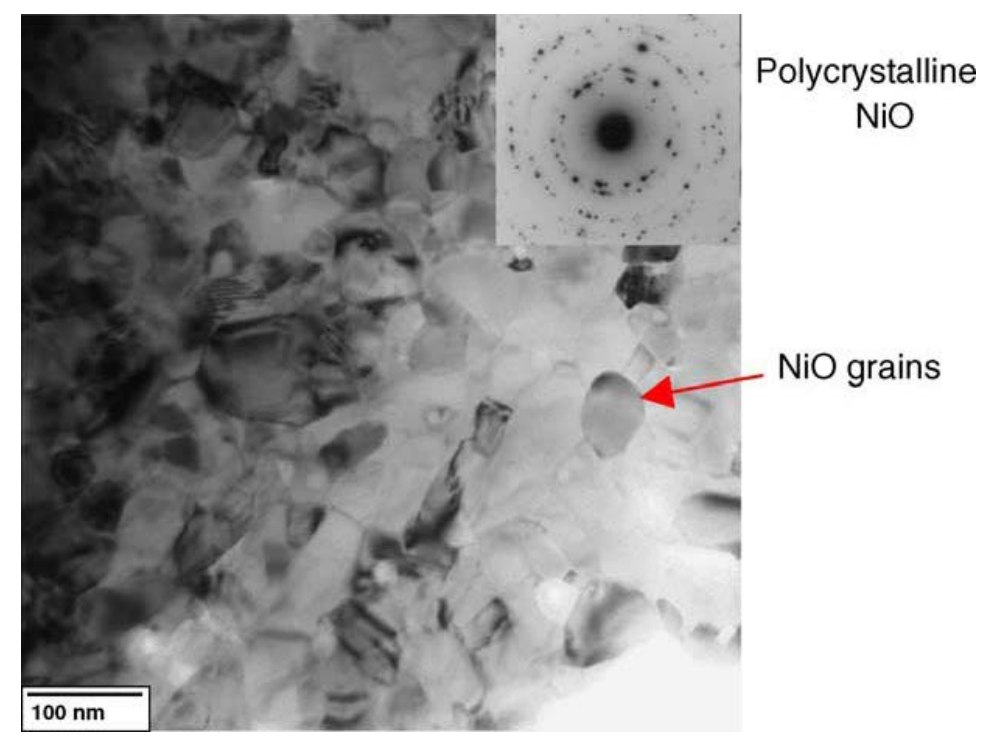

Figure 24. A BF TEM image of a reoxidized sample. Source: Waldbillig [83].

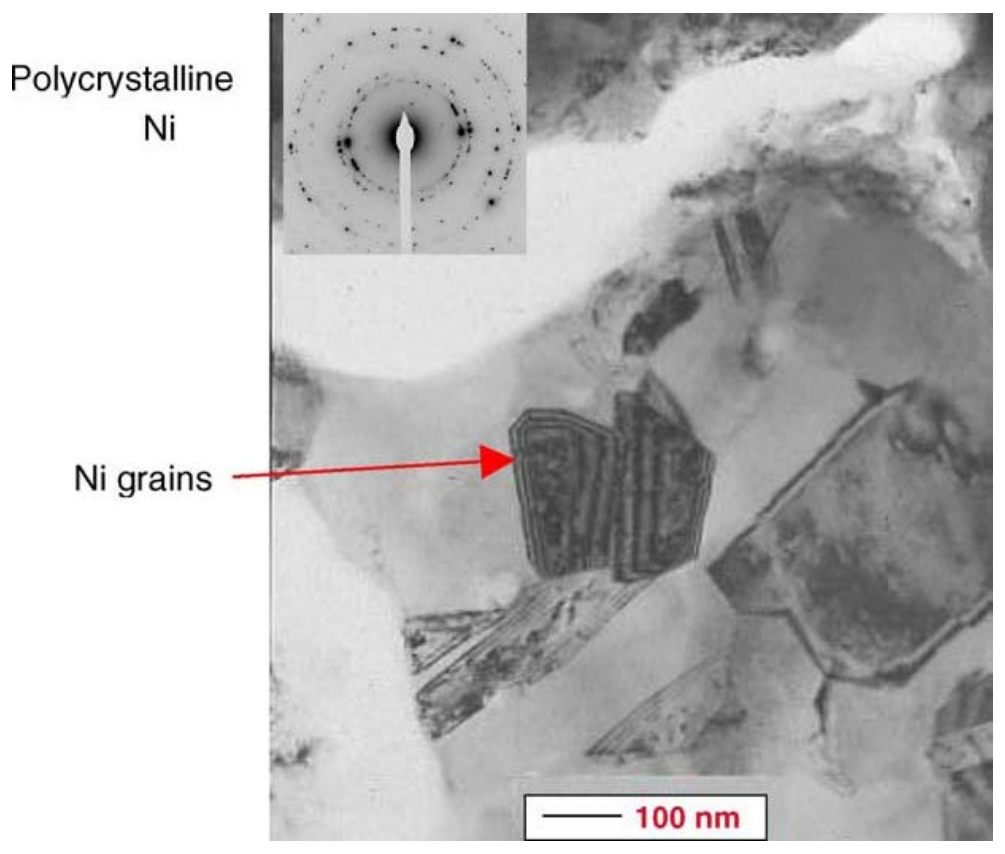

Figure 25. A BF TEM image of a rereduced sample. Source: Waldbillig [83].

In order to investigate the interface reaction or phase formation in term of elements diffusion, the chemical mapping method is a good choice. An interfacial reaction between Ni-samarium 
doped ceria (Ni-SDC) anodes and the Sr and Mg co-doped lanthanum gallate-based (LSGM) electrolyte was investigated using SEM and TEM to clarify its effect on the SOFC performance by K. Kawahara [84]. TEM/EDX analyses revealed that new particles were determined as MgO, which has a much lower electronic conductivity than Ni. The particles were localized on the surface of the Ni grains in the Ni-SDC anodes. The effect of MgO particle formation on the SOFC performance depended on the anode thickness. Figure 26 shows the TEM image and the chemical element distribution in the vicinity of the Ni-SDC/LSGM interface after cell performance evaluation. Figure 26 reveals that the anode network structure was well developed, suggesting low area-specific ohmic resistance. Figure 27 shows the TEM/EDX image and the chemical element distribution in the anode after cell performance evaluation. The observation area of Figure 27 was close to the Ni-SDC/LSGM interface; the distance from the interface to the observation area was less than $5 \mu \mathrm{m}$. Peaks of $\mathrm{Mg}$ and $\mathrm{O}$ were clearly detected at the $\mathrm{Ni}$ grain. The distribution of $\mathrm{Mg}$ and $\mathrm{O}$ was in good agreement with the size of the fine particles as shown in SEM images. The diffraction pattern taken at the area containing the fine particles showed a ring pattern that was in good agreement with the calculated ring pattern for MgO. Therefore, the fine particles were identified as MgO. 

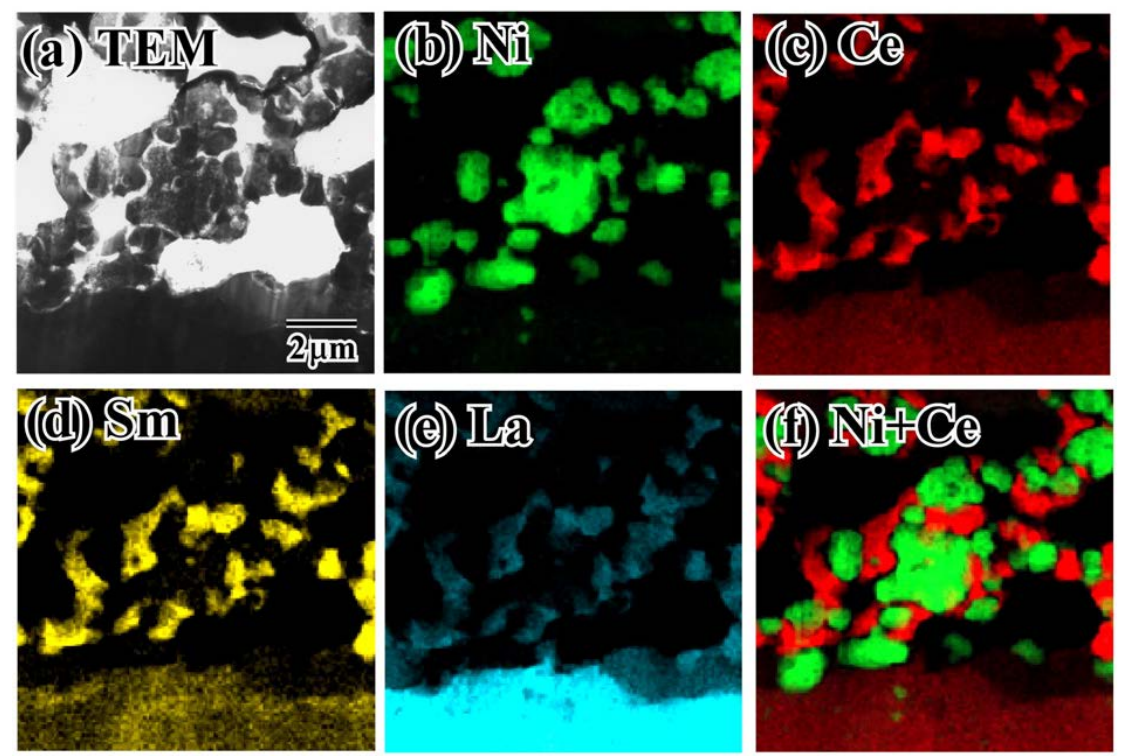

Figure 26. TEM image and chemical element distribution mapping analyzed in the vicinity of the NiSDC/LSGM interface after cell performance evaluation. Source: Kawahara [84].
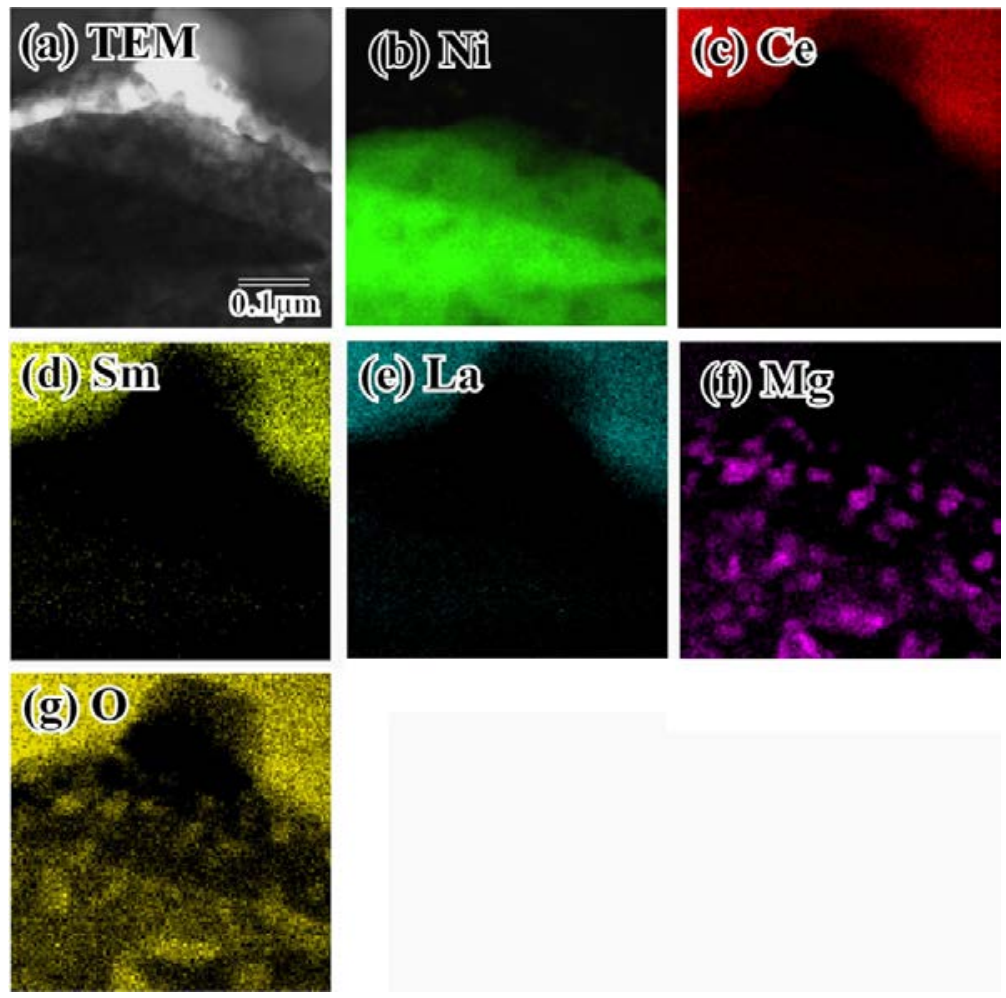

Figure 27. TEM image and chemical element distribution mapping of Ni-SDC anode after cell performance evaluation. Both Ni and SDC grains were in this area. Source: Kawahara [84]. 


\subsubsection{Cathode degradation and performance enhancement by infiltration}

In the cathode side, degradation is mostly caused by microstructure coarsening, decomposition of cathode materials, chemical reaction with electrolyte and poisoning of cathode [85]. From Mitterdorfer's work [86], $\mathrm{La}_{2} \mathrm{Zr}_{2} \mathrm{O}_{7}$ was observed when they co-sintered YSZ and LSM. The manganese concentration in the LSM perovskite affects the growth rate of the lanthanum zirconate. The preventing effect of excess $\mathrm{Mn}$ on the $\mathrm{La}_{2} \mathrm{Zr}_{2} \mathrm{O}_{7}$ formation was observed in another works [87, 88] as well. Other previous studies [89-92] reported that during cell operation, impurities and dopants in the SOFC cathode can segregate to grain boundaries (GBs), resulting in changes of the chemistry and atomic structure of the electrolyte/electrode interface, thus influence the cell performance.

In Arnaud Grosjean’s study [89], analytical and high resolution transmission microscopy was used to investigate the diffusion and reactivity at the interface between the electrolyte (YSZ) and the cathode (LSM) of planar SOFC single cells. The similar chemical mapping method was used to analyze the diffusion and reaction at the interface. To allow the cell to function at intermediate temperatures $\left(750-850^{\circ} \mathrm{C}\right)$, the final electrolyte thickness after co-sintering at $1350{ }^{\circ} \mathrm{C}$ must range between $40 \mu \mathrm{m}$ and $50 \mu \mathrm{m}$. As-sintered cells as well as cells that have been operated at $850^{\circ} \mathrm{C}$ have been considered here; it is shown that the electrical performances were one order of magnitude less than expected and that they deteriorated quickly under operating conditions. In order to explain this behavior, Analytical TEM was carried out. To obtain precisely located chemical and structural information, the "H-Shape" as well as the Lift Out FIB (Focused Ion Beam) techniques was used to extract $5 \times 10 \times 0.1 \mu \mathrm{m}$ TEM samples; additional High Resolution characterization was carried out at interfaces between LSM and YSZ grains on standard ionmilled samples. It was showed that the co-sintering temperature $\left(1350^{\circ} \mathrm{C}\right)$ was responsible for 
some diffusion of manganese through the electrolyte and the cathode, leading then to the rise of a significant electronic conduction and to the drop off of the ionic conductivity, and accounts for the germination and growth of the resistive pyrochlore phase $\mathrm{La}_{2} \mathrm{Zr}_{2} \mathrm{O}_{7}$. Operating the cell at $850^{\circ} \mathrm{C}$ do not aggravate these phenomena, but rather alters the anode microstructure. Figure 28 shows the spot analysis of YSZ grains in the electrolyte (A) and in the cathode (B). A significant amount of manganese, about 1 2 atom\% is found in YSZ grains in both electrolyte and cathode, which indicates that the sintering temperature is sufficiently high to allow a significant rise of electronic conduction and drop off of the ionic conductivity. Figure 29 is chemical map analyses of La, Sr, Mn, Zr, Y and O in the cathode. The chemical mapping on this small area shows different chemical composition in the three grains. The bottom one shows La, Sr, Mn and O rich; the middle left and right ones show $\mathrm{Sr}, \mathrm{Zr}$ and $\mathrm{O}$ rich; the top one shows $\mathrm{Zr}, \mathrm{Y}$ and $\mathrm{O}$ rich, which suggests the $\mathrm{LSM}, \mathrm{SrZrO}_{3}$ and YSZ grains respectively. 

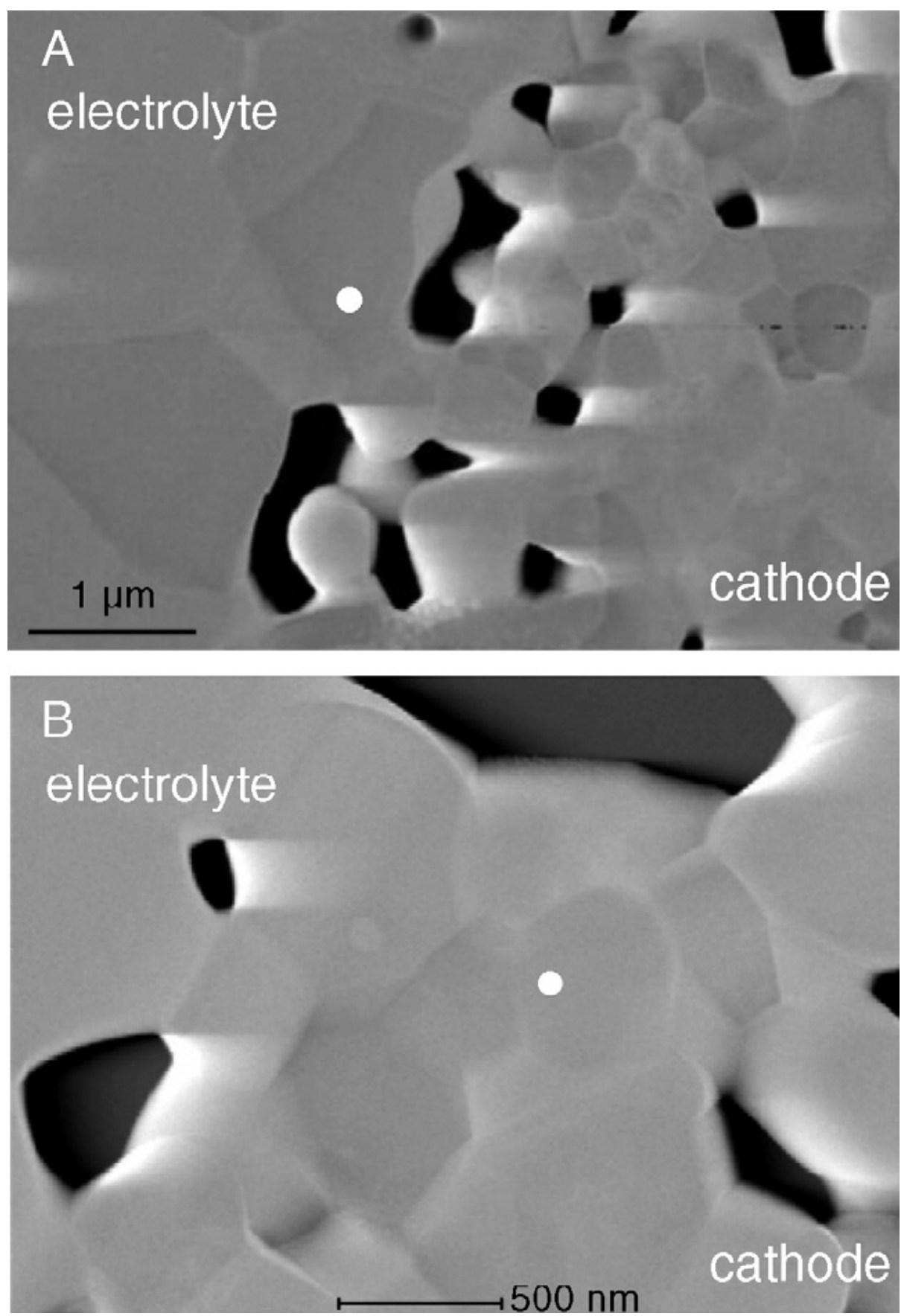

Figure 28. Spot analysis of YSZ grains in the electrolyte (A) and in the cathode (B). Source: Grosjean [89]. 


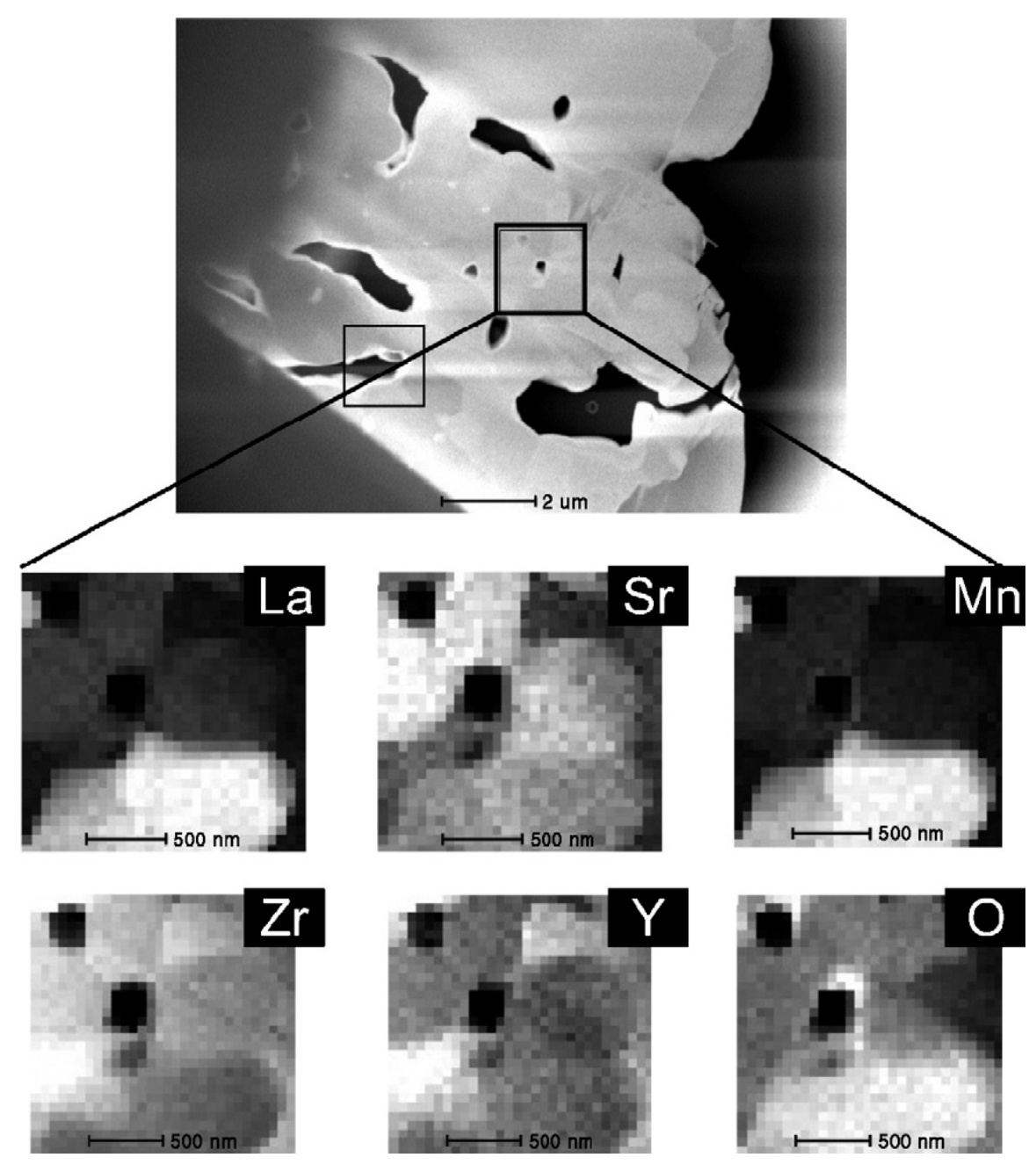

Figure 29. Chemical map analyses of La, Sr, Mn, Zr, Y and O in the cathode. Source: Grosjean [89].

Another work with similar lift-out FIB technique was done by S. Uhlenbruck [93] to investigate the influence of the different processing routes for the GDC interlayer on the interdiffusion phenomena. Figure 30 shows the cross section of the SOFC and the lift-out lamella prepared by FIB. The electrolyte and cathode are very clear in the bright field TEM image. From the Gd distribution in Figure 31, a slight enrichment of Gd in the cathode was observed. In conjunction with the observed depletion of Gd in the GDC layer, it suggested that part of the Gd of the GDC layer diffused into the cathode material, which could be one cause to the cathode degradation. 


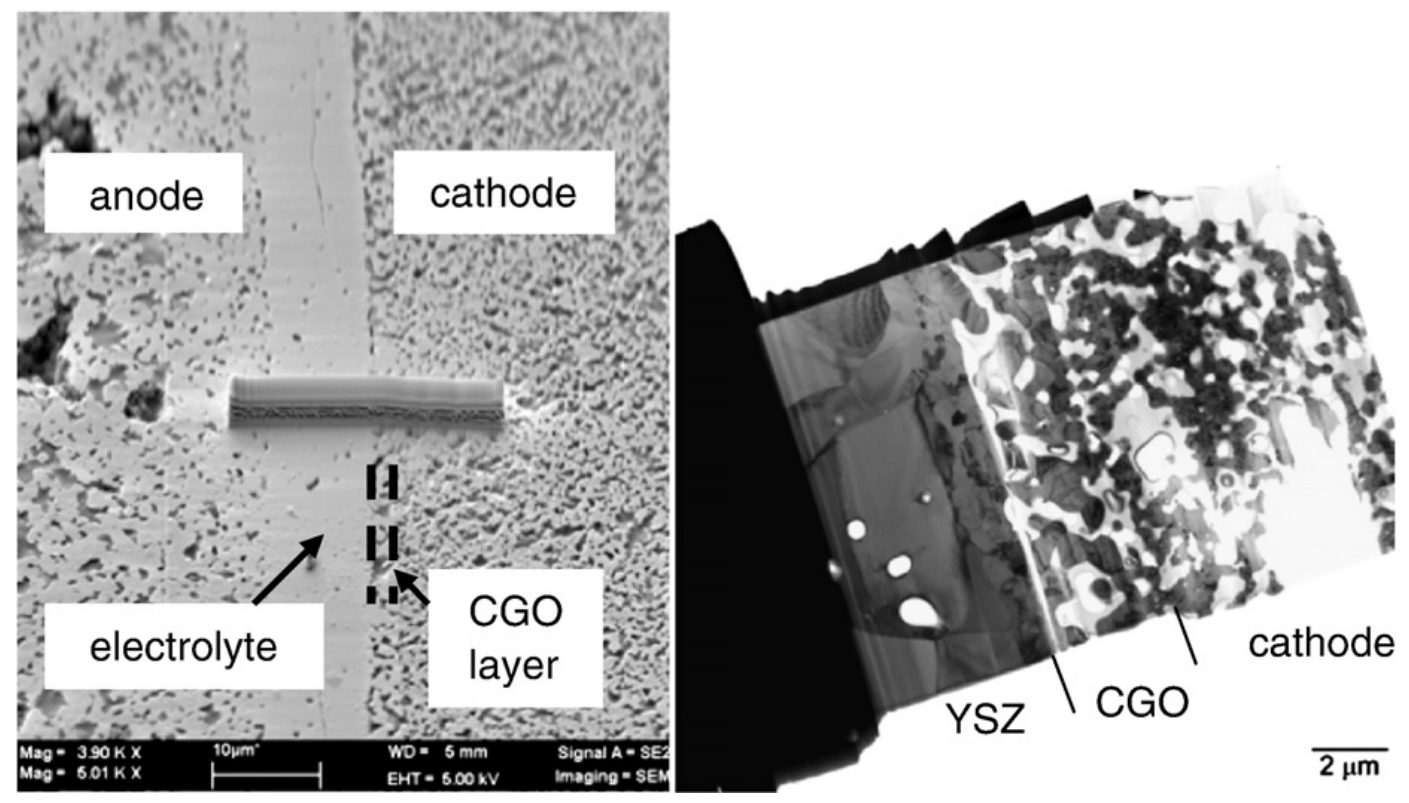

Figure 30. Cross section of an SOFC with screen-printed GDC layer. Tungsten (W) has been deposited indicating the lamella that is to be prepared by FIB. (left: SEM image, right: in situ lift-out lamella, TEM bright field image). Source: Uhlenbruck [93].

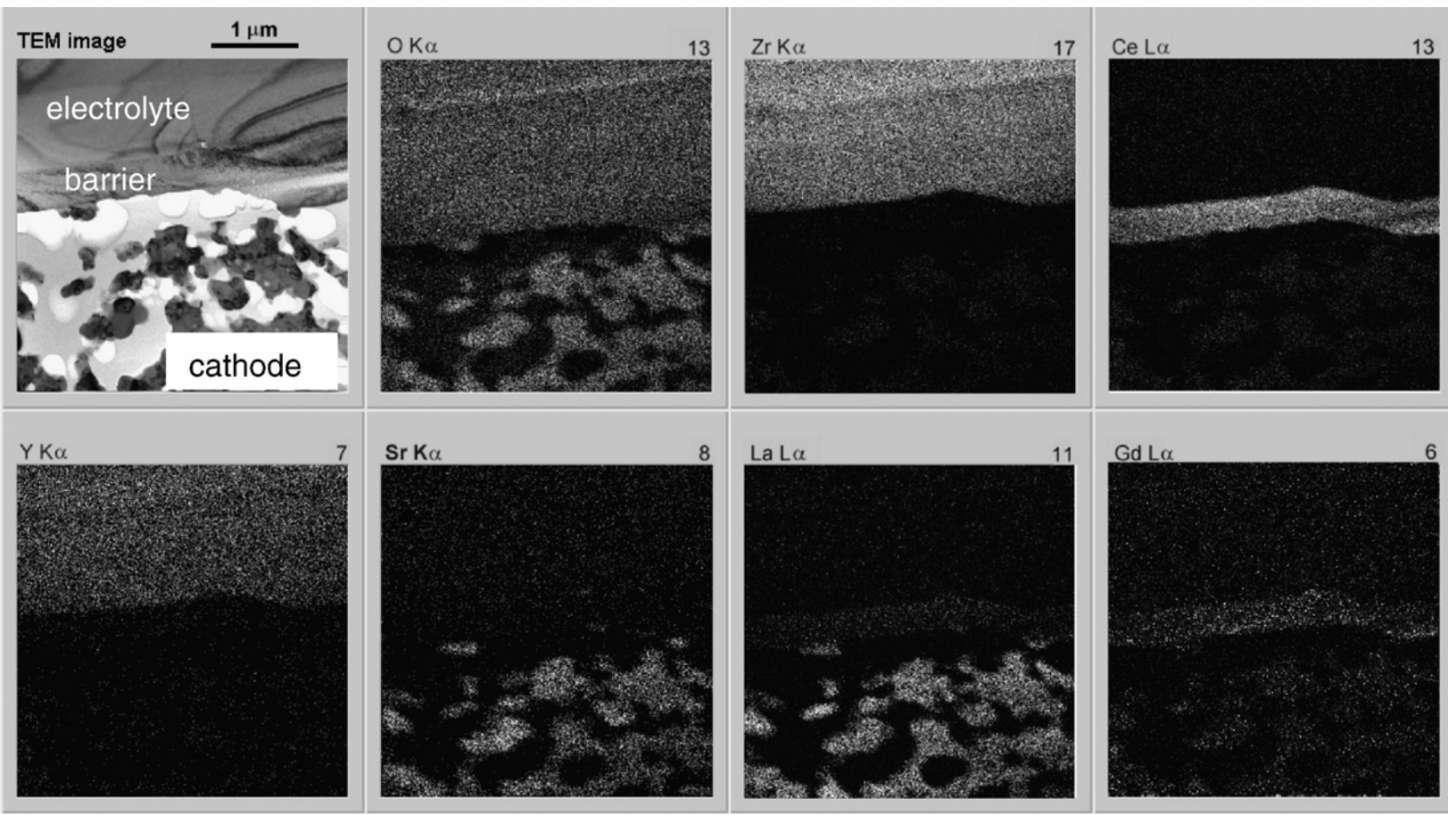

Figure 31. TEM bright-field image of an electrolyte-GDC interface of an SOFC with EB-PVD GDC layer with the element distribution map by TEM-EDS. Source: Uhlenbruck [93]. 
In the cathode side, the performance of cathodes can be enhanced by solution infiltration (or impregnation) [94] to introduce the nano reactive components into the porous scaffold to extend the TPB. Many cathode materials have been infiltrated into the porous, ionically conductive backbones, such as LSM [95], Sr-doped $\mathrm{LaFeO}_{3}$ (LSF) [96], Sr-doped $\mathrm{LaCoO}_{3}$ (LSCo) [97] and LSCF [98]. Hongpeng He reported the method to make composites of YSZ and LSM by impregnation of a porous YSZ matrix with aqueous solution of appropriate metal nitrate salts, followed by sintering to various temperatures. And the conventional composites made by physical mixing of oxide powders were used to compare the conductivity. The authors used SEM to check the status of the impregnation LSM-YSZ composites, which is shown in Figure 32. The small LSM particles were observed coating the walls of the YSZ matrix. The electrical conductivities of different LSM-YSZ composites were compared as shown in Figure 33. From the figure, several interesting points could be highlighted. First, the conductivity of the composites prepared by physical mixing increased rapidly when the LSM concentration increased to $28 \mathrm{vol} \%$. But at low LSM contents, the impregnated samples showed much higher conductivity than the conventional sample. And even with the sintered temperature of $1073 \mathrm{~K}$, the conductivity of LSM-YSZ impregnated sample was already high, indicating that with impregnation, the reasonable electronic properties could be obtained with very low processing temperatures. 


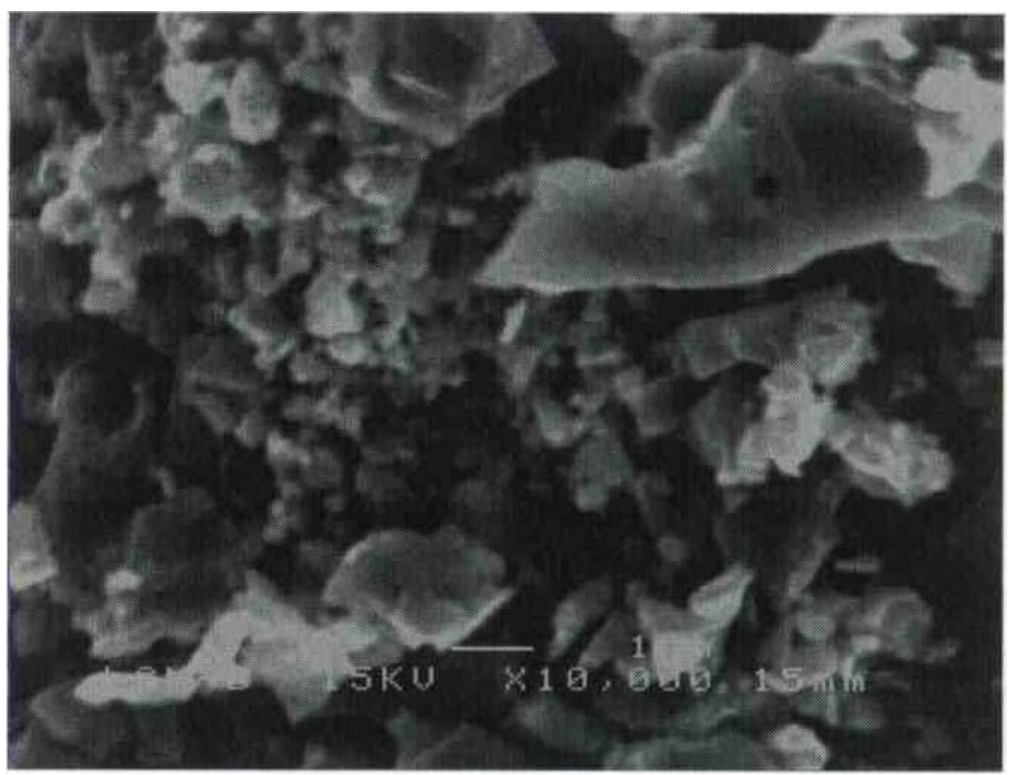

Figure 32. SEM image of LSM-YSZ composite prepared by impregation. Source: He [95].

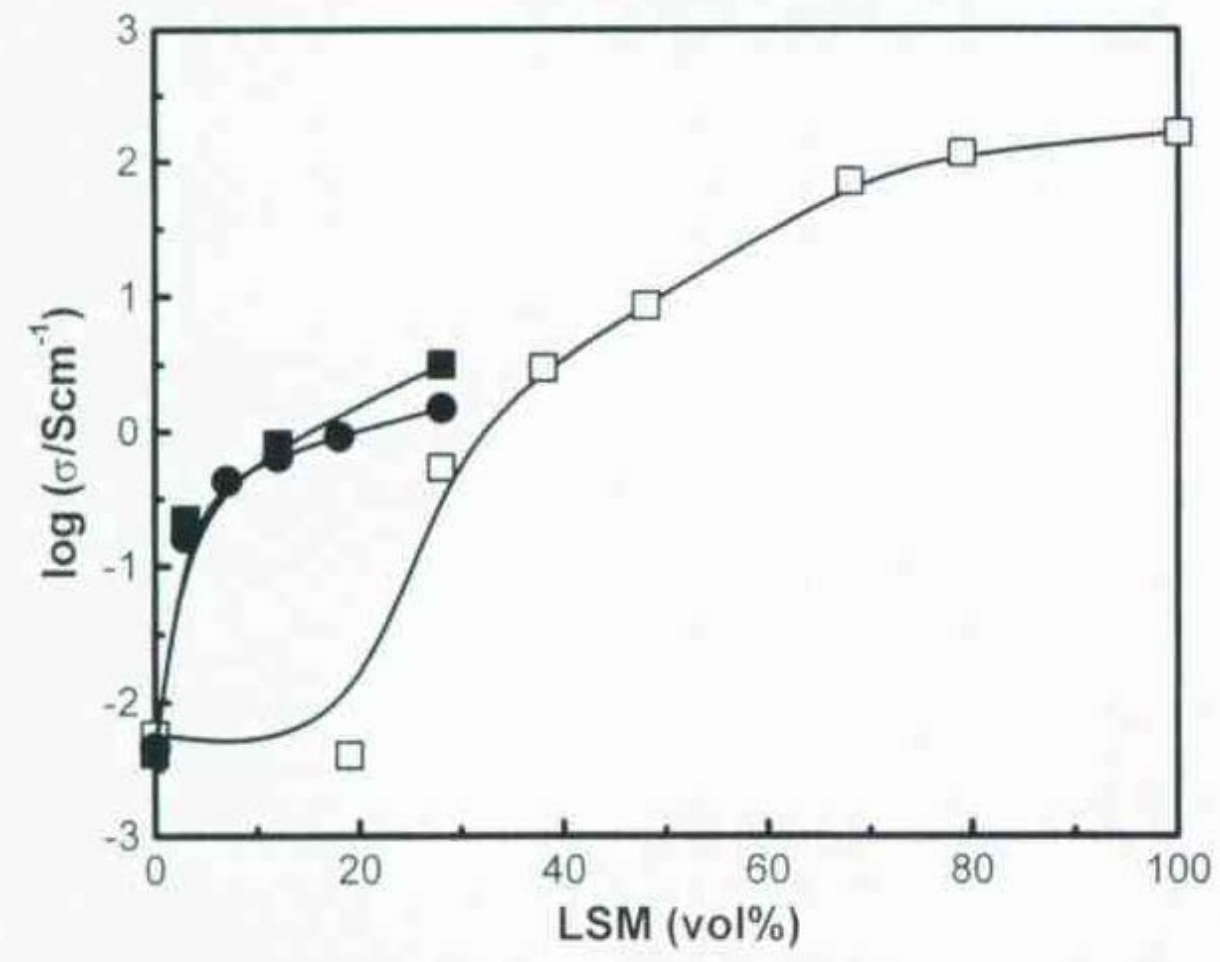

Figure 33. Electrical conductivities at 973K for LSM-YSZ composites as a function of composition. Data are shown for samples prepared from the ( $\square$ ) mixed powders and by 
impregnation followed by sintering to (•) 1523 or $(\bullet) 1073 \mathrm{~K}$. Source: He [95].

LSF and LSCo infiltrated cathodes were investigated with the similar method by F. Bidrawn [96] and Yingyi Huang [97] respectively from the same research lab. Figure 34 and Figure 35 show the morphology of the LSF-YSZ and LSCo-YSZ composites cathode prepared by infiltration. From the images, it shows that the infiltrated particles are usually small. Different calcination temperature can influence the morphology of the infiltrated particles. At high calcination temperature, the infiltrated particles can sinter together to form a continuous dense film, which can decrease the cathode performance. With the cell operation, cathode degradation could be observed with the increasing resistivity which was shown in impedance spectra (Figure 36).

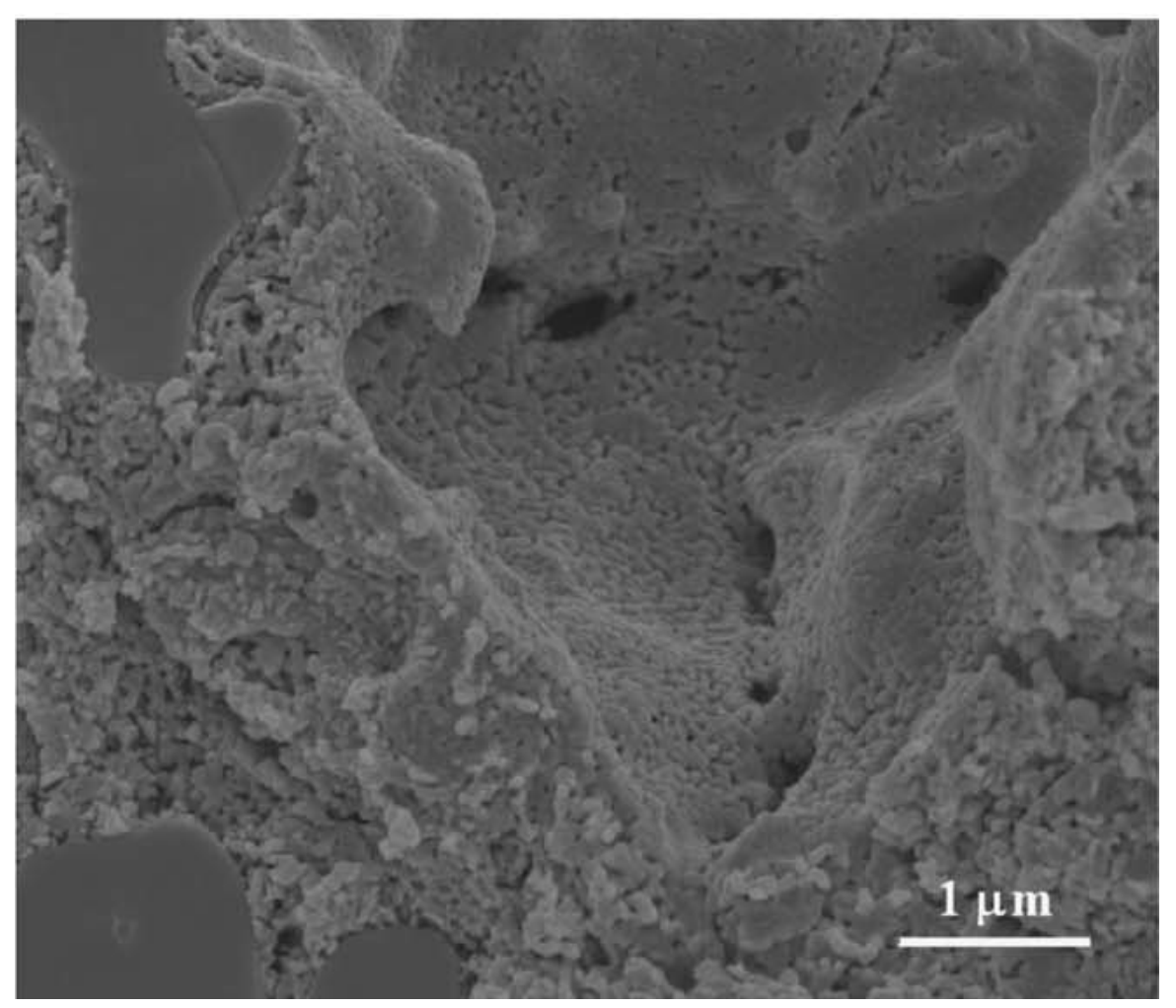

Figure 34. An SEM image of the electrode following infiltration of $40 \mathrm{wt} \% \mathrm{LSF}$ and calcination to $1123 \mathrm{~K}$. Source: Bidrawn [96]. 


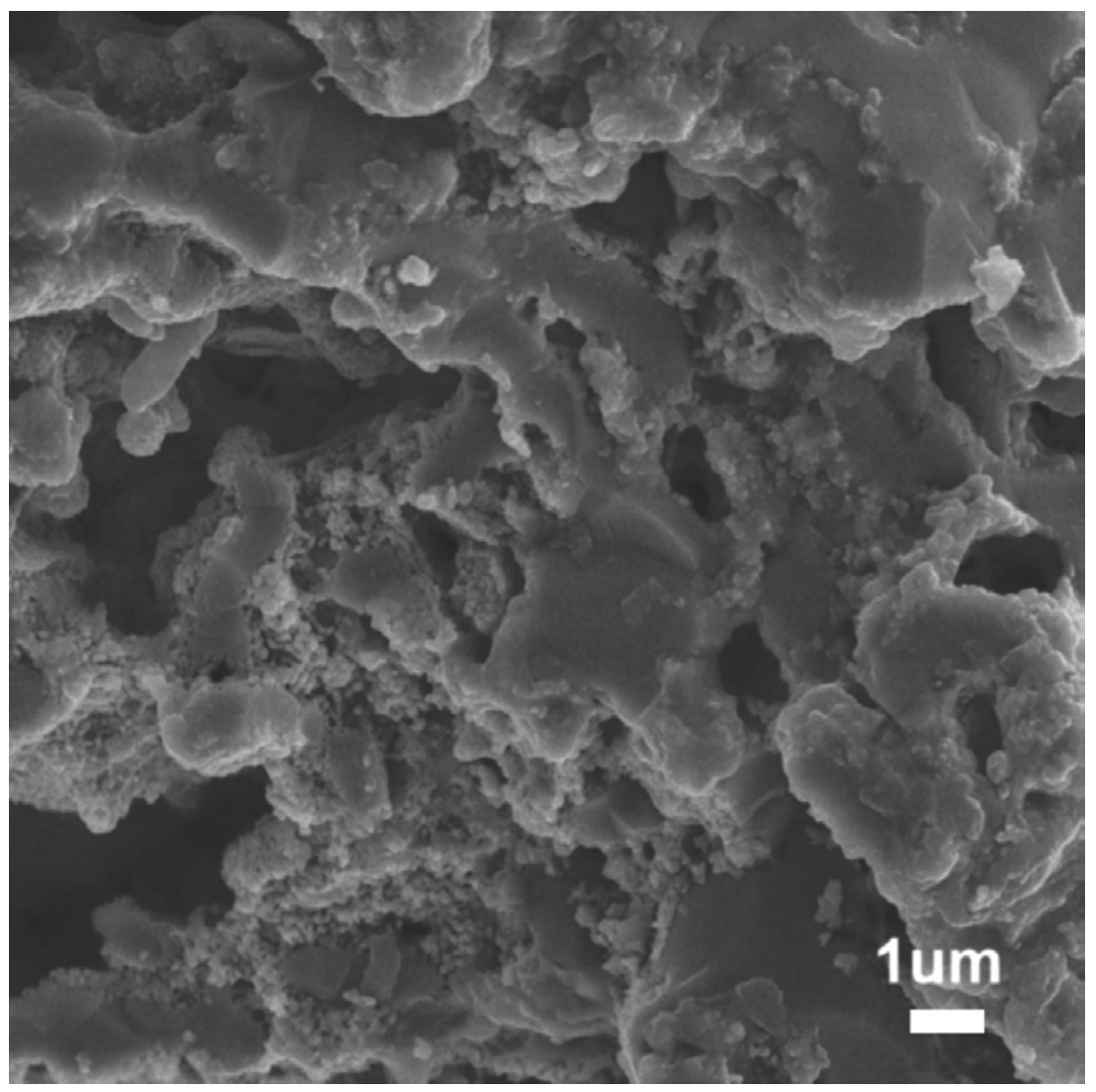

Figure 35. SEM of the LSCo-YSZ composite prepared by impregnation. Source: Huang [97].

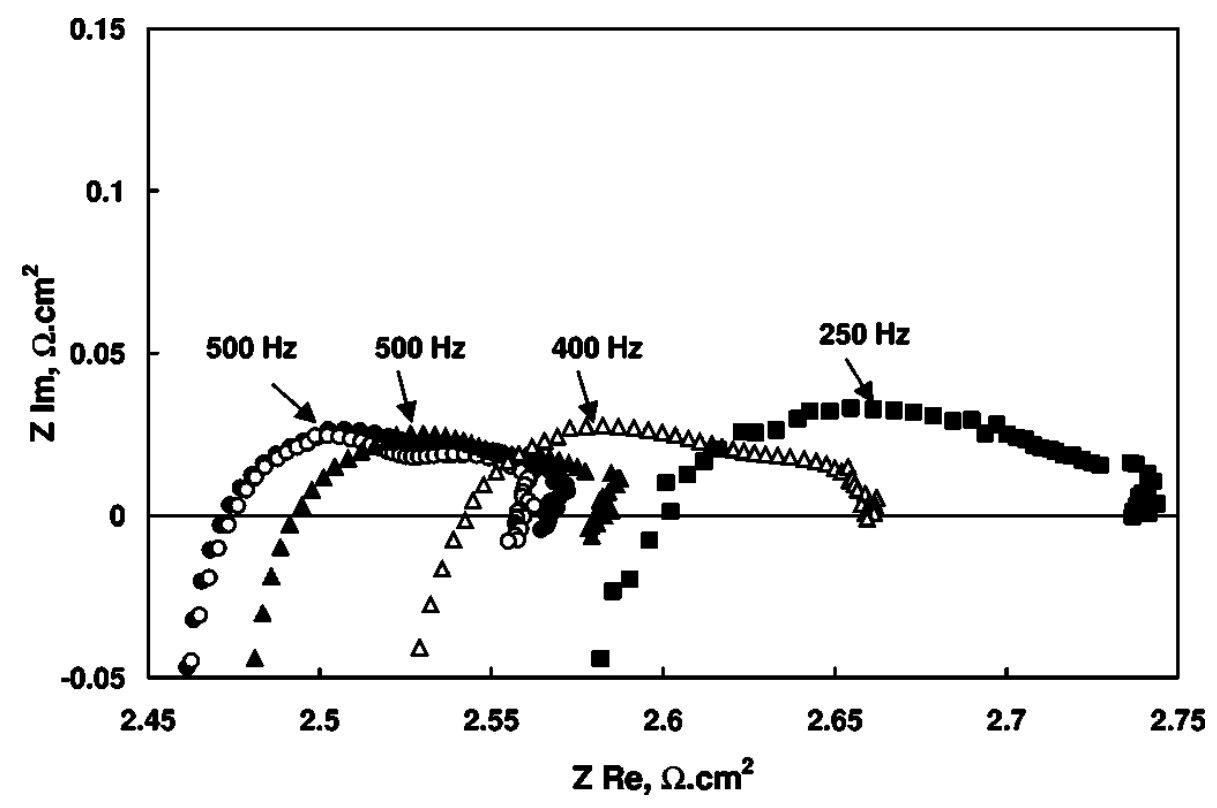

Figure 36. Impedance spectra from symmetric cells, measured in air at $973 \mathrm{~K}$ as a function of time, using $30 \mathrm{wt} \%$ LSCo in YSZ as electrodes. The measurements were taken after the following times: •2, ०5.5, A 24, $\Delta 72$, $\mathbf{m} 250$ h. Source: Huang [97]. 
In all three papers above, the porous YSZ was used as backbone and the electronic conductive materials (LSM, LSF and LSCo) were used infiltrated particles. In these cathodes, connectivity of the infiltrated phase is very important to reduce the ohmic resistance, since the infiltrated phase is the only part for the electrical conduction. A recent work by Shiwoo Lee [99], reported a comparative study by infiltrating LSCo and LaZrO3 respectively into a commercial SOFC with SDC-LSCF cathode. Since the SDC-LSCF composite cathode has both ionic and electrical conductivity, the connection of the infiltrated particles is not necessary. The infiltrated cathode in this study is shown in Figure 37. The overpotential data respect to the current density is shown in Figure 38. It is shown that the proper infiltration of LSCo can decreased electrode overpotential of the cell up to $40 \%$ compared to the baseline for the current density within the range of $250-400 \mathrm{~mA} / \mathrm{cm}^{2}$.

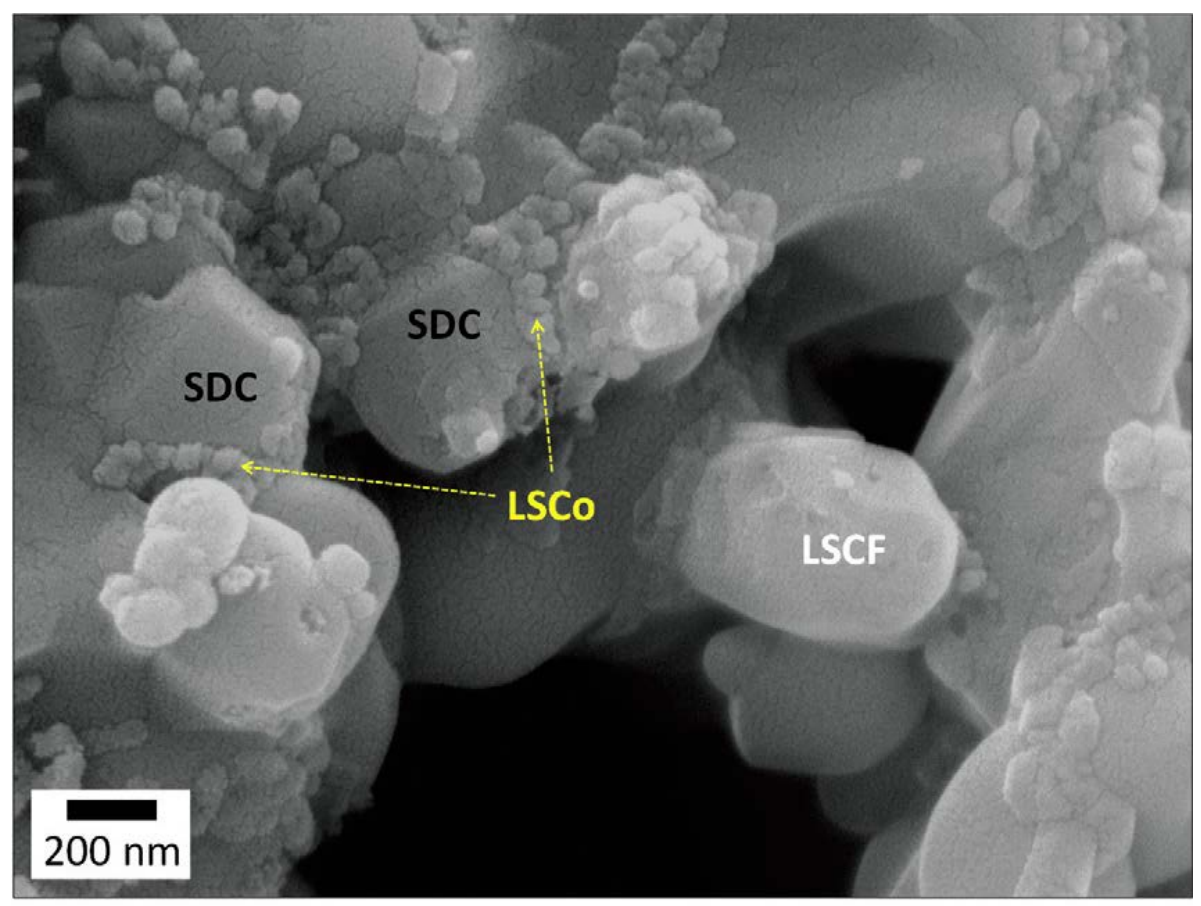

Figure 37. SEM image of cathode with 6 wt\% LSCo infiltration. Source: Lee [99]. 


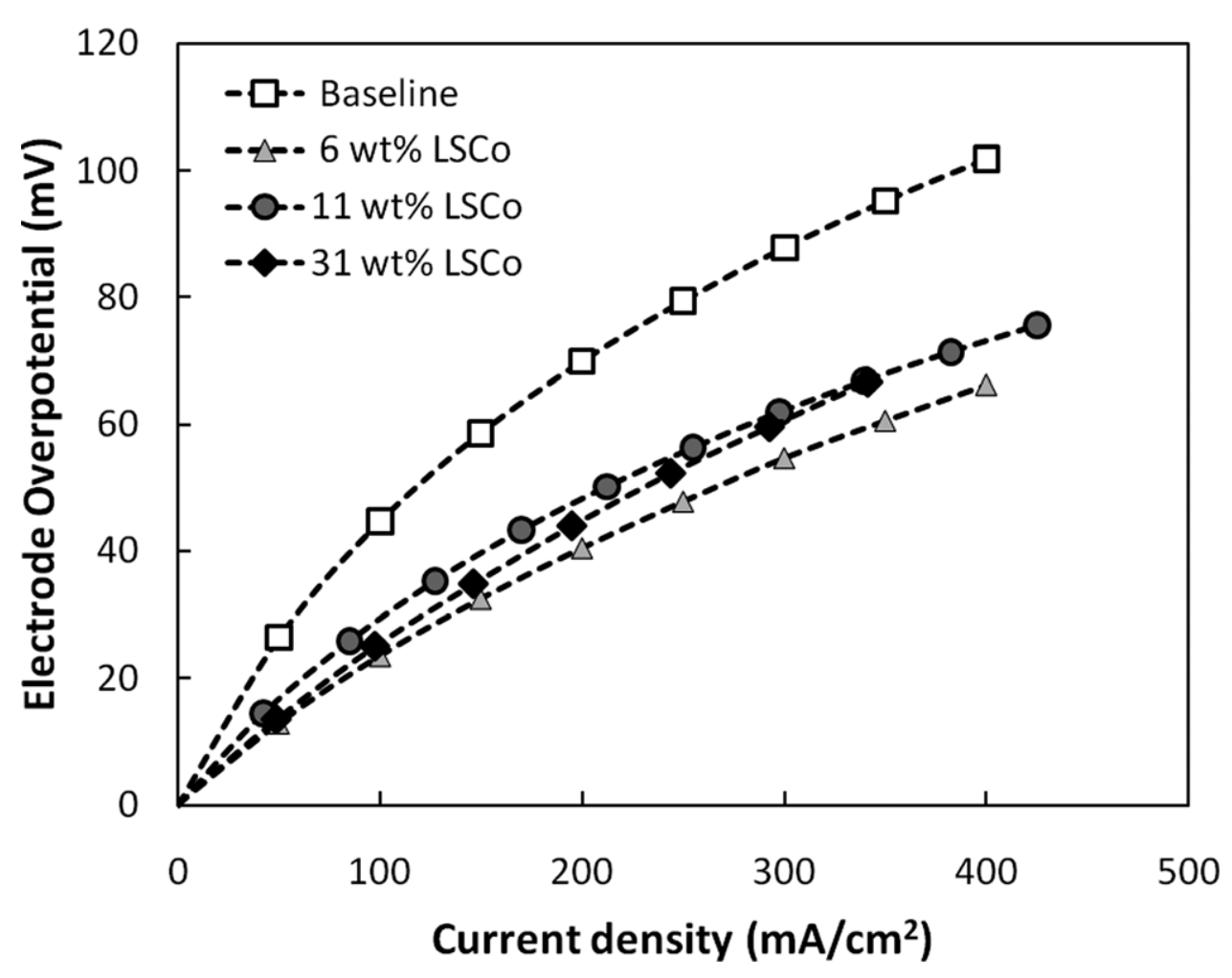

Figure 38. IR-corrected electrode overpotential-current desity plot for LSCo infiltrated SOFCs. Electrode overpotential was estimated by subtracting ohmic resistance contribution from an overall V-I polarization curve of the SOFCs, which was measured after applying a current density of $0.25 \mathrm{~A} / \mathrm{cm}^{2}$ for $24 \mathrm{~h}$ at $700{ }^{\circ} \mathrm{C}$. Source: Lee [99].

All the research about the cathode infiltration focused on the infiltrated particles morphology and the cathode performance, such as conductivity, polarization resistance and overpotential. To my best knowledge, there is only one paper using TEM to analyze the Pd infiltrated YSZ cathode [100]. In this study, the Pd is infiltrated with different methods into the YSZ backbone. 5 wt.\% Pd-loaded cathode prepared by infiltration-thermal decomposition process shows the lowest polarization resistance due to the well-connected Pd network. The Pd loading amount is very important for the good conductivity. However, even in this paper, the TEM only shows the distribution and connection of the Pd particles in the non-operational cell, which is shown in 
Figure 39. There is no work investigating the evolution of the infiltrated particles or the interaction between the infiltrated particles and cathode backbones.

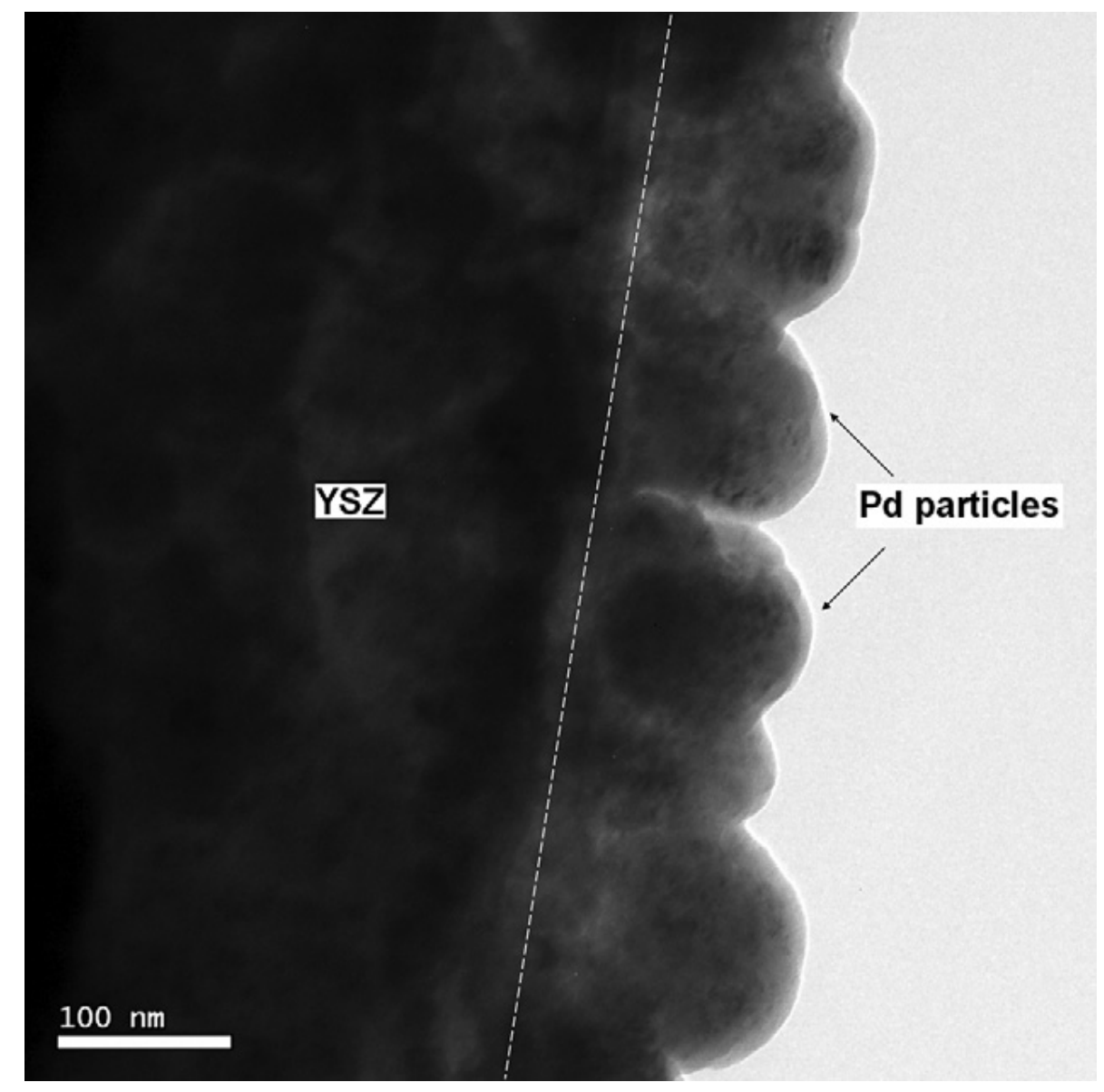

Figure 39. TEM image of Pd-YSZ cathode with a Pd loading of 5 wt.\%.Source: Liang [100].

Summary of the related nanostructure analysis reported in the literatures:

(1). There were a lot of works in SOFCs which were done by TEM. But some of them only focused on as-made materials themselves. The microstructure of the materials was not evaluated through the practical cell operation. Especially, there is no report on the effect of the different fuels and different operation time on the nanostructure and chemistry of the anode of the SOFC. 
(2). There is no report about the nanostructure and chemistry evolution of active layer, especially triple phase boundary area in the active layer, upon cell operation.

(3). Due to the cost, the cheaper fuel, like syngas, becomes more and more attractive in SOFC, the works on the effect of the fuel gas on the structure and chemistry of TPB in SOFC are desired. The commercial cell has stable and repeatable performance, so it is a good candidate to use as a platform to investigate the effect of the fuel gas. However, very limited experimental work has been devoted to studying the defects inside YSZ and the structure changes at TPB area in commercial cells, particularly the anode defect evolution upon cell operation with syngas.

(4). When the coal-derived syngas is applied to the SOFC as the fuel gas, the effect of contaminants in the syngas on the nanostructure and chemistry of the various anode in SOFC is desired.

(5). In the cathode side, many works proved that the infiltration was a good method to increase the cell performance by decreasing the polarization resistance. But to my best knowledge, there is no work about the evolution of the infiltrated particles or the interaction between the infiltrated particles and backbones during the cell operation. In order to understand the degradation mechanism of cathode with infiltration, the nanostructure and chemistry analysis of infiltrated particles and interface between infiltrated particles and cathode backbones is desired. 


\section{Chapter 3: Nanostructure and chemistry evolution of the anode in SOFCs operated in $\mathrm{H}_{2}$ or syngas}

\subsection{Introduction}

As mentioned in literature review, the commercial cell has stable and repeatable performance, so it is a good candidate to use as a platform to investigate the effect of the fuel gas and operation conditions on the nanostructure and chemistry of the SOFCs. To my best knowledge, there is very limited experimental work devoted to studying the defects inside YSZ and the structure changes at TPB area in commercial cells, particularly the anode defect evolution upon cell operation with syngas. In this chapter, the nanostructure and chemistry of the anode, especially the active layer, will be analyzed with different fuel gases and operation conditions. Some basic cathode results will be used for comparison.

\subsection{Materials and experimental method}

Commercially available, anode-supported solid oxide button cells fabricated by Materials and Systems Research, Inc. (MSRI, Salt Lake City, UT) were employed for all the experiments described in this chapter. MSRI button cells are composed of five layers as follows, starting from the anode: $\sim 0.9 \mathrm{~mm}$ thick Ni/YSZ cermet layer which supports the cell structure; $15 \mu \mathrm{m}$ thick Ni/YSZ active layer; $\sim 12 \mu \mathrm{m}$ thick YSZ electrolyte; $\sim 30 \mu \mathrm{m}$ thick $\mathrm{La}_{0.8} \mathrm{Sr}_{0.2} \mathrm{MnO}_{3}(\mathrm{LSM}) /$ YSZ active layer; and $50 \mu \mathrm{m}$ thick, pure LSM current collecting layer. The YSZ used throughout the cell is 8 mole\% $\mathrm{Y}_{2} \mathrm{O}_{3}$ doped YSZ. The cell active area (limited by the cathode) is $2 \mathrm{~cm}^{2}$. The exposure area of the anode to fuel is about $3.5 \mathrm{~cm}^{2}$.

The MSRI button cell was operated in a furnace controlled at $800^{\circ} \mathrm{C}$. Platinum mesh and 
nickel paste were used for lead connections. The wet hydrogen $\left(97 \% \mathrm{H}_{2}, 3 \% \mathrm{H}_{2} \mathrm{O}\right)$ or syngas with composition of 29 vol\% $\mathrm{H}_{2}$, 27 vol\% $\mathrm{H}_{2} \mathrm{O}, 12$ vol\% $\mathrm{CO}_{2}$, 29 vol\% $\mathrm{CO}$, and $3 \% \mathrm{~N}_{2}$ was used as fuel. The fuel and air stream flow rates and compositions were controlled separately using mass flow controllers. During the operation, a $1 \mathrm{~L} / \mathrm{min}$ air flow rate and a $300 \mathrm{~mL} / \mathrm{min}$ fuel flow rate were used. This sample was loaded at a constant current of $0.25 \mathrm{~A} / \mathrm{cm}^{2}$ for $550 \mathrm{~h}$.

The cells operated as described above and another as-received cell were each cross-sectioned and submitted to examination by using TEM. TEM samples were prepared by mechanical polishing and ion milling in a liquid-nitrogen cooled holder. Electron diffraction, diffraction contrast and high-resolution TEM imaging were performed in a JEM-2100 operated at $200 \mathrm{kV}$. Chemical analysis was carried out using energy dispersive X-ray Spectroscopy (EDS) equipped with TEM. The structure of the YSZ in different components of SOFC and the structure of the TPB area in the anode of the SOFC were investigated with TEM.

A series commercial SOFCs were analyzed in this study. The Table 1 shows the basic information of the SOFCs involved in this chapter. 
Table 1 The information of the operation and cooling condition of the SOFCs in chapter 3

\begin{tabular}{cccc}
\hline Cell No. & Cell operation time & Fuel gas & Cell cooling condition \\
\hline SOFC-0 & \multicolumn{3}{c}{ As-received cell without any operation } \\
SOFC-R & $72 \mathrm{~h} \mathrm{H}_{2}$ fully reduced cell, no electrochemical operation \\
SOFC-H-1 & $24 \mathrm{~h}$ & $97 \% \mathrm{H}_{2}+3 \% \mathrm{H}_{2} \mathrm{O}$ & Flowing Nitrogen \\
SOFC-H-2 & $540 \mathrm{~h}$ & $97 \% \mathrm{H}_{2}+3 \% \mathrm{H}_{2} \mathrm{O}$ & Flowing Nitrogen \\
SOFC-H-3 & $200 \mathrm{~h}$ & $97 \% \mathrm{H}_{2}+3 \% \mathrm{H}_{2} \mathrm{O}$ & Flowing Nitrogen \\
SOFC-H-4 & $200 \mathrm{~h}$ & $25 \% \mathrm{H}_{2}+3 \% \mathrm{H}_{2} \mathrm{O}+72 \% \mathrm{~N}_{2}$ & Flowing Nitrogen \\
SOFC-S-1 & $24 \mathrm{~h}$ & Simulated syngas & Flowing Nitrogen \\
SOFC-S-2 & $550 \mathrm{~h}$ & Simulated syngas & Flowing Nitrogen \\
\hline
\end{tabular}

\subsection{YSZ structure in different components and anode TPB area in as-received SOFC}

The YSZ grains in cathode and anode of the as-received cell are analyzed firstly. The diffraction contrast image (Figure 40) shows that the size of the YSZ grains in the anode is about $300 \mathrm{~nm}$, which is comparable to that (300-500 nm) in the cathode active layer of the same cell. No impurity and precipitate were found at NiO/YSZ interface in the as-received cell, which is shown in Figure 41. Figure 42 shows the electron diffraction patterns taken from the [110] direction of YSZ in different components of the as-received cell. The pattern from cathode (Figure 42a) has a cubic fluorite structure, while the patterns from electrolyte (Figure 42b) and anode (Figure 42c) are different. The latter two images show distinct extraneous weak diffraction spots that are otherwise kinematically forbidden. Multiple electron diffraction patterns are taken from YSZ grains in various regions of the cathode, electrolyte and anode. Those diffraction 
patterns difference is consistent, as shown in Figure 42, with no observed exceptions. The electron diffraction in Figure 42 is indexed based on the primary spots from the cubic fluorite structure. Representative EDS results indicating the Y/Zr ratio from YSZ in anode and cathode are shown in Table 2. The $\mathrm{Y}_{2} \mathrm{O}_{3}$ doping levels for anode, electrolyte and cathode are measured to be $\sim 8 \mathrm{~mol} \%$. The average $\mathrm{Y} / \mathrm{Zr}$ ratios appear to be narrowly distributed and consistent with ratios from YSZ in anode and cathode.

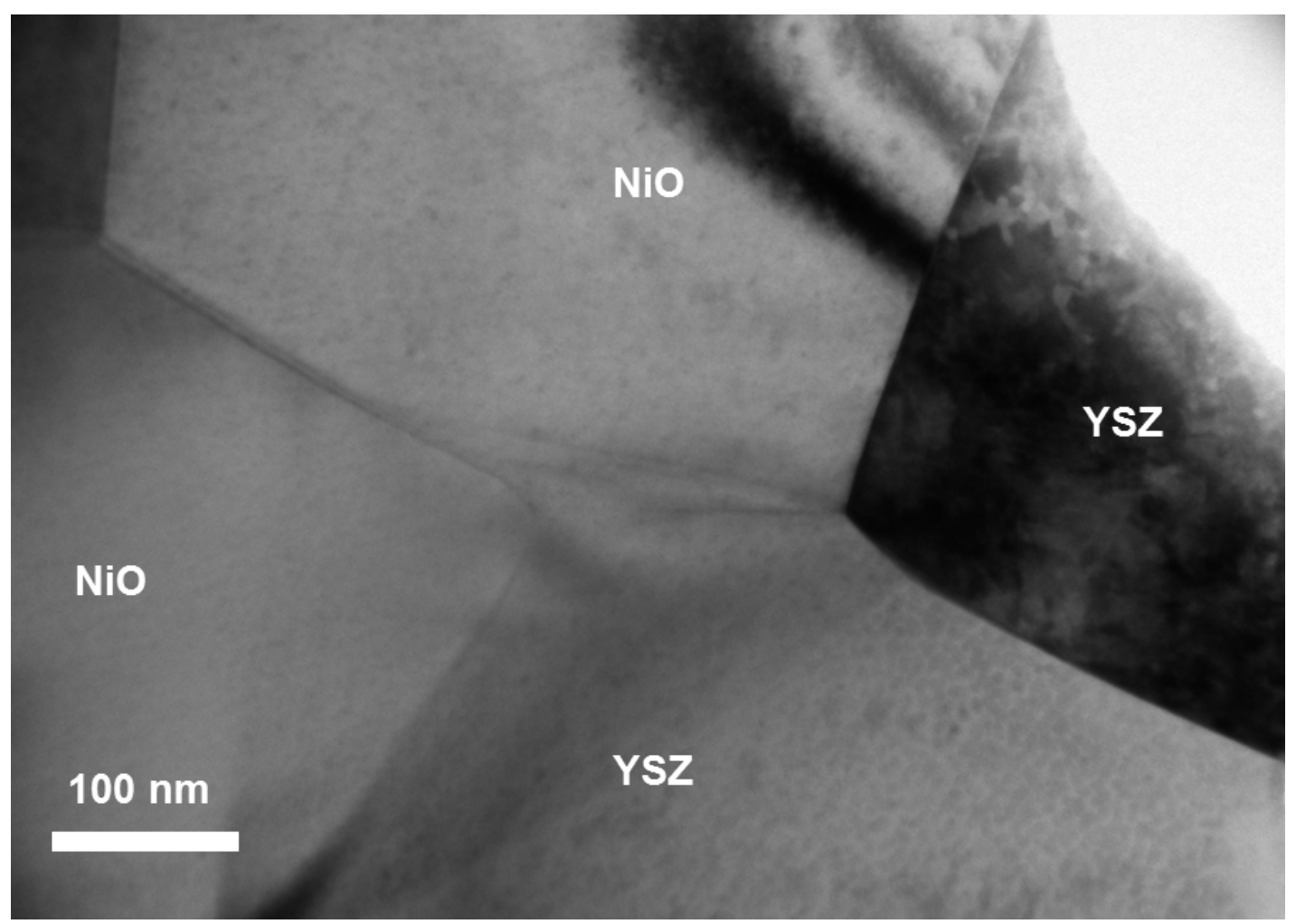

Figure 40. Diffraction contrast image from the anode side of the as-received cell. 


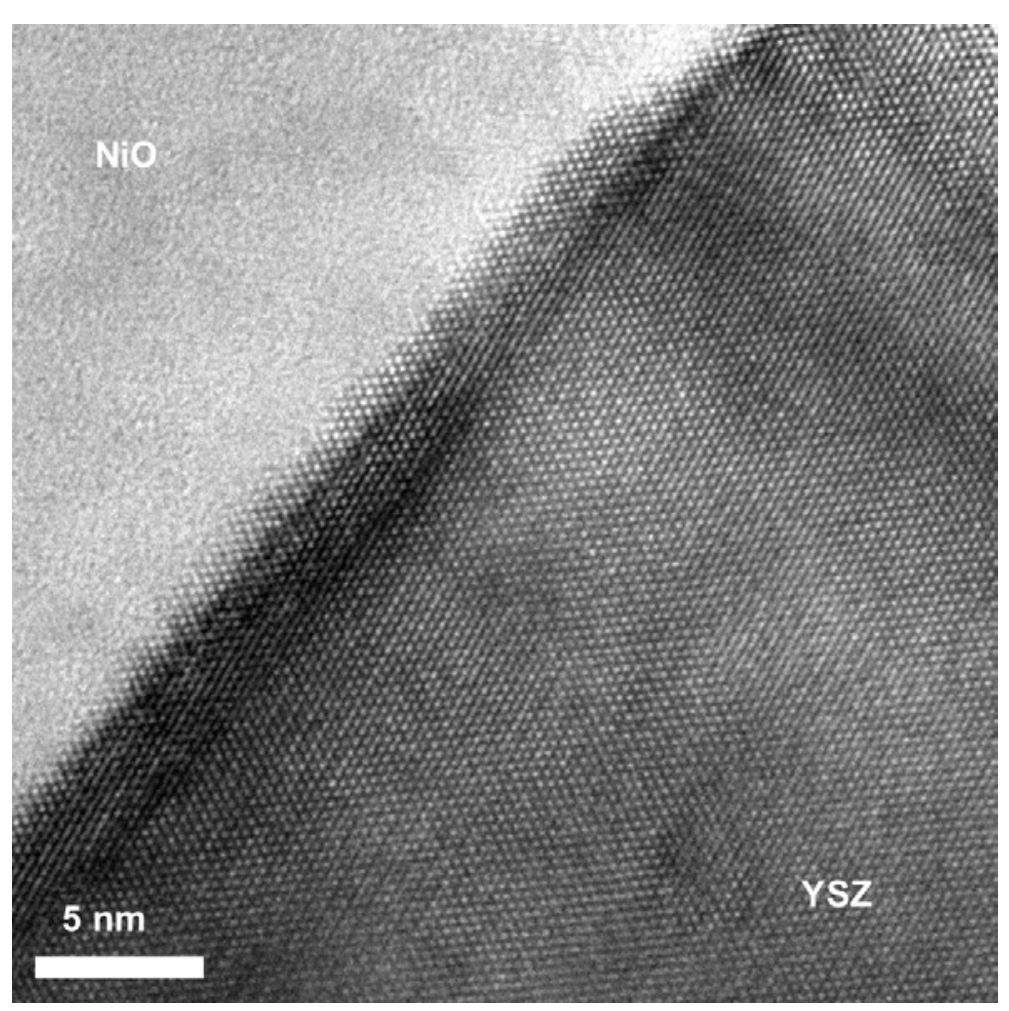

Figure 41. High resolution TEM image showing the morphology of the grain boundary between NiO and YSZ in the as-received cell. The YSZ grain is aligned in the [110] direction

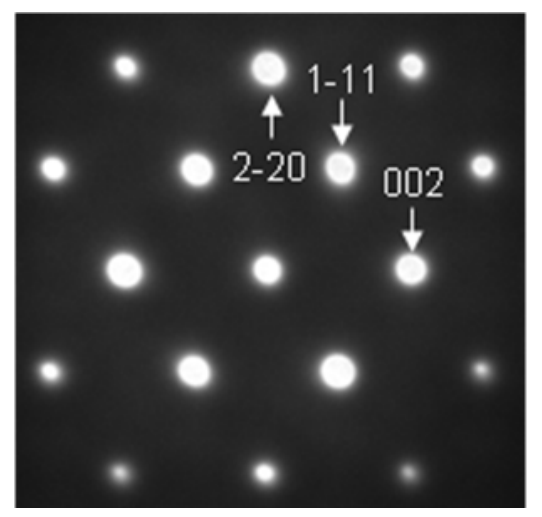

(a)

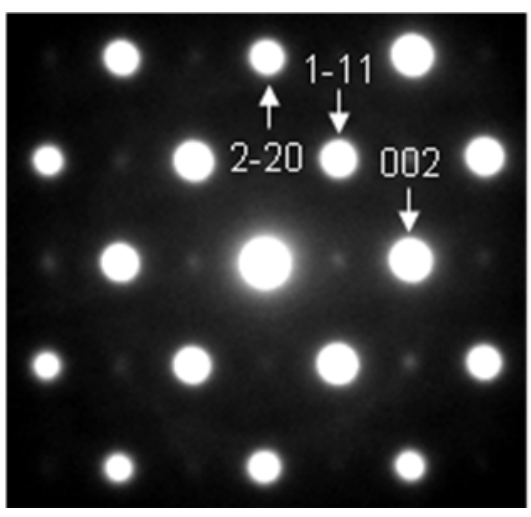

(b)

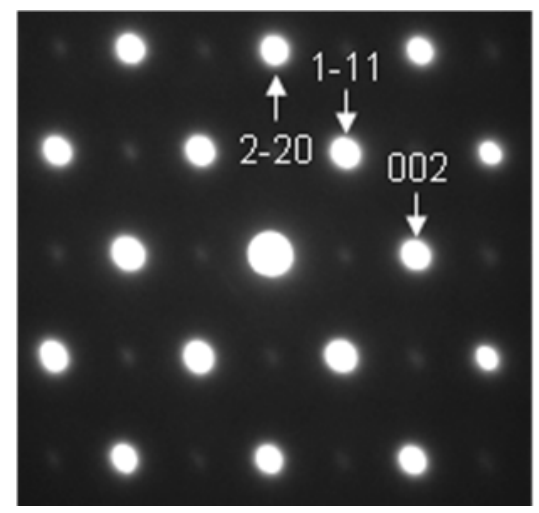

(c)

Figure 42. Electron diffraction patterns taken from the [110] zone axis of YSZ grains in the (a) cathode active layer (b) electrolyte, and (c) anode active layer. The indices are given according to the fcc fluorite structure. 
Table 2 EDS chemical composition examination on YSZ grains showing the Y/Zr Atomic Ratio in the anode, cathode, and electrolyte of the as-received cell (Three data points were taken for each position, concentrations of $\mathrm{Y}, \mathrm{Zr}$ and $\mathrm{O}$ were normalized to 100 at\%, c/e=cathode/electrolyte interface, a/e=anode/electrolyte interface)

\begin{tabular}{|c|c|c|}
\hline Position & $\begin{array}{c}\text { Average Y to Zr } \\
\text { atomic ratio } \\
\text { / standard deviation }\end{array}$ & $\begin{array}{l}\mathrm{Y}_{2} \mathrm{O}_{3} \text { in } \mathrm{YSZ} \text { at\% ratio / standard } \\
\text { deviation } \\
\text { calculated using } \mathrm{Y} \text { to } \mathrm{Zr} \text { ratio } \\
\text { (assuming all } \mathrm{Y} \text { is in } \mathrm{Y}_{2} \mathrm{O}_{3} \text {, } \mathrm{Zr} \text { is in } \\
\mathrm{ZrO}_{2} \text { ) }\end{array}$ \\
\hline In cathode, $\sim 1 \mu \mathrm{m}$ from c/e & $0.185 / 0.013$ & $0.085 / 0.007$ \\
\hline In cathode, $\sim 5 \mu \mathrm{m}$ from c/e & $0.178 / 0.002$ & $0.082 / 0.001$ \\
\hline In electrolyte, $\sim 1 \mu \mathrm{m}$ from c/e & $0.186 / 0.002$ & $0.085 / 0.001$ \\
\hline In electrolyte, $\sim 5 \mu \mathrm{m}$ from c/e & $0.191 / 0.002$ & $0.087 / 0.001$ \\
\hline In electrolyte, $\sim 1 \mu \mathrm{m}$ from a/e & $0.180 / 0.008$ & $0.083 / 0.004$ \\
\hline In anode, $\sim 1 \mu \mathrm{m}$ from c/e & 0.188 / 0.009 & $0.086 / 0.004$ \\
\hline In anode, $\sim 5 \mu \mathrm{m}$ from c/e & $0.194 / 0.010$ & $0.088 / 0.005$ \\
\hline
\end{tabular}

As we know, the cathode of the SOFCs is sintered at different temperature from the anode. So the sintering temperature may influence the YSZ structure. And the co-sintered materials may influence the structure with each other by diffusion or interaction during the sintering. In order to investigate the effect of the sintering parameters on the structure of the YSZ, the raw YSZ and LSM particles, which are used to make the SOFCs, are utilized to make thin pellets and sintered at $1100^{\circ} \mathrm{C}$. Two pellets are made in this study. One is pure YSZ pellet, the other is YSZ/LSM composite pellet. The diffraction patterns of YSZ grains from both pellets are obtained. The Figure 43a shows that YSZ from pure YSZ pellets exhibits similar weak diffraction spots as the ones in Figure 42b\&c, which indicates that the sintering temperature in this study cannot change the YSZ structure. In Figure 43b, the YSZ diffraction pattern from the YSZ/LSM composite 
pellet shows the weak diffraction spots as well, but the density is much less than the one from pure YSZ pellet, which indicates the co-sintered material may influence the structure of the YSZ. The chemical compositions of YSZ grain in YSZ/LSM pellet are obtained by EDS. The Mn peaks shown in the EDS spectrum indicate the existence of Mn in the YSZ grains in YSZ/LSM pellet. The results suggest that the difference of the YSZ structure in anode and cathode of SOFCs is tentatively due to the Mn diffusion from the LSM into the YSZ in cathode. The Mn in the YSZ grain can stabilize the cubic structure of the YSZ. In the previous work [101], the effect of $\mathrm{Mn}$ on the structure and conductivity of $8 \mathrm{~mol} \% \mathrm{Y}_{2} \mathrm{O}_{3}$ doping $\mathrm{YSZ}$ has been studied. The similar stabilizing effect of Mn on YSZ structure was observed in YSZ with 5\% Mn of metal ions sample. However, the presence of Mn reduced the ionic conductivity of the YSZ.

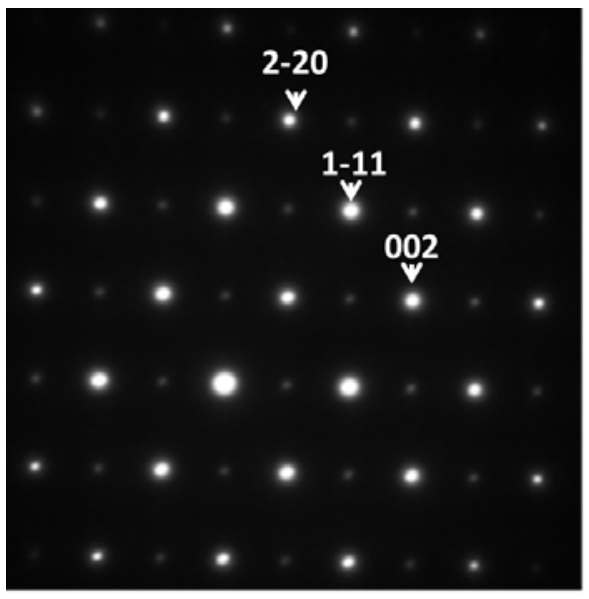

(a)

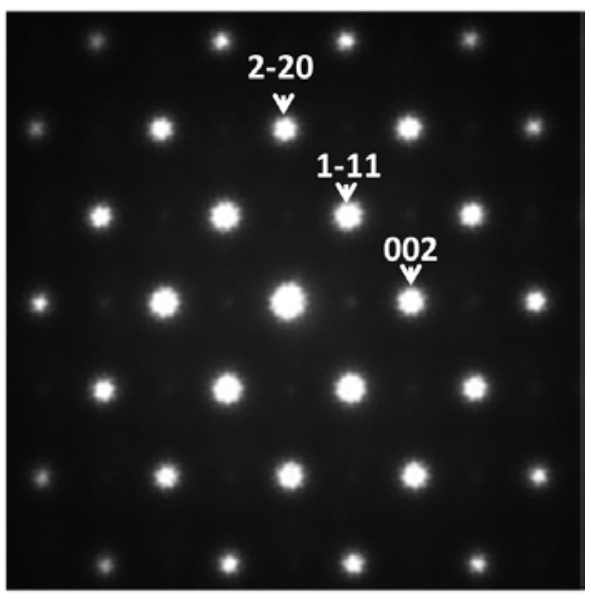

(b)

Figure 43. Electron diffraction patterns taken from the [110] zone axis of YSZ grains from (a) pure YSZ pellet and (b) YSZ/LSM composite pellet sintered at $1100^{\circ} \mathrm{C}$. 


\subsection{YSZ structure in the different components and anode TPB area in SOFC operated with syngas}

Weak diffraction spots from YSZ in anode and electrolyte were observed for the cell operated on syngas for $550 \mathrm{~h}$. The TEM results obtained from the operated cell consistently show crystallographic structure differences between the YSZ grains in the anode and the electrolyte compared to those in the cathode. Figure 44 shows typical diffraction contrast images and electron diffraction from the cathode active layer (a), and from the anode active layer (b) of the post-operational SOFC. The extraneous weak diffraction spots are present in the anode of the operated cell.

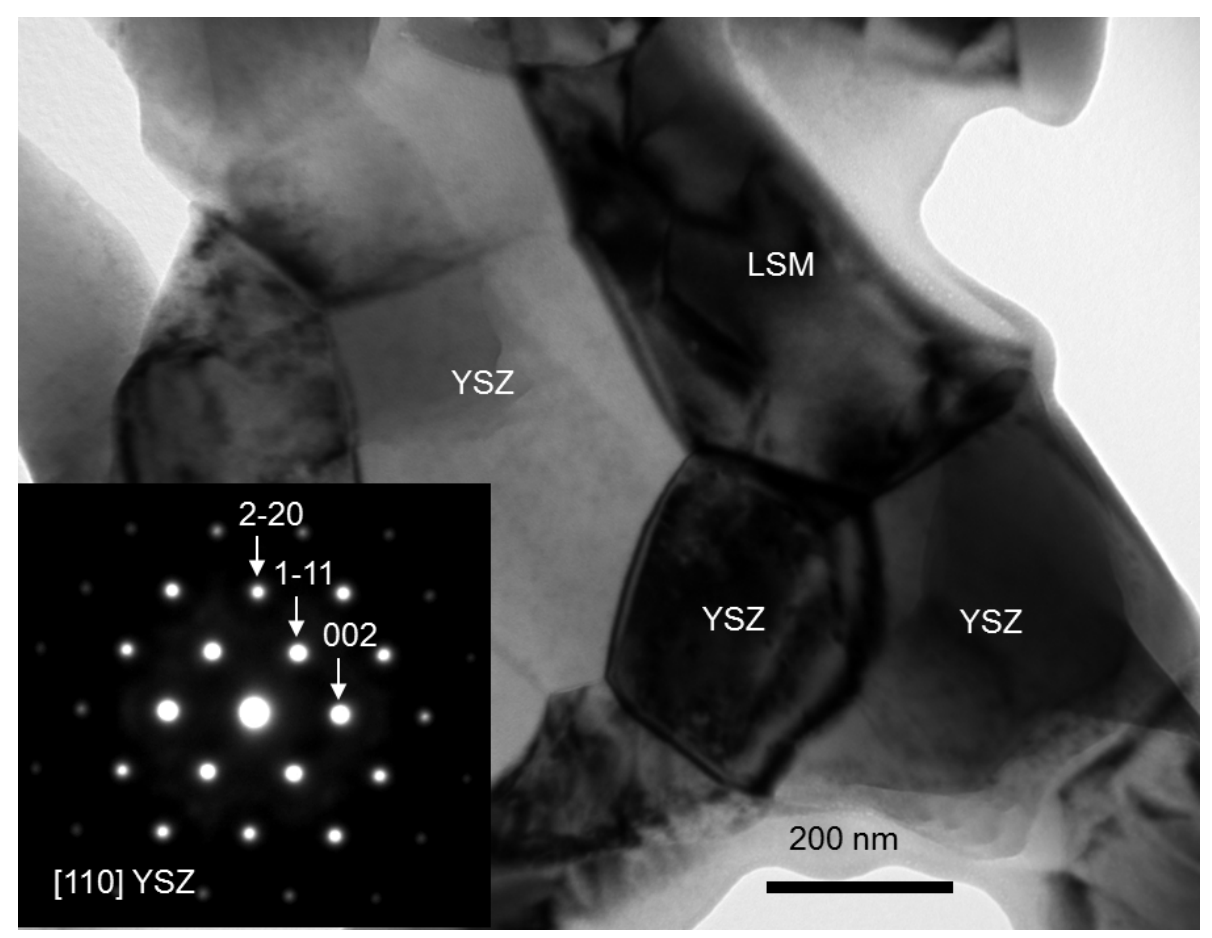

(a) 


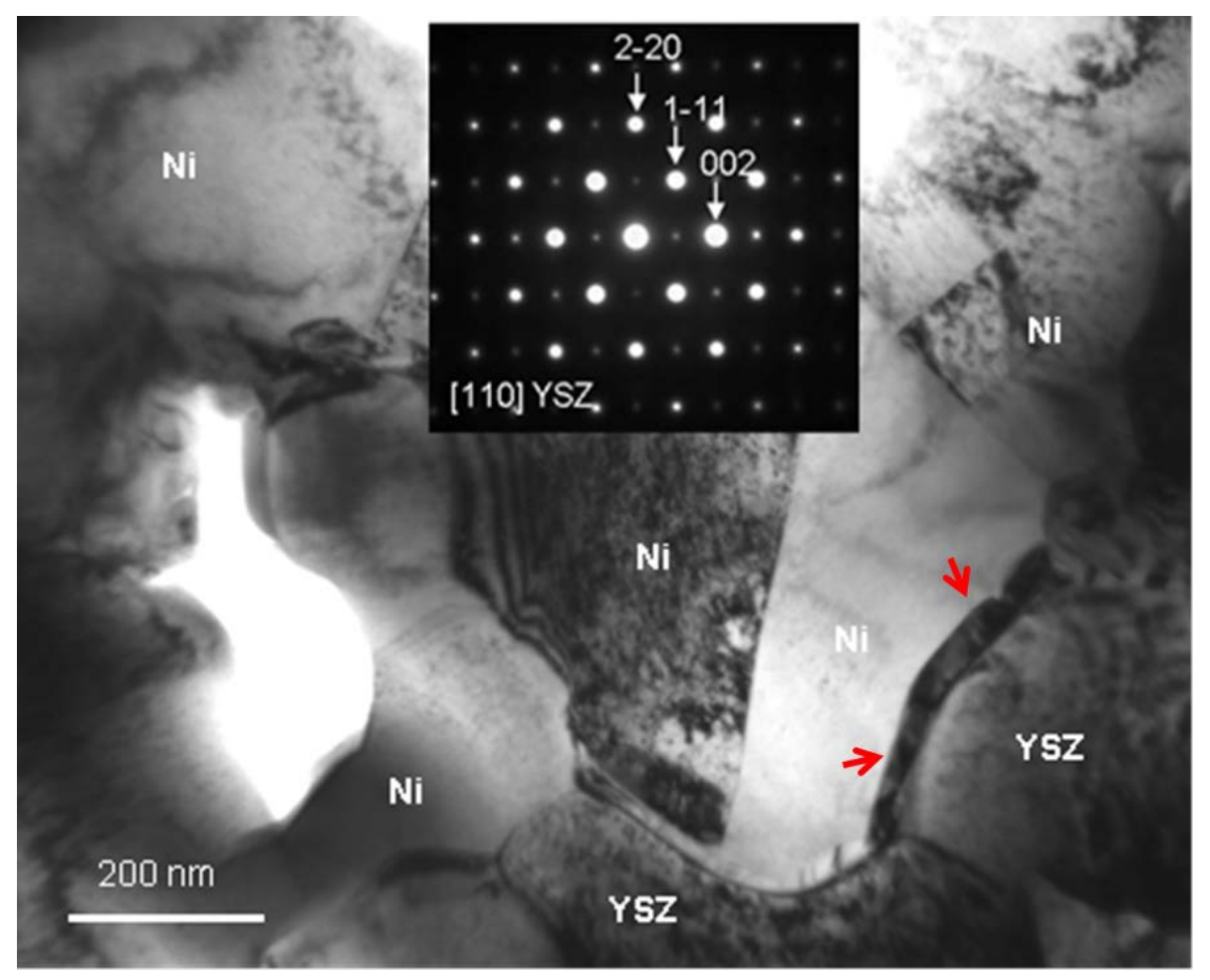

(b)

Figure 44. Electron diffraction and diffraction contrast images taken from 550 h operated cell. (a) cathode active layer, and (b) anode active layer. The inserted images show the diffraction patterns taken from [110] YSZ. In addition, an intergranular ribbon phase between YSZ and Ni can be observed and is pointed out by arrows.

In order to reveal the origin of the weak diffraction spots from the YSZ grain, a systematic tilting experiment was conducted in which the electron diffraction in the anode was obtained from different orientations, as shown in Figure 45. The diffraction patterns from different zone axes were indexed based on the primary diffraction from cubic fluorite YSZ (c-YSZ). The electron diffraction pattern including all kinematically forbidden spots shown in Figure 45 can be indexed as the pattern from a mixture of cubic YSZ ( $c$-YSZ) and tetragonal YSZ ( $t$-YSZ). 


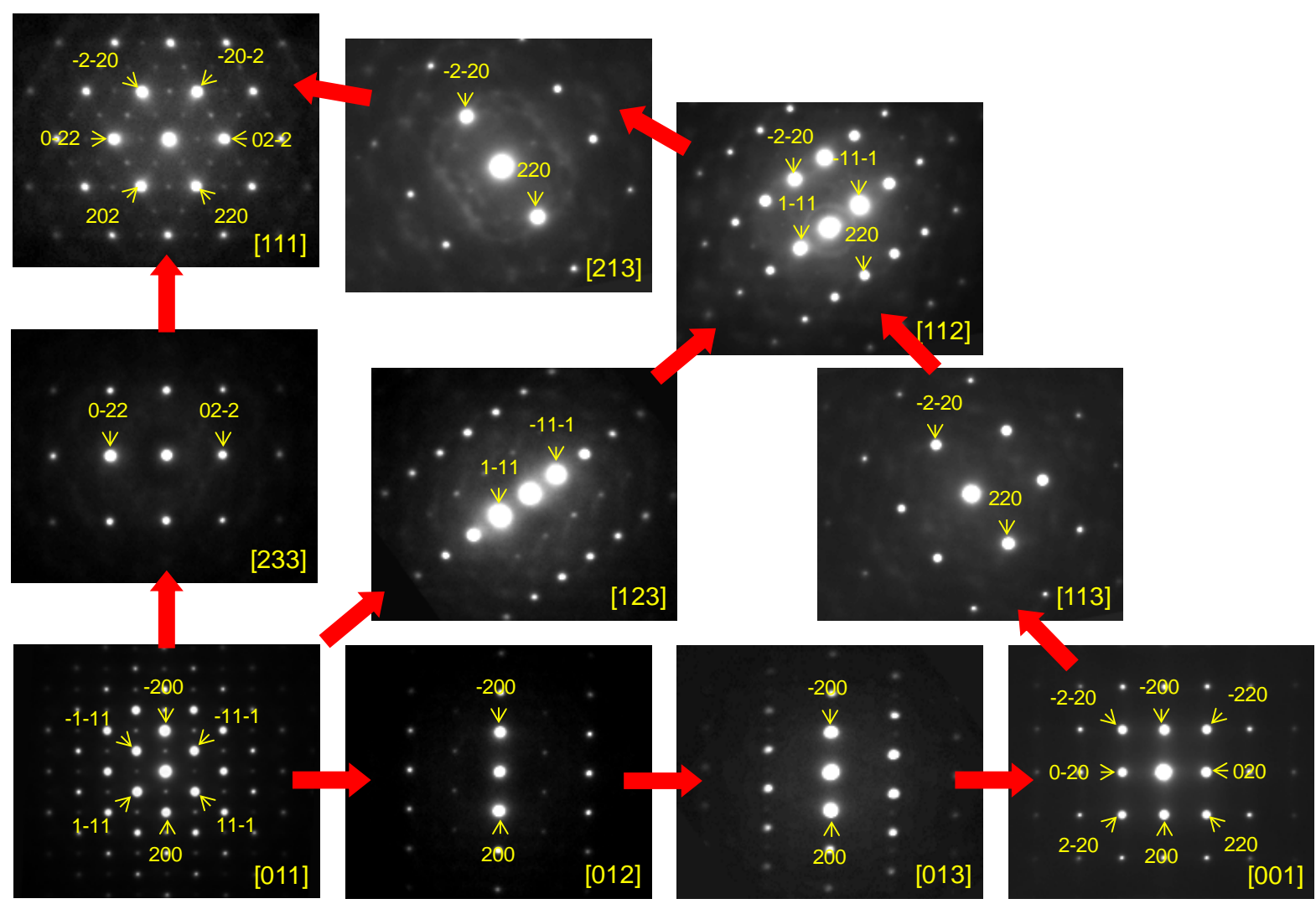

Figure 45. Systematic electron diffraction patterns from different zone axis of YSZ in the anode of the cell operated in syngas. The indices are given according to the fcc fluorite structure. 


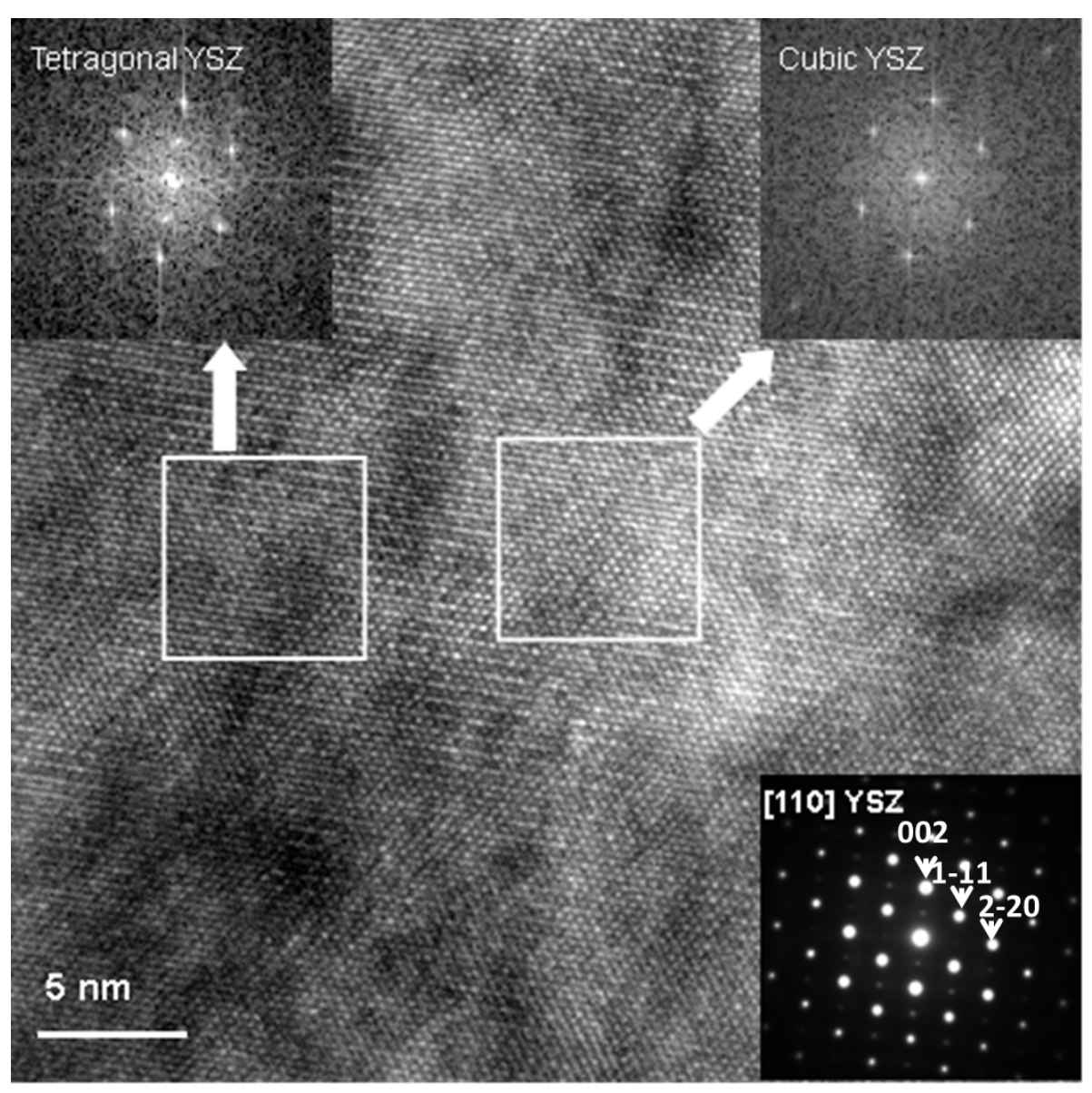

Figure 46. High resolution TEM image and the corresponding power spectrum from the YSZ in the SOFC anode of the cell operated in syngas.

Additionally, the anode active layer region of the operated cells was examined using high resolution TEM (HRTEM) imaging and the related fast Fourier transformation (FFT). The results are shown in Figure 46. YSZ grains in the anode and electrolyte contained nano-domains with different power spectrums, which can be indexed as either the $c$-YSZ structure or the $t$-YSZ structure. The HRTEM image of Figure 47 indicates that the dimensions of the $t$-YSZ are about 2-10 nm. Such results are in consistent with the selected area diffraction patterns in Figure 44(b) and Figure 46 (inserted SAD pattern), and verify the existence of a mixture of $c$-YSZ and $t$-YSZ structures in the SOFC anode. 


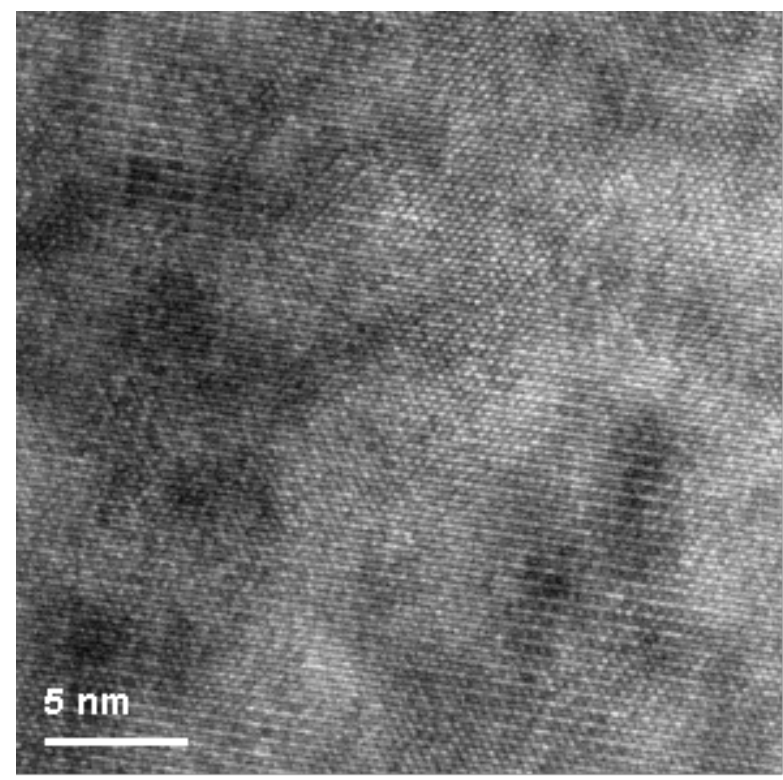

(a)

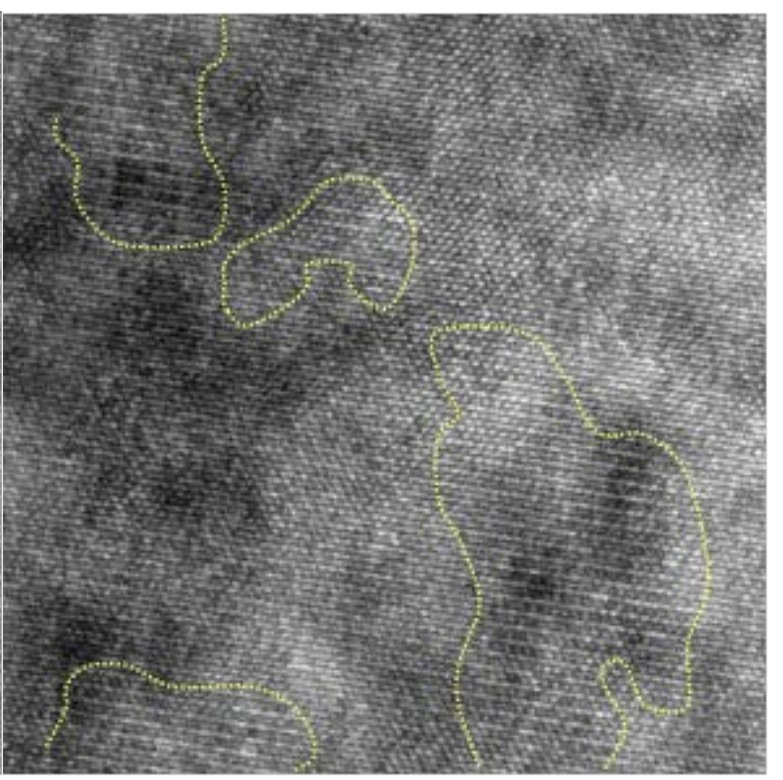

(b)

Figure 47. (a) High resolution TEM image taken from the YSZ in the anode side; and (b) the same HRTEM image with dot lines circling the regions which clearly feature $t$-YSZ domains.

Figure 44 (b) also depicts Ni/YSZ intergranular phases, which are indicated by arrows. The EDS spectrum in Figure 48a shows only two major elements, which are $\mathrm{O}$ and $\mathrm{Ni}$, are detected in the intergranular phase. And the diffraction pattern taken from the Ni-O phase matches the standard $\mathrm{NiO}$ pattern of [011] zone axis. The results confirm that the new intergranular phase is $\mathrm{NiO}$. The thickness of the $\mathrm{NiO}$ is about $50 \mathrm{~nm}$. The cell operated on syngas for $24 \mathrm{~h}$ shows the same Ni/YSZ intergranular $\mathrm{NiO}$ phase (Figure 50), but the thickness is about $10 \mathrm{~nm}$. For comparison, a cell (SOFC-R), which was fully reduced at $800^{\circ} \mathrm{C}$ but never operated electrochemically, was examined. No ribbon phase is observed at Ni/YSZ interfaces, as shown in Figure 49. This confirms that such a ribbon phase only forms in the electrochemically operated cells. The precise mechanisms for the formation of $\mathrm{NiO}$ are unclear, and the consequences to electrochemical performance of the SOFC are not known in this study. However, the phase growth may result from precipitation of accumulated oxygen, a process which could occur 
during open circuit cooling operations in non-reducing environments. At elevated temperatures, dissolution and diffusion of oxygen into the interstitial sites of nickel is possible.[102, 103] During cell polarization, oxygen could migrate to the nickel phase and develop a solid Ni/O solution film inside Ni grains near Ni/YSZ interfaces. This solid solution is composed of the unaltered $\mathrm{Ni}$ crystal containing interstitial oxygen atoms or ions in the Ni lattice. During polarized operations, the oxidation electrode reaction at the gas-exposed surface promotes consumption of the oxygen (with an increasing oxygen vacancy concentration gradient from the YSZ grain to the Ni grain), but the reaction ceases under open circuit conditions and the solvated oxygen becomes electrochemically isolated. During the cooling period, the oxygen trapped in the solid solution films/layers precipitates to form the $\mathrm{NiO}$ inter-phase layers. Though the mechanisms of initial oxygen ion transport into $\mathrm{Ni}$ grain are not known (and indeed such transport is speculative), the ribbon-like shape of the $\mathrm{NiO}$ phases hint at the existence of a short range oxygen gradient perpendicular to the Ni/YSZ interfaces. Such a concentration gradient could arise from chemical or electric potential differences between the YSZ and Ni phases, and further careful experimentation will be necessary to reveal the true source of the observed phases. Environmental SEM (ESEM) is a promising facility, which can provide the in-situ information for the phase formation. If we can equip the SOFC operation system into the ESEM and expose the Ni/YSZ interface to the lens and detector, we can obtain more information about the new phase $(\mathrm{NiO})$ formation at the $\mathrm{Ni} / \mathrm{YSZ}$ interface. And the kinetics of the $\mathrm{NiO}$ formation will be studied by modeling and further experiments. 

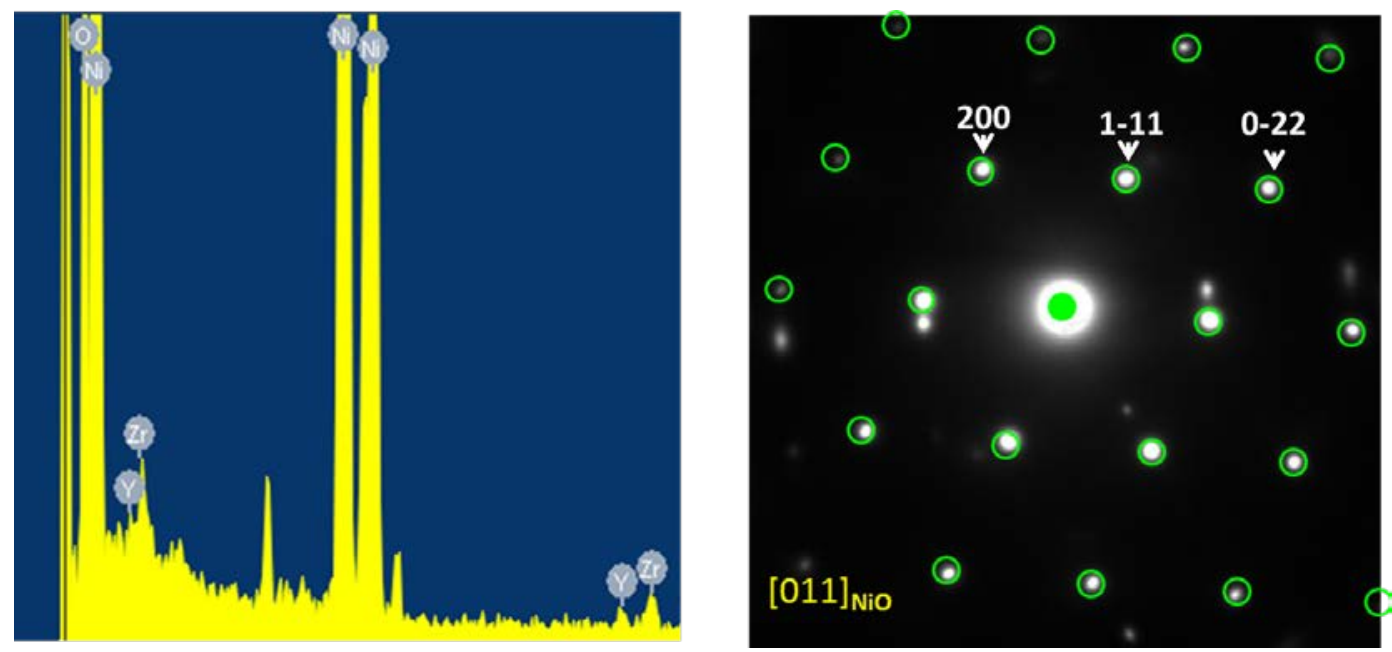

Figure 48. (a) EDS spectrum taken from the new Ni/YSZ intergranular phase. (b) Diffraction pattern taken from the new Ni/YSZ intergranular phase matching the diffraction pattern of $\mathrm{NiO}$ [011] zone axis.

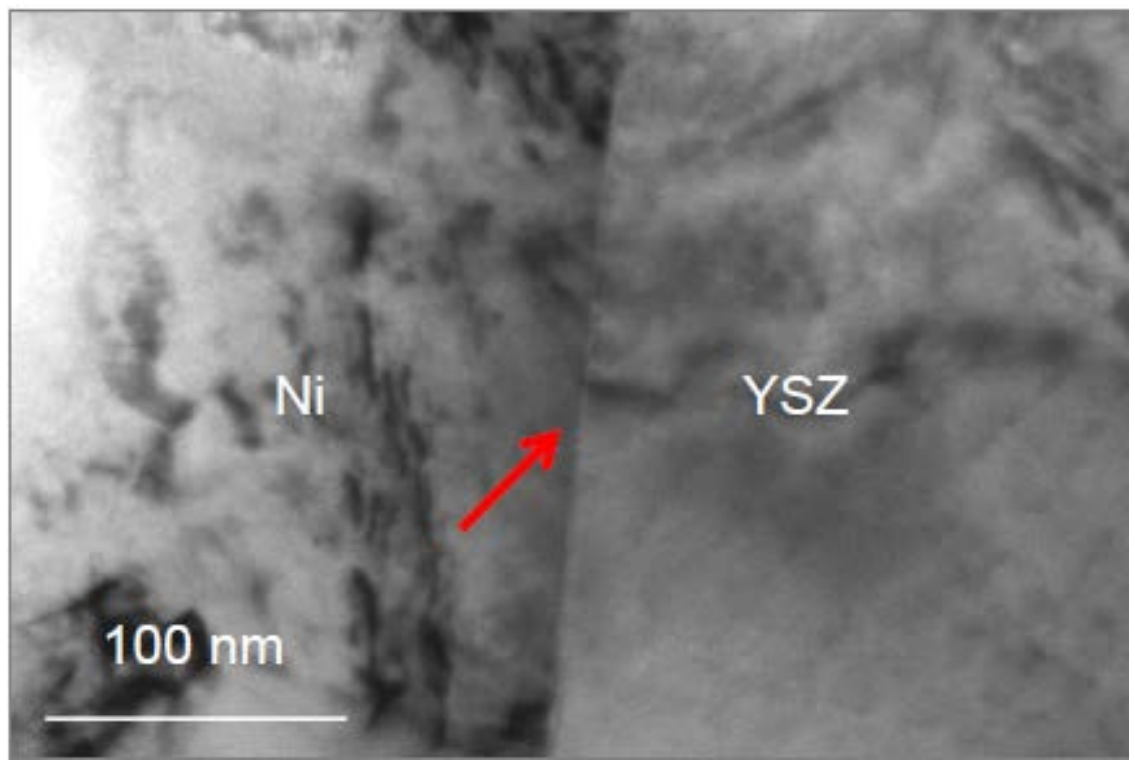

Figure 49 TEM image taken from the Ni/YSZ GBs (pointed out by a red arrow) close to TPB area in the fully reduced cell (SOFC-R), revealing free of $\mathrm{NiO}$ interphase at Ni/YSZ GBs in the anode of the unoperated cell. 


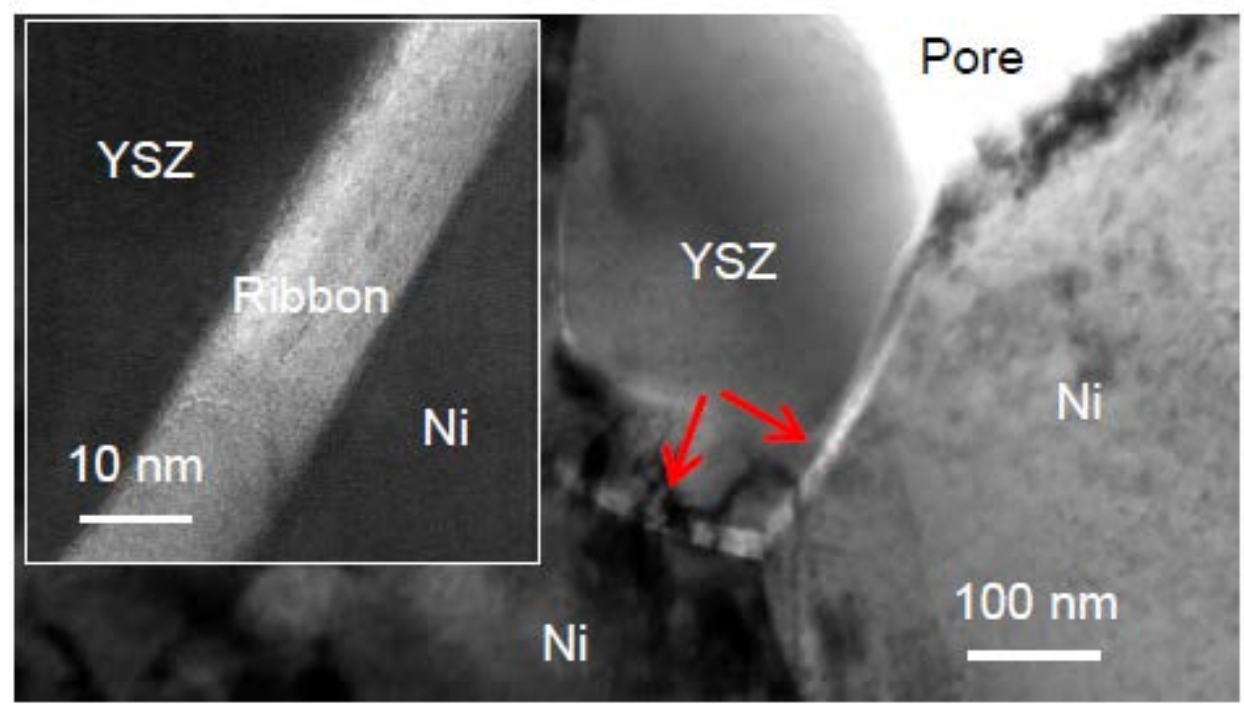

Figure 50. Microstructure of anode TPB and ribbon phase in the cell No.5 operated for $24 \mathrm{~h}$ in syngas.

The inserted image magnifies the thickness of the ribbon.

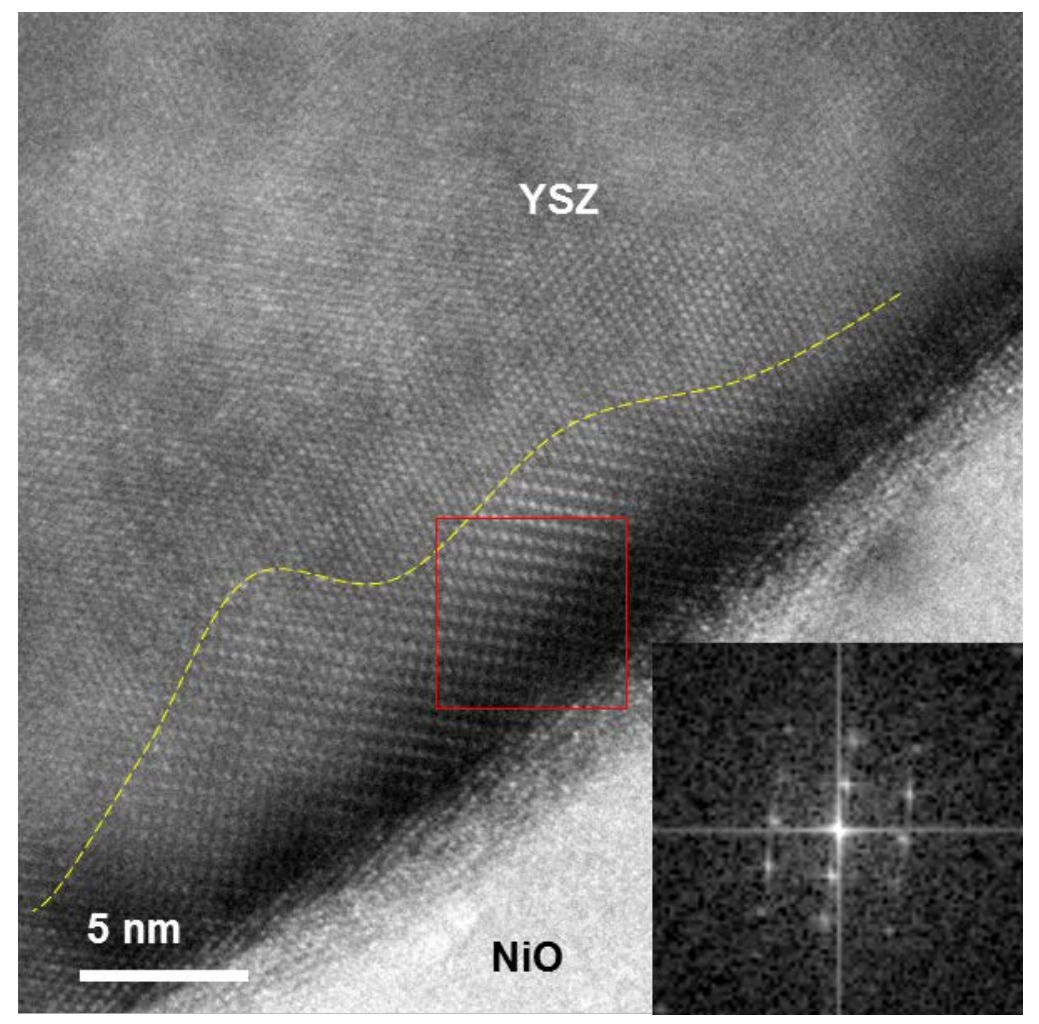

(a) 


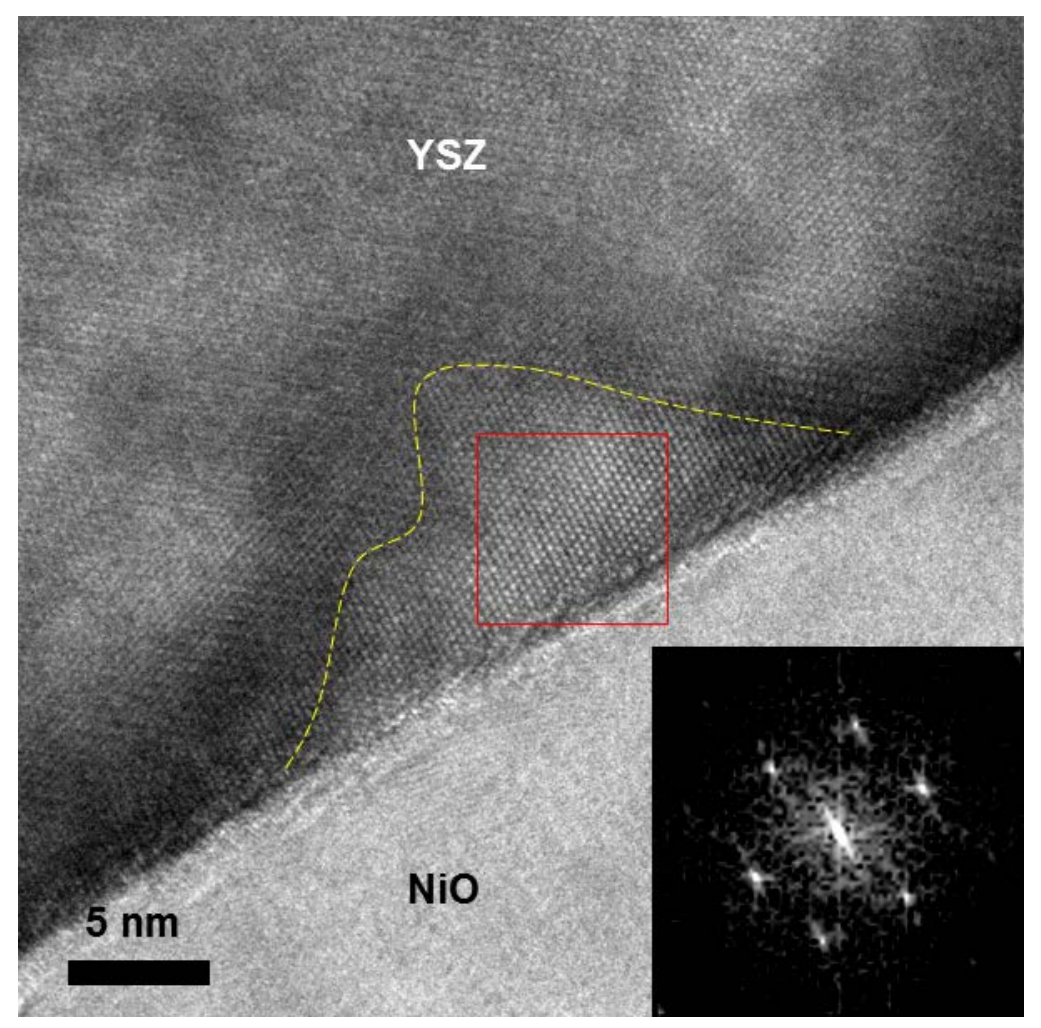

(b)

Figure 51. High resolution TEM images showing (a) a 5-10 nm t-YSZ layer and (b) a $c$-YSZ domain between $t$-YSZ layers along the original Ni/YSZ GB.

HRTEM images are taken from the area near the Ni/YSZ, LSM/YSZ interface and YSZ/YSZ GBs for the cell operated for $550 \mathrm{~h}$. In contrast to Liu et al [4], no glassy phase was observed in any of the above-mentioned interfaces or GBs. However, the YSZ/Ni interface structure changes in the operated cell. Figure 51 depicts a discretely ordered $t$-YSZ nano-domain (in Figure 51a) and a discretely ordered $c$-YSZ nano-domain (in Figure 51b) that are observed between the original Ni/YSZ interface and the bulk YSZ domain after operation. The $t$-YSZ interfacial domain is in the form of a distinct interface layer approximately 5-10 nm wide and $30 \mathrm{~nm}$ long. The $t$-YSZ interfacial layer is significantly larger than the 2-10 $\mathrm{nm}$ intragranular $t$-YSZ domains, and is hypothesized to develop as a result of cell operation. The FFT power spectrum obtained 
in the $t$-YSZ domain at the interface is identical to the spectrum obtained from the $t$-YSZ in the bulk domain. The interfacial $t$-YSZ does not form a continuous ribbon along the entire length of the Ni/YSZ interface, but is coupled with small $c$-YSZ domains, which quasi-periodically alternate with $t$-YSZ.

The YSZ/YSZ GB from the anode and the YSZ/LSM interface from the cathode of the same operated cell were also studied using TEM. Figure 52 clearly shows that YSZ/YSZ GB from the anode active layer of the operated SOFC is free of the NiO ribbon phase layer and interfacial $t$ YSZ phase. Furthermore, as shown in Figure 53, there are no apparent structural changes in the YSZ side of the YSZ/LSM interface whereas structural changes are obvious in the YSZ at the $\mathrm{Ni} /$ YSZ interface in the anode. Actually, the formation of the interfacial $t$-YSZ phase is accompanied with the formation of the $\mathrm{NiO}$ ribbon phase layer at $\mathrm{Ni} / \mathrm{YSZ}$ interface. The results suggest that the formation of $\mathrm{NiO}$ ribbon phase layer and the interfacial $t$-YSZ phase coupled with $c$-YSZ is attributed to an electrochemical operation effect, rather than a thermo-chemical effect. In previous work, with high temperature $\left(1000^{\circ} \mathrm{C}\right)$ thermal treatment, changes in the size of $t$-YSZ phase in 8YSZ grain from about $1 \mathrm{~nm}$ to about 10 15 $\mathrm{nm}$ were observed [72], which means the cations in 8YSZ can be redistributed in a certain treatment. When two $\mathrm{Y}$ atoms substitute for two $\mathrm{Zr}$ atoms in $\mathrm{ZrO}_{2}$, the substitution creates one $\mathrm{O}$ vacancy. Consequently, a higher $\mathrm{Y}_{2} \mathrm{O}_{3}$ doping in YSZ will lead to a lower oxygen content. A local oxygen concentration difference near the Ni/YSZ interface, which is caused by oxygen ion migration from YSZ to $\mathrm{Ni}$, may influence the local structure of YSZ during the cell operation. The area with high oxygen content is likely to be $t$-YSZ (based on the phase diagram discussed previously), while the area with low oxygen content is likely to be $c$-YSZ. This structural change, which can be treated as cation redistribution, may be kept during cell cooling. The cation redistribution in YSZ grain and 
near the Ni/YSZ can influence the oxide ions transport in YSZ grain or along the Ni/YSZ interface.

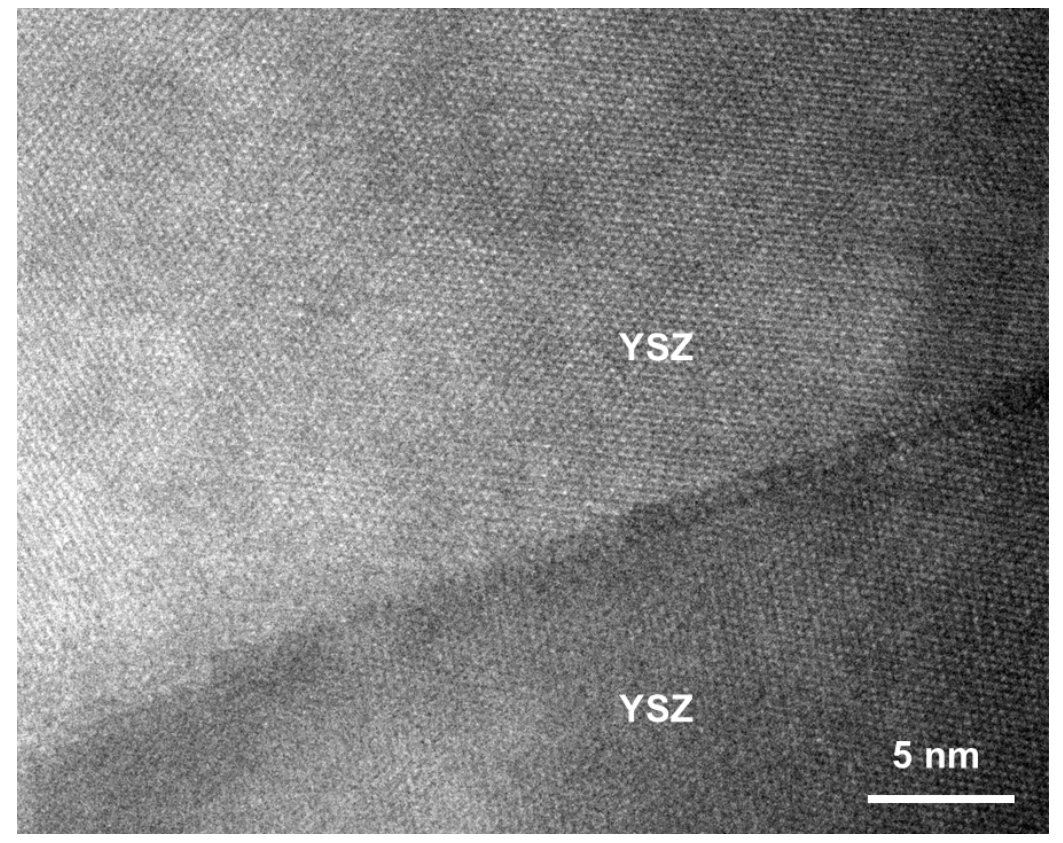

Figure 52. High resolution TEM image of a YSZ/YSZ grain boundary in the anode active layer.

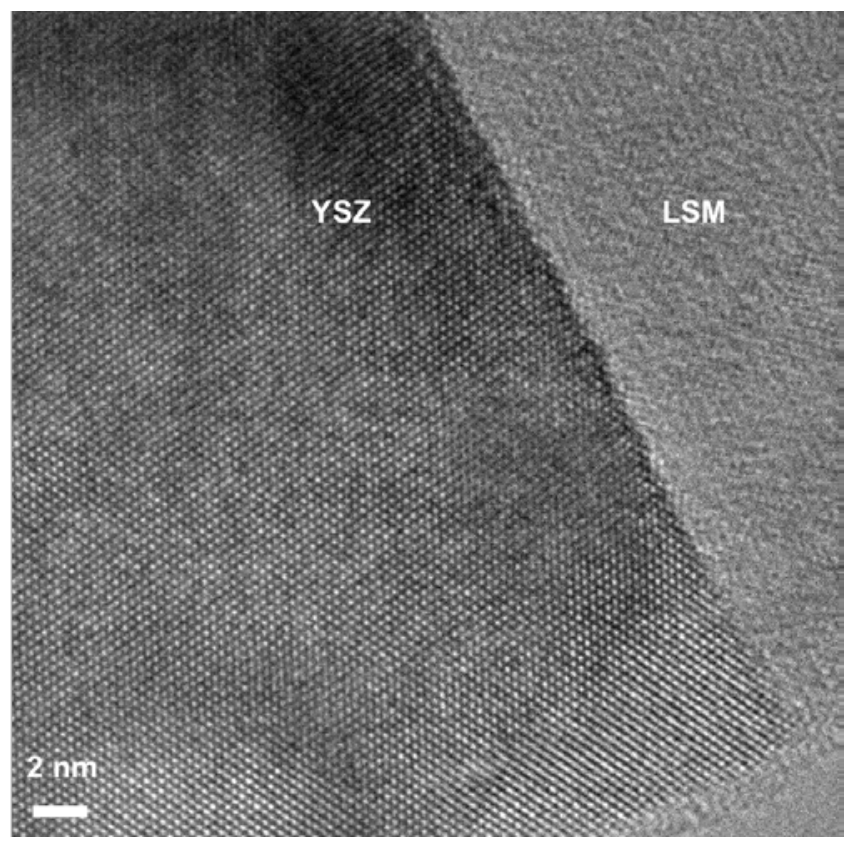

Figure 53. High resolution TEM image showing the grain boundary between a YSZ grain and a LSM grain. 


\subsection{YSZ structure in the different components and anode TPB area in SOFC operated with wet hydrogen}

The SOFCs operated on wet $\mathrm{H}_{2}$ for $24 \mathrm{~h}$ and $540 \mathrm{~h}$ are examined respectively. The results are shown in the Figure 54. The same crystallographic structure differences between the YSZ grains in the anode and electrolyte compared to those in the cathode are detected. A similar continuous $\mathrm{NiO}$ ribbon phase is observed along the $\mathrm{Ni} / \mathrm{YSZ}$ interfaces after $24 \mathrm{~h}$ operation. The ribbon is $\sim 5$ $\mathrm{nm}$ in thickness. This $\mathrm{NiO}$ phase nearly remains the same thickness in the cell operated with wet $\mathrm{H}_{2}$ for $540 \mathrm{~h}$ (Figure 55). The results in SOFCs operated with wet hydrogen suggest that the thickness of the $\mathrm{NiO}$ phase is not time dependent in wet $\mathrm{H}_{2}$ in this study, which is different from the one operated with syngas. Comparing with the SOFC-S-2 sample in Figure 51, there is no obvious $t$-YSZ interfacial layer coupled with $c$-YSZ domains at the original Ni/YSZ interface in the SOFC-H-2 sample (Figure 55).

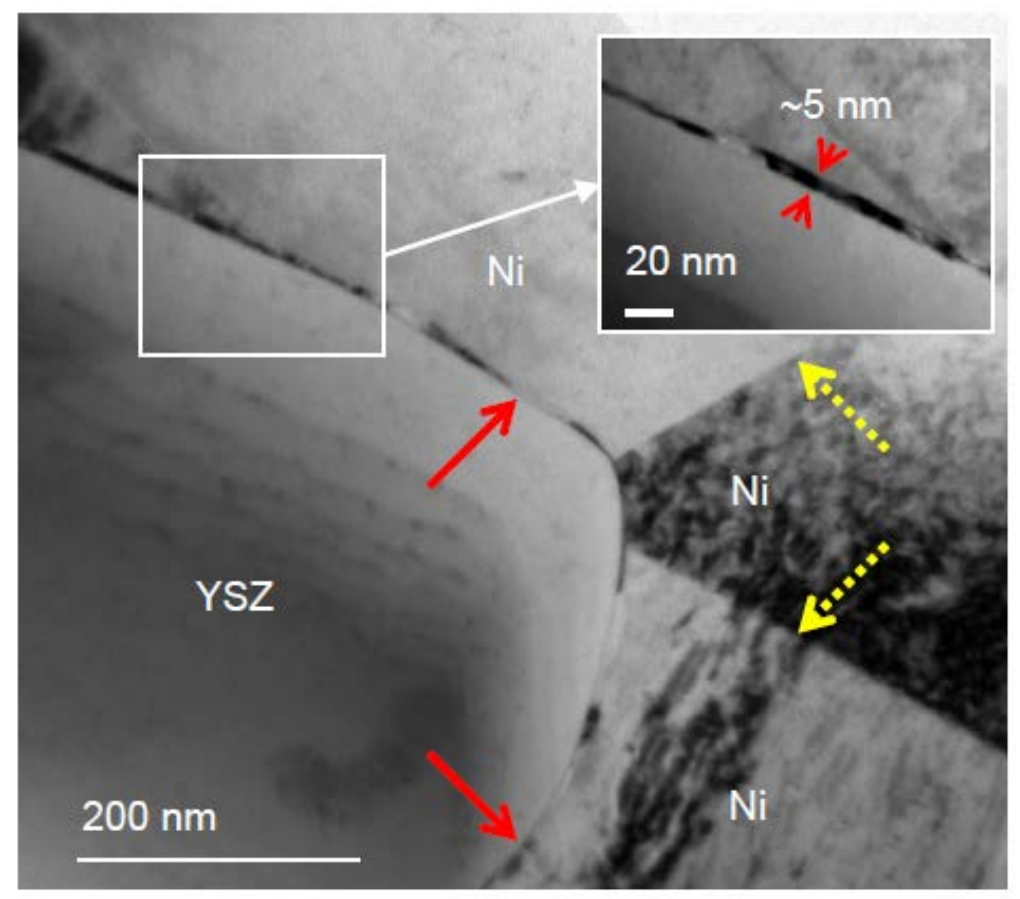


Figure 54. TEM image showing the Ni/Ni GBs and Ni/YSZ interface close to TPB area of the cell operated in $\mathrm{H}_{2}$ for $24 \mathrm{~h}$ (SOFC-H-1). Ni/YSZ GBs are indicated by red solid arrows, and Ni/Ni GBs are indicated by yellow dash arrows. The inserted image magnifies the thickness of the ribbon phase.

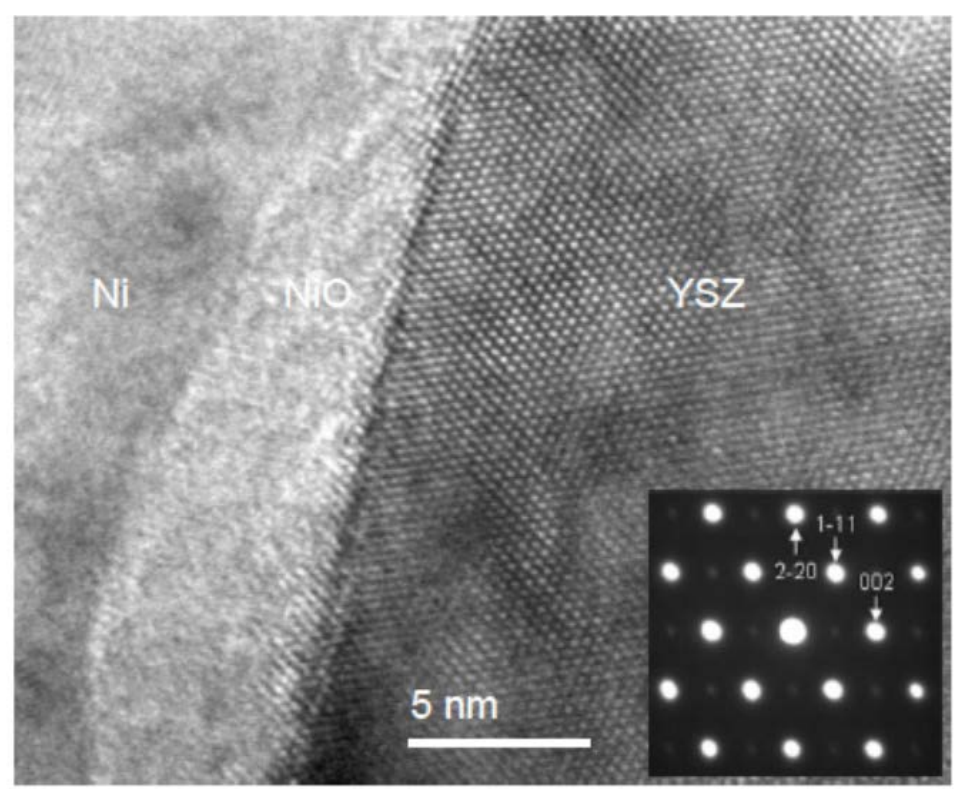

Figure 55. TEM image showing the NiO layer at Ni/YSZ interface close to TPB area of the cell operated in $\mathrm{H}_{2}$ for $540 \mathrm{~h}$ (SOFC-H-2). The inserted image showing the diffraction pattern from YSZ grain.

The SOFCs operated in $\mathrm{H}_{2}$ or syngas both exhibit the formation of the $\mathrm{NiO}$ layer at the $\mathrm{Ni}$ /YSZ interface, but the thickness of the NiO layer is different in these two cells. Since the cells are operated with same conditions (temperature, time, current density) except the fuel gas, it is suggested that the fuel gas can influence the microstructure and chemistry of the anode in SOFCs. Comparing with the wet hydrogen, the simulated syngas contains more $\mathrm{H}_{2} \mathrm{O}$, less $\mathrm{H}_{2}$ in terms of composition and extra fuel gas $\mathrm{CO}$ and $\mathrm{CO}_{2}$. In order to understand the effect of the gas composition on the microstructure and chemistry of the anode active layer, especially Ni/YSZ interface in SOFCs, two cells were operated respectively with (1) $97 \% \mathrm{H}_{2}+3 \% \mathrm{H}_{2} \mathrm{O}$ and (2) $25 \%$ $\mathrm{H}_{2}+3 \% \mathrm{H}_{2} \mathrm{O}+72 \% \mathrm{~N}_{2}$ at $800^{\circ} \mathrm{C}$ for 200 h. The post-operational cells were analyzed with TEM 
after proper sample preparation. The same crystallographic structure of YSZ in anode and electrolyte is observed in these two samples compared with the cells operated in syngas. The $\mathrm{NiO}$ layer was observed at Ni/YSZ interface in both samples, but the thickness of the layer is different in both samples. The diffraction contrast images from both samples anode active layer are shown in Figure 56, in which the dash line indicates the presence of the NiO layer. In SOFC$\mathrm{H}-3$, the thickness of the NiO layer is about $5 \sim 10 \mathrm{~nm}$, while in SOFC-H-4, the thickness of the $\mathrm{NiO}$ layer can vary from $\sim 30 \mathrm{~nm}$ to $>60 \mathrm{~nm}$. The SOFC-H-3 cell was operated under the same conditions compared with the SOFC-H-1 and SOFC-H-2 cells except the operation duration. So the thickness of the NiO layer in SOFC-H-3 is consistent with the ones $(\sim 5 \mathrm{~nm})$ in those two cells. When the $\mathrm{H}_{2}$ proportion in the fuel gas decreased from $97 \%$ to $25 \%$, which was in the SOFC-H-4 cell operation, the thickness of the $\mathrm{NiO}$ can increase over $60 \mathrm{~nm}$. The results indicate that the $\mathrm{H}_{2}$ proportion in the fuel gas plays an important role in the evolution of the microstructure and chemistry of anode active layer.

The NiO formation is believed to be due to the oxygen (ion) migration from YSZ into Ni. Two things can affect the observed NiO thickness: the speed of the oxygen migration and the limit depth of the oxygen migration. The faster and deeper the oxygen can go into the $\mathrm{Ni}$, the thicker the $\mathrm{NiO}$ can form. The $\mathrm{H}_{2}$ concentration in the fuel gas can definitely influence the oxygen migration. The $\mathrm{NiO}$ formation is believed to be due to the oxygen (ion) migration from YSZ into Ni. Two factors can affect the observed NiO thickness: the speed of the oxygen migration and the depth of the oxygen migration. The faster and deeper the oxygen can go into the $\mathrm{Ni}$, the thicker the $\mathrm{NiO}$ can form. The $\mathrm{H}_{2}$ concentration in the fuel gas can definitely influence the oxygen migration. We hypothesize that higher $\mathrm{H}_{2}$ concentrations on the nickel surface will decrease the amount of oxygen atoms or ions in the nickel and will also accelerate 
the removal of oxygen atoms or ions from the nickel surface. This hypothesis accounts for the thinner $\mathrm{NiO}$ phases in cells operated in nearly pure hydrogen.. Another possible factor, which can influence the $\mathrm{NiO}$ formation, is the overpotential. The overall overpotentials of the two cells operated in $97 \% \mathrm{H}_{2}$ (SOFC-H-3) and $25 \% \mathrm{H}_{2}$ (SOFC-H-4) are calculated as $248 \mathrm{mV}$ and $266 \mathrm{mV}$, respectively. The overpotentials of these two cells did not show much difference in this study. Also, the anode overpotential is not separated from the overall overpotential.

Consequently, we cannot conclude that overpotential, especially for the anode, has any effect on the $\mathrm{NiO}$ formation. In order to understand the effect of overpotential on the $\mathrm{NiO}$ formation, fuel gas with same $\mathrm{H}_{2}$ concentration will be used with different overpotentials (in wide range) in future experiments. On the other hand, if the overpotential of the anode can be separated from the cell overpotential, the effect of overpotential on $\mathrm{NiO}$ formation can be examined more closely.

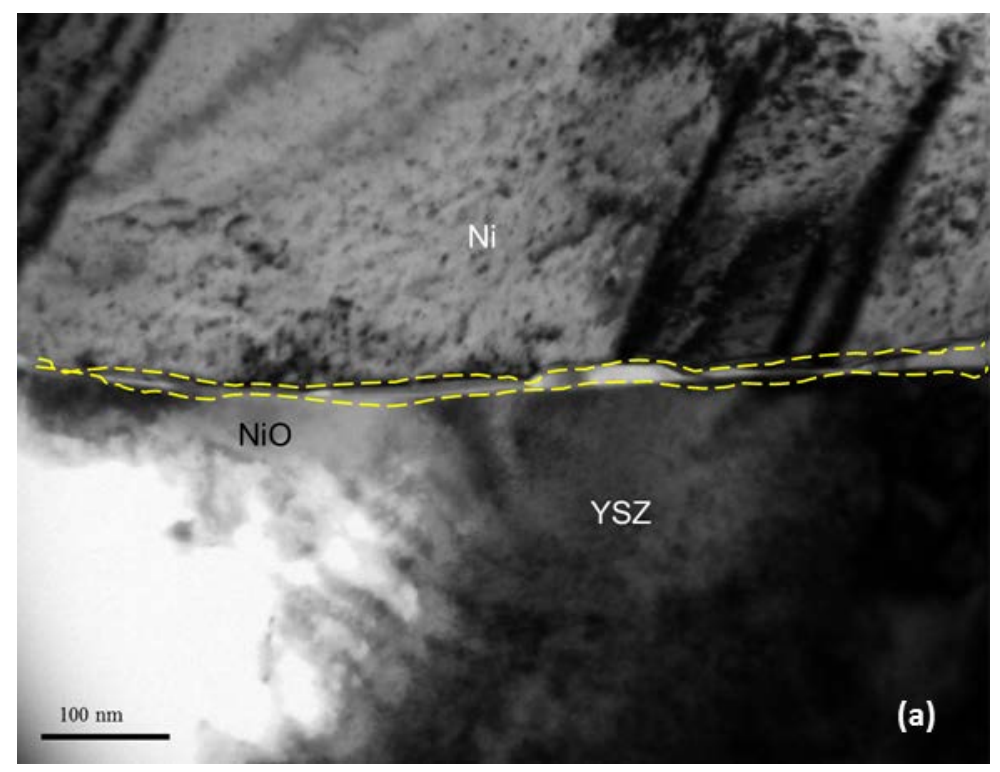




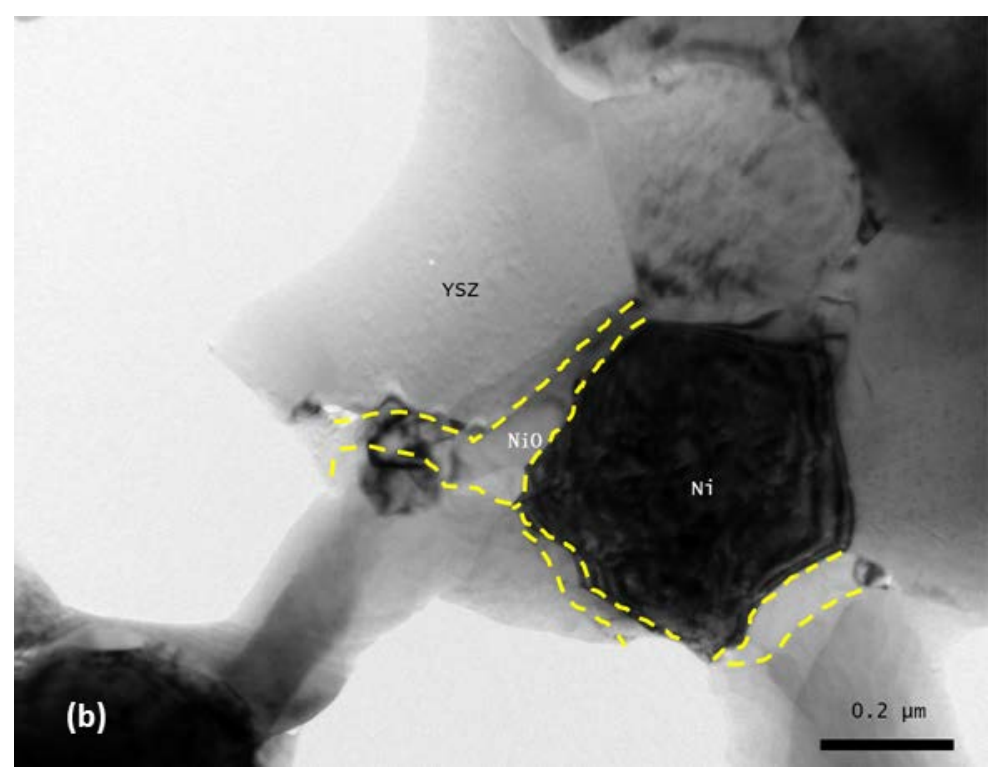

Figure 56. TEM image showing the NiO layer at Ni/YSZ interface close to TPB area of the cell operated in (a) $97 \% \mathrm{H}_{2}+3 \% \mathrm{H}_{2} \mathrm{O}(\mathrm{SOFC}-\mathrm{H}-3)$ and (b) $25 \% \mathrm{H}_{2}+3 \% \mathrm{H}_{2} \mathrm{O}+72 \% \mathrm{~N}_{2}(\mathrm{SOFC}-\mathrm{H}-4)$ for $200 \mathrm{~h}$.

\subsection{Summary}

The commercial SOFCs were operated with wet hydrogen and simulated syngas at $800^{\circ} \mathrm{C}$ for different time duration in this study. The as-received and post-operational SOFCs were analyzed with TEM and the microstructure and chemistry of the active layer and their evolution was examined and compared in terms of time duration and fuel composition. The results obtained in this chapter are summarized as follows:

1. In the as-received SOFCs, the YSZ grains in anode and cathode show the same grain size and same $\mathrm{Y}_{2} \mathrm{O}_{3}$ doping level ( 8 mol\%), but different diffraction patterns are obtain from these two components. The cathode YSZ has a cubic fluorite structure patterns while the anode YSZ presents a cubic structure with weak diffraction spots which are kinematically forbidden for the cubic structure. The presence of Mn in cathode YSZ, which is due to 
the diffusion from LSM, can stabilize the cubic structure of the YSZ in cathode. No impurity and precipitate were found at $\mathrm{NiO} / \mathrm{YSZ}$ interface in the as-received cell.

2. The structure difference of YSZ in anode and cathode is persisting no matter what kind of fuel gas is used and how long the cell is operated in this study. With the systematic tilting experiment for diffraction patterns and HRTEM imaging analyzed with FFT, the $t$-YSZ nano-domains in the cubic YSZ grains in anode were verified. In the SOFCs operated with simulated syngas for $550 \mathrm{~h}$, a discretely ordered $t$-YSZ nano-domain and a discretely ordered $c$-YSZ nano-domain are observed between the original Ni/YSZ interface and the bulk YSZ domain, which is believed to be due to the electrochemical effect. The other microstructure and chemistry change, which may be related to the electrochemical reactions, is the formation of the $\mathrm{NiO}$ ribbon phase layer at the $\mathrm{Ni} / \mathrm{YSZ}$ interface in the operated cell. The thickness of the NiO layer increases from about $10 \mathrm{~nm}$ to over $50 \mathrm{~nm}$, if the operation time increases from $24 \mathrm{~h}$ to $550 \mathrm{~h}$ in simulated syngas. This new $\mathrm{NiO}$ phase is suggested to form during the cooling step in non-reducing environments. At the cell operation condition, the oxygen ion is driven from the YSZ grain into Ni to develop a solid Ni/O solution film inside Ni grain near the Ni/YSZ interface. During the cooling step, the oxygen trapped in the $\mathrm{Ni}$ precipitates to form the $\mathrm{NiO}$ inter-phase layer. This oxygen gradient near the Ni/YSZ may influence the cations distribution near the Ni/YSZ interface. Local oxygen concentration difference near the Ni/YSZ interface, which is caused by oxygen ion migration from YSZ to Ni, may influence the local structure of YSZ during the cell operation. The area with high oxygen content is likely to be $t-Y S Z$, while the one with low oxygen content is likely to be $c$-YSZ. This structural change, which can be treated as cations redistribution, may be kept during cell cooling. 
3. In the SOFCs operated with wet $\mathrm{H}_{2}\left(97 \% \mathrm{H}_{2}+3 \% \mathrm{H}_{2} \mathrm{O}\right)$, a similar continuous $\mathrm{NiO}$ ribbon phase is observed along the Ni/YSZ interfaces. However, the NiO layer remains the same thickness, which is about $5 \mathrm{~nm}$, even though the cell was operated up to $540 \mathrm{~h}$. On the other hand, there is no obvious $t$-YSZ interfacial layer coupled with $c$-YSZ domains at the original Ni/YSZ interface in SOFCs operated in wet $\mathrm{H}_{2}$. But the $\mathrm{H}_{2}$ proportion in the fuel gas plays an important role in the formation of NiO layer. Decreasing the $\mathrm{H}_{2}$ proportion in the fuel gas can increase of thickness of the $\mathrm{NiO}$ layer. Two factors can affect the observed NiO thickness: the speed of the oxygen migration and the depth of the oxygen migration. The $\mathrm{H}_{2}$ concentration in the fuel gas can definitely influence the oxygen migration. Another possible factor, which can influence the $\mathrm{NiO}$ formation, is overpotential. Because the overall overpotentials of the two cells, SOFC-H3 and SOFC-H-4, are similar, no conclusion about the effect of the overpotential can be drawn. Systematic experiments will be done to further investigate the effect of overpotential, especially anode overpotential, and $\mathrm{H}_{2}$ concentration on the $\mathrm{NiO}$ formation. 


\section{Chapter 4: Effect of $\mathrm{PH}_{3}$ on anode structure of SOFCs}

\subsection{Introduction}

In chapter 3 , the SOFCs operated with clean gases $\left(\mathrm{H}_{2}\right.$ or simulated syngas) are analyzed. As we know, the coal-derived syngas contains a lot of contaminants. But it is impossible to remove all contaminants in the coal-derived syngas before using it due to the high cost. So it is essential to examine the effect of the contaminant on the SOFCs performance in terms of structure and chemistry changes. $\mathrm{PH}_{3}$ is an interesting contaminant, which was investigated by different research groups in Ni/YSZ anode SOFCs [19, 20, 104-107] or other anode SOFCs [108, 109]. In the Ni/YSZ anode SOFCs, the $\mathrm{PH}_{3}$ can react with $\mathrm{Ni}$ in the all cells in those previous works. However, different works showed different products with various operation conditions. Even with the syngas as the fuel gas, the $\mathrm{PH}_{3}$ can react with $\mathrm{Ni}$ to form phosphate $[19,105]$ or phosphide $[20,107]$ as the dominate product in different papers. In those previous works, the researcher mainly used SEM, XRD and XPS to analyze the structure and chemistry of the samples. Those techniques have some limitations on resolution and phase analysis. In order to understand the effect of $\mathrm{PH}_{3}$ on the microstructure and chemistry changes in anode, especially near the TPB in active layer, the TEM is used to analyze the SOFCs operated in $\mathrm{H}_{2}$ or syngas with $\mathrm{PH}_{3}$ as contaminant.

\subsection{Materials and experimental method}

The same commercially available, anode-supported solid oxide button cells fabricated MSRI were employed for all the experiments described in this chapter. The MSRI button cell was operated in a furnace controlled at $800^{\circ} \mathrm{C}$. Platinum mesh and Platinum paste were used for lead 
connections. The dry hydrogen or syngas with composition of $30 \mathrm{vol} \% \mathrm{H}_{2}, 26 \mathrm{vol} \% \mathrm{H}_{2} \mathrm{O}, 21$ vol\% $\mathrm{CO}_{2}$, and 23 vol\% $\mathrm{CO}$ was used as fuel. Before adding phosphine, all three cells were operated in dry hydrogen at $0.25 \mathrm{~A} / \mathrm{cm}^{2}$ for $24 \mathrm{~h}$ to establish the baseline condition. After activation, $10 \mathrm{ppm} \mathrm{PH}_{3}$ was added in the fuel gas. The fuel and air stream flow rates and compositions were controlled separately using mass flow controllers. During the operation, a 1 $\mathrm{L} / \mathrm{min}$ air flow rate and a $300 \mathrm{~mL} / \mathrm{min}$ fuel flow rate were used. The samples were loaded at a constant current of $0.25 \mathrm{~A} / \mathrm{cm}^{2}$ for $117 \mathrm{~h}$.

The cells were each cross-sectioned and submitted to examination by using SEM and TEM. TEM samples were prepared by mechanical polishing and ion milling in a liquid-nitrogen cooled holder. Electron diffraction, diffraction contrast and high-resolution TEM imaging were performed in a JEM-2100 operated at $200 \mathrm{kV}$. Chemical analysis was carried out using energy dispersive X-ray Spectroscopy (EDS) equipped with TEM. The structure of the YSZ in different components of SOFC and the structure of the TPB area in the anode of the SOFC were investigated with TEM. Table 3 shows the basic information of the SOFCs involved in this chapter.

Table 3 The information of the operation and cooling condition of the SOFCs in chapter 4

\begin{tabular}{cccc}
\hline Cell No. & Cell operation time & Fuel gas & Cell cooling condition \\
\hline SOFC-P-1 & $117 \mathrm{~h}$ & Syngas $+10{\mathrm{ppm} \mathrm{PH}_{3}}^{2}$ & $1 \% \mathrm{H}_{2}+99 \% \mathrm{~N}_{2}$ flow \\
SOFC-P-2 & $117 \mathrm{~h}$ & $\mathrm{H}_{2}+10 \mathrm{ppm} \mathrm{PH}_{3}$ & $\mathrm{~N}_{2}$ flow \\
\hline
\end{tabular}




\subsection{Effect of $\mathrm{PH}_{3}$ on $\mathrm{Ni}$ in anode of SOFCs}

The SEM image of Figure 57 shows the cross section of the SOFCs operated in dry hydrogen for $24 \mathrm{~h}$. The inserted image of Figure 57 shows the enlarged view of the anode surface, which is very clean without any extra phase. The SOFC-P-1 cell, which is operated with syngas containing $\mathrm{PH}_{3}$, shows a network of holes in the anode current collection layer (Figure 58). Moreover, there is a new phase, which is about $15 \sim 30 \mu \mathrm{m}$ thick, formation at the surface of the anode. The inserted SEM images in Figure 58 show the cross section (left) and plane-view (right) of this new phase layer. The SOFC-P-2 cell, which is operated with $\mathrm{H}_{2}$ containing $\mathrm{PH}_{3}$, shows the new phase formation (indicated by the rectangle area) at the anode surface (Figure 59), although the new phase is not as continuous as the one at the anode surface of SOFC-P-1 sample. And there is not network of holes in SOFC-P-2 cell.

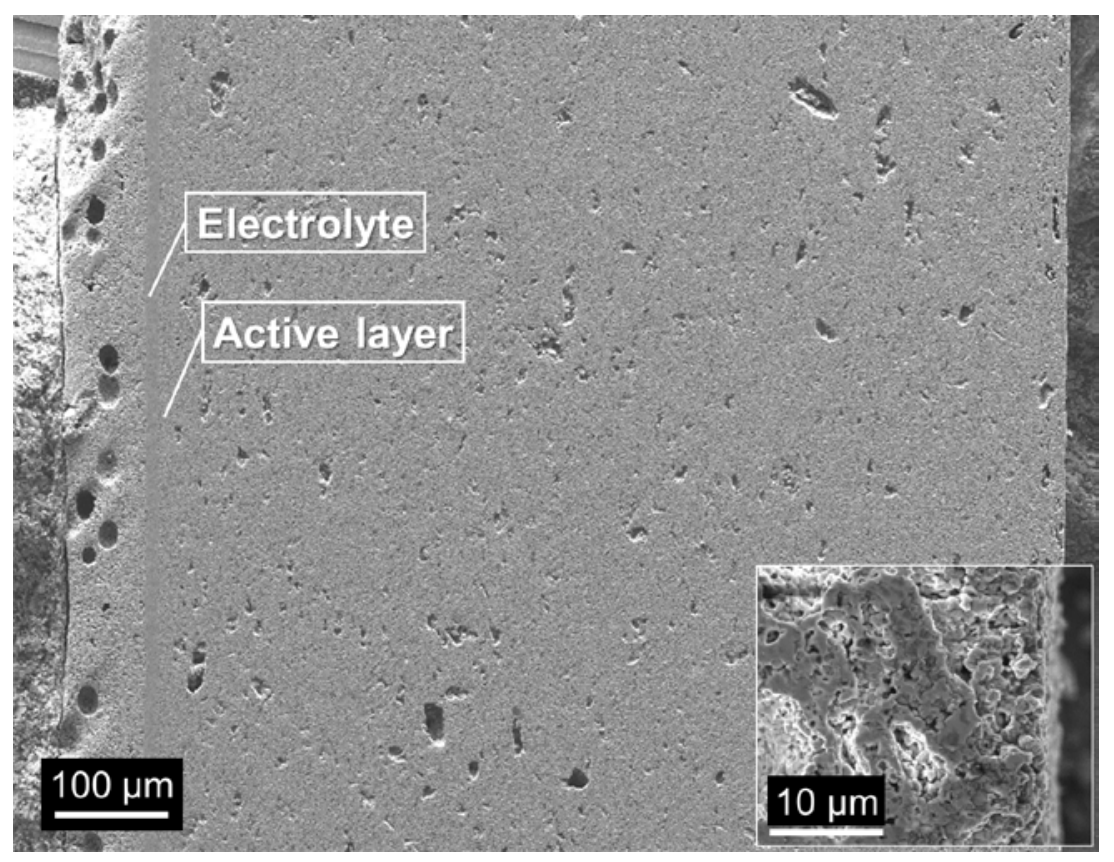

Figure 57. SEM cross-sectional image showing the baseline cell operated in hydrogen for only $24 \mathrm{~h}$, the inserted image showing the enlarged view of the anode surface. 


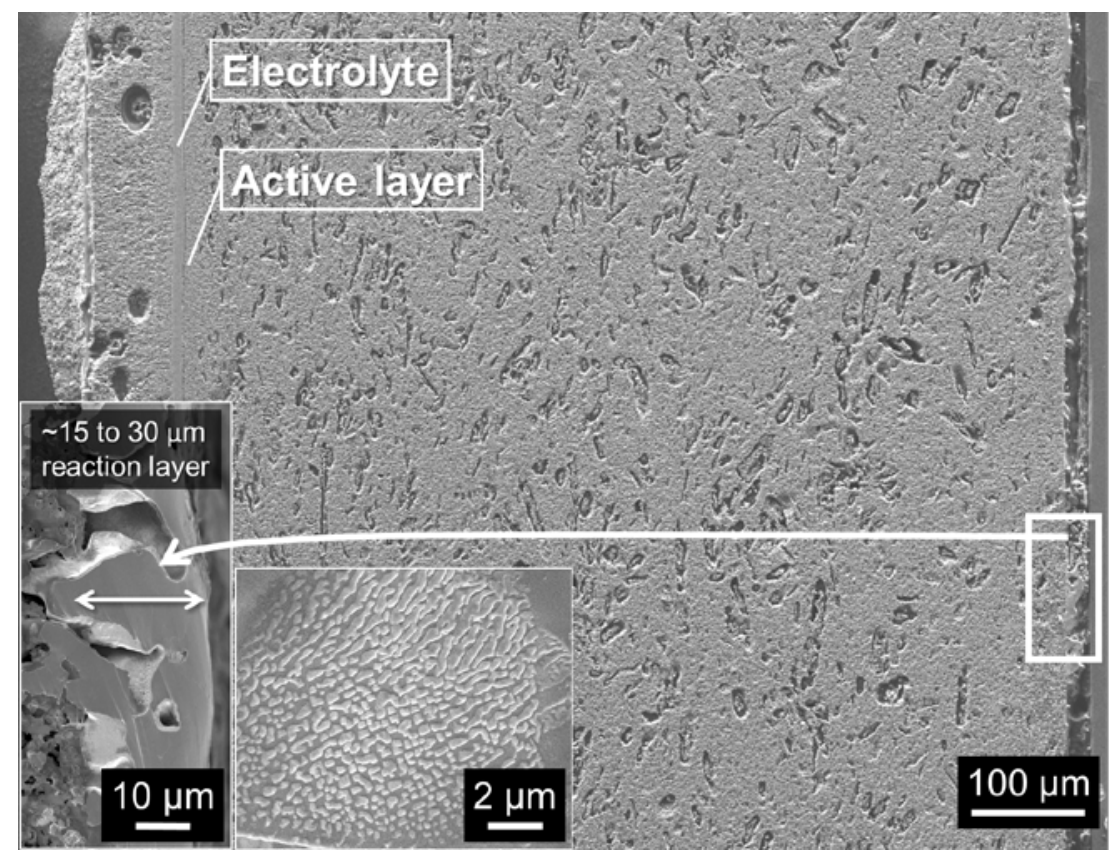

Figure 58. SEM cross-sectional image showing the cell SOFC-P-1 operated in syngas containing phosphine for $117 \mathrm{~h}$, the left inserted image showing the enlarged view of the anode surface and the right one showing the plane-view the anode surface.

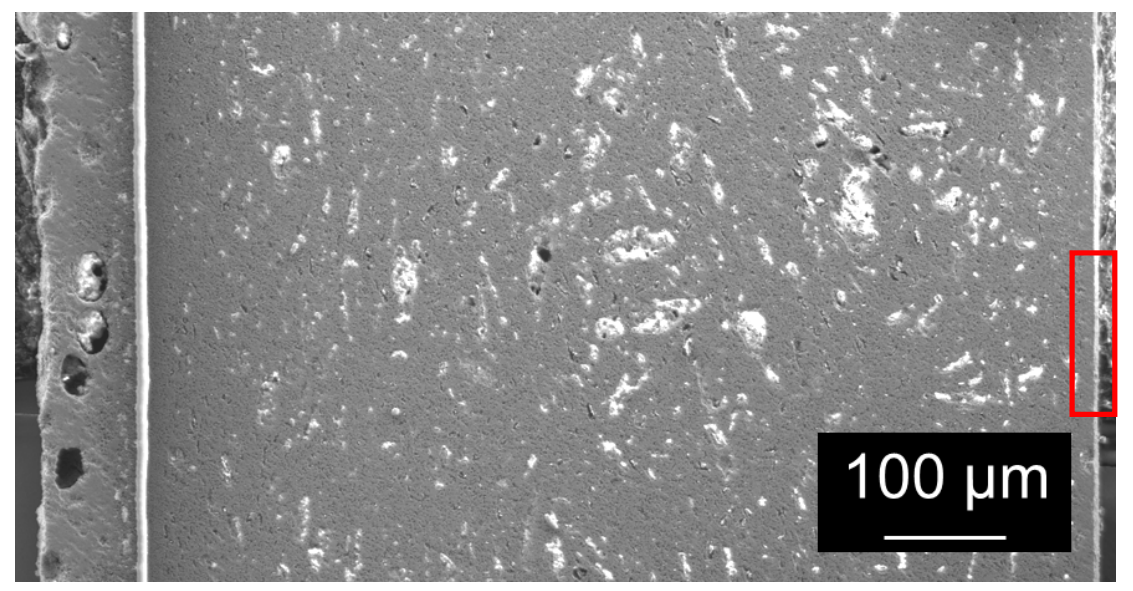

Figure 59. SEM cross-sectional image showing the the cell SOFC-P-2 operated in $\mathrm{H}_{2}$ containing phosphine for $117 \mathrm{~h}$.

In order to analyze the new phase formed at the anode surface, the TEM was used. The Figure 60a shows the anode side of the post-operational SOFC-P-1 cell. The rectangle area 
indicates the extra phase formation at the anode surface. The thickness of this phase is about 20 $\mathrm{nm}$, which is consistent with the SEM result. The Figure 60b shows the enlarged image of the new phase layer. The EDS was firstly used to analyze the chemical composition of the new phase. The dot in the grain is the position, where the EDS spectrum is obtained. The Figure 60c shows the spectrum, which indicates only two elements, Ni ( 79.28 at\%) and P ( 20.72 at\%), are detected in this grain. The EDS result suggests that the new phase could be single phase nickel phosphide or the mixture of nickel, phosphorus or/and several nickel phosphides. To confirm the phase, the SAED and HRTEM are used to analyze the new phase grain. Figure 61 shows the diffraction patterns with different zone axes and the corresponding HRTEM images taken from the grain in Figure 60b. But the SAED patterns in Figure 61 cannot match any nickel-phosphide patterns in the database. Figure 61a shows one set diffraction pattern and the Figure 61c confirms the one primary phase from this zone axis. But from another zone axis, weak spots exhibit in the diffraction pattern (Figure 61b) and the moire fringe obviously appear in the HRTEM (Figure 61d), which indicates some precipitates or particles embedded in the main phase. The different results from different zone axes suggest that the precipitates phase has some orientation relationship with the major phase. But the precipitate phase cannot be identified in this study.
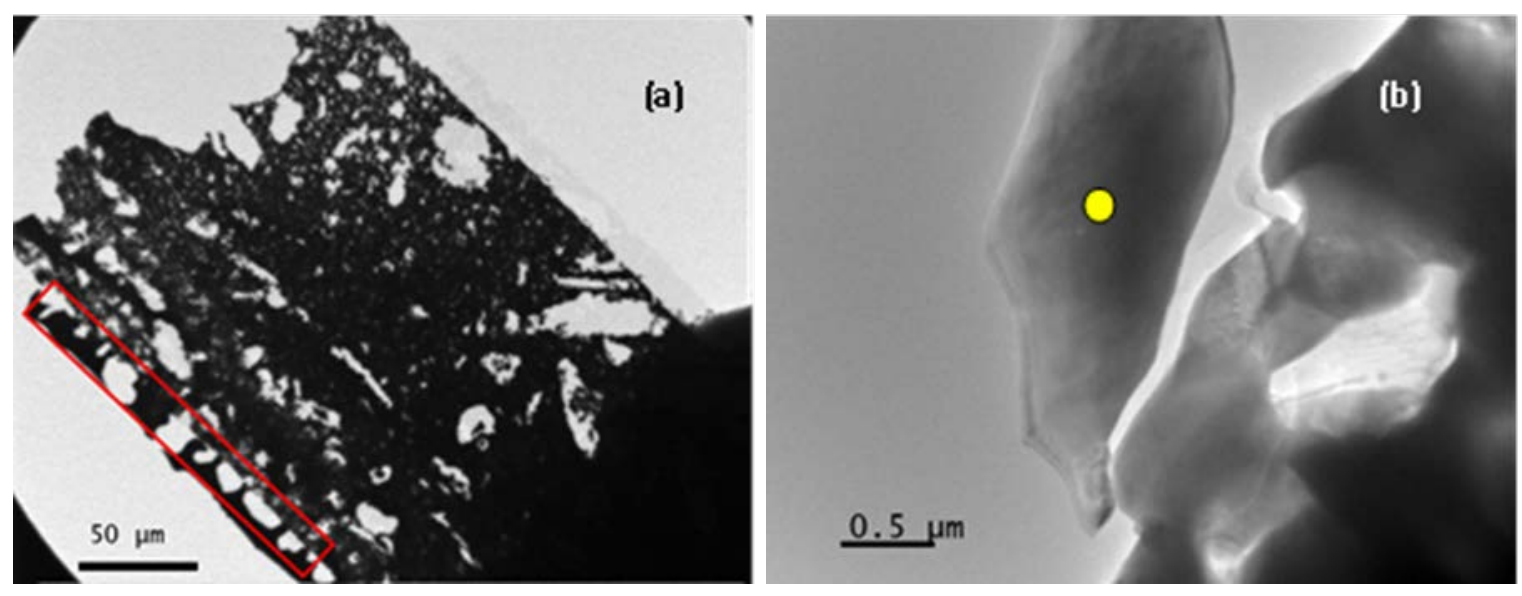


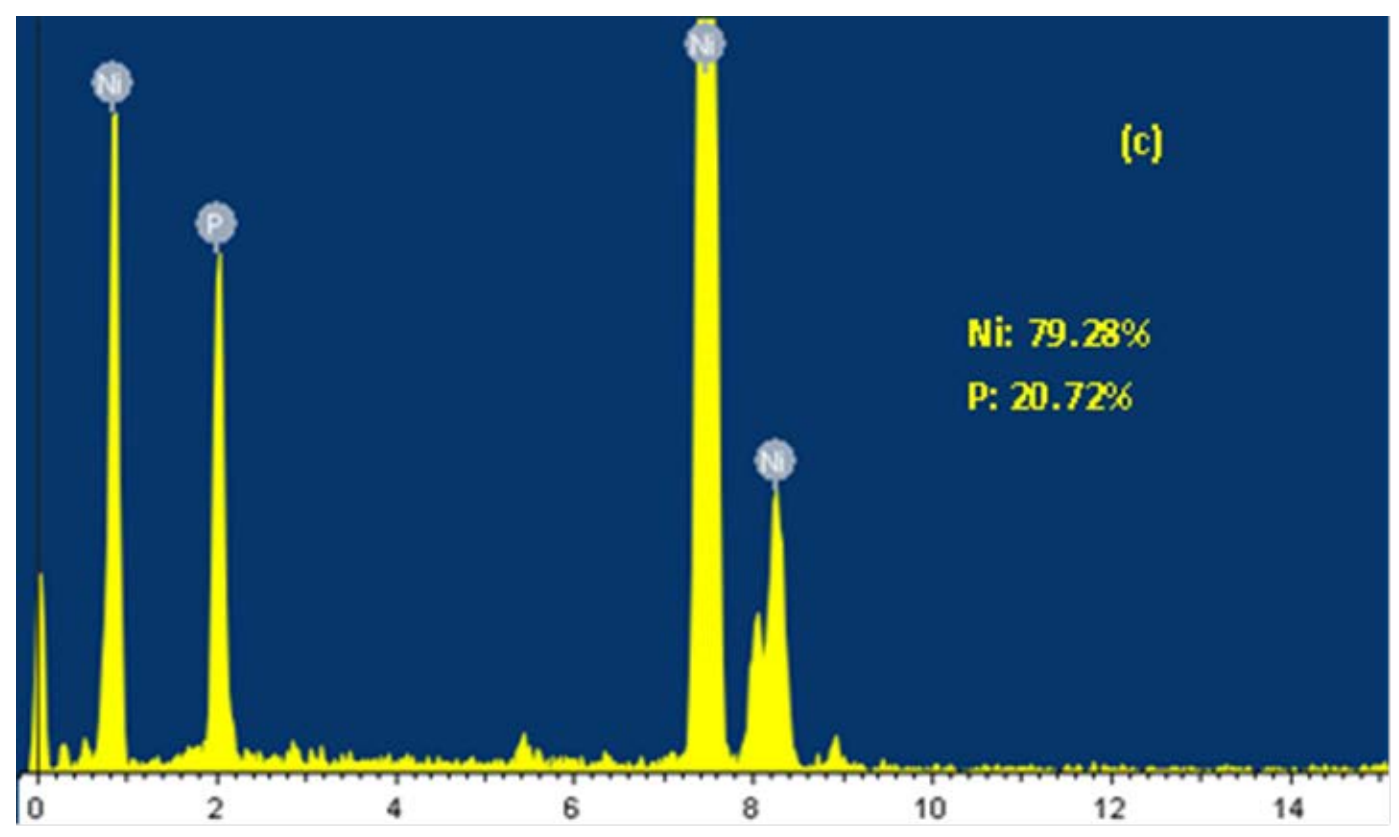

Figure 60. TEM contrast images of SOFC-P-1 (a) overall anode, rectangle area indicating the new phase and (b) enlarged image of the new phase area, the dot indicating the position of EDS spectrum (c) obtained.
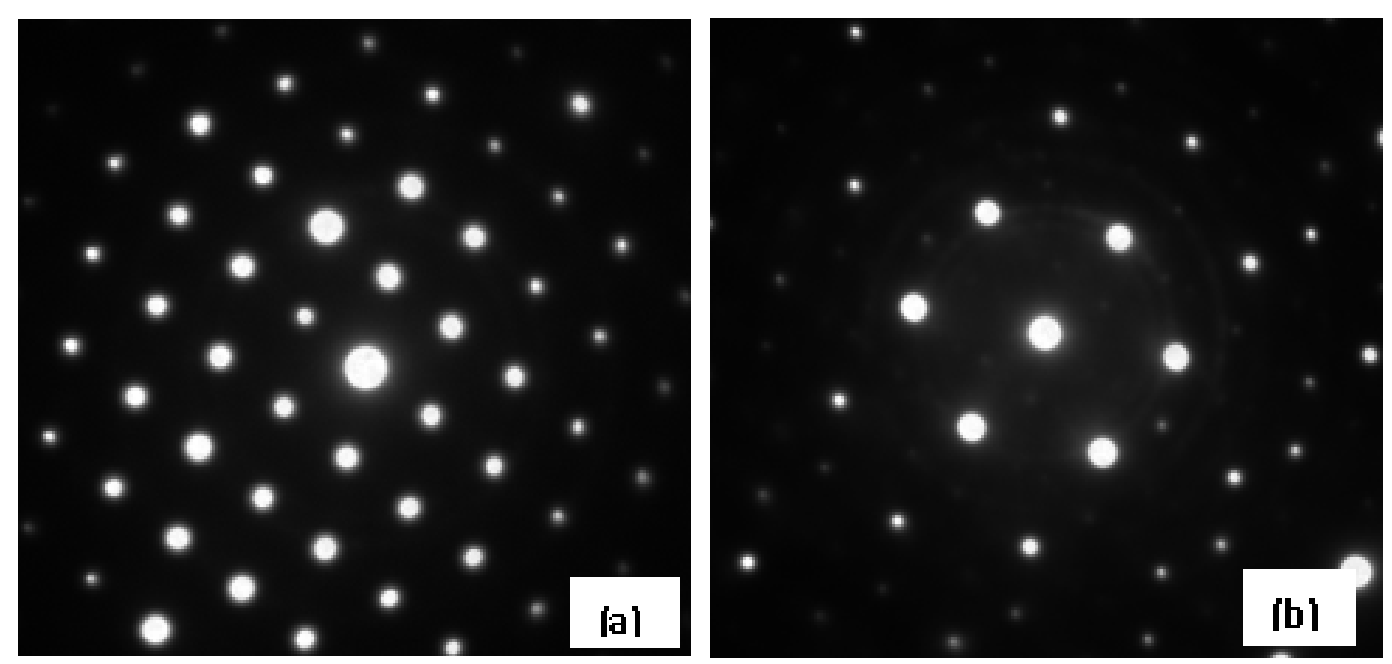


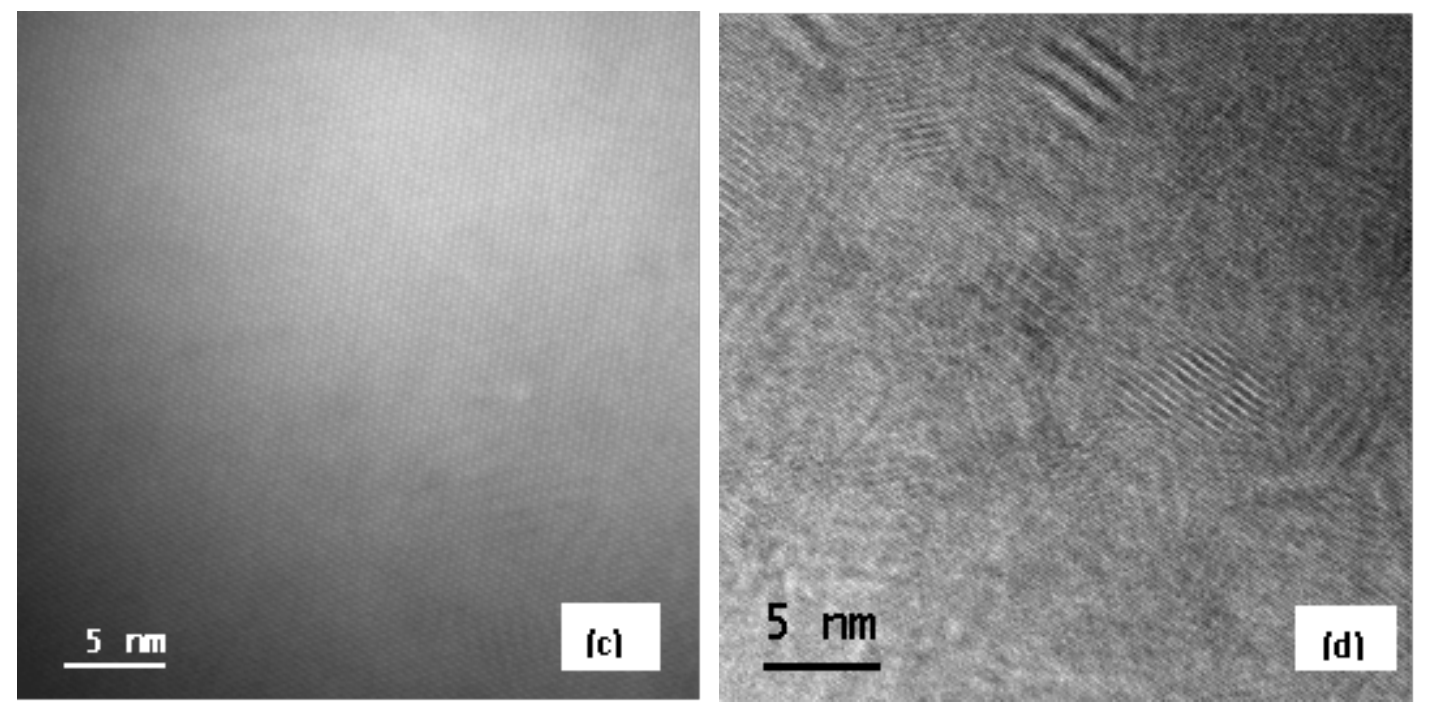

Figure 61. The SAED patterns and HRTEM images of Ni-P phase, taken from different zone axes (a) zone axis 1 SAED pattern, (b) zone axis 2 SAED pattern, (c) HRTEM image from zone axis 1, (d) HRTEM image from zone axis 2.

In the $\mathrm{Ni} / \mathrm{YSZ}$ anode SOFCs, the $\mathrm{PH}_{3}$ can react with $\mathrm{Ni}$ in the all cells in previous works [19, 20, 104-107]. In this study, similar morphology changes were observed. The Ni reacts with the $\mathrm{PH}_{3}$ to form phosphide phases. Because the nickel phosphide phases have lower melting point than $\mathrm{Ni}$, it is expected that they are more mobile than $\mathrm{Ni}$. Therefore the new nickel phosphide phases can migrate to the anode surface, which is consistent with previous works [20,107]. Based on the previous works and this study, it is suggested that the reaction between the $\mathrm{PH}_{3}$ and $\mathrm{Ni}$ in SOFCs can be very complicated. With different operated conditions, such as temperature and fuel gases composition, the process and products can be different. However, the structure change and new phase formation, phosphide or phosphate, can dramatically increase the resistivity and finally lead the cell degradation. 


\subsection{Effect of $\mathrm{PH}_{3}$ on YSZ in anode of SOFCs}

The HRTEM images are taken along the Ni/YSZ interface in the anode active layer of SOFC-P-1 cell, as shown in Figure 62. Based on the fast Fourier transformation (FFT) imaging, three types of domains are identified within the YSZ grains and include: (1) a layered domain that develops in the YSZ grain within 10-15 nm of the Ni/YSZ phase boundaries; (2) a YSZ grain bulk that is composed of a random mixture of cubic-based phase and 2-10 nm tetragonal phase nano-domains; and (3) a 10-20 nm wide cubic phase located between the inner mixture and the outer layered $t$-YSZ domain. The interfacial $t$-YSZ ribbon layer (shown in Figure 62a\&b) appears to grow from the original Ni/YSZ boundary. A similarly developing ribbon phase was observed in the anode active layer of SOFC operated with clean syngas (SOFC-S-2) in chapter 3.4. Compared to the previous results for clean syngas operation for $550 \mathrm{~h}$, the $t$-YSZ interfacial layer is thicker and can be found at Ni/YSZ boundaries within the active layer. The $t$-YSZ layer does not cover the entire Ni/YSZ interface, and in some local regions, large scale $c$-YSZ domains are observed along the Ni-YSZ interface as well. Such ribbon shaped $c$-YSZ interface domains are tens of nanometers long and 5-10 nm in width, as shown in Figure 62c, and are much larger than the $c$-YSZ domains observed along the Ni/YSZ interface of the sample SOFC-S-2 in chapter 3.4. 

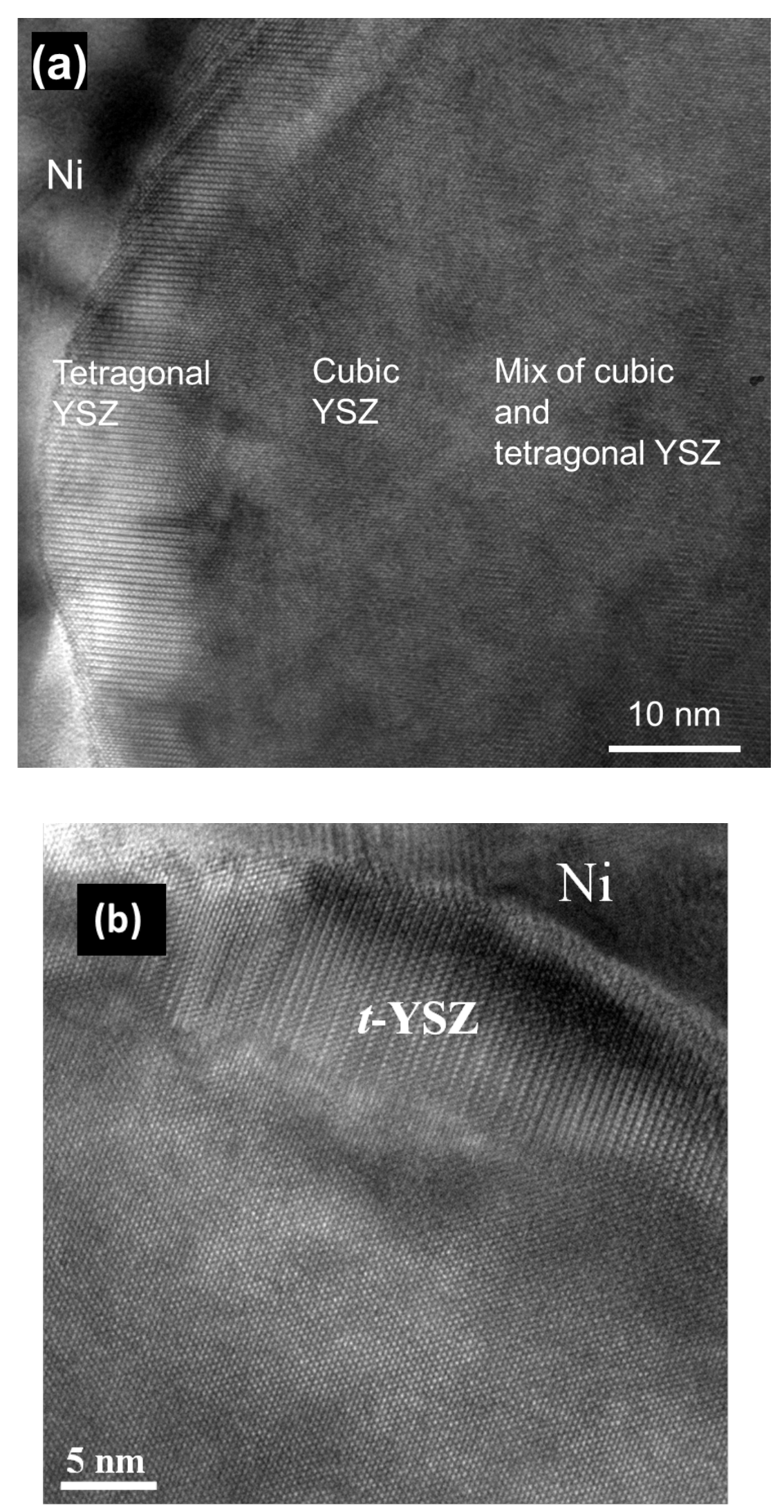


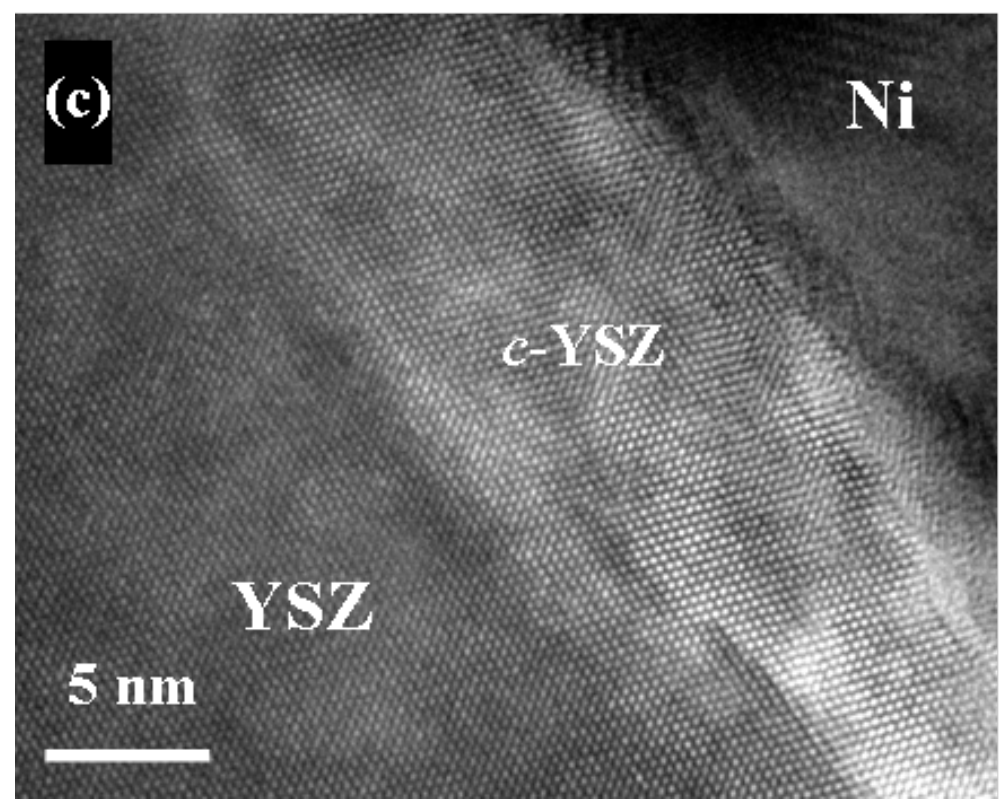

Figure 62. HRTEM images showing the $t$-YSZ ribbon phase (a\&b) and $c$-YSZ domain (c) along the $\mathrm{Ni} / Y S Z$ interface for the sample (SOFC-P-1) operated in syngas with phosphine for $117 \mathrm{~h}$.

The similar HRTEM images of Ni/YSZ interface in the anode active layer in SOFC-P-2 cell are obtained, as shown in Figure 63. Alternating $t$-YSZ (indicated by the dash circles in Figure 63a) and $c$-YSZ domains are observed along the Ni/YSZ interface, which is very similar as the one in SOFC-S-2 and SOFC-P-1. However, the approximate domain length dimension is only 5$10 \mathrm{~nm}$. The enlarged image of the $t$-YSZ is shown in Figure 63b. Two inserted FFT images are taken from two different regions as enclosed by a dash line box I and two dash line boxes II and III in Figure 63a, indicating mixture of $c$-YSZ and $t$-YSZ in YSZ grain and $t$-YSZ domains along the $\mathrm{Ni} / Y S Z$ interface, respectively. 

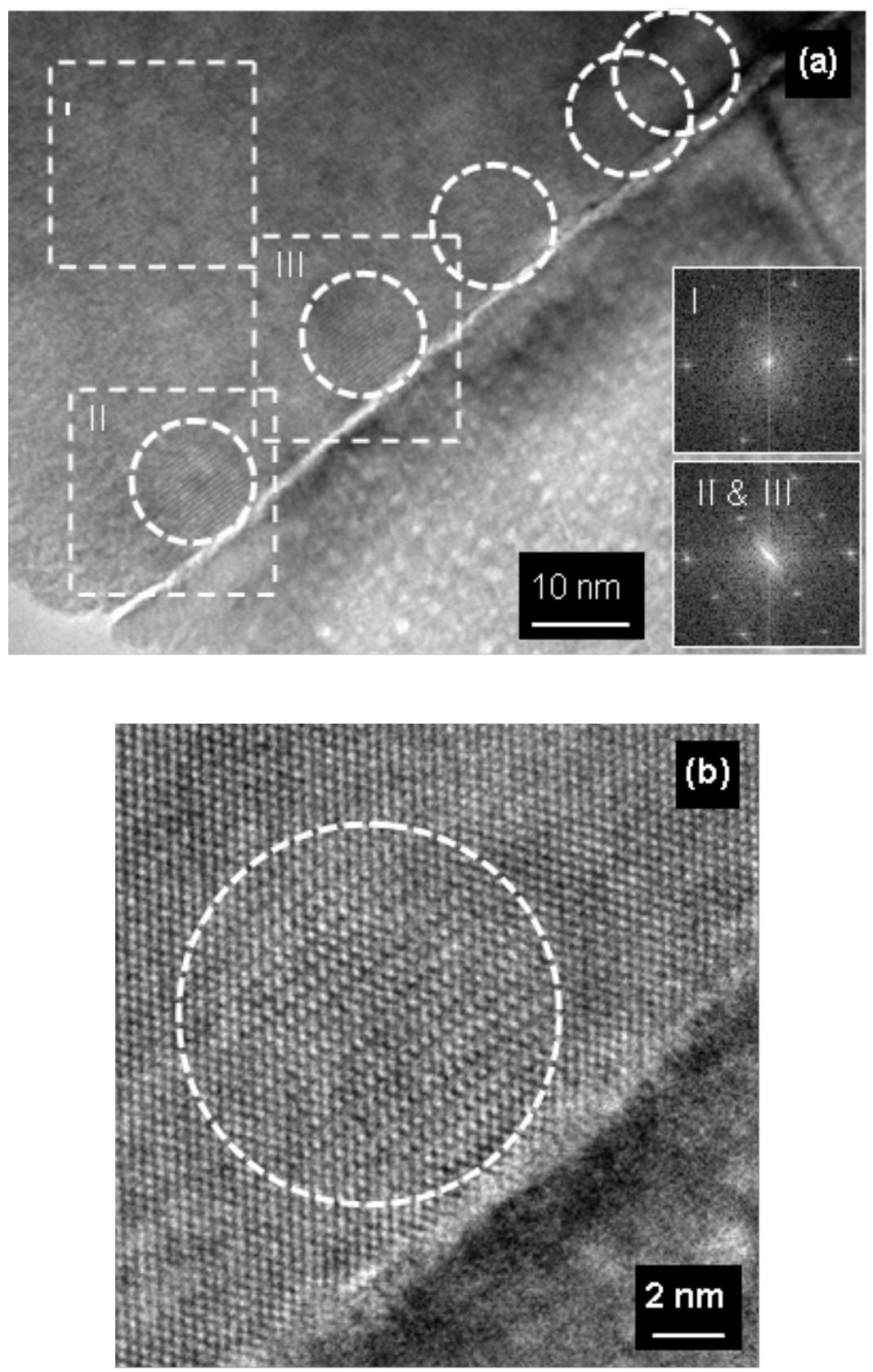

Figure 63. (a) TEM image showing a Ni/YSZ interface of the SOFC-P-2 operated in hydrogen with phosphine for $117 \mathrm{~h}$. Two insert fast Fourier transformation images were taken from two different regions as enclosed by a dash line box I and two dash line boxes II and III, indicating the mixture of $c$-YSZ and $t$ YSZ in YSZ grains and $t$-YSZ domains along the Ni/YSZ interface, respectively. $t$-YSZ domains indicated with the dash circles, the enlarged image of which is shown in (b), could be observed to form along the Ni/YSZ interface. 
Generally, different structure of YSZ results from the different $\mathrm{Y}_{2} \mathrm{O}_{3}$ doping concentration in the YSZ grain. The different structure of YSZ along the Ni/YSZ interface imply the concentration variation of $\mathrm{Y}$ in the vicinity of the Ni/YSZ interface, which suggests the $\mathrm{Y}$ migration along the Ni/YSZ interface. Comparison of the cell operated in $\mathrm{H}_{2}$ or syngas with or without $\mathrm{PH}_{3}$ indicates that $\mathrm{Y}$ migration is favored when phosphine is present in the syngas fuel. To further trace the migration of $\mathrm{Y}$ and the concentration variations along the Ni/YSZ interface, a series of EDS analysis are conducted near the Ni/YSZ interface in SOFC-P-1 cell with the electron beam positions schematically denoted in Figure 64b. Four directions EDS scanning is applied from one $t$-YSZ region to the left or right side along the Ni/YSZ interface and towards the Ni or YSZ grain, respectively. And the EDS results are calculated as the Y/Zr atomic ratio along these four directions, which is shown in Figure 64c.

From the Figure 64c, it is found that the $\mathrm{Y} / \mathrm{Zr}$ ratio is stable and as similar as 8YSZ, which is denoted as the dash line, when the beam is away from the interface. But the $\mathrm{Y} / \mathrm{Zr}$ ratio along the $\mathrm{Ni} / \mathrm{YSZ}$ interface can vary in a wide range, in which the lowest $\mathrm{Y} / \mathrm{Zr}$ is $8.7 \%$ in the left direction and the highest $\mathrm{Y} / \mathrm{Zr}$ is $55.1 \%$. The $\mathrm{Y} / \mathrm{Zr}$ ratios are consistent with the microstructure of the YSZ along these two directions. The left side has some big $t$-YSZ domains, while the right side has a big c-YSZ domain (Figure 62b\&c). 

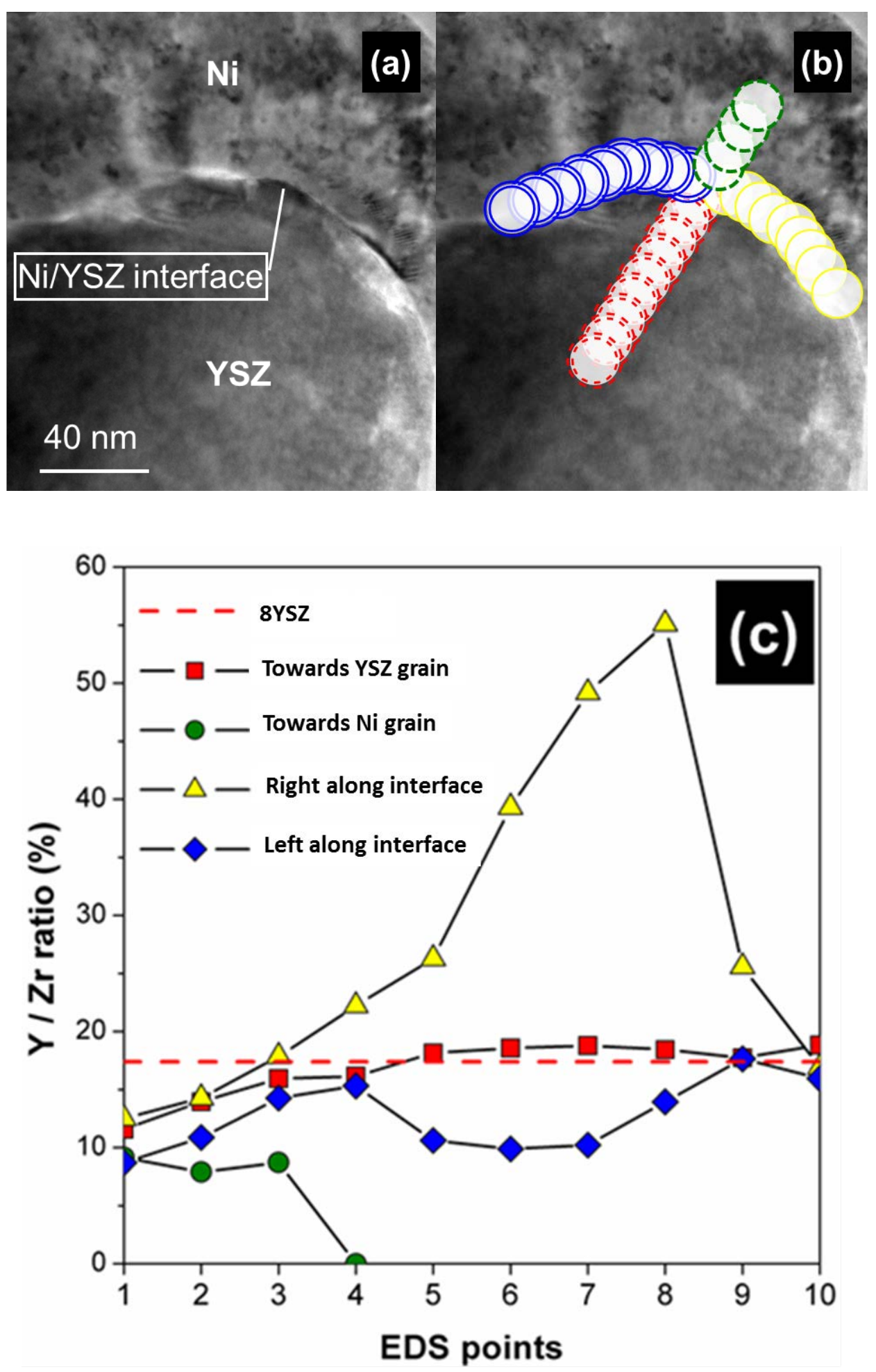

Figure 64. (a) TEM image showing a typical Ni/YSZ interface showing the $t$-YSZ and $c$-YSZ domains formation. (b) the EDS acquisition positions denoted by the circles along the Ni/YSZ interface and towards the Ni or YSZ grain. (c) Y/Z ratio along the four directions in the (b), dash line representing 
the $8 \mathrm{~mol} \% \mathrm{Y}_{2} \mathrm{O}_{3}$ doping YSZ (8YSZ), four sets of symbols representing four directions, each symbol representing one EDS acquisition.

Besides the Y migration along the Ni/YSZ interface, there is another phenomenon appearing at the YSZ/Ni/YSZ triple phase junctions in the SOFC operated with syngas containing $\mathrm{PH}_{3}$ contaminant, which is a new Y-P-O phase ( $100 \mathrm{~nm}$ wide) formation pointed with the arrows in Figure 65a. The EDS spectrum is taken from the large new grain and shown in Figure 65b, which contains $\mathrm{Y}, \mathrm{P}$ and $\mathrm{O}$ with the atomic percentages of 22\%, 26.2\% and 51.8\% respectively. The diffraction pattern from the same grain, which is shown in Figure 65c, matches the standard pattern of $\mathrm{YPO}_{4}$ from [001] zone axis. This is the first time to report the reaction phase containing $\mathrm{Y}$ at the Ni/YSZ interface in the SOFC operated with syngas containing $\mathrm{PH}_{3}$ contaminant. This new YPO4 phase is not observed in the SOFC operated with dry hydrogen containing $\mathrm{PH}_{3}$ contaminant or the SOFCs examined in chapter 3.

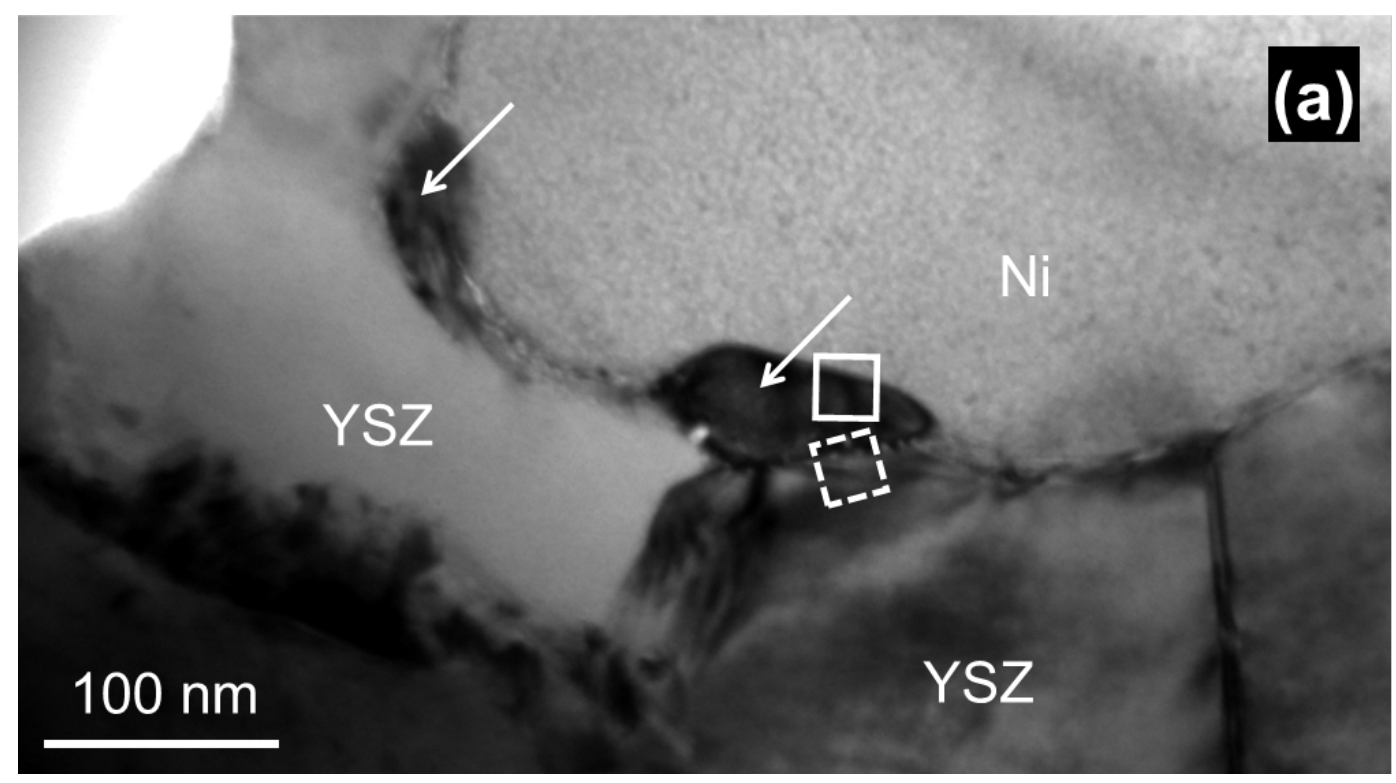



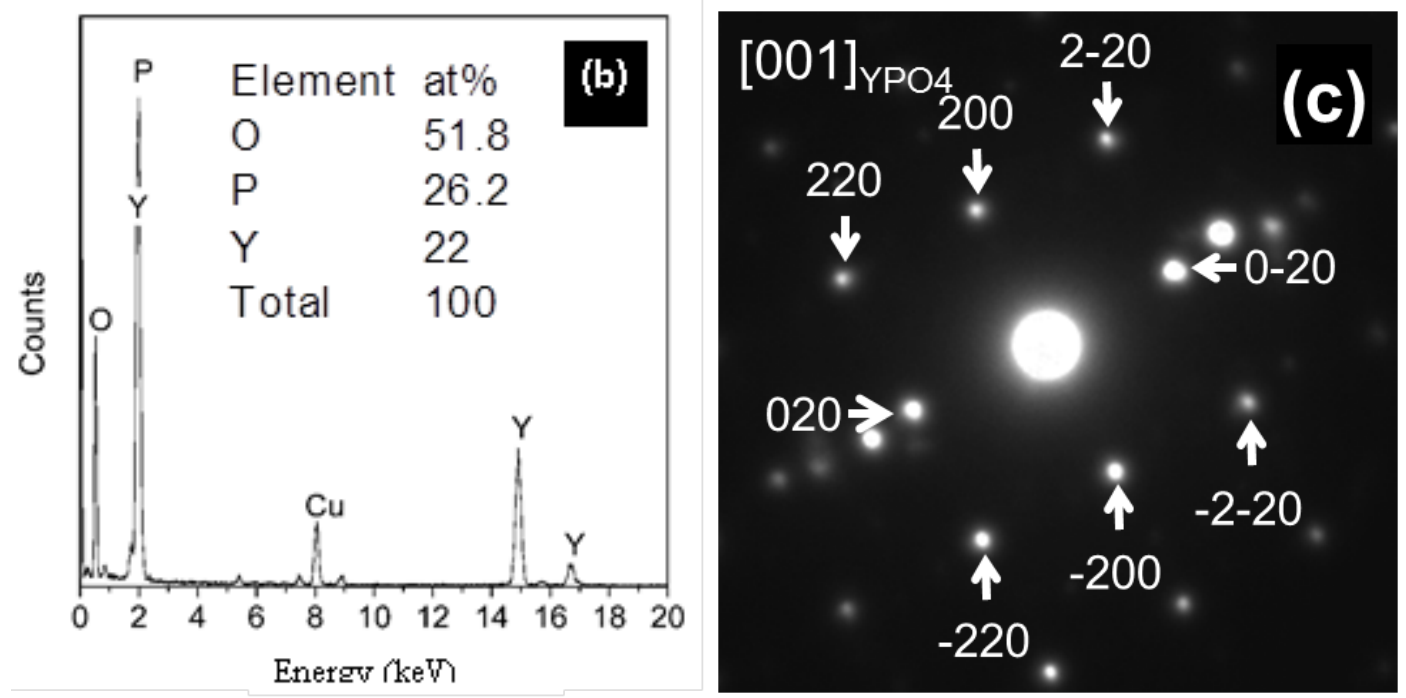

Figure 65. (a) TEM image of a new Y-P-O phase (arrow indicating) formation at the Ni/YSZ interface, (b) the EDS spectrum of the Y-P-O phase and (c) diffraction pattern of the Y-P-O phase matching the [001] zone axis of $\mathrm{YPO}_{4}$.

$\mathrm{YPO}_{4}$ grain boundaries are further examined to elucidate the growth mechanism of the $\mathrm{YPO}_{4}$ phase. HRTEM images collected at the interface between the $\mathrm{YPO}_{4}$ particle and the Ni grain (enclosed by a solid line in Figure 65a) and at the $\mathrm{YPO}_{4} / \mathrm{YSZ}$ interface (enclosed by a dashed line in Figure 65a) are depicted in Figure 66a\&b, respectively. No direct crystal orientation relationship is observed between $\mathrm{YPO}_{4}$ grain and Ni grain; however, the HRTEM image in Figure 66b shows that $\mathrm{YPO}_{4}$ particle have the atomic planes parallel to the atomic planes from the neighboring YSZ grain. Such an orientation relationship implies that YSZ grain is the parent phase and the $\mathrm{YPO}_{4}$ precipitates grow epitaxially aligning to the YSZ matrix during the solid state phase transformation. Since the $\mathrm{YPO}_{4}$ phase only forms at Ni/YSZ interface, it is suggested that the $\mathrm{YPO}_{4}$ formation is not due to the direct reaction between $\mathrm{YSZ}$ and $\mathrm{PH}_{3}$, otherwise, the $\mathrm{YPO}_{4}$ would be observed on the surface of YSZ grain. With the $\mathrm{H}_{2} \mathrm{O}$ in syngas, $\mathrm{H}_{3} \mathrm{PO}_{4}$ phase is a possible product. However, there is no nickel phosphate detected in this study, which suggests that in the reducing environment, $\mathrm{Ni}_{3}\left(\mathrm{PO}_{4}\right)_{2}$ is not the favorable phase in the 
anode. At the Ni/YSZ interface, there is a high concentration of oxygen ions flowing from YSZ into $\mathrm{Ni}$. In that special oxygen rich region, $\mathrm{Ni}_{3}\left(\mathrm{PO}_{4}\right)_{2}$ may be the favorable product [110]. The $\mathrm{Y}_{2} \mathrm{O}_{3}$ in high $\mathrm{Y}$ content region near Ni/YSZ interface can react with $\mathrm{Ni}_{3}\left(\mathrm{PO}_{4}\right)_{2}$ to form $\mathrm{YPO}_{4}$ phase. If this hypothesis is the right, the $\mathrm{YPO}_{4}$ should locate near the TPB. From the Figure 65a, it is hard to confirm whether the $\mathrm{YPO}_{4}$ is near the TPB, because the image can only show the 2D structure. In order to test this hypothesis, the Ni pattern on YSZ electrolyte could be one choice. In this system, it is easy to locate the TPB region. With changing gas composition or current loading, more information about the new phase formation and the location of the new phase will be obtained. The formation of $\mathrm{YPO}_{4}$ can also influence the structure of the YSZ near the Ni/YSZ interface. The original $c$-YSZ (with higher Y content) region near the interface can react with phosphate species (such as $\mathrm{Ni}_{3}(\mathrm{PO} 4)_{2}$ ) to form $\mathrm{YPO}_{4}$, which consume the $\mathrm{Y}$ in the YSZ. This new phase formation decreases the $\mathrm{Y}_{2} \mathrm{O}_{3}$ doping in $\mathrm{YSZ}$, therefore create large size $t$ YSZ region near the Ni/YSZ interface, which is shown in Figure 62.

In addition, very small square shaped domains ( $\sim \mathrm{nm}$ in diameter) can be observed in the $\mathrm{YPO}_{4}$ grain, as shown in Figure 66b (arrows pointing). Such features have never been reported before in the literature, and the atomic structure and chemistry characterization of the observed domains is ongoing. 

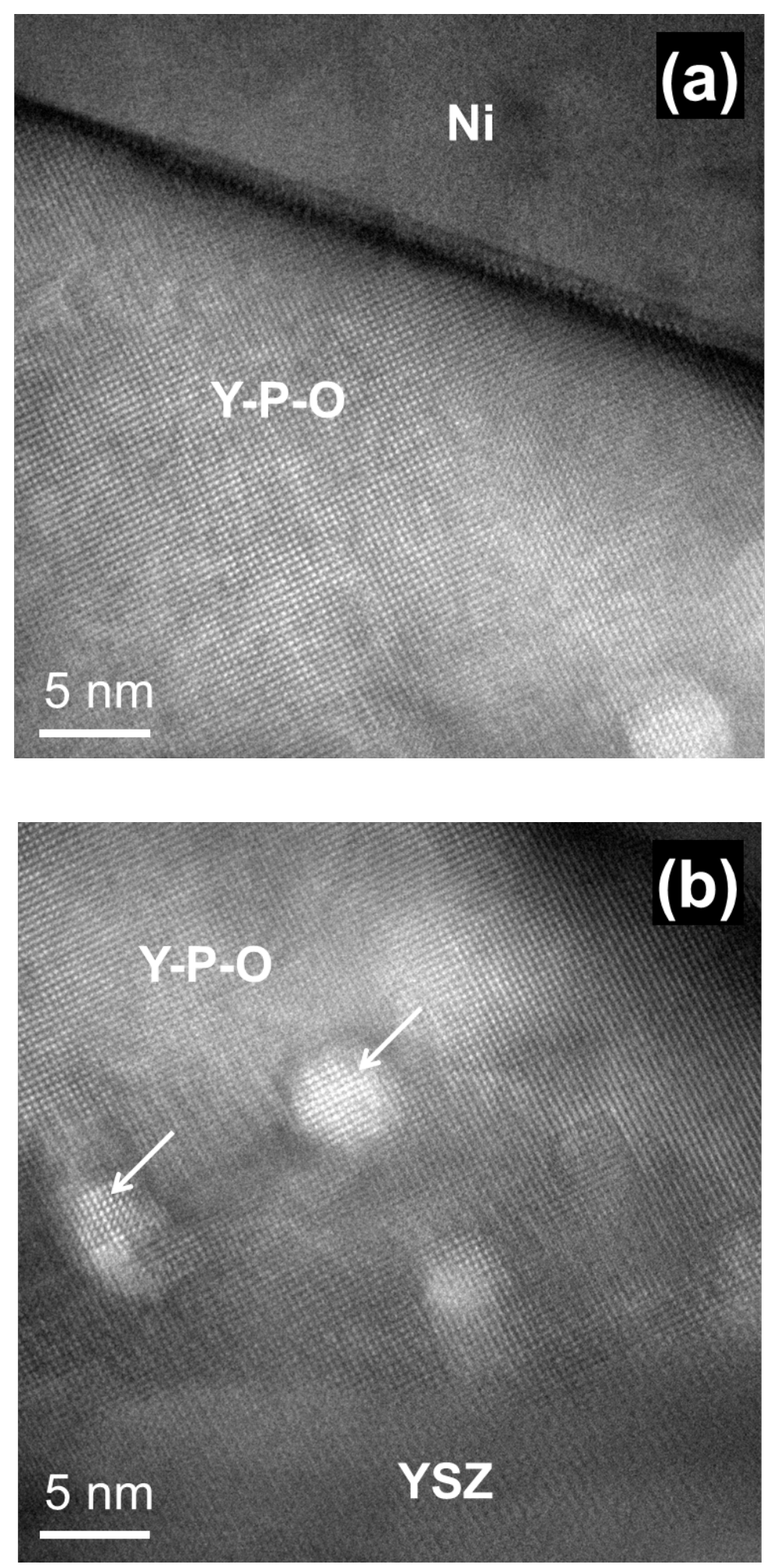

Figure 66. (a) and (b) show the microstructure of the $\mathrm{Ni} / \mathrm{YPO}_{4}$ and $\mathrm{YPO}_{4} / \mathrm{YSZ}$ boundaries, respectively. Two particles which were indicated by arrows are precipitates. 
In the previous works, almost all studies were focusing on the reaction between $\mathrm{Ni}$ and $\mathrm{PH}_{3}$ in anode of SOFCs when $\mathrm{PH}_{3}$ was added into the fuel gas as contaminant. The effect of the $\mathrm{PH}_{3}$ on YSZ was firstly systematically investigated in this study. The structure change of YSZ at the $\mathrm{Ni} / \mathrm{YSZ}$ interface was observed in this study. When the syngas was used as fuel gas with $\mathrm{PH}_{3}$ contaminant, large size $t$-YSZ layer and $c$-YSZ layer appearing at the Ni/YSZ interface indicate the concentration variation of $\mathrm{Y}$ in the vicinity of the Ni/YSZ interface, which could be due to the $\mathrm{Y}$ migration along the Ni/YSZ interface. Since the $\mathrm{Y}_{2} \mathrm{O}_{3}$ doping concentration can affect the conductivity of YSZ, the structure and chemistry change of YSZ can influence the cell performance. The new Y-P-O phase formation, which is indicated as $\mathrm{YPO}_{4}$, suggested the reaction between $\mathrm{PH}_{3}$ and YSZ. The $\mathrm{PH}_{3}$ contaminant in syngas can accelerate the structure and chemistry change of the YSZ during the cell operation.

\subsection{Summary}

In this chapter, the effect of the contaminant $\mathrm{PH}_{3}$ on structure and chemistry changes of SOFCs was investigated. The cells were operated with simulated syngas or dry hydrogen with 10 ppm $\mathrm{PH}_{3}$ for $117 \mathrm{~h}$. The structure and chemistry changes were examined and compared. The results obtained in this chapter are summarized as follows:

1. The SOFCs operated with $10 \mathrm{ppm} \mathrm{PH}_{3}$ as contaminant show new Ni-P phase formation at the surface of the cells, no matter what fuels (dry hydrogen or syngas) are used. But the cell operated with syngas (SOFC-P-1) shows more severe reaction between $\mathrm{Ni}$ and $\mathrm{PH}_{3}$. It shows continuous and thicker Ni-P phase at the anode surface and a network of holes in the anode current collection layer, which is not shown in dry hydrogen operation cell 
(SOFC-P-2). From the diffraction patterns and HRTEM images taken from the new Ni-P phase, it indicates that some precipitates or particles embedded in the main Ni-P phase and the precipitate phase has some orientation relationship with the major Ni-P phase.

2. The SOFC operated in syngas containing $\mathrm{PH}_{3}$ (SOFC-P-1) shows obvious structure changes in YSZ grain at the Ni/YSZ interface. Large scale $t$-YSZ layer and $c$-YSZ layer appear at the Ni/YSZ interface. Comparing with the SOFCs operated in clean syngas (SOFC-S-2) and in dry hydrogen containing $\mathrm{PH}_{3}$ (SOFC-P-2), the $t$-YSZ layer and $c$ YSZ layer appear at the Ni/YSZ interface in the SOFC-P-1 cell are much larger. These $t$ YSZ layer and $c$-YSZ layer appearing at the $\mathrm{Ni} / \mathrm{YSZ}$ interface indicate the concentration variation of $\mathrm{Y}$ in the vicinity of the Ni/YSZ interface, which could be due to the $\mathrm{Y}$ migration along the Ni/YSZ interface. From the comparison between the cells mentioned above, it shows that the Y migration is favored when phosphine is present in the syngas fuel. The EDS scanning shows the Y/Zr ratio can vary from 8.7 atom\% to 55.1 atom\% along the Ni/YSZ interface.

3. Besides the YSZ structure and chemistry changes at the Ni/YSZ interface, a new Y-P-O phase is observed at the YSZ/Ni/YSZ triple phase junctions of the SOFC operated in syngas containing $\mathrm{PH}_{3}$ (SOFC-P-1). From the EDS and diffraction pattern, the phase is indicated as $\mathrm{YPO}_{4}$. This new phase is only observed in SOFC-P-1 cell and is firstly reported in this study. It is suggested that the $\mathrm{YPO}_{4}$ formation is following these steps: (1) $\mathrm{H}_{3} \mathrm{PO}_{4}$ formation from the $\mathrm{PH}_{3}$ and $\mathrm{H}_{2} \mathrm{O}$ in syngas, (2) $\mathrm{Ni}_{3}\left(\mathrm{PO}_{4}\right)_{2}$ formation from the reaction between $\mathrm{H}_{3} \mathrm{PO}_{4}$ and $\mathrm{Ni}$ at the $\mathrm{Ni} / \mathrm{YSZ}$ interface near the TPB, which is a special oxygen rich region, (3) $\mathrm{YPO}_{4}$ phase formation from the reaction between the $\mathrm{Y}_{2} \mathrm{O}_{3}$ in high $\mathrm{Y}$ content region near $\mathrm{Ni} / \mathrm{YSZ}$ interface and $\mathrm{Ni}_{3}\left(\mathrm{PO}_{4}\right)_{2}$. In order to test this 
hypothesis, the Ni pattern on YSZ electrolyte could be one choice because of the clear TPB region. More information about the new phase formation and the location of the new phase will be obtained with further experiments. On the other hand, the formation of $\mathrm{YPO}_{4}$ can consume the $\mathrm{Y}$ in the $\mathrm{YSZ}$ near the Ni/YSZ interface, which decreases the $\mathrm{Y}_{2} \mathrm{O}_{3}$ doping in $\mathrm{YSZ}$, therefore create large size $t$-YSZ region near the Ni/YSZ interface. From the HRTEM images at the $\mathrm{Ni} / \mathrm{YPO}_{4}$ and $\mathrm{YSZ} / \mathrm{YPO}_{4}$ interface, we can find that there is no orientation relationship between the $\mathrm{Ni}$ and $\mathrm{YPO}_{4}$ grains, but a strong orientation relationship between $\mathrm{YSZ}$ and $\mathrm{YPO}_{4}$ grains are observed. This result implies that the YSZ is the parent phase and lead the $\mathrm{YPO}_{4}$ to grow expitaxially aligning to the YSZ matrix. A square shape small precipitates are observed in the $\mathrm{YPO}_{4}$ grain, which is not identified in this study. 


\section{Chapter 5: Evolution of the nanostructure and chemistry of SOFC cathode with infiltration}

\subsection{Introduction}

The studies in chapter $3 \& 4$ focus on the characterization of anode structure and chemistry with respect to the effects of fuel gases, operation duration and the contaminant. In this chapter, we will move to the cathode side. As we know, the oxygen reduction reaction in cathode is the limit step among the whole electrochemical reaction in SOFC, when the anode support SOFC is operated under $750^{\circ} \mathrm{C}[94,111]$. In order to improve the cathode performance, some materials with mixed ionic-electronic conductivity are used to replace the traditional LSM, such as LSCo[112], LSF[113], or LSCF[114]. To further develop the cathode performance, new approach in fabrication of cathode becomes more and more interesting. The infiltration is a promising method with different kinds of cathode backbones. But there is limited work focusing on the interaction between the infiltrated particles and backbones in terms of structure and chemistry changes. The effect of LSCo infiltrated particles on the cell performance with the SDC-LSCF composite as the cathode function layer has been investigated recently [99]. In that study, infiltrating LSCo particles into the cathode decreased the electrode overpotential by approximately 28-40\% compared to a baseline cell when operated under $0.25 \mathrm{~A} / \mathrm{cm}^{2}$ of current density at $750^{\circ} \mathrm{C}$. Based on this study, the preliminary study in this chapter will focus on the characterization of the evolution of the nanostructure and chemistry of cathode with LSCo infiltration in operated SOFCs. 


\subsection{Materials and experimental method}

A commercially available anode-supported button cell from MSRI (Salt Lake City, UT) is used in this study as the baseline cell. The $10 \mu \mathrm{m}$-thick YSZ electrolyte is supported by an approximately $750 \mu \mathrm{m}$-thick Ni-YSZ anode, $30 \mathrm{~mm}$ in diameter. The $2.0 \mathrm{~cm}^{2}$ cathode is composed of a functional layer of SDC-LSCF (10 $\mu$ m thick), situated between a dense SDC buffer layer on the electrolyte and the LSCF current collecting layer (50 $\mu$ m thick). $\mathrm{La}_{0.6} \mathrm{Sr}_{0.4} \mathrm{CoO}_{3}$ (LSCo) were prepared from aqueous solutions of $\mathrm{La}\left(\mathrm{NO}_{3}\right)_{3} * 6 \mathrm{H}_{2} \mathrm{O}$ (Alfa Aesar, 99.9\%), $\mathrm{Sr}\left(\mathrm{NO}_{3}\right)_{2}$ (Alfa Aesar, 99\%), and $\mathrm{Co}\left(\mathrm{NO}_{3}\right)_{2} * 6 \mathrm{H}_{2} \mathrm{O}$ (GFS Chemicals) at the desired molar ratios. Citric acid (Alfa Aesar, 99.5\%) was added to the solution in a one part citrate to one part metal ion ratio as a chelating agent to facilitate formation of the desired structures at lower temperatures. A $5 \mu \mathrm{l}$ dose of $0.5 \mathrm{M}$ solution was infiltrated into the baseline cathode scaffold through the LSCF current collecting layer. Infiltration of the cells was followed by calcination at $450^{\circ} \mathrm{C}$ for $30 \mathrm{~min}$ in air to decompose the nitrate ions. Infiltration-calcination processes were repeated to achieve the desired total loading, which is $6 \mathrm{wt} \%$ LSCo in cathode. Electrical connections were generated with Pt mesh and Pt paste for the cathode and Pt mesh and Ni paste for the anode. The fuel was $97 \% \mathrm{H}_{2} / 3 \% \mathrm{H}_{2} \mathrm{O}$ with a flow rate of $400 \mathrm{sccm}$. A $400 \mathrm{sccm}$ flow of air was delivered into the cathode compartment. Two cells were investigated in this chapter. One is the baseline cell with infiltration but no operation; the other cell is with infiltration operated at $750^{\circ} \mathrm{C}$ for $1500 \mathrm{~h}$.

The cells were each cross-sectioned and submitted to examination by using TEM. After embedded in the epoxy, the TEM samples were prepared by mechanical polishing and ion milling in a liquid-nitrogen cooled holder. Electron diffraction, diffraction contrast and highresolution TEM imaging were performed in a JEM-2100 operated at $200 \mathrm{kV}$. Chemical analysis 
was carried out using energy dispersive X-ray Spectroscopy (EDS) equipped with TEM.

\subsection{Cathode structure of LSCo infiltrated SOFCs without operation}

The Figure 67 shows the typical cathode active layer diffraction contrast images containing SDC, LSCF and some small particles coating on both SDC and LSCF grains. Since the particles are sintered together or with the SDC or LSCF grains. It is hard to tell the exact size of the particles. The approximate size of the particles is about $10 \sim 20 \mathrm{~nm}$. The particles do not cover the entire SDC or LSCF surface, which is good for the gas diffusion and increase the catalytic sites. The chemical compositions of the infiltrates are examined in different positions which are indicated as the numbers in the Figure 67. The EDS results are shown in Table 4. From the EDS results, it is shown that there is a small amount of Fe in most of the infiltrates, which could be the diffusion from the near LSCF grains during the sintering. It is also shown there is deficit of Co and $\mathrm{Sr}$ in the LSCo infiltrates, comparing to the $\mathrm{La}_{0.6} \mathrm{Sr}_{0.4} \mathrm{CoO}_{3}$ formula. However, The diffraction pattern taken from the LSCo infiltrates matches the standard LSCo pattern rings, which are indicated as the dash circles in the Figure 68. So the formation of LSCo infiltrates are consistent with the XRD results in the previous work [99]. 


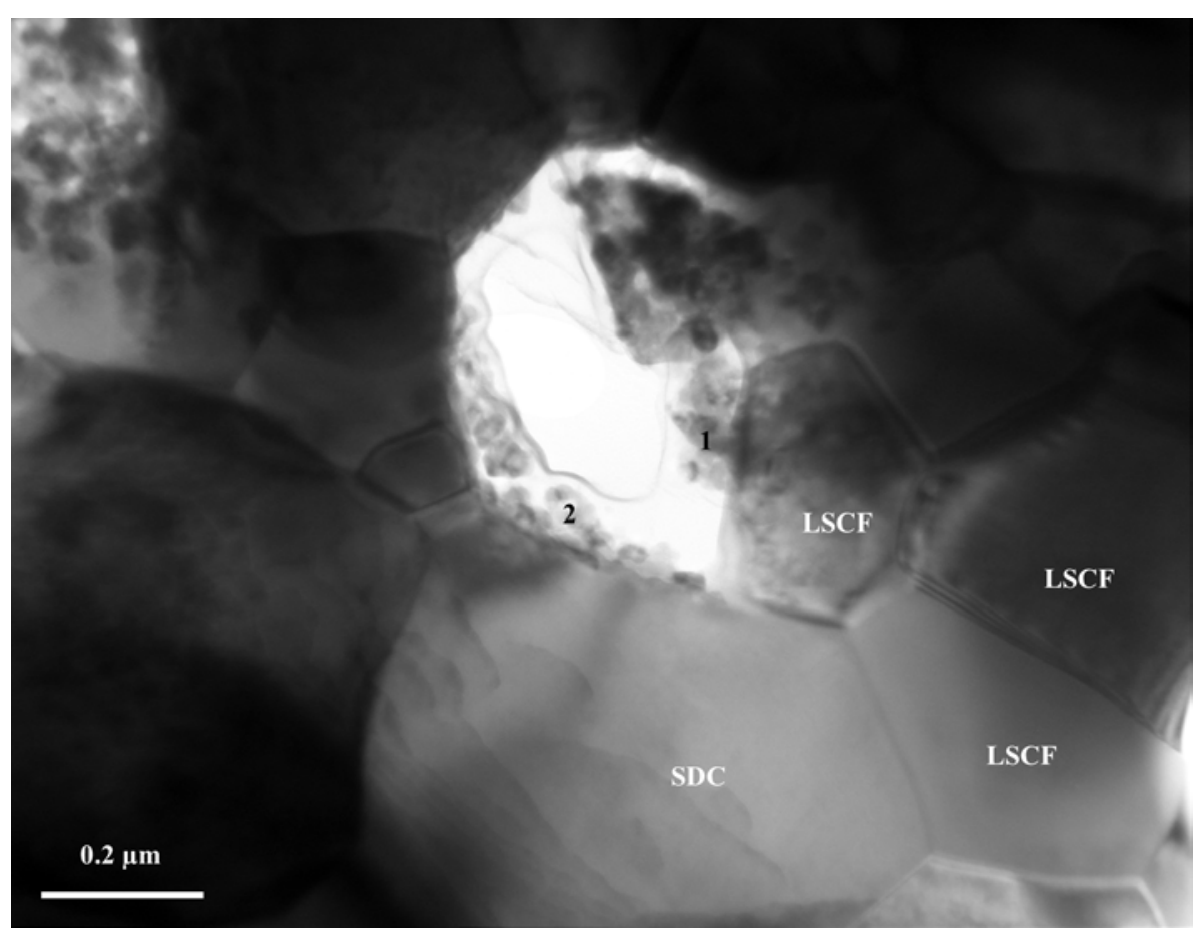

(a)

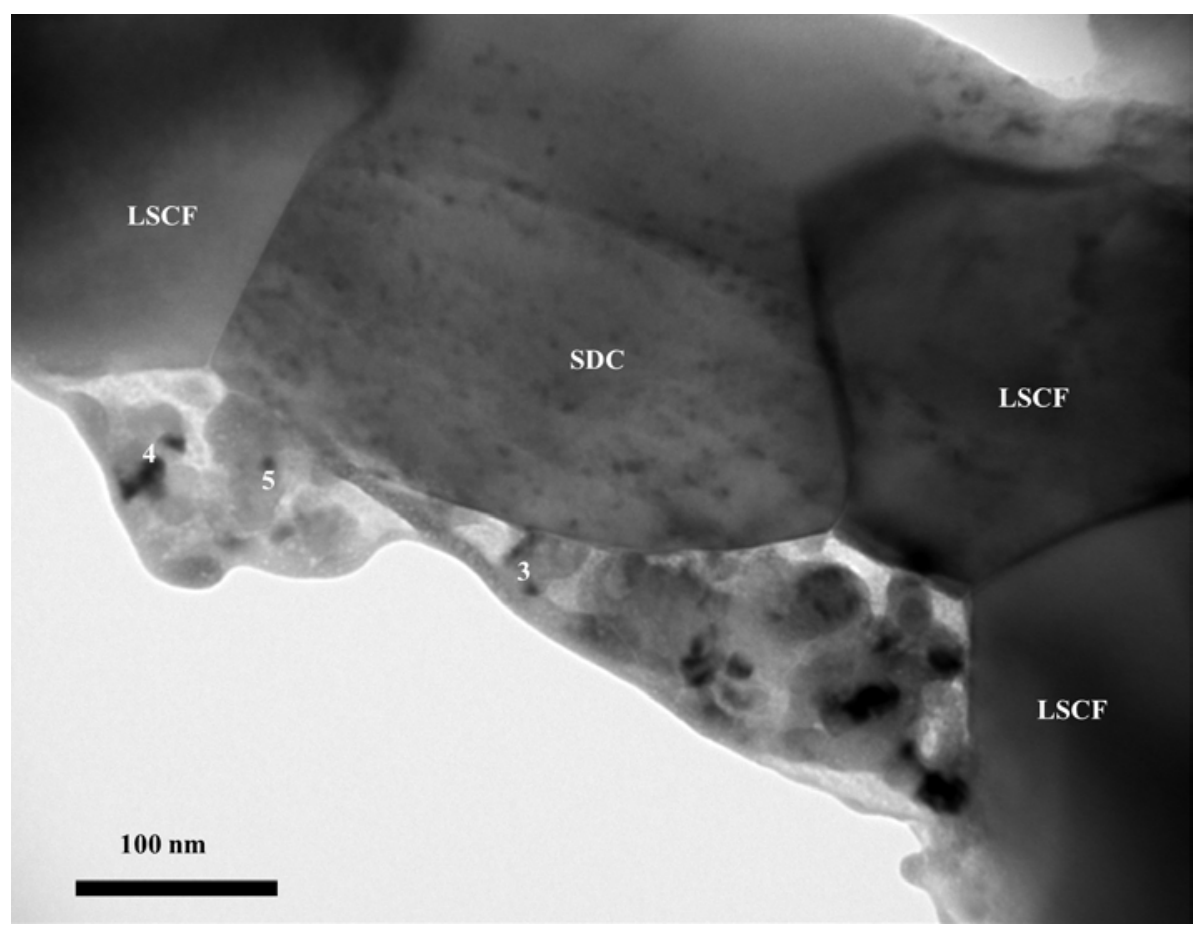

(b)

Figure 67. Diffraction contrast images from the cathode side of the as-received cell with $6 \mathrm{wt} \%$ LSCo infiltration. The numbers in the images showing the EDS acquisition positions. 
Table 4 EDS chemical composition examination on LSCo infiltrates in Figure 67 (atomic percentage is used in this table)

\begin{tabular}{cccccc}
\hline & $\mathrm{O}$ & Fe & Co & Sr & La \\
\hline 1 & 54.2 & 1.31 & 20.89 & 6.48 & 17.13 \\
2 & 63.66 & 0.72 & 15.52 & 5.42 & 14.68 \\
3 & 66.82 & 1.38 & 14.17 & 4.94 & 12.69 \\
4 & 63.52 & & 16.89 & 3.63 & 15.97 \\
5 & 61.1 & 1.33 & 16.58 & 6.35 & 14.63 \\
\hline
\end{tabular}

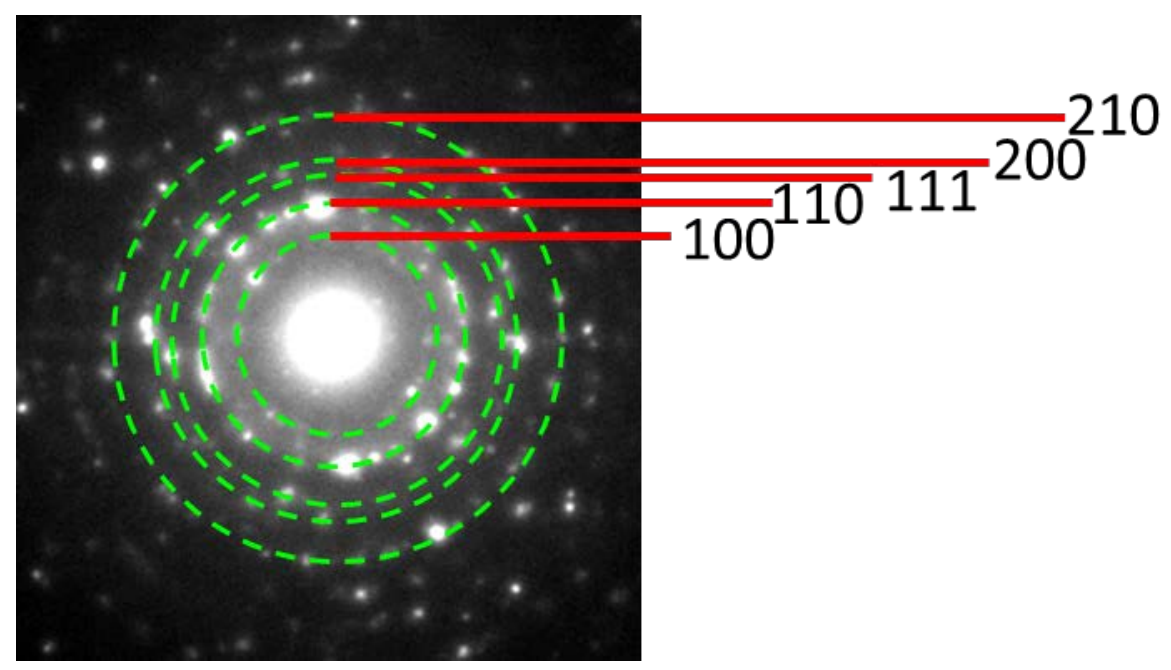

Figure 68. Diffraction pattern taken from the infiltrates in infiltrated SOFC without operation, diffraction rings are indexed as those from different planes of LSCo with cubic structure.

\subsection{Cathode structure of the cathode infiltrated SOFC operated for $1500 \mathrm{~h}$}

After $1500 \mathrm{~h}$ operation, the cathode structure in the infiltrated SOFC is examined with TEM. The first interesting position is the LSCo infiltrates. Figure 69 shows the typical diffraction contrast images of the cathode with infiltrations under different magnifications. From the Figure 69b, it is shown that the size of the infiltrates varies $30 \sim 100 \mathrm{~nm}$, which is larger than the original 
infiltrate in the as-received infiltrated cell. The EDS is taken from the position 1,2 and 3 in

Figure 69b and the result is summarized in Table 5. From the EDS result, it is shown that the Co is the major metal ion in position 1. The HRTEM image of Figure 69c shows a single phase of that grain. The diffraction pattern (inserted image in Figure 69c) taken from that grain matches the $\mathrm{Co}_{3} \mathrm{O}_{4}[110]$ zone axis. Based on the results from Figure 69, it is suggested that the new $\mathrm{Co}_{3} \mathrm{O}_{4}$ phase forms during the cell operation. Since the infiltrated $\mathrm{Co}_{3} \mathrm{O}_{4}$ has been reported to decrease the effective charge transfer resistance of the cathode [115], the $\mathrm{Co}_{3} \mathrm{O}_{4}$ formation may not become an issue for the cathode performance. The spectra of points $2 \& 3$ show higher Fe content than the LSCo infiltrates in non-operational cell. But the Fe content is lower than the LSCF grain. And the content of Fe and Co together is as equal as the content of Sr and La together at position 2 and 3. The EDS results from Figure 69b indicate a new Fe doped LSCo phase, which is with different from LSCF backbone, forms during the cell operation. It is suggested that the Fe in LSCF backbone can diffused into the LSCo infiltrates to form a new Fe doped LSCo phase. And the Co in LSCo migrates out to generate $\mathrm{Co}_{3} \mathrm{O}_{4}$.
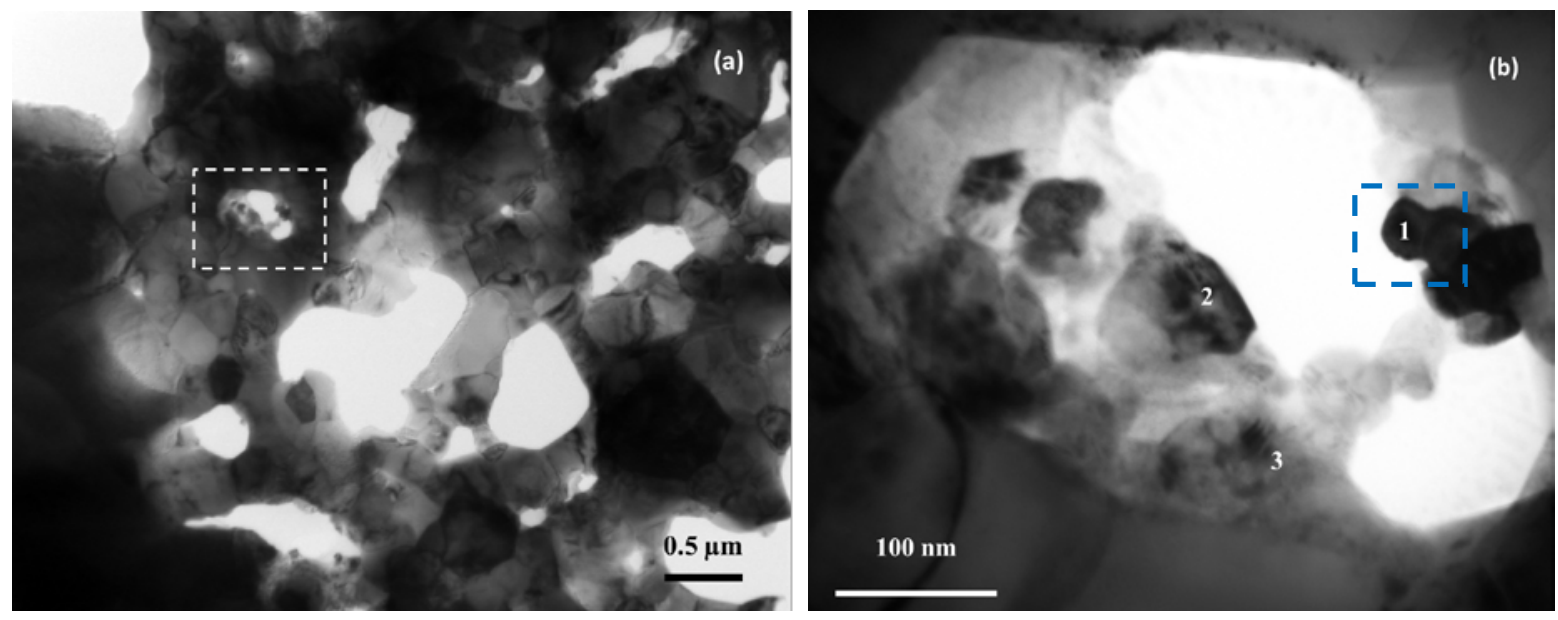


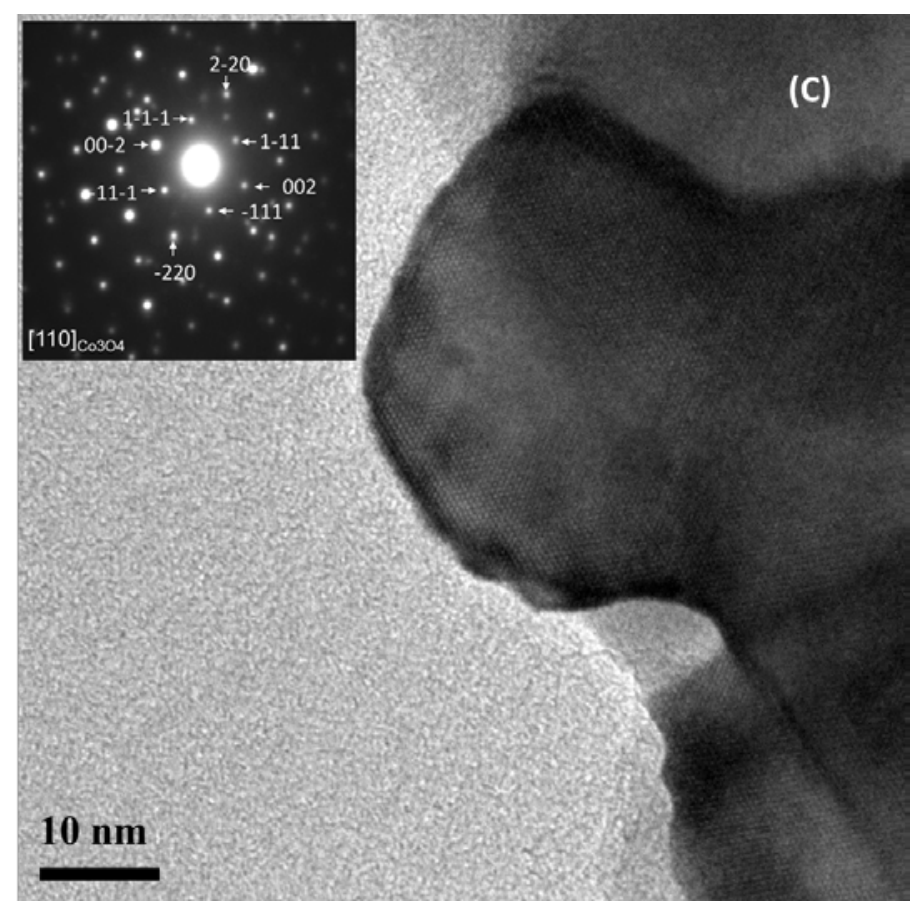

Figure 69. (a) Typical diffraction contrast image of cathode with LSCo infiltration in SOFC operated at $750^{\circ} \mathrm{C}$ for $1500 \mathrm{~h}$. (b) enlarged image of dashed area in (a) showing the infiltration particles. (c) HRTEM image of dashed area in (b) showing the new phase formation, inserted diffraction pattern is taken from the new phase confirming it is $\mathrm{Co}_{3} \mathrm{O}_{4}$.

Table 5 EDS chemical composition examination on LSCo infiltrated cathode in SOFC operated at $750^{\circ} \mathrm{C}$ for $1500 \mathrm{~h}$ (atomic percentage is used in this table)

\begin{tabular}{ccccccc}
\hline & $\mathrm{O}$ & $\mathrm{Fe}$ & $\mathrm{Co}$ & $\mathrm{Sr}$ & $\mathrm{La}$ & $\mathrm{Pt}$ \\
\hline 1 & 50.62 & 1.72 & 42.35 & 2.14 & 3.17 & \\
2 & 55.61 & 7.26 & 13.39 & 7.6 & 14.9 & 1.23 \\
3 & 45.12 & 8.24 & 18.89 & 10.44 & 16.43 & 0.87 \\
\hline
\end{tabular}

The interface of YSZ electrolyte and SDC buffer layer is investigated in this chapter. The Figure 70 and Figure 71 show the image of the interface of YSZ electrolyte and SDC buffer layer. In Figure 70, EDS are taken from the positions indicated by the numbers. From the 
spectra, it is shown that there are two major groups of grains in this area. One is YSZ grain with different concentration of SDC, the other is $\mathrm{SrZrO}_{3}$ grain with minor La and Fe, which forms during the cell operation. The results from Figure 70 indicate that even with SDC buffer layer, the $\mathrm{Zr}$ can diffuse through the SDC to react with the Sr in the LSCF to generate insulate phase $\mathrm{SrZrO}_{3}$, which could increase the cathode resistivity. From the Figure 71, it is shown that the cations in SDC can diffuse into the electrolyte. And the diffusion can change the microstructure of the YSZ electrolyte from mixture of $t$-YSZ and $c$-YSZ into pure $c$-YSZ, which are indicated by the SAED patterns in Figure 71. Since the $8 \mathrm{~mol} \% \mathrm{YSZ}$ has highest ionic conductivity and the structure is mixture of $t$-YSZ and $c$-YSZ, the structure change due to the diffusion of cations from SDC can decrease the ionic conductivity, which could be one reason for cell degradation.

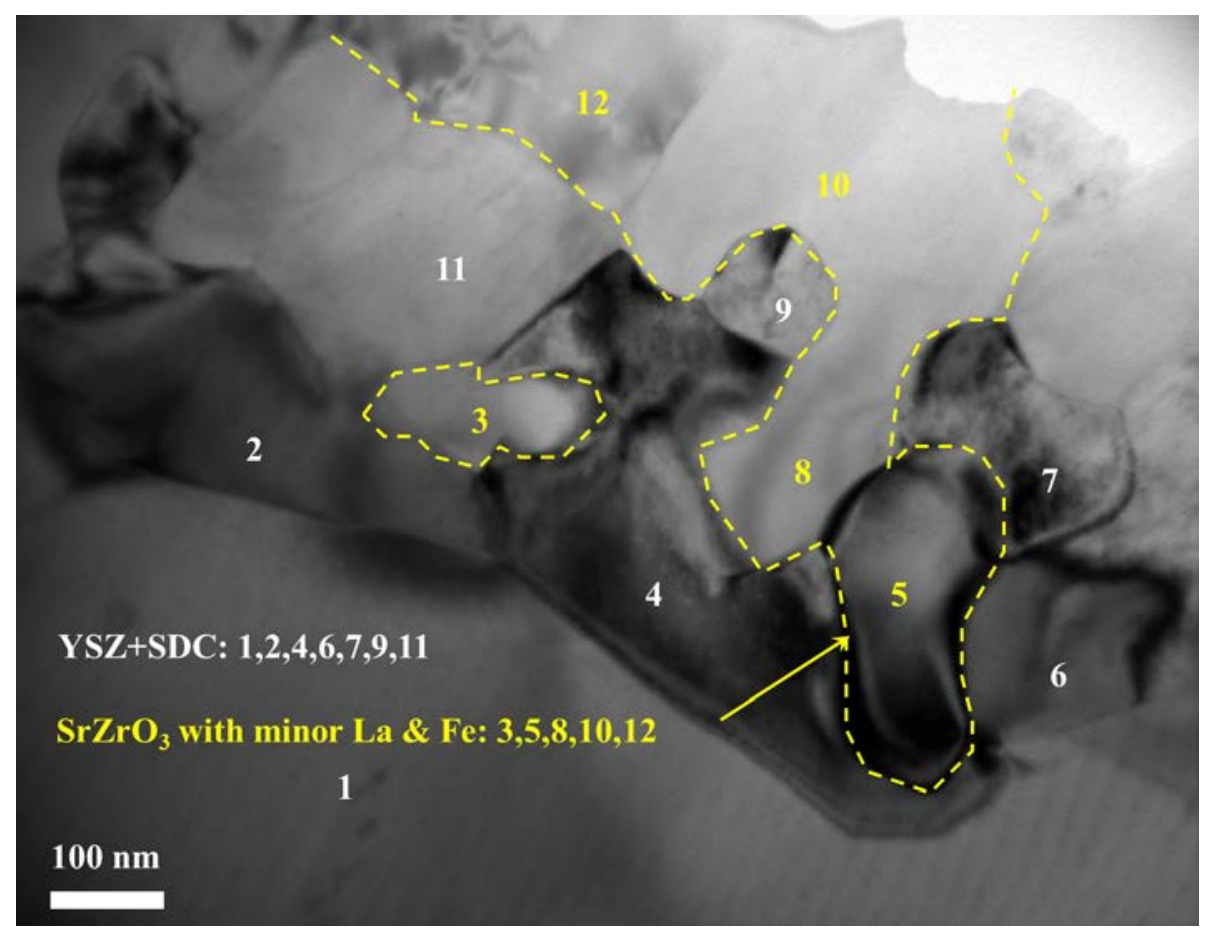

Figure 70. Diffraction contrast image at interface of YSZ electrolyte and SDC buffer layer showing the $\mathrm{SrZrO}_{3}$ formation and YSZ/SDC inter-diffusion. 


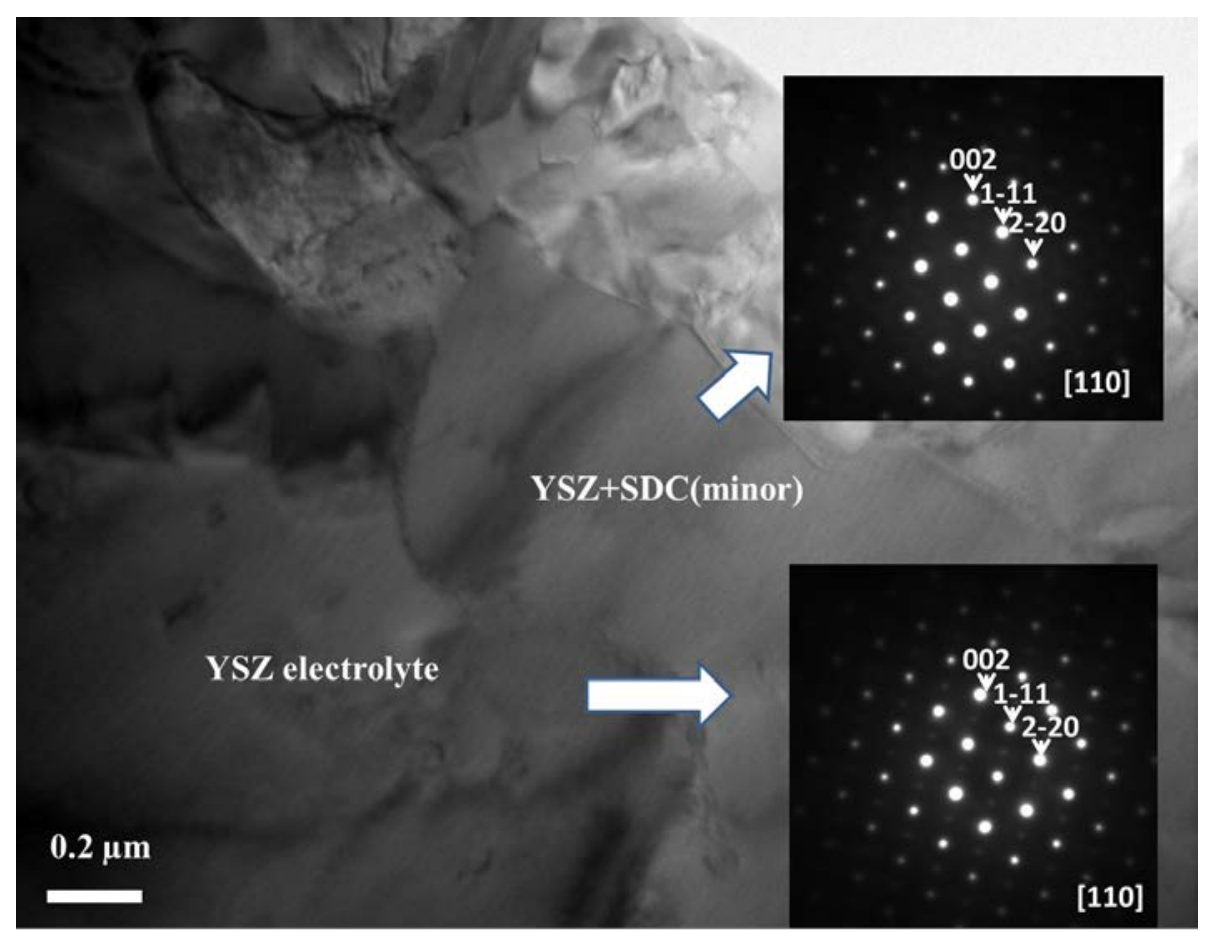

Figure 71. Diffraction contrast image showing the YSZ electrolyte and YSZ with minor SDC diffusion, the inserted SAED patterns taken from different regions in this area.

To prevent the reaction between YSZ electrolyte and LSCF cathode, the SDC is usually used as buffer layer between these two parts. However, the $\mathrm{SrZrO}_{3}$ phase was still observed in this study. Since the YSZ and SDC have similar crystal structure, the inter-diffusion between YSZ and SDC is hard to avoid during the co-sintering process or cell operation. The Zr diffusion through SDC grain can react with $\mathrm{Sr}$ in LSCF to form insulating phase $\mathrm{SrZrO}_{3}$ to make the cathode degradation. On the other hand, the cations in SDC diffusion into YSZ electrolyte can change the YSZ structure, which may influence the conductivity of YSZ electrolyte. 


\subsection{Summary}

In this chapter, the cathode of LSCo infiltrated SOFC was investigated in terms of the structure and chemistry changes. The non-operation cell and $1500 \mathrm{~h}$ operated cell are examined and compared. The detailed results obtained in this chapter are summarized as follows:

1. Particles with the size of 10 20 nm are observed on the SDC and LSCF surface in the cathode of baseline infiltrated SOFC. But the surface is not totally covered, which is good for the gas diffusion and increase the catalytic sites. The diffraction pattern taken from the infiltrated particles matches the standard LSCo pattern rings, indicating the formation of the LSCo. There is some Fe detected in the infiltrates, which may be due to the diffusion from the LSCF during the sintering.

2. The operated cell shows larger infiltrates on the SDC and LSCF surface. A new $\mathrm{Co}_{3} \mathrm{O}_{4}$ phase is detected in the infiltrates after cell operation. The EDS is applied to analyze the $\mathrm{Co}_{3} \mathrm{O}_{4} / \mathrm{LSCF}$ interface. In this interface area, a higher Fe content than baseline cell is observed, but the Fe content is lower than LSCF backbone. And the content of Fe and Co together is as equal as the content of Sr and La together at this area indicating a new high Fe doped LSCo phase formation due to the Fe diffusion from the LSCF backbone into LSCo particles. Based on the formation of $\mathrm{Co}_{3} \mathrm{O}_{4}$ and the new high Fe doped LSCo, it is suggested there is some relationship between the Fe diffusion and the $\mathrm{Co}_{3} \mathrm{O}_{4}$ formation, which can be further studied in the future.

3. Near the interface of YSZ electrolyte and SDC buffer layer, a new formed $\mathrm{SrZrO}_{3}$ phase is observed, which may increase the resistivity. The YSZ and SDC inter- 
diffusion is observed in this interface area. The cations in YSZ can diffuse through the SDC to react with the Sr in LSCF to generate the $\mathrm{SrZrO}_{3}$ phase. And the cations in SDC diffusion into the YSZ can change the YSZ structure from the mixture of $t$ YSZ and $c$-YSZ into pure $c$-YSZ, which may decrease the ionic conductivity of the YSZ electrolyte. 


\section{Chapter 6: Conclusions and recommendations for the future works}

\subsection{Conclusions}

The nanostructure and chemistry of the anode in SOFCs, including the as-received cell and the cells with operated under different conditions, were studied systematically. The evolution of the nanostructure and chemistry of cathode in infiltrated SOFC is also investigated. Based on the results presented in this dissertation, the main conclusions, on the nanostructure and chemistry evolution of SOFCs upon cell operation, are summrized as following:

1. In the as-received SOFCs, YSZ grains in anode and cathode show the same $\mathrm{Y}_{2} \mathrm{O}_{3}$ doping, but different structure. The cathode YSZ has a cubic fluorite structure patterns while the anode YSZ presents a cubic structure with weak diffraction spots which are kinematically forbidden for the cubic structure. The presence of Mn in cathode YSZ, which is due to the diffusion from LSM, stabilizes the cubic structure of the YSZ in cathode. The structure difference of YSZ in anode and cathode is persistent in all operated cells. The t-YSZ nano-domains in the cubic YSZ grains in anode were verified. In the SOFCs operated with simulated syngas for $550 \mathrm{~h}$, a discretely ordered $t$-YSZ nano-domain and a discretely ordered $c$-YSZ nano-domain are observed between the original Ni/YSZ interface and the bulk YSZ domain, which is attributed to the electrochemical reactions. This feature is not observed in SOFCs operated with wet $\mathrm{H}_{2}\left(97 \% \mathrm{H}_{2}+3 \% \mathrm{H}_{2} \mathrm{O}\right)$. The other microstructure and chemistry change, which results from the electrochemical reactions, is the formation of the $\mathrm{NiO}$ ribbon phase layer at the Ni/YSZ interface. 
The thickness of the NiO layer increases from about $10 \mathrm{~nm}$ to over $50 \mathrm{~nm}$ with increasing the operation time in simulated syngas. But in the SOFCs operated on wet $\mathrm{H}_{2}$, the $\mathrm{NiO}$ layer remains the same thickness, which is about $5 \mathrm{~nm}$, even though the cell was operated up to $540 \mathrm{~h}$. This new $\mathrm{NiO}$ phase is suggested to form during the cooling step in non-reducing environments. Under the polarization (current loading) condition, the oxygen ion can migrate from the YSZ grain into $\mathrm{Ni}$ as a solute near $\mathrm{Ni} / \mathrm{YSZ}$ interface, and then react with $\mathrm{Ni}$ to form $\mathrm{NiO}$ during the cooling step. This oxygen migration near the Ni/YSZ may also affect the cation distribution near the Ni/YSZ interface, which creates $t$-YSZ domain with high oxygen content and c-YSZ domain with low oxygen content near the Ni/YSZ interface. The $\mathrm{H}_{2}$ proportion in the fuel gas plays an important role in the formation of $\mathrm{NiO}$ layer. The thickness of the $\mathrm{NiO}$ layer increases with decreasing the $\mathrm{H}_{2}$ proportion in the fuel gas. Since the $\mathrm{NiO}$ formation is tentatively due to the oxygen migration from $\mathrm{YSZ}$ to $\mathrm{Ni}$, thicker $\mathrm{NiO}$ will be observed when oxygen (ion) goes faster and deeper into the Ni. Besides the $\mathrm{H}_{2}$ concentration in the fuel gas, the overpotential is another possible factor to influence the $\mathrm{NiO}$ formation. But from the results in this study, no conclusion about the effect of the overpotential can be drawn. Further investigation is recommended to analyze the effect of overpotential, especially anode overpotential, and $\mathrm{H}_{2}$ concentration on the $\mathrm{NiO}$ formation.

2. The SOFCs operated with $10 \mathrm{ppm} \mathrm{PH}_{3}$ as contaminant show new Ni-P phase formation at the surface of the cells, no matter what fuels (dry hydrogen or syngas) are used. But the cell operated with syngas shows more severe reaction between $\mathrm{Ni}$ and $\mathrm{PH}_{3}$. It shows continuous and thicker Ni-P phase at the anode surface and a 
network of holes in the anode current collection layer, which is not shown in dry hydrogen operation cell. Some precipitates or particles embedded in the newly formed Ni-P phase are observed and the precipitate phase has some orientation relationship with the major Ni-P phase. The SOFC operated in syngas containing $\mathrm{PH}_{3}$ (SOFC-P-1) shows obvious structure changes in YSZ grain at the Ni/YSZ interface. Large scale $t$-YSZ layer and $c$-YSZ layer appear at the Ni/YSZ interface. These $t$-YSZ layer and $c$-YSZ layer appear at the Ni/YSZ interface indicate the concentration variation of $\mathrm{Y}$ in the vicinity of the Ni/YSZ interface, which could be due to the $\mathrm{Y}$ migration along the Ni/YSZ interface. $\mathrm{Y}$ migration is favored when phosphine is present in the syngas fuel. The EDS scanning shows the Y/Zr ratio can vary from 8.7 atom\% to 55.1 atom\% along the Ni/YSZ interface. A new $\mathrm{YPO}_{4}$ phase is observed at the $\mathrm{YSZ} / \mathrm{Ni} / \mathrm{YSZ}$ triple phase junctions of the SOFC operated in syngas containing $\mathrm{PH}_{3}$. The $\mathrm{YPO}_{4}$ formation is suggested to start from the reaction between $\mathrm{PH}_{3}$ and $\mathrm{H}_{2} \mathrm{O}$ in syngas to forms $\mathrm{H}_{3} \mathrm{PO}_{4}$, which reacts with $\mathrm{Ni}$ to forms $\mathrm{Ni}_{3}\left(\mathrm{PO}_{4}\right)_{2}$ in the oxygen rich region at $\mathrm{Ni} / \mathrm{YSZ}$ interface near TPB. And then $\mathrm{Ni}_{3}\left(\mathrm{PO}_{4}\right)_{2}$ reacts with $\mathrm{Y}_{2} \mathrm{O}_{3}$ in high $\mathrm{Y}$ content region near Ni/YSZ interface to form $\mathrm{YPO}_{4}$ phase. The formation of $\mathrm{YPO}_{4}$ drives the $\mathrm{Y}_{2} \mathrm{O}_{3}$ out of the $\mathrm{YSZ}$ near the $\mathrm{Ni} / \mathrm{YSZ}$ interface, which therefore creates large size $t$-YSZ domains near the $\mathrm{Ni} / \mathrm{YSZ}$ interface. From the HRTEM images at the Ni/YPO${ }_{4}$ and $\mathrm{YSZ} / \mathrm{YPO}_{4}$ interface, we can find that there is no orientation relationship between the $\mathrm{Ni}$ and $\mathrm{YPO}_{4}$ grains, but a strong orientation relationship between $\mathrm{YSZ}$ and $\mathrm{YPO}_{4}$ grains are observed. This result implies that the YSZ is the parent phase and that the $\mathrm{YPO}_{4}$ grows expitaxially in alignment to the YSZ matrix. 
3. In the cathode infiltrated non-operated SOFCs, LSCo infiltrated particles with the size of 10 20 nm are observed to partially cover the SDC and LSCF surface. A new $\mathrm{Co}_{3} \mathrm{O}_{4}$ phase is detected in the infiltrates after cell operation. At the $\mathrm{Co}_{3} \mathrm{O}_{4} /$ LSCF interface, a new high Fe doped LSCo phase formation is detected, which is due to the Fe diffusion from the LSCF backbone into LSCo particles. The new high Fe doped LSCo phase is believed to be related to the formation of $\mathrm{Co}_{3} \mathrm{O}_{4}$. Near the interface of YSZ electrolyte and SDC buffer layer, a new formed $\mathrm{SrZrO}_{3}$ phase is observed, which is probably caused by the diffusion of cations Zr (in YSZ) through the SDC layer and reacting with the Sr (in LSCF). The inter-diffusion of cations between SDC and YSZ also changes the YSZ structure from the mixture of $t$-YSZ and $c$-YSZ into pure $c$-YSZ. The cation inter-diffusion and the resulting insulating phases such as $\mathrm{SrZrO}_{3}$ may decrease the ionic conductivity of the YSZ electrolyte and increase the resistivity of the cathode.

\subsection{Recommendations for the future works}

Based on the results obtained from this dissertation, the following aspects are highly recommended for the future works:

\section{To further investigate the mechanism of NiO formation.}

In this dissertation, all cells are operated for one heating-cooling cycle in simple conditions, in which the temperature and fuel gas are not changed. Under this operation condition, it is suggested the $\mathrm{NiO}$ formation is due to the oxygen diffusion 
from YSZ into Ni with the electrochemical operation. And the thickness of $\mathrm{NiO}$ can vary from several nanometers to over $60 \mathrm{~nm}$ with different fuel gas and operation time. However, the formation rate and the thickness limitation of the NiO layer are not clarified in this study. In order to understand the effect of the $\mathrm{H}_{2}$ concentration and overpotential, especially anode overpotential, on the NiO formation, two parts of the work can be done in the future work: (1) The different concentration $\mathrm{H}_{2}$ diluted by $\mathrm{N}_{2}$ can be used as the fuel gas to operate the SOFCs with same operation conditions. (2) Same fuel gas with same $\mathrm{H}_{2}$ can be used to operate the SOFCs under different overpotentials. The overpotential, especially anode overpotential, and the $\mathrm{NiO}$ will be examined and the relationship between $\mathrm{NiO}$ formation $\mathrm{H}_{2}$ concentration and overpotential can be analyzed. On the other hand, the operation condition in this study is not the same as the real application requirement. So in the future research, the more complicated operation conditions can be applied and the $\mathrm{NiO}$ formation can be investigated under the complicated conditions. The multi-cycles test, not only changing the temperature, but also alternating the fuel gas, can be used. The loading current can be adjusted as well. Based on these tests and structure analysis of the SOFCs, the deeper understanding about the $\mathrm{NiO}$ formation can be obtained.

\section{To further investigate the YSZ structure changes near Ni/YSZ interface.}

YSZ structure changes, especially near the Ni/YSZ interface or TPB, are very important in SOFC performance. The results about the YSZ in this dissertation indicate that the YSZ structure changes near the interface are accompanied with new phase formation, such as $\mathrm{NiO}$ in clean syngas operated cell and $\mathrm{YPO}_{4}$ in the $\mathrm{PH}_{3}$ contaminating syngas. In the future works, the relationship between the YSZ structure 
change near the Ni/YSZ interface and the new phase formation at that interface can be further investigated. For the clean syngas operated cell, because the YSZ structure change is tentatively due to the oxygen concentration difference near the $\mathrm{Ni} / \mathrm{YSZ}$ interface, it is proposed that the thicker $\mathrm{NiO}$ will be correlated with more extensive YSZ structural changes near the Ni/YSZ interface. The specimens obtained from the above section (Mechanism of $\mathrm{NiO}$ formation) can be analyzed to check if there is any YSZ structure changes near the Ni/YSZ interface. All the YSZ in this study contains about 8 mole\% $\mathrm{Y}_{2} \mathrm{O}_{3}$ doping, which is near the YSZ phase transformation point. In previous work, $10 \mathrm{YSZ}$ exhibits a stable structure even heated up to $1000^{\circ} \mathrm{C}$. So the YSZ with different $\mathrm{Y}_{2} \mathrm{O}_{3}$ doping can be used in anode to check if the YSZ structure will change in more stabilized YSZ grain. With those studies, the mechanism of YSZ structure change near Ni/YSZ interface will be clearer and the more reliable YSZ materials can be designed for the SOFCs. For the dirty syngas (with $\mathrm{PH}_{3}$ contaminant), the process of $\mathrm{YPO}_{4}$ formation is still not fully understood in this study. The SOFC with Ni pattern on YSZ electrolyte is a good method to investigate the reaction at TPB, because the TPB in this system is easy to locate. With changing the gas composition or current loading, more information about the new phase formation and the location of the new phase will be obtained.

\section{Effect of long-term operation on the anode nanostructure and chemistry.}

The present work clearly shows that the nanostructure and chemistry of anode, including the formation of $\mathrm{NiO}$ layer, the cation migration in $\mathrm{YSZ}$, will change upon the change of fuels and change of operation duration. However, all cells operated in clean gas ( $\mathrm{H}_{2}$ or syngas) did not show obvious degradation. Although the phenomena 
observed from this study can provide a possible guess about the degradation, the long term test and the examination of long term operated cell are desired. How the phenomena (NiO formation, YSZ structure change) will change upon the long term operation can be understood only if the cell is operated for long term and analyzed after the operation.

\section{Systematic analysis on the cathode backbone and infiltration, and their evolution} upon cell operation.

The work on the cathode presented in this dissertation has shown that the cation inter-diffusion and formation of different phases are critical for LSCF with LSCo infiltrates. In order to further understand the process of new Fe doped LSCF and $\mathrm{Co}_{3} \mathrm{O}_{4}$ formation, the LSCF and LSCo particles can be investigated by thermal treatment to test the stability. The LSCF pellet deposited with the LSCo particles can be used to analyze the new phase formation by thermal treatment. As we know, there are a lot of materials, which can be used as infiltrates to enhance the cathode performance. If the infiltrates can not only enhance the cell performance, but also alleviate the cell degradation, the structure of the cathode backbone, infiltrates, and their evolution upon cell operation need to be analyzed systematically.

\section{To set up simulating models to discuss the cell degradation.}

It is impossible to run all experiments to test every possible condition. Using limited data to set up a reasonable model is a good way to save time and money. Taking $\mathrm{NiO}$ formation as an example, based on the results obtained in this dissertation and the following work suggested in the first part in this section, the 
model for $\mathrm{NiO}$ formation with different gas composition and overpotential could be set up to discuss the possible degradation mechanism in SOFCs. And the results from the model could be verified by the further experiments. 


\section{Reference}

1. Minh, N.Q., CERAMIC FUEL-CELLS. Journal of the American Ceramic Society, 1993. 76(3): p. 563588.

2. Horita, T., et al., Oxygen reduction sites and diffusion paths at $\mathrm{La}(0.9) \operatorname{Sr}(0.1) \mathrm{MnO}(3-x) / y$ ttriastabilized zirconia interface for different cathodic overvoltages by secondary-ion mass spectrometry. Solid State Ionics, 2000. 127(1-2): p. 55-65.

3. Hansen, K.V., K. Norrman, and M. Mogensen, H-2-H2O-Ni-YSZ electrode performance - Effect of segregation to the interface. Journal of the Electrochemical Society, 2004. 151(9): p. A1436A1444.

4. Liu, Y.L., S. Primdahl, and M. Mogensen, Effects of impurities on microstructure in Ni/YSZ-YSZ half-cells for SOFC. Solid State Ionics, 2003. 161(1-2): p. 1-10.

5. Backhaus-Ricoult, M., Interface chemistry in LSM-YSZ composite SOFC cathodes. SOLID STATE IONICS, 2006: p. 2195-2200.

6. Hauch, A., et al., Nanoscale chemical analysis and imaging of solid oxide cells. ELECTROCHEMICAL AND SOLID STATE LETTERS, 2008. 11(3): p. B38-B41.

7. Grove, W., On Voltaic Series and the Combination of Gases by Platinum. Philos. Mag., 1839. 14: p. 4.

8. $\quad$ Nernst, W., Uber Die Elektrolytische Leitung Fester Korper Bei Sehr Hohen Temperaturen. Z. Electrochem, 1899. 6: p. 41-43.

9. Baur, E. and H. Preis, Uber Brennstoff-Ketten Mit Feestleitern. Z. Elektrochem., 1937. 43: p. 72732.

10. NASA. Available from: http://science.nasa.gov/science-news/science-atnasa/2003/18mar fuelcell/.

11. Administration, U.S.E.I. Nonrenewable Sources-coal-how much coal is left. Available from: http://www.eia.gov/energyexplained/index.cfm?page=coal reserves.

12. Vollmar, H.E., et al., Innovative concepts for the coproduction of electricity and syngas with solid oxide fuel cells. Journal of Power Sources, 2000. 86(1-2): p. 90-97.

13. Costa-Nunes, O., R.J. Gorte, and J.M. Vohs, Comparison of the performance of Cu-CeO2-YSZ and $\mathrm{Ni}$-YSZ composite SOFC anodes with H-2, CO, and syngas. Journal of Power Sources, 2005. 141(2): p. 241-249.

14. Gemmen, R.S. and J. Trembly, On the mechanisms and behavior of coal syngas transport and reaction within the anode of a solid oxide fuel cell. Journal of Power Sources, 2006. 161(2): p. 1084-1095.

15. Suwanwarangkul, R., et al., Experimental and modeling study of solid oxide fuel cell operating with syngas fuel. Journal of Power Sources, 2006. 161(1): p. 308-322.

16. Colpan, C.O., I. Dincer, and F. Hamdullahpur, Thermodynamic modeling of direct internal reforming solid oxide fuel cells operating with syngas. International Journal of Hydrogen Energy, 2007. 32(7): p. 787-795.

17. Cayan, F.N., et al., Effects of coal syngas impurities on anodes of solid oxide fuel cells. Journal of Power Sources, 2008. 185(2): p. 595-602.

18. Liu, K., et al., Conducting oxide formation and mechanical endurance of potential solid-oxide fuel cell interconnects in coal syngas environment. JOURNAL OF POWER SOURCES, 2008. 183(1): p. 247-252. 
19. Zhi, M., et al., Electrochemical and microstructural analysis of nickel-yttria-stabilized zirconia electrode operated in phosphorus-containing syngas. JOURNAL OF POWER SOURCES, 2008. 183(2): p. 485-490.

20. $\mathrm{Xu}, \mathrm{C}$., et al., The effect of phosphine in syngas on Ni-YSZ anode-supported solid oxide fuel cells. JOURNAL OF POWER SOURCES, 2009. 193(2): p. 739-746.

21. Miao, H., et al., Effects of coal syngas major compositions on Ni/YSZ anode-supported solid oxide fuel cells. Journal of Power Sources, 2010. 195(8): p. 2230-2235.

22. Subbarao, E.C. and H.S. Maiti, SOLID ELECTROLYTES WITH OXYGEN ION CONDUCTION. Solid State lonics, 1984. 11(4): p. 317-338.

23. Scott, H.G., Phase relationships in the zirconia-yttria system. Journal of Materials Science, 1975. 10: p. 1527-1535.

24. Fergus, J.W., Electrolytes for solid oxide fuel cells. Journal of Power Sources, 2006. 162(1): p. 3040.

25. Badwal, S.P.S., F.T. Ciacchi, and D. Milosevic, Scandia-zirconia electrolytes for intermediate temperature solid oxide fuel cell operation. Solid State lonics, 2000. 136: p. 91-99.

26. Nomura, K., et al., Aging and Raman scattering study of scandia and yttria doped zirconia. Solid State lonics, 2000. 132(3-4): p. 235-239.

27. Kharton, V.V., F.M.B. Marques, and A. Atkinson, Transport properties of solid oxide electrolyte ceramics: a brief review. Solid State lonics, 2004. 174(1-4): p. 135-149.

28. Fergus, J.W., Doping and defect association in oxides for use in oxygen sensors. Journal of Materials Science, 2003. 38(21): p. 4259-4270.

29. Yamamoto, O., et al., ELECTRICAL-CONDUCTIVITY OF STABILIZED ZIRCONIA WITH YTTERBIA AND SCANDIA. Solid State Ionics, 1995. 79: p. 137-142.

30. Sarat, S., N. Sammes, and A. Smirnova, Bismuth oxide doped scandia-stabilized zirconia electrolyte for the intermediate temperature solid oxide fuel cells. Journal of Power Sources, 2006. 160(2): p. 892-896.

31. Chiba, R., T. Ishii, and F. Yoshimura, Temperature dependence of ionic conductivity in (1-x)ZrO2$(x-y) S c 203-y Y b(2) O(3)$ electrolyte material. Solid State lonics, 1996. 91(3-4): p. 249-256.

32. Dalslet, B., et al., Assessment of doped ceria as electrolyte. Journal of Solid State Electrochemistry, 2006. 10(8): p. 547-561.

33. Yahiro, H., K. Eguchi, and H. Arai, ELECTRICAL-PROPERTIES AND REDUCIBILITIES OF CERIA RARE EARTH OXIDE SYSTEMS AND THEIR APPLICATION TO SOLID OXIDE FUEL-CELL. Solid State lonics, 1989. 36(1-2): p. 71-75.

34. Gordon, R.S. in Electrochemical Society Proceedings. 2003.

35. Ralph, J.M., A.C. Schoeler, and M. Krumpelt, Materials for lower temperature solid oxide fuel cells. Journal of Materials Science, 2001. 36(5): p. 1161-1172.

36. Ralph, J.M., C. Rossignol, and R. Kumar, Cathode materials for reduced-temperature SOFCs. Journal of the Electrochemical Society, 2003. 150(11): p. A1518-A1522.

37. Charojrochkul, S., K.L. Choy, and B.C.H. Steele, Cathode electrolyte systems for solid oxide fuel cells fabricated using flame assisted vapour deposition technique. Solid State Ionics, 1999. 121(14): p. 107-113.

38. Rossignol, C., et al., $\operatorname{Ln}(1-x) \operatorname{Sr}(x) \operatorname{CoO}(3)(L n=G d, P r)$ as a cathode for intermediate-temperature solid oxide fuel cells. Solid State lonics, 2004. 175(1-4): p. 59-61.

39. Mai, A., et al., Ferrite-based perovskites as cathode materials for anode-supported solid oxide fuel cells - Part II. Influence of the CGO interlayer. Solid State lonics, 2006. 177(19-25): p. 21032107.

40. Shiono, M., et al., Effect of CeO2 interlayer on $\mathrm{ZrO} 2$ electrolyte/La(Sr)CoO3 cathode for lowtemperature SOFCs. Solid State Ionics, 2004. 170(1-2): p. 1-7. 
41. Nguyen, T.L., et al., Fabrication and characterization of anode-supported tubular SOFCs with zirconia-based electrolyte for reduced temperature operation. Journal of the Electrochemical Society, 2004. 151(8): p. A1230-A1235.

42. Nguyen, T.L., et al., Preparation and evaluation of doped ceria interlayer on supported stabilized zirconia electrolyte SOFCs by wet ceramic processes. Solid State Ionics, 2004. 174(1-4): p. 163174.

43. Gorte, R.J. and J.M. Vohs, Nanostructured anodes for solid oxide fuel cells. Current Opinion in Colloid \& Interface Science, 2009. 14(4): p. 236-244.

44. Dees, D.W., et al., CONDUCTIVITY OF POROUS NI/ZRO2-Y2O3 CERMETS. Journal of the Electrochemical Society, 1987. 134(9): p. 2141-2146.

45. Park, S., R.J. Gorte, and J.M. Vohs, Tape cast solid oxide fuel cells for the direct oxidation of hydrocarbons. Journal of the Electrochemical Society, 2001. 148(5): p. A443-A447.

46. Gross, M.D., J.M. Vohs, and R.J. Gorte, Recent progress in SOFC anodes for direct utilization of hydrocarbons. Journal of Materials Chemistry, 2007. 17(30): p. 3071-3077.

47. Park, S.D., J.M. Vohs, and R.J. Gorte, Direct oxidation of hydrocarbons in a solid-oxide fuel cell. Nature, 2000. 404(6775): p. 265-267.

48. Pena-Martinez, J., et al., Anodic performance and intermediate temperature fuel cell testing of La0.75Sr0.25Cr0.5Mn0.503-delta at lanthanum gallate electrolytes. Chemistry of Materials, 2006. 18(4): p. 1001-1006.

49. Fu, Q.X., F. Tietz, and D. Stover, La0.4Sr0.6Ti1-xMnxO3-delta perovskites as anode materials for solid oxide fuel cells. Journal of the Electrochemical Society, 2006. 153(4): p. D74-D83.

50. Ovalle, A., et al., Mn-substituted titanates as efficient anodes for direct methane SOFCs. Solid State lonics, 2006. 177(19-25): p. 1997-2003.

51. McPhee, W.A.G., et al., Demonstration of a Liquid-Tin Anode Solid-Oxide Fuel Cell (LTA-SOFC) Operating from Biodiesel Fuel. Energy \& Fuels, 2009. 23: p. 5036-5041.

52. Jayakumar, A., et al., A Comparison of Molten Sn and Bi for Solid Oxide Fuel Cell Anodes. Journal of the Electrochemical Society, 2010. 157(3): p. B365-B369.

53. McPhee, W.A.G., et al., Direct JP-8 Conversion Using a Liquid Tin Anode Solid Oxide Fuel Cell (LTA-SOFC) for Military Applications. Journal of Fuel Cell Science and Technology, 2011. 8(4).

54. Abernathy, H., et al., Basic properties of a liquid tin anode solid oxide fuel cell. Journal of Power Sources, 2011. 196(10): p. 4564-4572.

55. Tsipis, E.V. and V.V. Kharton, Electrode materials and reaction mechanisms in solid oxide fuel cells: a brief review. Journal of Solid State Electrochemistry, 2008. 12(11): p. 1367-1391.

56. Teraoka, Y., et al., MIXED IONIC-ELECTRONIC CONDUCTIVITY OF LA1-XSRXCO1-YFEYO3-DELTA PEROVSKITE-TYPE OXIDES. Materials Research Bulletin, 1988. 23(1).

57. Godickemeier, M., et al., Perovskite cathodes for solid oxide fuel cells based on ceria electrolytes. Solid State lonics, 1996. 86-8.

58. Torres-Huerta, A., J. Vargas-Garcia, and M. Dominguez-Crespo, Preparation and characterization of IrO2-YSZ nanocomposite electrodes by MOCVD. SOLID STATE IONICS, 2007: p. 1608-1616.

59. Fuentes, R.O. and R.T. Baker, Structural, morphological and electrical properties of $\mathrm{Gd}(0.1) \mathrm{Ce}(0.9) \mathrm{O}(1.95)$ prepared by a citrate complexation method. Journal of Power Sources, 2009. 186(2): p. 268-277.

60. Keech, P., D. Trifan, and V. Birss, Synthesis and performance of sol-gel prepared Ni-YSZ cermet SOFC anodes. JOURNAL OF THE ELECTROCHEMICAL SOCIETY, 2005. 152(3): p. A645-A651.

61. Liu, J., et al., Oxygen reduction at sol-gel derived La0.8Sr0.2Co0.8Fe0.2O3 cathodes. SOLID STATE IONICS, 2006. 177(3-4): p. 377-387.

62. Muccillo, E.N.S., R.A. Rocha, and R. Muccillo, Preparation of Gd2O3-doped ZrO2 by polymeric precursor techniques. Materials Letters, 2002. 53(4-5): p. 353-358. 
63. Marrero-Lopez, D., et al., Preparation of thin layer materials with macroporous microstructure for SOFC applications. JOURNAL OF SOLID STATE CHEMISTRY, 2008. 181(4): p. 685-692.

64. He, X., et al., Electron beam physical vapor deposition of YSZ electrolyte coatings for SOFCs. Applied Surface Science, 2008. 254(22): p. 7159-7164.

65. Yoon, J., et al., Nanostructured cathode thin films with vertically-aligned nanopores for thin film SOFC and their characteristics. Applied Surface Science, 2007. 254(1).

66. Imanishi, N., et al., Impedance study and TEM characterization of a PLD perovskite air electrode. SOLID STATE IONICS, 2006. 177(19-25): p. 2165-2173.

67. Knibbe, R., et al., Effect of alumina additions on the anode vertical bar electrolyte interface in solid oxide fuel cells. JOURNAL OF POWER SOURCES, 2008. 179(2): p. 511-519.

68. Knibbe, R., J. Drennan, and J.G. Love, Effect of alumina additions in YSZ on the microstructure and degradation of the LSM-YSZ interface. Solid State lonics, 2009. 180(14-16).

69. Kondoh, J., et al., Effect of aging on yttria-stabilized zirconia I. A study of its electrochemical properties. Journal of the Electrochemical Society, 1998. 145(5): p. 1527-1536.

70. Kondoh, J., et al., Effect of aging on yttria-stabilized zirconia II. A study of the effect of the microstructure on conductivity. Journal of the Electrochemical Society, 1998. 145(5): p. 15361550.

71. Kondoh, J., et al., Effect of aging on yttria-stabilized zirconia III. A study of the effect of local structures on conductivity. Journal of the Electrochemical Society, 1998. 145(5): p. 1550-1560.

72. Butz, B., et al., Correlation between microstructure and degradation in conductivity for cubic Y2O3-doped ZrO2. Solid State Ionics, 2006. 177(37-38): p. 3275-3284.

73. Ciacchi, F.T., S.P.S. Badwal, and J. Drennan, The system $\mathrm{Y}_{2} \mathrm{O}_{3}-\mathrm{Sc}_{2} \mathrm{O}_{3}-\mathrm{ZrO}_{2}$ : Phase characterisation by XRD, TEM and optical microscopy. Journal of the European Ceramic Society, 1991. 7(3): p. 185-195.

74. Haering, C., A. Roosen, and H. Schichl, Degradation of the electrical conductivity in stabilised zirconia systems Part I: yttria-stabilised zirconia. Solid State lonics, 2005. 176(3-4).

75. Hattori, M., et al., Effect of annealing on the electrical conductivity of theY(2)O(3)-ZrO2 system. JOURNAL OF POWER SOURCES, 2004. 131(1-2): p. 247-250.

76. Wang, C.M., et al., Distortion of the oxygen sublattice in pure cubic-ZrO2. Journal of Materials Research, 2004. 19(5): p. 1315-1319.

77. Wang, C.M., et al., Microstructure of ZrO2-CeO2 hetero-multi-layer films grown on YSZ substrate. Acta Materialia, 2005. 53(7): p. 1921-1929.

78. Chun, C.M., J.D. Mumford, and T.A. Ramanarayanan, Carbon-induced corrosion of nickel anode. Journal of the Electrochemical Society, 2000. 147(10): p. 3680-3686.

79. Steele, B.C.H., Survey of materials selection for ceramic fuel cells .2. Cathodes and anodes. Solid State lonics, 1996. 86-8: p. 1223-1234.

80. Wagner, T., R. Kirchheim, and M. Ruhle, ELECTROCHEMICALLY-INDUCED REACTIONS AT NI/ZRO2 INTERFACES. Acta Metallurgica Et Materialia, 1992. 40: p. S85-S93.

81. Coors, W.G., J.R. O'Brien, and J.T. White, Conductivity degradation of NiO-containing 8YSZ and 10YSZ electrolyte during reduction. Solid State lonics, 2009. 180(2-3).

82. Liu, Y.L. and C.G. Jiao, Microstructure degradation of an anode/electrolyte interface in SOFC studied by transmission electron microscopy. Solid State lonics, 2005. 176(5-6): p. 435-442.

83. Waldbillig, D., A. Wood, and D. Ivey, Electrochemical and microstructural characterization of the redox tolerance of solid oxide fuel cell anodes. JOURNAL OF POWER SOURCES, 2005. 145(2): p. 206-215.

84. Kawahara, K., et al., Effect of MgO formation in the vicinity of Ni-SDC/LSGM interface on SOFC performance. SOLID STATE IONICS, 2009. 180(2-3): p. 236-240. 
85. Yokokawa, H., et al., Fundamental mechanisms limiting solid oxide fuel cell durability. Journal of Power Sources, 2008. 182(2).

86. Mitterdorfer, A. and L. Gauckler, La2Zr2O7 formation and oxygen reduction kinetics of the La0.85SrO.15MnyO3, O-2(g)vertical bar YSZ system. SOLID STATE IONICS, 1998. 111(3-4): p. 185218.

87. OSTERGARD, M., et al., MANGANITE-ZIRCONIA COMPOSITE CATHODES FOR SOFC - INFLUENCE OF STRUCTURE AND COMPOSITION. ELECTROCHIMICA ACTA, 1995. 40(12): p. 1971-1981.

88. CLAUSEN, C., et al., MICROSTRUCTURAL AND MICROCHEMICAL CHARACTERIZATION OF THE INTERFACE BETWEEN LA0.85SR0.15MNO3 AND Y2O3-STABILIZED ZRO2. SOLID STATE IONICS, 1994. 70: p. 59-64.

89. Grosjean, A., et al., Reactivity and diffusion between La0.8SrO.2MnO3 and $\mathrm{ZrO} 2$ at interfaces in SOFC cores by TEM analyses on FIB samples. SOLID STATE IONICS, 2006. 177(19-25): p. 19771980.

90. Hughes, A.E., SEGREGATION IN SINGLE-CRYSTAL FULLY STABILIZED YTTRIA-ZIRCONIA. Journal of the American Ceramic Society, 1995. 78(2): p. 369-378.

91. de Ridder, M., et al., The limiting factor for oxygen exchange at the surface of fuel cell electrolytes. Solid State Ionics, 2003. 156(3): p. 255-262.

92. Ingo, G.M. and G. Padeletti, SEGREGATION ASPECTS AT THE FRACTURE SURFACES OF 8 WTPERCENT YTTRIA-ZIRCONIA THERMAL BARRIER COATINGS. Surface and Interface Analysis, 1994. 21(6-7): p. 450-+.

93. Uhlenbruck, S., et al., Element interdiffusion at electrolyte-cathode interfaces in ceramic hightemperature fuel cells. SOLID STATE IONICS, 2009. 180(4-5): p. 418-423.

94. Vohs, J.M. and R.J. Gorte, High-Performance SOFC Cathodes Prepared by Infiltration. Advanced Materials, 2009. 21(9): p. 943-956.

95. He, H.P., et al., Low-temperature fabrication of oxide composites for solid-oxide fuel cells. Journal of the American Ceramic Society, 2004. 87(3): p. 331-336.

96. Bidrawn, F., et al., The effect of $\mathrm{Ca}$, $\mathrm{Sr}$, and Ba doping on the ionic conductivity and cathode performance of LaFeO(3). Journal of the Electrochemical Society, 2008. 155(7).

97. Huang, Y.Y., et al., Characterization of Sr-doped LaCoO3-YSZ composites prepared by impregnation methods. Journal of the Electrochemical Society, 2004. 151(10).

98. Shah, M. and S.A. Barnett, Solid oxide fuel cell cathodes by infiltration of La0.6Sr0.4Co0.2Fe0.8O3-(delta) into Gd-Doped Ceria. Solid State Ionics, 2008. 179(35-36).

99. Lee, S., et al., Effect of Sr-Doped LaCoO3 and LaZrO3 Infiltration on the Performance of SDC-LSCF Cathode. Journal of the Electrochemical Society, 2011. 158(6): p. B735-B742.

100. Liang, F., et al., Pd-YSZ composite cathodes for oxygen reduction reaction of intermediatetemperature solid oxide fuel cells. International Journal of Hydrogen Energy, 2011. 36(13).

101. Appel, C.C., et al., Ageing behaviour of zirconia stabilised by yttria and manganese oxide. Journal of Materials Science, 2001. 36(18).

102. Megchiche, E.H., M. Amarouche, and C. Mijoule, First-principles calculations of the diffusion of atomic oxygen in nickel: thermal expansion contribution. Journal of Physics-Condensed Matter, 2007. 19(29).

103. Park, J.W. and C.J. Altstetter, THE DIFFUSION AND SOLUBILITY OF OXYGEN IN SOLID NICKEL. Metallurgical Transactions a-Physical Metallurgy and Materials Science, 1987. 18(1).

104. Demircan, O., et al., In situ Van der Pauw measurements of the Ni/YSZ anode during exposure to syngas with phosphine contaminant. JOURNAL OF POWER SOURCES, 2009. 194(1): p. 214-219.

105. Zhi, M., et al., Temperature and Impurity Concentration Effects on Degradation of Nickel/Yttriastabilised Zirconia Anode in PH3-Containing Coal Syngas. Fuel Cells, 2010. 10(1). 
106. Guo, H., G. Iqbal, and B.S. Kang, Effects of PH3 Contaminant on Solid Oxide Fuel Cells Performance and Related Anode Surface Temperature Measurements. International Journal of Applied Ceramic Technology, 2011. 8(1).

107. $\mathrm{Xu}, \mathrm{C}$., et al., Effect of PH3 poisoning on a Ni-YSZ anode-supported solid oxide fuel cell under various operating conditions. Journal of Power Sources, 2011. 196(1).

108. Gong, M., et al., Degradation of LaSr2Fe2CrO9-delta solid oxide fuel cell anodes in phosphinecontaining fuels. Journal of Power Sources, 2010. 195(13).

109. Gansor, P., et al., Phosphine impurity tolerance of Sr2MgMoO6-delta composite SOFC anodes. Journal of Power Sources, 2012. 198.

110. Xu, C., et al., The effect of phosphine in syngas on Ni-YSZ anode-supported solid oxide fuel cells. Journal of Power Sources, 2009. 193(2).

111. Sholklapper, T.Z., et al., Nanostructured solid oxide fuel cell electrodes. Nano Letters, 2007. 7(7).

112. Mineshige, A., et al., Metal-insulator transition and crystal structure of La1-xSrxCoO3 as functions of Sr-content, temperature, and oxygen partial pressure. Journal of Solid State Chemistry, 1999. 142(2).

113. Simner, S.P., et al., Optimized lanthanum ferrite-based cathodes for anode-supported SOFCs. Electrochemical and Solid State Letters, 2002. 5(7).

114. Esquirol, A., et al., Electrochemical characterization of La0.6SrO.4Co0.2Fe0.803 cathodes for intermediate-temperature SOFCs. Journal of the Electrochemical Society, 2004. 151(11).

115. Yamahara, K., et al., Catalyst-infiltrated supporting cathode for thin-film SOFCs. Solid State lonics, 2005. 176(5-6). 


\section{Appendix: Publications during the Ph.D study}

- Chen, Song; Chen, Yun; Finklea, Harry; et al. Crystal defects of yttria stabilized zirconia in Solid Oxide Fuel Cells and their evolution upon cell operation, Solid State lonics , 206, 104111,2012

- Chen, Yun; Chen, Song; Hackett, Gregory; et al. Microstructural and chemical evolution near anode triple phase boundary in Ni/YSZ solid oxide fuel cells, Solid State Ionics, 204, 8790,2011

- Yun Chen, Song Chen, Gregory Hackett, Harry Finklea, John Zondlo, Ismail Celik, Xueyan Song, Kirk Gerdes, Microstructure degradation of SOFC anodes operated in phosphine contained fuels, (Solid State lonics- Under review).

- Dogan, O.; Hu, R.; Song, X.; Chen, S; et al. Ordered bcc phases in a Cu-Pd-Mg hydrogen separation membrane alloy, Journal of Alloys and Compounds, 528, 10-15, 2012.

- Dogan, Oemer N.; Chen, Song; Song, Xueyan; et al. Structurally modulated precipitates in a refractory Cr-V alloy, Journal of Alloys and Compounds, 509, 6556-6560, 2011

- Ömer N. Do־gan, Xueyan Song, Song Chen, M.C. Gao, Microstructural Study of HighTemperature Cr-Ni-Al-Ti Alloys Supported by First-Principles Calculations, Metallurgical and materials Transactions A, (Accepted, 2012)

- Xueyan Song, Yun Chen, Song Chen, Ever Barbero, Evan L. Thomas, Paul Barnes, Significant Enhancement of Electrical Transport Properties of Thermoelectric Ca3Co4O9+d through Yb Doping, Solid State Communications, 152, 1509-1512, 2012

- Chen, Song; Emery, Sanford E.; Pei, Ming, Coculture of Synovium-Derived Stem Cells and Nucleus Pulposus Cells in Serum-Free Defined Medium With Supplementation of Transforming Growth Factor-beta 1 A Potential Application of Tissue-Specific Stem Cells in Disc Regeneration, Spine, 34, 1272-1280,2009. 